\title{
Pon: \\ (FINAL ENVIRONMENTAL IMPACT STATEMENT) \\ Decommissioning of Eight Surplus Production Reactors at the Hanford Site, Richland, Washington
}

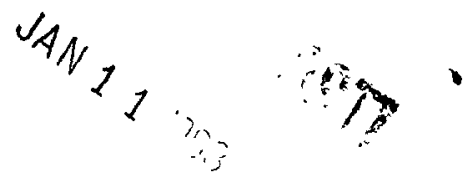

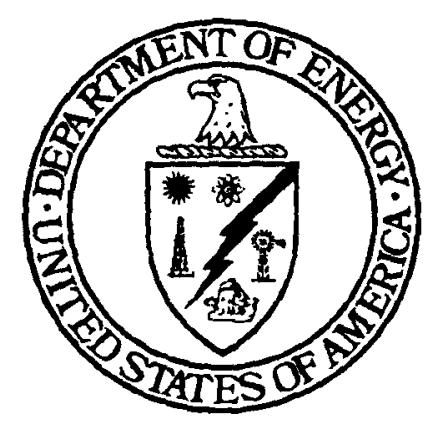

December 1992

\section{U.S. DEPARTMENT OF ENERGY}

WASHINGTON, D.C. 20585 


\section{DISCLAIMER}

This report was prepared as an account of work sponsored by an agency of the United States Government. Neither the United States Government nor any agency Thereof, nor any of their employees, makes any warranty, express or implied, or assumes any legal liability or responsibility for the accuracy, completeness, or usefulness of any information, apparatus, product, or process disclosed, or represents that its use would not infringe privately owned rights. Reference herein to any specific commercial product, process, or service by trade name, trademark, manufacturer, or otherwise does not necessarily constitute or imply its endorsement, recommendation, or favoring by the United States Government or any agency thereof. The views and opinions of authors expressed herein do not necessarily state or reflect those of the United States Government or any agency thereof. 


\section{DISCLAIMER}

Portions of this document may be illegible in electronic image products. Images are produced from the best available original document. 
ADDENDUM (FINAL ENVIRONMENTAL IMPACT STATEMENT)

DECOMMISSIONING OF EIGHT SURPLUS PRODUCTION

REACTORS AT THE HANFORD SITE,

RICHLAND, WASHINGTON

December 1992

U.S. Department of Energy.

Washington, D.C. 20585 


\section{COVER SHEET}

RESPONSIBLE AGENCY. U.S. Department of Energy

TITLE: Addendum (Final Environmental Impact Statement), Decomissioning of Eight Surplus Production Reactors at the Hanford Site, Richland, Washington

\section{FOR FURTHER INFORMATION CONTACT:}

Mr. Michae T Talbot, Acting Director

office of Communications, Richland Fie ld office

U.S. Department of Energy

Richland. Washington 99352

Telephone: (509) 376-7501

Ms. Carol Borgstrom, Director

Office of NEPA Oversight

EH-25, Office of the Assistant Secretary

for Environment, Safety and Health

U.S. Department of Energy

1000 Independence Avenue S.W.

Washington. O C 20585

Telephone: (202) $586-4600$ or $800-472-2756$

To request coples of the Addendum (Final Environmental Impact Statement), contact Mr Talbot at the above address

ABSTRACT. The purpose of this Environmental Impact Statement (EIS) is to provide environmental information to assist the US. Department of Energy (DOE) in the selection of a decormissioning alternative for the eight surplus production reactors at the Hanford Site, Richland, Washington

Five alternatives are considered in this EIS 1) No Action, in which the reactors are left in place and the present maintenance and survelllance programs are continued, 2) Immediate One-Piece Removal, in which the reactor bulldings are demolished and the reactor blocks are transported in one piece on a tractor-transporter across the $S_{i}$ te along a predetermined route to an onsite low-level waste-burial area, 3) Safe Storage Followed by Deferred OnePiece Removal, in which the reactors are temporarily stored in a safe, secure status for up to 75 years, after which the reactor buildings are demolished and the reactor blocks are transported in one piece on a tractor-transporter across the Site along a predetermined route to an onsite low-level waste-burial area, 4) Safe Storage Followed by Deferred Dismantlement, in which the reactors are temporarily stored in a safe, secure status for up to 75 years, after which they are fully dismantled and any remaining radioactive waste is transported to a low-level waste-burial area on the Hanford Site, and 5) In Situ Decomissioning, in which the reactors remain at their present locations, contamination is immobilized, major volds are filled, potential pathways (openings such as large pipes, air ducts and doors) are sealed, and an engineered mound of bullding rubble, earth, and gravel is constructed over each decomissioned reactor to act as a long-term protective barrier aga inst human intrusion and water and wind erosion In each alternative other than no action, an engineered barrier is placed over the waste form in order to $11 \mathrm{mit}$ water inf 11 tration A second No Action alternative of closing the facilities and doing nothing further is neither responsible nor acceptable and is not considered

The DOE has selected safe storage followed by deferred one-plece removal as its preferred decomissioning alternative 


\section{FOREWORD}

This environmental impact statement (EIS) presents analyses of potential environmental impacts of decommissioning the eight surplus production reactors at the Hanford Site near Richland, Washington.

In 1980, the U.S. Department of Energy (DOE) issued an Environmental Assessment (EA) of the F-Area Decommissioning Program (DOE/EA-0120), which addressed the dismantlement of the $F$ Reactor and disposal of radioactive materials in burial grounds in the 200 Areas of the Hanford Site. Four alternatives were considered at that time: layaway, protective storage, entombment, and dismantlement. Based on the $E A$, a finding of no significant impact for the dismantlement alternative was published in the Federal Register on August 22, 1980 (45 FR 56125).

Subsequent to that action, the DOE concluded that it would be more appropriate to consider and implement a consolidated decommissioning program for all eight of the surplus production reactors located at Hanford, and decided to examine all reasonable decommissioning alternatives in greater depth. Accordingly, on May 16, 1985, the DOE published in the Federal Register (50 FR 20489) a "Notice of Intent to Prepare an Environmental Impact Statement on Decommissioning the Eight Shutdown Production Reactors Located at the Hanford Site Near Richland, Washington." The notice of intent presented pertinent background information on the proposed scope and content of the EIS. The scope of the EIS includes only the disposition of the eight reactors, associated fuel storage basins, and the buildings used to house these systems. Decommissioning of the $N$ Reactor is not within the scope of this EIS. Thirtyfive comment letters were received in response to the notice of intent; all comments were considered in preparing the draft EIS.

The draft EIS was published in March 1989 and announced in the Federal Register on April 28, 1989 (54 FR 18325). Copies were made available to appropriate federal, state, and local officials and units of government, environmental organizations, and the general public in order to provide al 1 interested parties the opportunity to review and comment on the draft EIS. During the 90-day comment period, public hearings on the draft EIS were held 
in Richland, Washington; Spokane, Washington; Portland, Oregon; and Seattle, Washington. Fifty-four persons or organizations sent letters to the DOE containing comments on the draft EIS, and 29 persons or organizations presented comments on the draft EIS at public hearings. These comments were considered by the DOE in the preparation of the final EIS. Comments on the draft EIS did not require DOE to modify any alternatives presented in the draft EIS, to evaluate any new alternatives, or to supplement, improve, or modify its analyses in the draft EIS (40 CFR 1503.4); therefore, the final EIS consists of two volumes. The first volume is the draft EIS as written. The second volume (Addendum) consists of a summary; five appendixes containing additional health effects information, costs of decommissioning in 1990 dollars, additional graphite leaching data, a discussion of accident scenarios, and errata; a chapter containing responses to individual comments; and an appendix containing reproductions of the letters, transcripts, and exhibits that constitute the record of the public comment period.

The EIS was prepared in accordance with the requirements of the National Environmental Policy Act of 1969 (NEPA), as amended, the implementing regulations of the Council on Environmental Quality (CEQ) in 40 CFR 1500-1508, and DOE's NEPA regulations in 10 CFR 1021 (57 FR 15122, April 24, 1992). The EIS was written early in the decision-making process to ensure that environmental values and alternatives could be fully considered before any decisions were made that might lead to unacceptable environmental impacts or that might limit the choice of reasonable alternatives. To comply with the NEPA requirement for early preparation of environmental documentation, the EIS was prepared before detailed engineering $\mathrm{plans}$ for decommissioning the reactors were prepared. As with any major action, it is expected that once a decommissioning alternative is selected, detailed engineering design will be carried out that may improve upon the conceptual engineering plans presented here. However, the engineering design will be such as to result in environmental impacts not significantly greater than those described here.

Decommissioning is dependent on future federal funding actions, and the actual start date cannot be predicted at this time. However, in the interim, 
the $D O E$ is conducting a comprehensive program of surveillance, maintenance, and monitoring to ensure the safety of the reactors.

The Addendum will be sent to those who received the draft EIS, will be made available to members of the public, and will be filed with the U.S. Environmental Protection Agency (EPA). A notice of availability of the Addendum will be published by the DOE in the Federal Register. The DOE will make a decision on the proposed action not earlier than 30 days after the EPA's notice of filing of the Addendum is published in the Federal Register. The DOE will record its decision in a Record of Decision published in the Federal Register. 



\section{CONTENTS}

FOREWORD

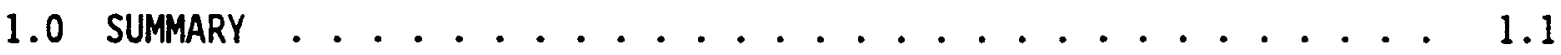

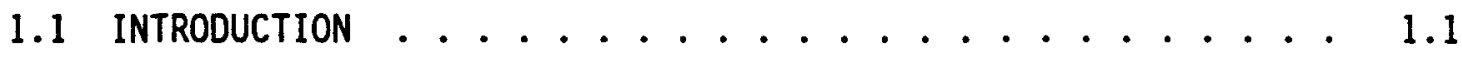

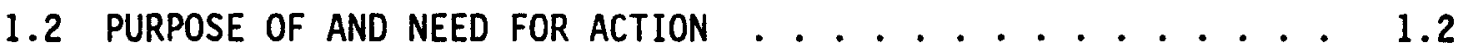

1.3 DESCRIPTION AND COMPARISON OF DECOMMISSIONING

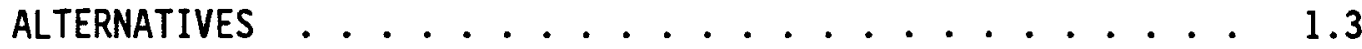

1.3.1 No Action Alternative . . . . . . . . 1.8

1.3.2 Immediate One-Piece Removal Alternative . . . . 1.9

1.3.3 Safe Storage Followed by Deferred One-Piece

Removal Alternative............ 1.10

1.3.4 Safe Storage Followed by Deferred Dismantlement

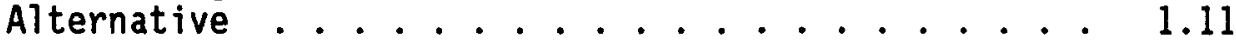

1.3.5 In Situ Decommissioning Alternative ....... 1.12

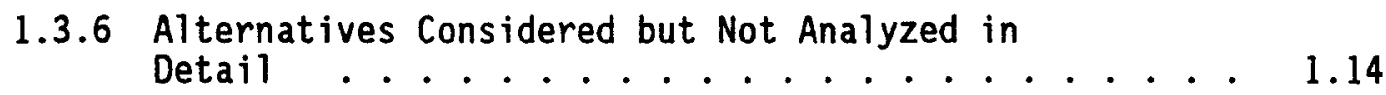

1.3.7 Evaluation of Alternatives .......... 1.14

1.3.8 Preferred Alternative . . . . . . . . . 1.14

1.4 AfFECTEd ENVIRONMENT $\ldots \ldots \ldots \ldots \ldots$

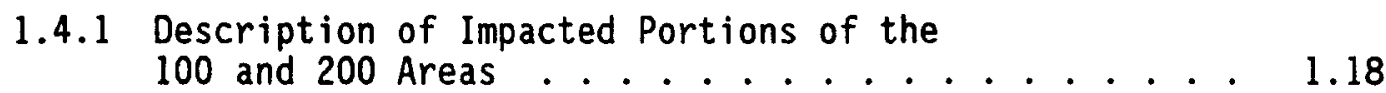

1.4.2 Geology and Hydrology of the Site ........ 1.19

1.4.3 Climate, Meteorology, and Seismology

1.4.4 Air Quality, Water Quality, and Environmental
Monitoring of the Site ...................... 1.21

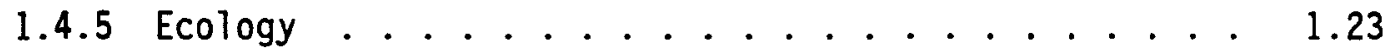

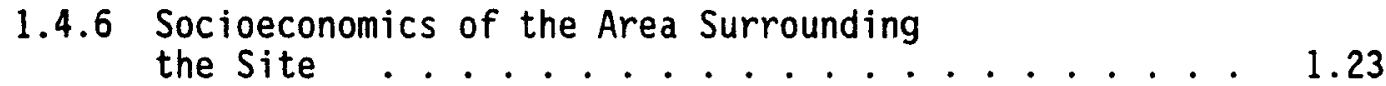


1.4.7 Transportation .................. 1.24

1.5 ENVIRONMENTAL CONSEQUENCES . . . . . . . . . . 1.24

1.5.1 - 1.5.6 Radiological Consequences . . . . . . 1.24

1.5.7 Impacts from Hazardous Wastes . . . . . . . 1.26

1.5.8 Socioeconomic Impacts ........... 1.26

1.5.9 Commitment of Resources .......... 1.26

1.5.10 Unavoidable Adverse Impacts ......... 1.26

1.5.11 Short-Term Versus Long-Term Use of
the Environment . . . . . . . . . . 1.27

1.5.12 Means to Mitigate Adverse Environmental
Impacts . . . . . . . . . . . 1.27

1.5 .13 Cumulative Impacts ............ 1.28

1.6 STATUTORY AND REGULATORY REQUIREMENTS $\ldots \ldots \ldots \ldots$

9.0 RESPONSES TO COMMENTS ON THE DRAFT ENVIRONMENTAL

IMPACT STATEMENT . . . . . . . . . . . . . . . 9.1

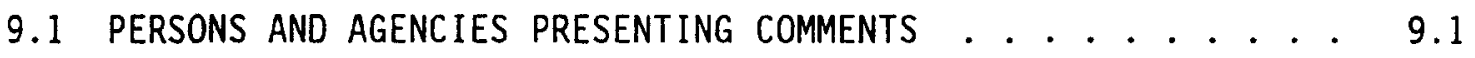

9.1 .1 Letters . . . . . . . . . . . . 9.2

9.1 .2 Transcripts ................... 9.5

9.1 .3 Exhibits ............... 9.6

9.1.4 Alphabetical List of Commenters ....... . 9.7

9.2 DECOMMISSIONING AND HISTORIC PRESERVATION
PREFERENCES

9.2.1 Decommissioning Alternatives ......... 9.12

9.2.2 Historic Preservation of B Reactor . . . . . . . 9.12

9.3 COMMENTS AND RESPONSES . . . . . . . . . . . . . . . 9.12

APPENDIX F: ADDENDUM TO SECTION F.3 OF APPENDIX F:

BIOLOGICALLY RELATED HEALTH EFFECTS . . . . . . . . F.1 
APPENDIX K: DECOMMISSIONING COSTS ............. K.1

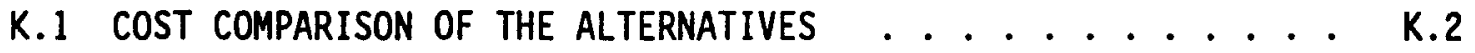

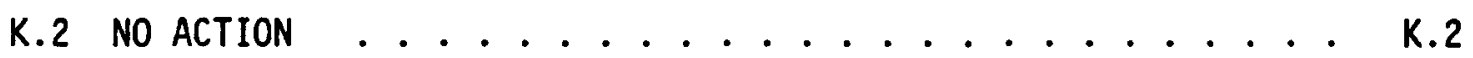

K.2.1 No Further Action .................. K.2

K.2.2 Continue Present Action ................ K.4

K.3 IMMEDIATE ONE-PIECE REMOVAL . ............ K.4

K.3.1 Costs of Immediate One-Piece Removal . . . . . K.4

K.3.2 Waste-Site Costs ............. K.7

K.3.3 Transporter Shipment of the Reactor Blocks . . . . K.7

K.4 SAFE STORAGE FOLLOWED BY DEFERRED ONE-PIECE REMOVAL . . . . K.11

K.4.1 Costs of Safe Storage Followed by Deferred
One-Piece Removal . . . . . . . . K.11

K.4.2 Waste-Site Costs .................. K.13

K.5 SAFE STORAGE FOLLOWED BY DEFERRED DISMANTLEMENT . . . . . K.14

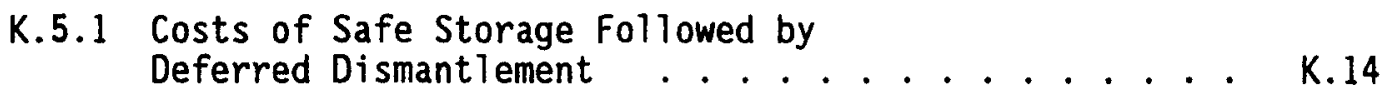

K.5.2 Waste-Site Costs ............ . K.17

K.6 IN SITU DECOMMISSIONING . . . . . . . . . . . K.17

K.6.1 Costs of In Situ Decommissioning ........ K.17

K.6.2 Waste-Site Costs . . . . . . . . . K.18

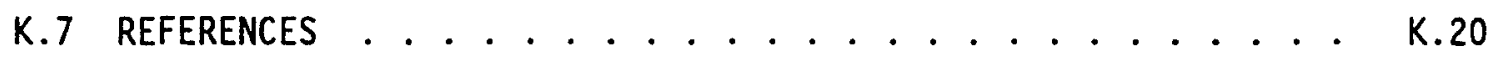

APPENDIX L: SUPPLEMENTAL INFORMATION ON THE RELEASE

RATES OF RADIONUCLIDES FROM THE GRAPHITE

MODERATOR BLOCKS ................. L.1

L.1 RESULTS OF SUBSEQUENT STUDIES . . . . . . . . . . L.I

L.2 IMPLICATIONS OF NEW RESULTS . . . . . . . . . . L.3

L.3 REFERENCES . . . . . . . . . . . . . . . . . . . . L.4 


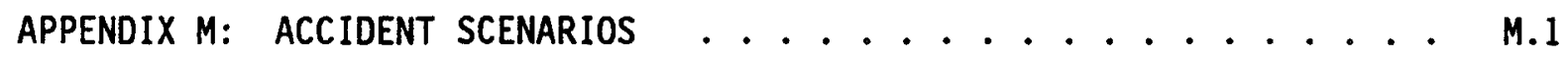

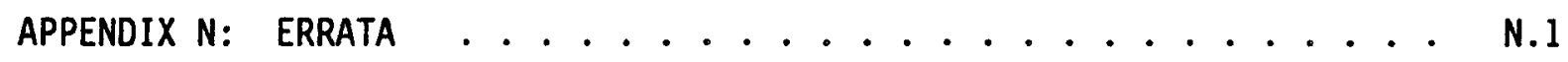

APPENDIX 0 : LETTERS, TRANSCRIPTS, EXHIBITS ......... 0.1 


\section{FIGURES}

1.1 The Hanford Site and Surrounding Region .......... 1.2

1.2 Reactor-Block Construction .............. 1.5

1.3 Barrier Configuration for In Situ Decommissioning . . . . . 1.13 


\section{TABLES}

1.1 Costs of Decommissioning Alternatives .......... 1.15

1.2 Comparison of Alternatives . . . . . . . . . 1.16

F.5 Comparison of Cancer Fatalities for the Disposal Alternatives . . F.2

K.l Costs of Decommissioning Alternatives ........... K.3

K.2 Summary of Estimated Costs for Immediate One-Piece Removal of the Eight Surplus Production Reactors . . . . . K. K

K.3 Estimated Costs for Immediate One-Piece Removal of a Typical Reactor ........................ K

K.4 Estimated Construction Costs for Burial of Reactor Blocks with Liner/Leachate Collection System in the 200-West Area . . . . . . . . . . . . . . K.9

K.5 Summary of Costs for Transporters and Removal of Eight Surplus Production Reactors ............ K.10

K.6 Summary of Estimated Costs for Safe Storage Followed by Deferred One-Piece Removal of the Eight Surplus Production

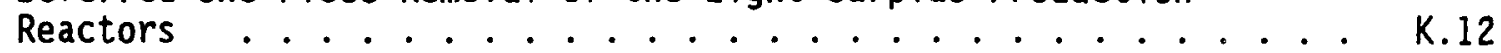

K.7 Summary of Costs for Safe Storage Followed by Deferred Dismant lement for Eight Surplus Production Reactors . . . . . K.15

K.8 Estimated Costs for Deferred Dismantlement of a Surplus Production Reactor . . . . . . . . . . . . . K.16

K.9 Estimated 200-West Area Burial-Site Costs Associated with Burial of the Dismantled Reactor Blocks ......... K.18

K.10 Estimated Costs for In Situ Decommissioning of an "Average" Surplus Production Reactor ............ K.19

K.11 Estimated Burial-Site Costs for the In Situ Decommissioning A7ternative 


\section{ADDENDUM (FINAL ENVIRONMENTAL IMPACT STATEMENT) \\ DECOMMISSIONING OF EIGHT SURPLUS PRODUCTION \\ REACTORS AT THE HANFORD SITE, RICHLAND, WASHINGTON}

\subsection{SUMMARY}

This section summarizes the content of the draft environmental impact statement (DEIS) and this Addendum, which together constitute the final environmental impact statement (FEIS) prepared by the U.S. Department of Energy (DOE) on the decommissioning of eight surplus plutonium production reactors located at the Hanford Site near Richland, Washington (see Figure 1.1). The FEIS consists of two volumes. The first volume is the DEIS as written. The second volume (this Addendum) consists of a summary; Chapter 9, which contains comments on the DEIS and provides DOE's responses to the comments; Appendix $F$, which provides additional health effects information; Appendix K, which contains costs of decommissioning in 1990 dollars; Appendix $L$, which contains additional graphite leaching data; Appendix M, which contains a discussion of accident scenarios; Appendix $N$, which contains errata; and Appendix 0, which contains reproductions of the letters, transcripts, and exhibits that constitute the record for the public comment period. The objectives of the summary are to state the major results of the environmental analyses and to serve as a guide to the body of the DEIS. Section numbers and headings in this summary correspond to section numbers in the DEIS (e.g., Section 1.3.4 of the summary corresponds to Section 3.4 of the DEIS).

\subsection{INTRODUCTION}

Nine water-cooled, graphite-moderated plutonium production reactors were constructed along the Columbia River by the U.S. government at the Hanford Site near Richland, Washington, between the years 1943 and 1963. All are now retired from service. Eight of these reactors ( $B, C, D, D R, F, H, K E$, and $K W$ ) have been declared surplus by the DOE, and are available for decommissioning. Decommissioning of the $\mathrm{N}$ Reactor is not within the scope of this EIS. 


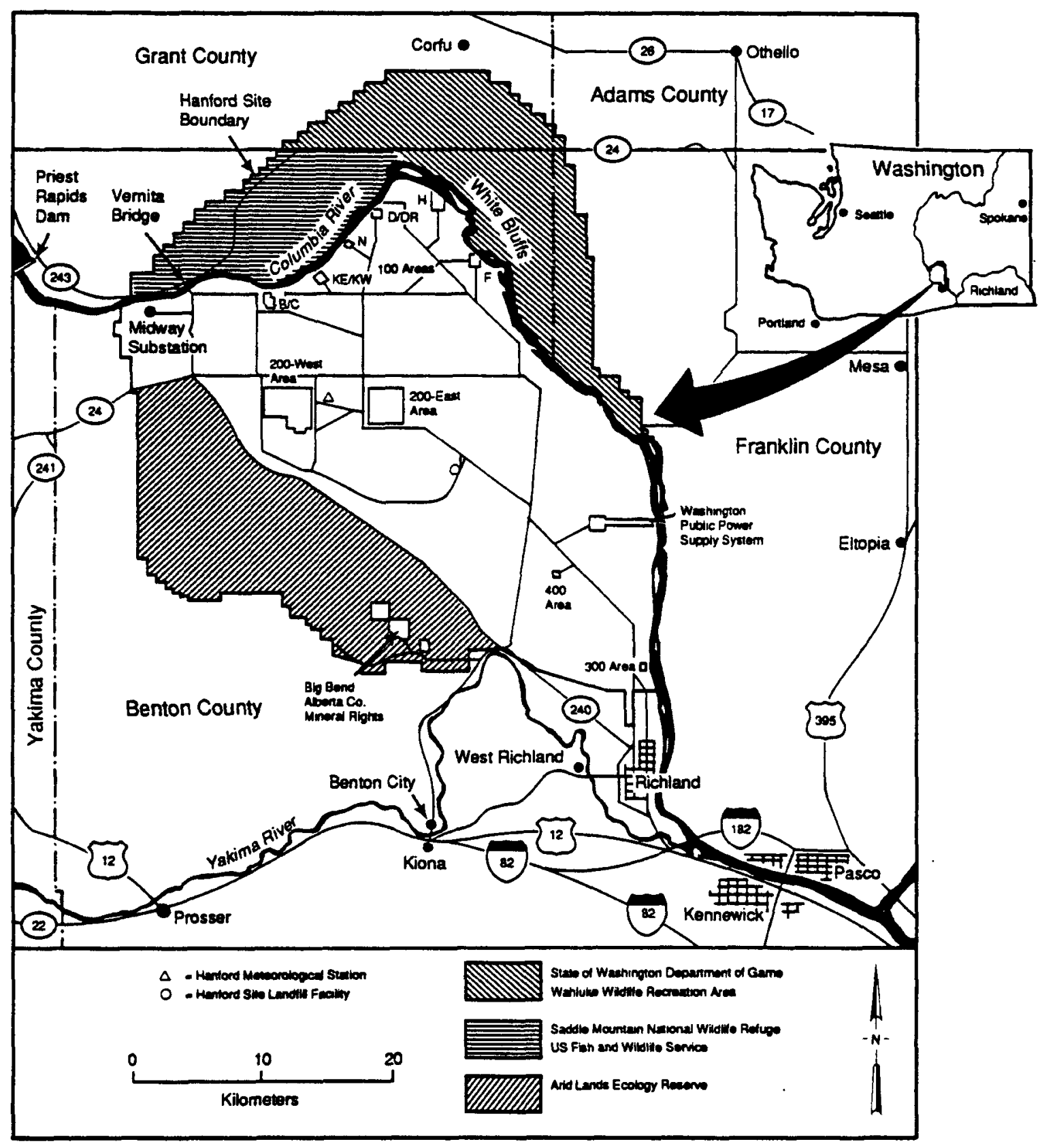

FIGURE 1.1. The Hanford Site and Surrounding Region

\subsection{PURPOSE OF AND NEED FOR ACTION}

The proposed action is to decommission the eight surplus production reactors. Facilities included within the scope of the proposed action are 
the eight surplus reactors, their associated nuclear fuel storage basins, and the buildings that house these systems. The purpose of decommissioning is to isolate any remaining radioactive or hazardous wastes in a manner that will minimize environmental impacts, especially potential health and safety impacts on the public. No future long-term use of any of the eight surplus production reactors has been identified by the DOE with the exception of B Reactor, which has been placed on the National Register of Historic Places. Because the reactors contain irradiated reactor components and because the buildings that house the reactors are contaminated with low levels of radioactivity, the DOE has determined that there is a need for action and that some form of decommissioning or continued surveillance and maintenance is necessary.

\subsection{DESCRIPTION AND COMPARISON OF DECOMMISSIONING ALTERNATIVES}

The alternatives considered in this DEIS are no action, immediate onepiece removal, safe storage followed by deferred one-piece removal, safe storage followed by deferred dismantlement, and in situ decommissioning. Evaluation of the alternatives has been carried out on the basis of several conditions and assumptions, the more important of which are listed below:

- The reactors are similar in design, construction, and radiological condition. Major differences are noted in the DEIS, but these are not significant for decommissioning purposes.

- The residual radioactive materials within the surplus facilities are low-level radioactive wastes (Low-Level Radioactive Waste Policy Act and DOE 5820.2A), which are suitable for disposal at Hanford by shallow-land burial. Waste disposal would be in the Hanford 200-West Area for the removal and dismantlement alternatives, and in the Hanford 100 Areas for the in situ decommissioning alternative.

- Each disposal site, whether located in the 100 Areas or 200-West Area, will have a protective barrier, a ground-water monitoring system, and a marker system. The 200 -West Area disposal site may be provided with a liner/leachate collection system. The protective barrier is designed to limit the infiltration of water and is assumed to limit infiltration to 0.1 centimeter per year.

- Costs are estimated on the basis of efficient, overlapping work schedules and are given in 1990 dollars. 
The reactors and their associated fuel storage basins are briefly described in the following paragraphs (see Appendix $A$ in the DEIS for a detailed description).

The eight surplus production reactors were constructed during the period 1943 to 1955 in the Hanford 100 Areas adjacent to the Columbia River, where the large volume of water necessary for reactor cooling was available. All of the surplus production reactors have been inactive since 1971. The reactors are similar in design, except that the newer KE and KW Reactors differ from the others in the number, size, and types of process tubes; the size of the moderator (graphite) stack; and the type of reactor-block shielding employed. While noted in the EIS, these differences are not significant for decommissioning purposes.

Each reactor building, designated as a 105 building, contains a reactor block, a reactor control room, a spent-fuel discharge area, a fuel storage basin, fans and ducts for ventilation and recirculating inert gas systems, water cooling systems, and supporting offices, shops, and laboratories. A typical reactor facility is a reinforced concrete and concrete-block structure approximately 76 meters long, by 70 meters wide, by 29 meters high. Outside the reactor block, the building has massive reinforced concrete walls ( 0.9 meter to 1.5 meters thick) that extend upward to the height of the reactor block to provide shielding, with lighter construction above. Roof construction is primarily precast concrete slab or poured insulating concrete. The reactor block is located near the center of the building. Horizontal control-rod penetrations are on the left side of the reactor block (when facing the reactor front face), and vertical safety-rod penetrations are on top of the reactor. Process tubes, which held the uranium fuel and carried the cooling water, penetrate the block from front to rear. Fuel discharge and storage areas are located adjacent to the rear face of the reactor. Experimental test penetrations are located on the right side of most of the reactors.

A typical reactor block (Figure 1.2) consists of a moderator stack consisting of graphite bars encased in a thermal shield surrounded by a biological shield. The entire block rests on a massive concrete base and 


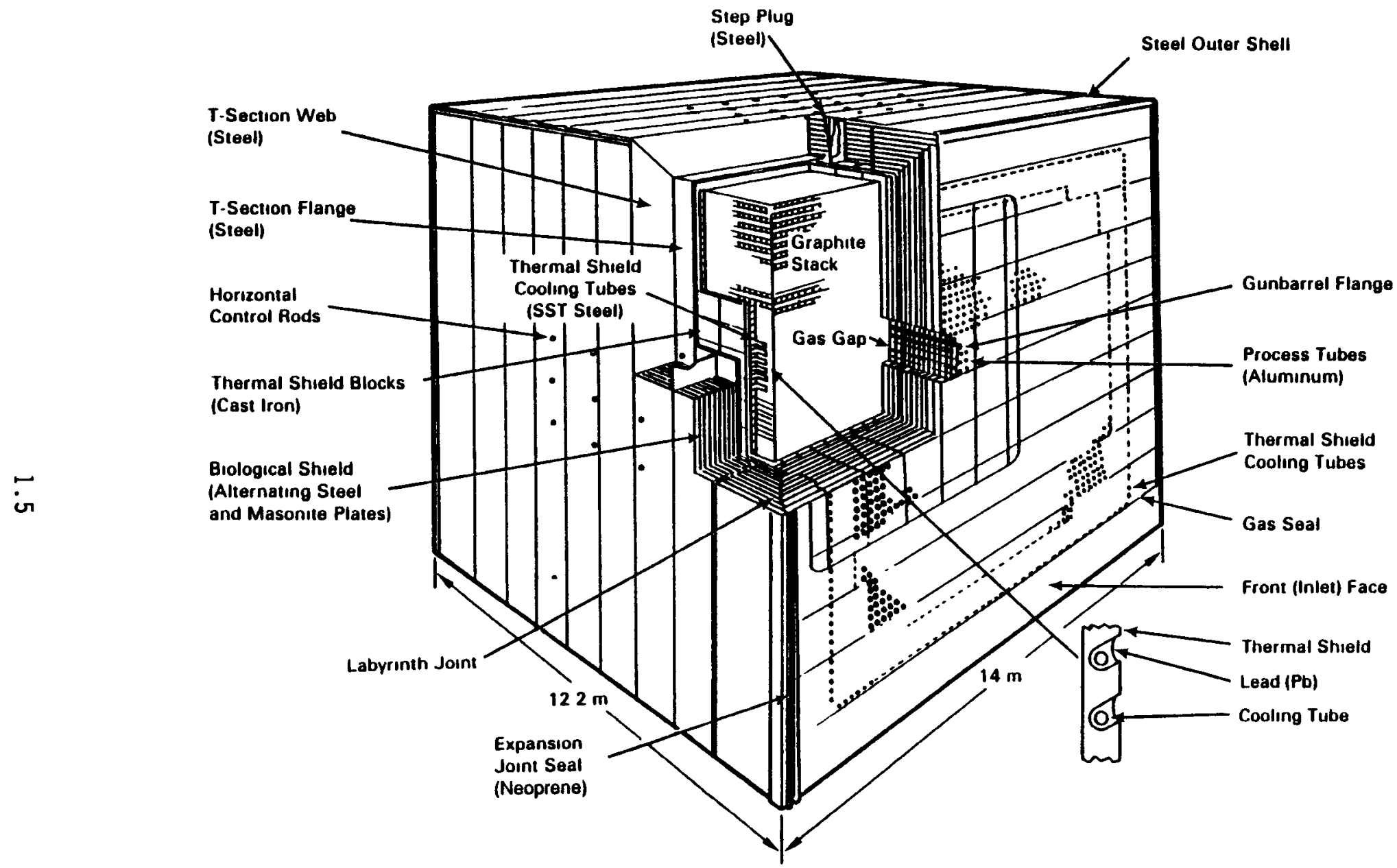

FIGURE 1.2. Reactor-Block Construction (base not shown) 
foundation. Each older reactor-block assembly (graphite stack, thermal shield, biological shield, and base) weighs approximately 8,100 tonnes, and has overall dimensions of 14 meters wide, 12.2 meters deep, and 14 meters high. The $\mathrm{K}$ Reactor blocks are larger than the older reactor blocks and weigh approximately 11,000 tonnes each.

The graphite moderator stack consists of individual graphite blocks 10.6 centimeters square by 121.9 centimeters in length. The 105-F Reactor contains approximately 80,000 graphite blocks. The full, six-sided thermal shield is composed of a single layer of approximately 3,300 cast-iron blocks. The biological shield (outside of the thermal shield) is 132 centimeters thick and forms an integral casement on the top and four sides. In the older reactors, the biological shield is constructed of alternating layers of steel and masonite, and in the K Reactors, the biological shield is composed mainly of high-density concrete.

The fuel storage basins are concrete structures 6 meters deep, varying in area from 650 to 929 square meters. The top of each basin is at ground level. The typical fuel storage basin has a fuel discharge area adjacent to the reactor rear face, a large storage area, and a transfer area. The fue 1 storage basins at 105-KE and 105-KW are currently being used to store $\mathrm{N}$ Reactor fuel, which will be removed before decommissioning begins. The basins at $105-\mathrm{F}$ and $105-\mathrm{H}$ contain residual sludge and are filled with rubble and dirt. The transfer pits at $105-B$ and $105-C$ al so contain some residual sludge from a previous clean-up operation. This sludge is low-level waste and will be removed or left in place, depending on the decommissioning alternative finally selected.

Radioactive inventories have been estimated for all of the surplus production reactors. The $C$ Reactor has the largest inventory of the older reactors, and the KE Reactor has the larger inventory of the $K$ Reactors. Radionuclides of primary interest (described in terms of their half-lives and total curie amounts in all eight reactors as of March 1985) include tritium (12.3 years, 98,100 curies), carbon-14 (5,730 years, 37,400 curies), chlorine-36 (300,000 years, 270 curies), cobalt-60 (5.3 years, 74,400 curies), cesium-137 ( 30.2 years, 267 curies), and uranium-238 ( 4.5 billion years, 
0.013 curies). Cobalt-60 and cesium-137 are of importance because they contribute to the radiation dose received by decommissioning workers. Carbon-14, chlorine-36, and uranium-238 are of importance because of their long halflives and because of their contribution to long-term individual and population public radiation doses. Tritium is not of particular importance either with respect to worker doses or to public doses, but it is mentioned here because it is present in large amounts.

On November 3, 1989, the Hanford Site was placed on the National Priorities List (NPL) by the U.S. Environmental Protection Agency (EPA) for cleanup under the Comprehensive Environmental Response, Compensation, and Liability Act (CERCLA). On May 15, 1989, in anticipation of this designation, the DOE, the EPA, and the Washington Department of Ecology (WDOE) entered into the Hanford Federal Facility Agreement and Consent Order (Tri-Party Agreement). The Tri-Party Agreement addresses all of the active and inactive waste sites at Hanford under either the Resource Conservation and Recovery Act (RCRA) or CERCLA, but not the reactors themselves, except for hazardous wastes that might be generated during decommissioning. The Tri-Party Agreement provides for the cleanup of inactive waste sites under CERCLA and for the permitting of active waste sites under RCRA. If in situ decommissioning is chosen, the barriers covering the reactors and fuel storage basins may cover 16 inactive waste-disposal sites. These sites are being evaluated by the DOE within the scope of the DOE's responsibilities under the Tri-Party Agreement. If the in situ decommissioning alternative is selected, any evaluation and remedial action required for any of these 16 sites beyond the actions proposed for in situ decommissioning will be completed before decommissioning of the reactors begins. These actions are outside the scope of this EIS.

Several materials that may be considered to be hazardous materials under RCRA, the Toxic Substances Control Act (TOSCA), or the Clean Air Act (CAA) are or have been present in the facilities. These materials include mercury (RCRA), friable asbestos (CAA), polychlorinated biphenyls (TOSCA), cadmium (RCRA), and nonirradiated lead (RCRA). These materials are being recycled, stored, or disposed of according to applicable regulations. Lead (RCRA, 653 tonnes) used as an integral component in the reactor structure in the 
thermal shields has been irradiated and will either be left in place under the in situ decommissioning alternative, or moved to a 200-West Area low-level waste burial ground under the dismantlement or removal alternatives. The impacts of the irradiated lead are evaluated in the DEIS.

Decommissioning alternatives are discussed in the following sections.

\subsubsection{No Action Alternative}

For the purpose of this EIS, no action means to continue present actions indefinitely. A second no action alternative of doing nothing further is not reasonable and is not considered in detail.

\subsubsection{Continue Present Action Al ternative}

Continue present action means to continue routine surveillance, monitoring, and maintenance. These activities are the same as those required during the safe-storage period of deferred decommissioning, and the annual (or unit) costs and radiation doses are similar. Over the 100-year period assumed for active institutional control (and over any successive 100-year period), the cost to continue present action is estimated to be $\$ 44$ million in 1990 dollars for all eight reactors. The occupational radiation dose over the same 100-year period for surveillance, monitoring, and maintenance is estimated to be 24 person-rem. At the end of the 100-year period of active institutional control, problems similar to those faced in the no further action alternative would be present with respect to the isolation of remaining radioactive materials from the environment and with respect to the protection of human health and safety, even though 100 years of radioactive decay would have taken place. The presence of long-lived isotopes and other safety hazards within the facilities would require further action.

Continue present action is subsequently referred to as the no action alternative because the no further action case was not evaluated as a feasible alternative.

\subsubsection{No Further Action Alternative}

No further action means to close the facility and to discontinue all activities related to the facility. Although no decommissioning cost would be 
incurred and there would be no further occupational radiation dose, this alternative is not reasonable and is not acceptable to the DOE because it would not properly isolate the remaining radioactivity in the facility from the environment, would not provide for any maintenance or repair of the structures, and would not make any other provision for the protection of human health and safety. No further action would eventually result in deterioration of the reactor buildings, potential release of radionuclides to the environment, and potential human exposure to radioactivity and to other safety hazards by intrusion. This alternative is not considered further.

\subsubsection{Immediate One-Piece Removal Alternative}

Immediate one-piece removal means to transport each reactor block, intact on a tractor-transporter, from its present location in the 100 Areas to the 200-West Area for disposal, a distance of about 5 to 14 miles, depending on the reactor. The reactor block includes the graphite core, the thermal and biological shields, and the concrete base. Contaminated areas of the associated fuel storage basins would be removed for disposal in the 200-West Area, along with other contaminated equipment and components in the buildings that house the reactors and the fuel storage basins. The uncontaminated portion of the fuel storage basins would also be removed to provide access for the tractor-transporter. Each reactor building would then be demolished and an excavation prepared under the reactor block through the former location of the fuel storage basin. Before excavation, the weight of the reactor block would be transferred to I-beams that would be inserted through holes drilled in the concrete base and grouted in place. If contaminated soil was identified during the excavation, it would be removed and transported to the 200-West Area for disposal. A tractor-transporter would then be driven under the block, and the block would be lifted from its remaining foundation by hydraulic apparatus on the transporter and carried intact on a specially constructed haul road to the 200-West Area for disposal. The complete immediate one-piece removal process would take about 2.5 years for each reactor and about 12 years for a11 eight reactors. Following reactor removal, the site formerly occupied by the 
reactor would be backfilled, graded, seeded, and released for other DOE use. (The term "other DOE use" means that a new or alternative use is not precluded by the presence of radioactivity.)

The estimated total cost for immediate one-piece removal of all eight reactors is about $\$ 228$ million in 1990 dollars. This includes $\$ 13$ million for purchase of the two tractor units and fabrication of the transporter, and about $\$ 22$ million for haul-road construction.

Public radiation doses during the decommissioning period are estimated to be zero, and occupational radiation doses are estimated to be 159 personrem for immediate one-piece removal of all eight reactors.

\subsubsection{Safe Storage Followed by Deferred One-Piece Removal Alternative}

Safe storage followed by deferred one-piece removal means a multidecade safe-storage period during which surveillance, monitoring, and maintenance are continued, followed by the transport of each reactor block intact on a tractor-transporter from its present location in the 100 Areas to the 200-West Area for disposal.

During preparation for safe storage, building components and structures are repaired as needed to ensure the security of the facility during the safestorage period. Building security, radiation monitoring, and fire detection systems are upgraded to provide safety, security, and surveillance as long as required.

The safe-storage period used as a basis for this EIS is 75 years, which is an adequate time for decay of cobalt-60, a radionuclide that contributes significantly to occupational dose. This period permits the reactors to be decommissioned with less occupational radiation dose than in the case of immediate one-piece removal. The safe-storage period for all but the first reactor is actually longer than 75 years because the reactors would be decommissioned in sequence at estimated 1- to 2-year intervals. During the safestorage period, surveillance, site and facility inspections, radiological and environmental surveys, and site and facility maintenance would be carried out. Major building maintenance would be performed at estimated 5-year and 20-year intervals. 
At the end of the safe-storage period, deferred one-piece removal would take place. The sequence of events is the same as for immediate one-piece removal. Deferred one-piece removal is estimated to take about 2.5 years for each reactor and about 12 years for all eight reactors. The entire safe storage followed by deferred one-piece removal alternative would take about 87 years for all eight reactors.

The estimated total cost for safe storage followed by deferred one-piece removal of all eight reactors is about $\$ 235$ million in 1990 dollars. This includes about $\$ 36$ million for safe storage and preparation for safe storage, and about $\$ 199$ million for deferred one-piece removal.

Public radiation doses are estimated to be zero, and occupational radiation doses are estimated to be 51 person-rem, including 23 person-rem during the safe-storage period and 28 person-rem during deferred one-piece removal, for all eight reactors.

\subsubsection{Safe Storage Followed by Deferred Dismantlement Alternative}

Safe storage followed by deferred dismantlement means a multidecade safe-storage period (75 years), during which surveillance, monitoring, and maintenance are continued, followed by piece-by-piece dismantlement of each reactor, and transport of radioactive waste to the 200-West Area for burial. Piece-by-piece dismantlement is a reasonable alternative to consider at a delayed point in time because radioactive decay, primarily of cobalt-60, will significantly reduce occupational radiation exposure compared to immediate piece-by-piece dismantlement. Activities during preparation for safe storage and during the safe-storage period are the same as for the safe storage followed by deferred one-piece removal alternative, except for slightly longer storage periods for all but the first reactor in the deferred dismantlement case.

At the end of the safe-storage period, deferred dismantlement takes place. Each reactor block would be disassembled piece by piece, and all contaminated equipment and components would be packaged and transported to the 200-West Area for disposal. Contaminated structural surfaces, including contaminated surfaces of the fuel storage basins, would also be removed, 
packaged, and transported to the 200-West Area for disposal. Noncontaminated material and equipment would be released for salvage or disposed of in place or in an ordinary landfill. Remaining noncontaminated structures would be demolished and the site backfilled, graded, seeded, and released for other DOE use. An estimated 6.5 years would be required for deferred dismantlement of each reactor. The entire safe storage followed by deferred dismantlement process would take about 103 years for all eight reactors.

The estimated total cost for safe storage followed by deferred dismantlement of all eight reactors is about $\$ 311$ million in 1990 dollars. This includes about $\$ 38$ million for safe storage and preparation for safe storage, and about $\$ 273$ million for deferred dismantlement.

Public radiation doses during the decommissioning period are estimated to be zero, and occupational radiation doses are estimated to be 532 personrem, including 23 person-rem during the safe-storage period and 509 person-rem during deferred dismantlement, for all eight reactors. The occupational radiation dose for deferred dismantlement is higher than the occupational radiation doses for immediate or deferred one-piece removal because of the need to work at the interior of the carbon block where dose rates are higher than in the work areas utilized for one-piece removal. Even after 75 years of decay, the occupational dose (i.e., the product of worker hours times dose rates, summed over all tasks), would exceed that for immediate one-piece removal. It is possible, however, that in 75 years advances in robotics would reduce the occupational radiation dose.

\subsubsection{In Situ Decommissioning Alternative}

In situ decommissioning means to prepare the reactor block for covering with a protective mound (barrier) and to construct the mound. Surfaces within the facility that are potentially contaminated would be painted with a fixative to ensure retention of contamination during subsequent activities. The voids beneath and around the reactor block would be filled with grout and/or gravel as a further sealant and to prevent subsidence of the final overburden. Roofs, superstructures, and concrete shield walls would be removed down to the level of the top of the reactor block. Structures surrounding the reactor shield walls would be demolished. Piping and other channels of access into 
the reactor building would be backfilled with grout or similar material to ensure isolation of the reactor from the surrounding environment. Finally, the reactor block, its adjacent shield walls, and the spent-fuel storage basin, together with the contained radioactivity, gravel, and grout, would be covered to a depth of at least 5 meters with a mound containing earth and gravel. The mound would include an engineered barrier designed to limit water infiltration through the barrier to 0.1 centimeter per year. Riprap on the sides of the mounds would ensure structural stability of the mounds and mitigate the impacts of any flood that might reach the reactors. An artist's conception of the barrier configuration for one of the reactors is shown in Figure 1.3. The mounds may cover the existing locations of 16 inactive waste-disposal sites. Necessary remedial actions for these sites will be taken prior to or in conjunction with in situ decommissioning.

In situ decommissioning of one reactor is estimated to take about 2 years, and in situ decommissioning of all eight reactors is estimated to take about 5 to 6 years. The estimated total cost for in situ decommissioning of all eight reactors is about $\$ 193$ million in 1990 dollars.

Public radiation doses during the decommissioning period are estimated to be zero, and occupational radiation doses are estimated to be 33 person-rem for in situ decommissioning of all eight reactors.

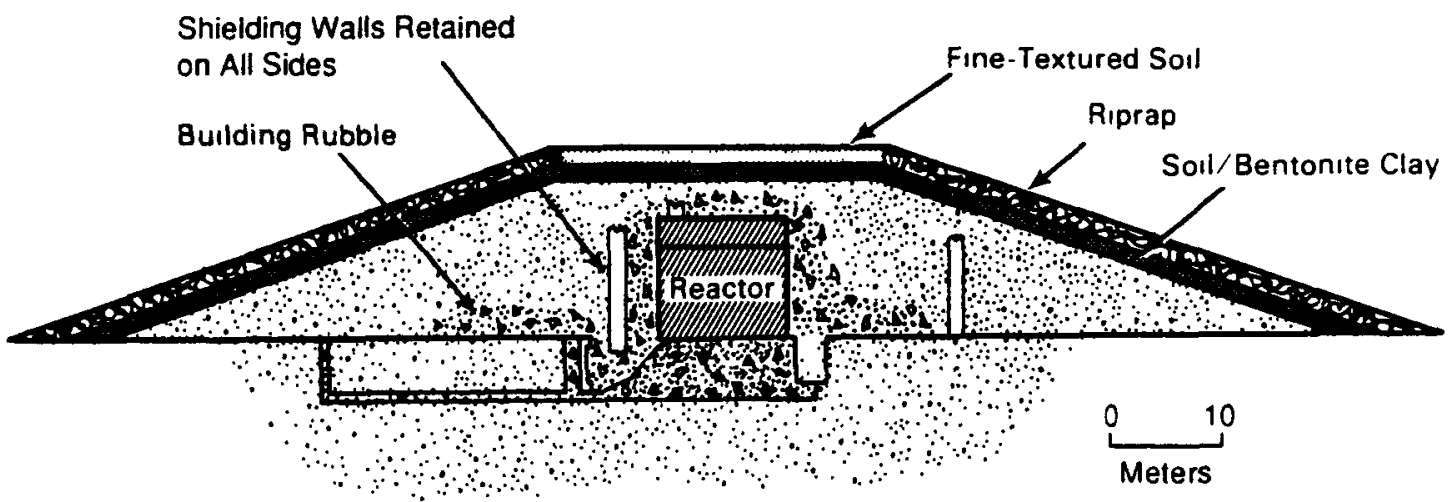

FIGURE 1.3. Barrier Configuration for In Situ Decommissioning 


\subsubsection{Alternatives Considered but Not Analyzed in Detail}

One major alternative, immediate dismantlement, was identified but not analyzed in detail because of its high cost (in the same range as safe storage followed by deferred dismantlement) and high occupational dose (higher than safe storage followed by deferred dismantlement because of the shorter radioactive isotope decay time). Minor variations within each decommissioning alternative also were not analyzed in detail because they offered no apparent advantages. Alternative disposal sites (i.e., other than Hanford) also were not analyzed in detail because they would result in increased costs, the possibility of increased radiation exposures to the public from cross-country transport of radioactive waste, and the possibility of transportation accidents with no compensating benefit.

\subsubsection{Evaluation of Alternatives}

Estimated costs of the alternatives are shown in Table 1.1, segregated to show the costs of safe storage, construction of monitoring wells, well monitoring, waste disposal, and other decommissioning costs.

The total costs and principal environmental impacts of the alternatives considered are summarized in Table 1.2. The impacts include short-term occupational radiation doses and long-term public radiation doses as a result of releases of radioactivity from the 100-Area or 200-West Area disposal sites (from Section 1.5). (A distinction is made in the DEIS between short-term impacts that occur during decommissioning operations and long-term impacts that occur following the completion of decommissioning operations to 10,000 years.) Other impacts afford little or no basis for choice among al ternatives.

\subsubsection{Preferred Alternative}

The DOE has analyzed the environmental impacts of decommissioning the eight surplus production reactors at the Hanford Site and has analyzed public and agency comments received on the DEIS during the public comment period.

The environmental impacts of the alternatives do not offer a strong basis for selection among the alternatives (see Table 1.2). For example, the difference in worker dose between immediate one-piece removal and deferred 
IABLE 1.1. Costs of Decommissioning Alternatives ${ }^{(a)}$

\begin{tabular}{|c|c|c|c|c|c|}
\hline Activity & No Action & $\begin{array}{c}\text { Immediate } \\
\text { One-Piece } \\
\text { Removal }\end{array}$ & $\begin{array}{c}\text { Safe Storage } \\
\text { Followed by } \\
\text { Deferred } \\
\text { One-Piece } \\
\text { Removal } \\
\end{array}$ & $\begin{array}{l}\text { Safe Storage } \\
\text { Followed by } \\
\text { Deferred } \\
\text { Dismantlement }\end{array}$ & $\begin{array}{l}\text { In Situ } \\
\text { Decommissioning }\end{array}$ \\
\hline Safe storage & 43.5 & -- & 35.9 & 38.0 & -- \\
\hline Mound/barrier & -- & - & -- & - & 61.9 \\
\hline Burial site/barrier & -- & 46.6 & 46.6 & 15.9 & -- \\
\hline $\begin{array}{l}\text { Construct ground-water } \\
\text { monitoring wells }\end{array}$ & -- & 1.6 & 1.6 & 1.6 & 2.1 \\
\hline Ground-water monitoring & - & 38.1 & 8.8 & 10.3 & 101.6 \\
\hline $\begin{array}{l}\text { Other decommissioning } \\
\text { costs }\end{array}$ & $\ldots$ & 142.0 & $\underline{142.0}$ & 245.5 & 27.4 \\
\hline TOTALS & 43.5 & 228.3 & 234.9 & 311.3 & 193.0 \\
\hline
\end{tabular}

(a) Costs are for 100 years, in millions of 1990 dollars. 


\begin{tabular}{|c|c|c|c|c|c|c|}
\hline Alternat ive & $\begin{array}{l}\text { Occupational } \\
\text { Radiation } \\
\text { Dose } \\
\text { (person-rem) }\end{array}$ & $\begin{array}{c}\text { Occupationa } 1 \\
\text { Cancer } \\
\text { Fatalities } \\
\end{array}$ & $\begin{array}{l}\text { Total Cost } \\
\text { (millions } \\
\text { of } 1990 \mathrm{~s})\end{array}$ & $\begin{array}{l}\text { Population } \\
\text { Dose ove } \\
10,000 \mathrm{yr}^{\text {(b) }} \\
\text { (person-rem) }\end{array}$ & $\begin{array}{c}\text { Population } \\
\text { Cancer } \\
\text { Fatalities }\end{array}$ & $\begin{array}{l}\text { Maximum } \\
\text { We } 11 \text { Dose } \\
\text { (rem/yr) } \\
\end{array}$ \\
\hline $\begin{array}{l}\text { No action (con- } \\
\text { tinue present } \\
\text { action) }\end{array}$ & 24 & 0 & 44 & 50,000 & 20 & 1.2 \\
\hline $\begin{array}{l}\text { Immediate one- } \\
\text { piece remova } 1\end{array}$ & 159 & 0 & 228 & 1,900 & 1 & 0.04 \\
\hline $\begin{array}{l}\text { Safe storage fol- } \\
\text { lowed by deferred } \\
\text { one-piece removal }\end{array}$ & 51 & 0 & 235 & 1,900 & 1 & 0.04 \\
\hline $\begin{array}{l}\text { Safe storage fol- } \\
\text { lowed by deferred } \\
\text { dismant lement }\end{array}$ & 532 & 0 & 311 & 1.900 & 1 & 0.04 \\
\hline $\begin{array}{l}\text { In situ decom- } \\
\text { missioning }\end{array}$ & 33 & 0 & 193 & 4,700 & 2 & 0.03 \\
\hline
\end{tabular}

(a) Quantities are for all eight reactors. Costs are for 100 years.

(b) The same population would receive 9 billion person-rem over 10,000 years and 900.000 to $9 \mathrm{million}$ health effects from natural radiation.

(c) This is the maximum dose rate to a person drinking water from a well drilled near the waste form at any time up to 10.000 years.

one-piece removal is not significant. But based on its review of environmental impacts, total project costs, and the results of the public hearing process, the DOE selects safe storage followed by deferred one-piece removal as the agency's preferred alternative for decommissioning the Hanford surplus production reactors.

In May 1989, subsequent to issuing the DEIS, the DOE entered into the Hanford Federal Facility Agreement and Consent Order (Tri-Party Agreement). This agreement includes the management of hazardous wastes at the Hanford Site and the administration of remedial and corrective actions (cleanup) for hazardous wastes, hazardous substances, and other pollutants and contaminants at the Hanford Site under RCRA and CERCLA. While this agreement does not explicitly include decommissioning of the eight surplus reactors, it does recognize that certain activities related to decommissioning may be subject to RCRA. The agreement provides that whenever decommissioning activities "result in the generation of hazardous wastes, the treatment, storage, and disposal of those wastes shall be subject to this Agreement." The Tri-Party Agreement 
further provides that "in the event a contaminated structure is found to be the source of a release (or presents a substantial threat of a release) of hazardous substances, hazardous wastes, or hazardous constituents to the environment, the investigation and remediation of such a release (to include remediation of structures, as necessary), where subject to CERCLA or RCRA, shall also be subject to this Agreement." The Tri-Party Agreement also contemplates completion of remedial and corrective action at Hanford in 30 years.

The DOE proposes to complete this decommissioning action consistent with the proposed 30-year Hanford clean-up schedule for those Hanford remedial actions included in the Tri-Party Agreement Action Plan. Therefore, the safestorage period would be for less than 30 years versus the 75 years assumed in the DEIS for the deferred one-piece removal alternative. (This shortened safe-storage period results in costs and environmental impacts that are bounded by the immediate and the deferred one-piece removal alternatives discussed in the DEIS.) The DOE also intends to evaluate the priority of this decommissioning action relative to the priority of RCRA/CERCLA remediation of the 100-Area past-practice units being conducted under the Tri-Party Agreement. Should the selection of this alternative eventually be shown to be inconsistent with subsequent RCRA and CERCLA remediation decisions, the DOE will reevaluate the appropriateness of proceeding with this alternative on an area-by-area basis. DOE will continue to conduct routine maintenance, surveillance, and radiological monitoring activities in order to ensure continued protection of the public and the environment during the safe-storage period.

The DOE nominated the B Reactor for inclusion in the National Register of Historic Places in accordance with the opinion of the Washington State Historic Preservation Officer and the provisions of 36 CFR 800, "Protection of Historic and Cultural Properties." On April 3, 1992, the National Park Service entered the B Reactor in the National Register. Specific actions to mitigate the impact of decommissioning on the historic preservation of B Reactor will be determined later in accordance with 36 CFR 800 . Actions to preserve this historic resource may include extensive recordation by photographs, drawings, models, exhibits, and written histories, and may also 
Summary; Affected Environment

include preservation of some portions of the B Reactor for display on or near its present location or at some other selected location.

\subsection{AFFECTED ENVIRONMENT}

The affected environment includes areas both on the Hanford Site and external to the Hanford Site that might be impacted by decommissioning (see Figure 1.1). These areas are briefly described in the following sections.

\subsubsection{Description of Impacted Portions of the 100 and 200 Areas}

In early 1943, the U.S. Army Corps of Engineers selected the Hanford Site as the location for reactor and chemical separation facilities for the production and purification of plutonium for possible use in nuclear weapons. Areas of the Site that may be impacted by the decommissioning of the eight surplus production reactors are described in the following sections.

\subsubsection{100 Areas}

The 100 Areas are all on relatively flat terraces and bars near the Columbia River with elevations generally between 120 meters and 150 meters above mean sea level, and from about 11 meters to 30 meters above normal river level. The topography is characterized by low relief and gentle slopes. Small gravel mounds to 10 meters in height are found between the $100-\mathrm{K}$ and 100-D Areas.

The 100-B/C Area occupies about 263 hectares, and is the farthest upstream of the 100 Areas, at river mile 384. Essentially all facilities in the area are surplus, with the principal exception of the $100-B / C$ water system, which supplies water for the 200 Areas. The 100-K Area occupies about 55 hectares at river mile 381.5. The KE and $K W$ fuel storage basins are in operation for the purpose of storing irradiated fuel from the $\mathrm{N}$ Reactor. The 100-N Area occupies about 36 hectares at river mile 380 . Its facilities are now retired. The 100-D/DR Area occupies about 389 hectares at river mile 377.5. While the reactor and fuel storage basins are surplus, other facilities remain in operation at the 100-0/DR Area. Sanitary and fire-protection water is transported by pipeline from the 100-D/DR Area to the 100-H and 100-F Areas, and back-up water is supplied to the 200 Areas in support of the 
100-B/C water system. The 100-H Area occupies 130 hectares at river mile 372.5. Al1 major buildings have been removed from the 100-H Area except the 105 building. The 100-F Area occupies 219 hectares at river mile 369. A11 facilities except the 105, 108, and 1608 buildings have been removed from the 100-F Area.

Contaminated solid and liquid wastes from the 100 Areas are buried in approximately 110 inactive waste-disposal sites in the 100 Areas. These sites are currently being reviewed by the DOE pursuant to its responsibilities under CERCLA, RCRA, and the Tri-Party Agreement.

\subsubsection{200 Areas}

The 200 Areas are located near the middle of the Hanford Site, about 11 kilometers from the Columbia River. The topography is nearly flat and varies in elevation from about 190 to 245 meters above mean sea level. Facilities and sites exist in the 200 Areas for nuclear fuel processing, plutonium separation, plutonium fabrication, high-level and transuranic radioactive waste handling and storage, and low-level radioactive waste handling and disposal.

Contaminated solids and liquids from the entire Hanford Site are buried in both inactive and active low-level waste burial grounds in the 200 Areas. Low-level wastes from the removal and dismantlement decommissioning alternatives would be buried in the 200 -West Area.

\subsubsection{Geology and Hydrology of the Site}

The Hanford Site is located in the semiarid Pasco Basin, a structural and topographic depression within the Columbia Plateau in southeastern Washington State. The 100 Areas are located adjacent to the Columbia River on the lowest of several levels of alluvial terraces on the Site. The normal elevation of the river is 116 meters above mean sea level, and the elevations of the reactor ground-floor levels range from 125.7 to 150.6 meters. The 200 Areas are located near the center of the Site on a large bar of sand and gravel known as the 200-Area Plateau. The 200-Area Plateau ranges in elevation from 190 to 245 meters above mean sea level. 


\subsubsection{Geology of the Site}

The principal stratigraphic units at the Hanford Site are the Columbia River Basalt Group with interbedded sediments of the Ellensburg Formation, which forms the bedrock beneath the Site; the Ringold Formation, consisting of semiconsolidated clays, silts, sands, and gravels lying directly over the bedrock; and the Hanford Formation, composed of a thin surface mantle of sands, gravels, and wind-blown silts overlying the Ringold Formation. The basalt is as much as 5,000 meters thick, and the Ringold and Hanford Formations are up to 360 meters and 100 meters thick, respectively.

\subsubsection{Hydrology of the Site}

The primary surface water features of the Hanford Site are the Columbia and Yakima Rivers. Surface run-off from the site to these two rivers is extremely low. The average annual flow of the Columbia River at Hanford is about 3,400 cubic meters per second, and the average annual flow of the Yakima River at Kiona (see Figure 1.1) is about 104 cubic meters per second. Normal Columbia River elevations range from 120 meters above mean sea level at Vernita, where the river enters the Site, to 104 meters at the 300 Area, where it leaves the Site. The dam-regulated probable maximum flood would produce a flow of about 40,800 cubic meters per second in the Columbia River and would reach the elevation of the bottom of the fuel storage basins at $100-F$ and $100-\mathrm{H}$, but would not reach the floor of any reactor building. A $50 \%$ failure of Grand Coulee Dam would create a maximum flow of about 226,500 cubic meters per second and flood elevations of 143 to 148 meters in the 100 Areas. Parts of the 100 and 300 Areas and most downstream cities would be flooded. The 200 Areas would not be reached by this flood.

Ground water occurs under the Site in both unconfined and confined aquifers. The unconfined (upper) aquifer is contained within the glaciofluvial sands and gravels in the Ringold Formation. The bottom of the unconfined aquifer is the basalt surface of the Columbia River Basalt Group or the clay zones of the lower member of the Ringold Formation. The confined aquifer consists of sedimentary interbeds and/or interflow zones that occur between dense basalt flows in the Columbia River Basalt Group. Direct interconnections occur between the unconfined and uppermost confined aquifers. Natural 
recharge to the unconfined aquifer may occur in small amounts from precipitation and surface run-off. Artificial recharge to the unconfined aquifer in the 200 Areas results from the disposal of waste cooling and process water to the ground. Depth to the water table averages about 12 meters in the 100 Areas and from 55 to 95 meters in the 200 Areas.

\subsubsection{Climate, Meteorology, and Seismology of the Site}

The Hanford climate can be described as arid, hot in summer and cool in winter. Rainfall averages 16 centimeters per year, and average temperatures range from $1.5^{\circ} \mathrm{C}$ in January to $24.7^{\circ} \mathrm{C}$ in July. The prevailing wind is from the northwest with a secondary maximum from the southwest. Summer winds frequently reach velocities of 50 kilometers per hour. The 100 -year extreme wind is estimated to have a velocity of 137 kilometers per hour. Tornado probabilities are small.

The Columbia Plateau is in an area of moderate seismicity. Swarms of smal1, shallow earthquakes are the predominant seismic events, with magnitudes of 1.0 to 3.5 on the Richter scale.

\subsubsection{Air Quality, Water Quality, and Environmental Monitoring of the Site}

Air quality in the vicinity of the Hanford Site is good except for occasional episodes of wind-blown dust from dry plowed fields and construction areas. The major nonradioactive industrial air pollutant release is from the PUREX and Uranium Oxide Plants, which discharge oxides of nitrogen under a Prevention of Significant Deterioration (PSD) permit issued by the EPA. Average annual $\mathrm{NO}_{2}$ concentrations at all Hanford Site and nearby monitoring locations were well below federal and state ambient air standards in 1987.

The WDOE classifies the Columbia River as Class $A$ (excellent) between Grand Coulee Dam and the mouth of the river. The DOE holds a National Pollutant Discharge Elimination System (NPDES) permit issued by the EPA for eight point source discharges into the Columbia River.

Radiological monitoring of the atmosphere, ground water, Columbia River water, foodstuffs, plants, animals, and soil is conducted routinely by the Pacific Northwest Laboratory (PNL). Measurements made in 1987 showed slight elevations of krypton-85, uranium, polonium, and iodine-129 concentrations in 
air at site perimeter monitoring stations relative to background concentrations measured at more distant monitoring stations. Only iodine-129 showed a statistically significant difference. Water measurements made in 1987 showed that radionuclides have entered ground water in the 200 Areas and migrated easterly to the Columbia River. Samples collected from the Columbia River upstream and downstream from the Hanford Site indicate that tritium, iodine-129, gross alpha, and uranium concentrations were measurable at higher concentrations downstream from Hanford than upstream, but that all offsite concentrations are well within EPA drinking water standards. The major sources of radionuclides entering the river are from $\mathbf{N}$ Reactor liquid-disposal facilities (no longer in service) and from 200-Area ground water moving below the Hanford Site and into the river. Foodstuffs from the area, including those irrigated with Columbia River water, were sampled, and the concentrations of radionuclides were shown to be similar to the low concentrations in foodstuffs grown in other adjacent areas. Some waterfowl, fish, and rabbits showed low levels of cesium-137 attributable to Hanford operations. Dose rates from external penetrating radiation measured in the vicinity of local residential areas were similar to those obtained in previous years, and no contribution from Hanford activities could be identified. Nonradiological monitoring for chemical constituents included routine sampling and a special effort involving hazardous materials. Some elevated levels of nitrate, chromium, fluoride, and carbon tetrachloride were found in ground-water samples. Columbia River waters were within State of Washington water quality standards, with the exception of $\mathrm{pH}$ and fecal coliform bacteria. These latter contaminants are not attributable to Hanford Site activities.

Measured and calculated radiation doses to the general public from Hanford operations during 1987 were well below applicable regulatory limits. The calculated effective dose potentially received by a hypothetical maximally exposed individual for 1987 was about 0.05 millirem, compared with a dose of 0.09 millirem estimated for 1986 . The collective effective dose to the population living within 80 kilometers of the Site estimated for 1987 was 4 person-rem, compared with 9 person-rem estimated for 1986. 
These doses can be compared with the 300 millirem and 100,000 person-rem received annually by an average individual and by the surrounding population, respectively, as a result of naturally occurring radiation.

\subsubsection{Ecology}

The ecology of the Hanford Site is that of a cool desert or shrub steppe. Because of the arid climate, the productivity of both plants and animals is relatively low compared with that of other natural communities with higher rainfall.

\subsubsection{Terrestrial and Aquatic Ecology}

The dominant plants on the Hanford Site are large sagebrush, rabbitbrush, cheatgrass, and Sandberg bluegrass. Cottonwoods, willows, cattails, and bulrushes grow along ponds and ditches. Cheatgrass and Russian thistle invade areas where the ground surface has been disturbed. More than 300 species of insects, 11 species of reptiles and amphibians, more than 125 species of birds, and 27 species of mammals are found on the Site. Coyote, elk, and mule deer are the largest mammals observed on the Site. The Columbia River supports the most important aquatic ecosystem on the Site. Forty-five species of fish have been identified in the Hanford Reach.

\subsubsection{Threatened and Endangered Species}

None of the plant species occurring on the Site are federally listed as threatened or endangered. The bald eagle and peregrine falcon are animal species federally listed as threatened and endangered, respectively. While the bald eagle is a regular winter resident and the peregrine falcon is a casual migrant, neither species nests on the site.

\subsubsection{Socioeconomics of the Area Surrounding the Site}

The Tri-Cities (Kennewick, Pasco, and Richland, Washington) and the surrounding area have been designated a Metropolitan Statistical Area (MSA) by the U.S. Bureau of the Census. About 376,000 people live within an 80-kilometer radius of the center of the Site according to the 1990 census. About 16,000 persons are employed on DOE-related projects at Hanford. 


\section{Summary; Environmental Consequences}

Service amenities in the Tri-Cities are provided by various agencies and units of government and by private organizations in the MSA (e.g., schools, fire and police protection, utilities, medical facilities, parks, and shopping facilities).

Major 1 and use in the area includes the Hanford Site, urban and industrial development in and around incorporated cities, irrigated farming, and dry farming.

Nine archaeological properties located on the Hanford Site have been identified and listed in the National Register of Historic Places, but none are within the 100 or 200 Areas. Preoperational surveys at proposed borrowpit sites and around the reactors will be conducted in advance of any decommissioning operations to ensure that no cultural resource or archaeological site is inadvertently impacted or disturbed.

The DOE nominated the B Reactor for inclusion in the National Register of Historic Places in accordance with the opinion of the Washington State Historic Preservation Officer. On April 3, 1992, the National Park Services entered the $B$ Reactor into the National Register.

The Hanford Site is located on lands ceded to the U.S. government by the Yakima and Umatilla Indians and is near lands ceded by the Nez Perce Indians.

\subsubsection{Transportation}

The area is served by major interstate, U.S., and state highways; by commercial airlines; by two railroads; and by barge service on the Columbia River. DOE-owned railway and highway systems serve the Hanford Site.

\subsection{ENVIRONMENTAL CONSEQUENCES}

Environmental consequences other than those discussed in Section 1.3 are discussed in this section.

\subsection{1 - 1.5 .6 Radiological Consequences}

Radiological consequences may occur as part of decommissioning operations, as a result of accidents during decommissioning, and as a result of long-term, postdecommissioning releases of radionuclides from the disposed 
low-level radioactive wastes. In all three cases, the radionuclide inventory described in Section 1.3 provides the basis for the calculated potential radiological impact. Occupational radiation doses are discussed in Section 1.3 (Table 1.2) and result from external exposure to gamma radiation. Accidental and long-term radiation doses are discussed below.

During decommissioning operations, the most probable source of radiation exposure to the public is inhalation of airborne radionuclides released by accidents. Several postulated accidents were analyzed. The one of largest radiological consequence was determined to be a railroad-crossing collision of a gasoline tanker with a boxcar carrying reactor graphite; this postulated accident occurred under the safe storage followed by deferred dismantlement alternative. Although the graphite would not burn, the resulting 30-minute fire would release radioactive particulates to the atmosphere sufficient to cause a lifetime dose of 0.2 rem to the maximally exposed individual member of the public.

The radiological consequences of long-term releases of radionuclides to the ground water over 10,000 years from the 200-Area disposal site and from the 100-Area in situ sites were also calculated, based on calculated release rates from the solid wastes and on estimated travel times to the Columbia River. Population doses from these releases were calculated to be about 50,000 person-rem ( 5 to 50 heal th effects) for no action (continued present action), 1,900 person-rem ( 0.2 to 2 health effects) for the removal and dismantlement alternatives, and 4,700 person-rem ( 0.5 to 5 health effects) for in situ decommissioning. During the same time period $(10,000$ years $)$, the same population (410 million affected individuals) would receive 9 billion person-rem ( 900 thousand to 9 million health effects) from natural radiation sources.

Maximum annual individual doses over 10,000 years were also calculated for persons drinking water from wells drilled near the waste-disposal sites. These calculated doses are 1.2 rem per year for no action, 0.04 rem per year for the removal and dismantlement alternatives, and 0.03 rem per year for in situ decommissioning. 


\subsubsection{Impacts from Hazardous Wastes}

Based on known release rates and on estimated travel times, estimates were made of the maximum concentration of lead in well water near the wastedisposal sites over 10,000 years. For the no action alternative, the maximum concentration of lead is estimated to be $6 \times 10^{-4}$ milligrams per liter; for the removal and dismantlement alternatives, the concentration of lead is estimated to be $4.9 \times 10^{-4}$ milligrams per liter; and for the in situ decommissioning alternative, the concentration of lead is estimated to be $1.2 \times 10^{-4}$ milligrams per liter.

\subsubsection{Socioeconomic Impacts}

Socioeconomic impacts are caused primarily by the influx (or egress) of workers required by the project. The maximum number of workers required onsite at any one time for any decommissioning alternative is 100 . This number is less than $1 \%$ of the workers presently on the Site and would produce negligible socioeconomic impacts.

\subsubsection{Commitment of Resources}

Resources committed to the decommissioning of the Hanford surplus reactors would include the land on which the reactors now stand and the necessary grout and fill material for in situ decommissioning, the land required for low-level waste disposal for either the one-piece removal or dismantlement alternatives, and the energy necessary to carry out the alternative for any of the alternatives. 'Land commitments are discussed in the next section.

It is estimated that approximately 98,000 cubic meters of grout and $1,600,000$ cubic meters of fill material would be required for in situ decommissioning of all eight reactors.

Approximately 6 million, 2 million, and 5 million liters of fuel would be consumed for one-piece removal, dismantlement, and in situ decommissioning, respectively.

\subsubsection{Unavoidable Adverse Impacts}

Unavoidable adverse impacts would result from each decommissioning alternative. The most important of these is occupational radiation dose, 
which is greatest for safe storage followed by deferred dismantiement (532 person-rem), less for immediate one-piece removal (159 person-rem) and safe storage followed by deferred one-piece removal (51 person-rem), and least for in situ decommissioning (33 person-rem). The occupational radiation dose is least for in situ decommissioning because the reactor block is neither handled nor disassembled.

Another adverse impact is the dedication of land to the disposal of radioactive waste. The 1 and required for radioactive-waste disposal in the 200 Areas is about 6 hectares, which is offset by the 5 hectares that would become available for other DOE use in the 100 Areas following removal or dismantlement of all eight reactors. For in situ decommissioning, however, about 20 hectares of land would be occupied in the 100 Areas by the eight reactor mounds, although no additional 1 and would be required in the 200 Areas for radioactive-waste disposal.

Approximately 16 hectares of Iand could be disrupted for excavation of earth and gravel for in situ decommissioning (depending on the depth of the excavation), but this land can be reclaimed and would remain available for other use.

\subsubsection{Short-Term Versus Long-Term Use of the Environment}

Each decommissioning alternative will require the use of some land for disposal of radioactive wastes and will restrict that 1 and from other beneficial uses for long periods of time because of the presence of long-lived radionuclides, principally carbon-14 and chlorine-36. The amount of land thus restricted was discussed in Section 1.5.10.

\subsubsection{Means to Mitigate Adverse Environmental Impacts}

Adverse environmental impacts that can be mitigated include occupational radiation doses, disruption to land areas, and migration of chemicals and radionuclides caused by water infiltration through waste-disposal sites.

Decommissioning workers will wear dosimeters, and radiation zones will be monitored before workers are allowed to enter. Protective shields, remotely operated tools, and contamination control envelopes will be employed when appropriate. Standard contamination monitoring devices will be used. 
ALARA (as low as reasonably achievable) principles will be applied in every phase of engineering planning that deals with radioactive material to reduce worker exposure.

Sites used for the acquisition of dirt and gravel will be surveyed for archaeological resources and endangered species, and will be rehabilitated when no more material need be acquired from the site.

Water migration through the waste-disposal sites (both the 200-West Area and the 100-Area sites) will be mitigated by the installation of a multilayer, engineered barrier consisting of a capillary layer of fine-textured soil underlain by an impervious layer of soil/bentonite clay. Calculations in the DEIS are based on a water infiltration rate through the barrier of 0.1 centimeter per year.

\subsubsection{Cumulative Impacts}

No significant additional cumulative impact from decommissioning the surplus production reactors is expected in conjunction with existing or reasonably foreseeable future actions at the Hanford Site.

\subsection{STATUTORY AND REGULATORY REQUIREMENTS}

Decommissioning will be carried out in accordance with DOE's environmental policy, which is "to conduct its operations in an environmentally safe and sound manner... in compliance with the letter and spirit of applicable environmental statutes, regulations, and standards."

Environmental regulations and standards of potential relevance to decommissioning are those promulgated by the EPA under the Atomic Energy Act (AEA), the CAA, Clean water Act (CWA), Safe Drinking water Act (SDWA), RCRA, and CERCLA. State environmental regulations, including dangerous waste regulations, have also been promulgated under the authority of some of these federal statutes. Other relevant environmental statutes include the National Historic Preservation Act, the Archaeological Resources Protection Act, the American Indian Religious Freedom Act, the American Antiquities Act, the Endangered Species Act, the Bald and Golden Eagle Protection Act, the Migratory Bird Treaty Act and Public Law 100-605, the Hanford Reach Study Act. The DOE will 
consult with affected Indian tribes during decommissioning to ensure that Indian treaty and statutory rights are not abridged and that Indian historic sites are protected. Regulations of the U.S. Nuclear Regulatory Commission do not apply to the decommissioning of the surplus production reactors.

No EPA or state-issued permit is expected to be required for decommissioning purposes, with the possible exception of a RCRA permit for permanent disposal of the reactor blocks. No existing EPA or state standard is expected to be exceeded either by decommissioning operations or by disposal actions. 


\subsection{RESPONSES TO COMMENTS ON THE}

\section{DRAFT ENVIRONMENTAL IMPACT STATEMENT}

Specific comments, included in letters received by DOE and in oral testimony at the public hearings, are presented in this chapter along with DOE's responses. Persons and agencies who provided comments are listed in Section 9.1. Preferences for one decommissioning alternative over another and preferences for or against historic preservation of the B Reactor are recorded in Section 9.2. Comments and responses are presented in Section 9.3.

Letters were reviewed first, followed by the exhibits and then the transcripts. In those cases where an individual or organization made the same comment in more than one format, an attempt was made to respond (or record a preference) only once. Comments were edited by the reviewers for brevity, consistency of style, and focus; however, a conscious effort was made in all cases to capture the intent of the commenter. In some cases (most often in transcript comments), the reviewers were unable to discern the meaning of the comment, and these comments are not presented here.

Letters, transcripts, and exhibits are reproduced in their entirety in Appendix 0.

\subsection{PERSONS AND AGENCIES PRESENTING COMMENTS}

Section 9.1.1 lists the letters, 9.1.2 the transcript pages, and 9.1.3 the exhibits containing comments on the DEIS. The letters and exhibits are numbered according to the order in which they were received; the transcripts are identified according to the city in which each hearing was held. Section 9.1.4 contains an alphabetical list of all groups and individuals who provided comment, along with the corresponding letter, transcript, or exhibit number(s) for each. 
Responses to Comments; Persons and Agencies

The following notations are used:
$C=$ Comment
Tr $-P=$ Portl and transcript
Ex = Exhibit
$T r-R=R i c h l$ and transcript
$\mathrm{L}=$ Letter
$R=$ Response
$T r-S e=$ Seattle transcript ${ }_{(a)}$
$T r-S p=$ Spokane transcript

\subsubsection{Letters}

LOO1A

LOO1B

L002

L003

L004

L005

L006

L007

L008

L009

L010

L011

L012

L013

L014, L015
D'Arcy P. Banister

U.S. Department of the Interior

Alton Haymaker

Dennis R. Arter

J. R. Young

Roger C. Gibson

Jacob E. Thomas

Washington Historic Preservation Officer

Lourdes Fuentes-Williams

Coalition Organizing Hanford Opposition

June A. Sawyer

Richard L. Larson

Washington Department of Transportation

John T. Greeves

U.S. Nuclear Regulatory Commission

Dr. and Mrs. Michael Berg

H. Dale Hellewell

Ora Mae and Floyd Orton

Dennis D. Skeate

Benton County Management Team

M. J. Szulinski

(a) All of the comments in the Spokane transcripts are contained in the exhibits and were addressed in that way. 
Responses to Comments; Persons and Agencies

L016

L017

L018

L019

L020

L021

L022

L023

L024

L025

L026

L027

L028

L029

L030

L031

L032

L033

L034

L035

L036
Beulah L. Sumner

Beth D. Marsau

Jim Thomas

Hanford Education Action League

J. Ross and Lois H. Adams

Stephen J. Doyle

Bonnie Tucker Doyle

The Honorable John Poynor

Richl and City Council

Johnson

Mr. and Mrs. M. W. Bradshaw

The Honorable Max E. Benitz

Washington State Senate

Barbara Richardson

Theresa Potts

Al an Richards

Barbara Harrah

Lantz Rowland

Thomas M. Clement

Colleen Bennett and Adele Newton League of Women Voters of Oregon

The Honorable Brad Fisher

Kennewick City Counci1

The Honorable Ed Hendler

Pasco City Council

Hans C. F. Ripfel

Tri-Cities Technical Council

Tom Lande 
Responses to Comments; Persons and Agencies

L037

L038

$\mathbf{L O 3 9}$

L040

L041

L042

L043

L044

L045

L.046

L047

L048

L049

L050

L051

L052

L053
David E. Clapp

Washington Department of Health and Human Services

The Honorable Robert Drake

Benton County Board of Commissioners

Richard J. Leaumont

Lower Columbia Bas in Audubon Society

Richard J. Leaumont

Columbia River Conservation League

T. H. McGreer

Christine 0 . Gregoire

Washington Department of Ecology

J. Ernesto Baldi

Michael R. Cummings

Ray 01ney

Yakima Indian Nation

[duplicate of L045]

Tom Wynn

Trail and District Environmental Network

Michael Gilfillan

Kootenay Nuclear Study Group

Ronald A. Lee

U.S. Environmental Protection Agency, Region 10

Rex Buck, Jr.

Wanapum Tribe

Laurel Kay Grove

The Honorable Dean Sutherland Washington State Senate

C. M. Conselman

Columbia Section, American Society of Civil Engineers 
Responses to Comments; Persons and Agencies

\subsubsection{Transcripts}

\section{Richland}

Tr-R17

$\operatorname{Tr}-\mathrm{R} 20$

$\operatorname{Tr}-\mathrm{R} 24$

$\operatorname{Tr}-\mathrm{R} 27$

$\operatorname{Tr}-\mathrm{R} 29$

$\operatorname{Tr}-\mathrm{R38}$

$\operatorname{Tr}-\mathrm{R} 43$

$\operatorname{Tr}-\mathrm{R} 45$

$\operatorname{Tr}-\mathrm{R} 49$

$\operatorname{Tr}-\mathrm{R} 53$

Spokane

Tr-Sp16

$\operatorname{Tr}-\operatorname{Sp22}$

Portland

Tr-P16

$\operatorname{Tr}-\mathrm{P} 20$

Tr-P22

Tr-P24
Alton Haymaker

John Burnham

Tri-Cities Industrial Development Council

Gordon Rogers

Jim Stoffels

The Honorable $\mathrm{Claude} 01$ iver

Benton County Treasurer

Harry Brown

Columbia Basin Section

American Society of Mechanical Engineers

Dick Hammond

Milton Lewis

Eleanor Finkbeiner

The Honorable Raymond Isaacson

Benton County Commissioner

Jim Thomas

Hanford Education Action League

Mary Wieman

Eugene Rosalie Northwest Environmental Advocates

T. H. McGreer

Ruth McGreer

David Stewart-Smith

Oregon Department of Energy 
Responses to Comments; Persons and Agencies

$\operatorname{Tr}-\mathrm{P} 36$

JoAnn Oleksiak

Tr-P39

Martha Odom

$\operatorname{Tr}-\mathrm{P} 47$

Bi11 Jones

$\operatorname{Tr}-\mathrm{P} 50$

Eugene Rosalie

Northwest Environmental Advocates

Tr-P52

Kathleen Maloney

Seattle

$\operatorname{Tr}-\operatorname{Se} 15^{(\mathrm{a})}$

Dan Silver

Washington State Governor's Office

$\operatorname{Tr}-\mathrm{Se} 24$

Barbara Zepeda

Washington Democratic Council

$\operatorname{Tr}-\mathrm{Se} 48$

Sharon Gann

$\operatorname{Tr}-\mathrm{Se} 48$

Frank Hammond

Sierra Club, Cascade Chapter

$\operatorname{Tr}-\mathrm{Se} 52$

Mark B1oome

Heart of America Northwest

$\operatorname{Tr}-\mathrm{Se} 55$

Brendon Mahaffey

$\operatorname{Tr}-\mathrm{Se} 60$

Donna Bernstein

Heart of America Northwest

$\operatorname{Tr}-\mathrm{Se} 65$

Russ Childers

$\operatorname{Tr}-\mathrm{Se} 68$

Mark Bloome

Heart of America Northwest

\subsubsection{Exhibits}

ExO1

CEQ Guidelines

ExO2

Notice of Intent

Ex03

Notice of Availability

Ex04

Schedule of Public Involvement Activities

Ex05

Ivan M. A. Garcia

(a) These comments repeat those of $\mathrm{L} 042$, and are recorded under $\mathrm{LO} 42$. 
Ex06

Ex07

Ex08

Ex09

Ex10

Ex11

Ex11
Alton Haymaker

John Burnham

Tri-Cities Industrial Development Council

Jim Stoffel(s)

The Honorable Claude 01 iver

Benton County Treasurer

Harry Brown

Columbia Basin Section

American Society of Mechanical Engineers

The Honorable Raymond E. Isaacson

Benton County Commissioner

Jim Thomas

Hanford Education Action League

(Exhibit 11 was misnumbered by the hearing reporter. The comments are recorded in the FEIS under L018.)

Ex12

Mary R. Wieman

Ex12, Ex13

David Stewart-Smith

Oregon Department of Energy

(Exhibit 12 was misnumbered by the hearing reporter. Ali of the State of Oregon's comments are recorded in the FEIS under Exhibit 13.)

Ex14

Hale Weitzman

Ex15

Barbara Zepeda

Washington Democratic Counci1

Ex16

Frank Hammond

Sierra Club, Cascade Chapter

Ex17

Donna Bernstein

Heart of America Northwest

\subsubsection{Alphabetical List of Commenters}

Adams, J. Ross and Lois $H$.

Arter, Dennis R.

Baldi, J. Ernesto

Banister, D'Arcy P.

U.S. Department of Interior 
Responses to Comments; Persons and Agencies

Benitz, The Honorable Max E.

LO25

Washington State Senate

Bennett, Colleen

League of Women Voters

L032

Berg, Dr. and Mrs Michael

L010

Bernstein, Donna

Heart of America Northwest

Ex17, Tr-Se60

Bloome, Mark

Heart of America Northwest

$\operatorname{TrSe52,} \operatorname{Tr}-\mathrm{Se} 68$

Bradshaw, Mr. and Mrs. M. W.

Brown, Harry

Columbia Basin Section, American

Ex10, $\mathrm{Tr}-\mathrm{R} 38$

Society of Mechanical Engineers

Buck Jr., Rex

Wanapum Tribe

L050

Burnham, John

Tri-Cities Industrial Development

Council

Childers, Russ

$\operatorname{Tr}-\operatorname{Se} 65$

Clapp, David E. Washington Department of Health and Human Services

Clement, Thomas $M$.

Conselman, C. M.

Columbia Section, American Society of

Civil Engineers

Cummings, Michael R.

L044

Doyle, Bonnie Tucker

L021

Doyle, Stephen $\mathrm{J}$.

L020

Drake, The Honorable Robert

Benton County Board of Commissioners

L038

Finkbeiner, Eleanor

Tr-R49 
Responses to Comments; Persons and Agencies

Fisher, The Honorable Brad

Kennewick City Council

Fuentes-Wil1 iams, Lourdes

Coalition Organizing Hanford Opposition

L006

Garcia, Ivan M. A.

Ex05

Gibson, Roger C.

LO04

Gilfillan, Michael

Kootenay Nuclear Study Group

L048

Greeves, John T.

U.S. Nuclear Regulatory Commission

L009

Gregoire, Christine 0.

Washington Department of Ecology

L042

Grove, Laurel Kay

L051

Hammond, Dick

$\mathrm{Tr}-\mathrm{R} 43$

Hammond, Frank

Sierra Club, Cascade Chapter

Ex16, $\mathrm{Tr}-\mathrm{Se} 48$

Harrah, Barbara

L029

Haymaker, Alton

L001B, Ex06, Tr-R17

Hellewe11, H. Dale

L011

Hendler, The Honorable Ed

L034

Pasco City Council

Isaacson, The Honorable Raymond E.

Benton County Commissioner

Johnson

L023

Jones, Bill

$\operatorname{Tr}-\mathrm{P} 47$

Lande, Tom

L036

Larson, Richard L.

L008

Washington Department of Transportation 
Responses to Comments; Persons and Agencies

Leaumont, Richard J.

Lower Columbia Basin Audubon Society

Leaumont, Richard $J$.

Columbia River Conservation League

L040

Lee, Ronald A.

L049

U.S. Environmental Protection Agency, Region 10

Lewis, Milton

$\operatorname{Tr}-\mathrm{R} 45$

Mahaffey, Brendon

$\operatorname{Tr}-\operatorname{Se} 55$

Maloney, Kathleen

Tr-P52

Marsau, Beth D.

L017

McGreer, Ruth

Tr-P22

McGreer, T. H.

L041, Tr-P20

Newton, Adele

L.032

League of Women Voters of Oregon

Odom, Martha

Tr-P39

Oleksiak, JoAnn

Tr-P36

01 iver, The Honorable $\mathrm{Cl}$ aude

Ex09, Tr-R29

Benton County Treasurer

01ney, Ray

Yakima Indian Nation

Orton, Ora Mae and Floyd

$\mathrm{LO} 12$

Potts, Theresa

Poynor, The Honorable John

Richland City Council

Richards, Alan

L028

Richardson, Barbara

L026

Ripfel, Hans C. F.

Tri-Cities Technical Council 
Rogers, Gordon

Rosalie, Eugene

Northwest Environmental Advocates

Rowl and, Lantz

Sawyer, June A.

Silver, Dan

Washington State Governor's Office

Skeate, Dennis $D$.

Benton County Management Team

Stewart-Smith, David

Oregon Department of Energy

Stoffel(s), Jim

Sumner, Beulah L.

Sutherland, The Honorable Dean Washington State Senate

Szulinski, M. J.

Thomas, Jacob E.

Washington Historic Preservation Officer

Thomas, Jim

Hanford Education Action League

Weitzman, Hale

Wieman, Mary R.

Wynn, Tom

Trail and District Environmental Network

Young, J. R.

Zepeda, Barbara

Washington Democratic Council
$\operatorname{Tr}-\mathrm{R} 24$

Tr-P16

L030

$\llcorner 007$

Tr-Sel5

L013

Ex12, Ex13, Tr-P24

Ex08, Tr-R27

L016

L052

L014, L015

L005

L018, Ex11, Tr-Sp16

Ex14

Ex12, Tr-Sp22

L047

L003

Ex15, Tr-Se24 
Responses to Comments; Comments and Responses

\subsection{DECOMMISSIONING AND HISTORIC PRESERVATION PREFERENCES}

Comments expressing a preference for one decommissioning alternative over another and comments expressing a preference for historic preservation of the B Reactor are listed in Sections 9.2 .1 and 9.2 .2 by letter number, exhibit number, or transcript page number.

\subsubsection{Decommissioning Alternatives}

No Action: L015, Ex05, Ex06, Tr-R44.

Immediate One-Piece Removal: L006, L010, L012, L018, L019, L020, L021, L026, L027, L028, L029, L030, L032, L036, L037, L039, L040, L042, L043, LO44, L045, L047, L048, L053, Ex12, Ex13, Ex16, Tr-P16, Tr-P37, Tr-Se52, Tr-Se56, Tr-Se63, Tr-Se65.

Safe Storage Followed by Deferred One-Piece Removal: 1041.

Safe Storage Followed by Deferred Dismantlement: None.

In Situ Decommissioning: L007, L011, L017, L031, L035, Tr-R25.

Other: Ex14.

\subsubsection{Historic Preservation of B Reactor}

Do not preserve B Reactor as an historic site: L019, L020, L021, L028, L036, Ex12, Tr-P17, Tr-P37, Tr-P46.

Preserve B Reactor in place: L005, L014, L022, L025, L033, L034, L035, L038, L053, Ex05, Ex07, Ex08.

Preserve B Reactor by recordation: L007, L030, L031, L042, Ex10, Tr-R26.

\subsection{COMMENTS AND RESPONSES}

References in this section to page numbers, sections, and chapters are to pages, sections, and chapters in the DEIS.

LOO1A-CO1. The EIS should address mineral and energy resources, such as petroleum and methane, that may exist at the site and the environmental effects that may result from their exploration or extraction. 
R. The existence of large-scale mineral, petroleum, or methane resources beneath the Hanford Site has not yet been demonstrated. Large-scale exploration or extraction of resources discovered in the future would be the subject of another EIS.

L001A-C02. The EIS should discuss ground-water contamination resulting from deep drilling in search of hydrocarbon (primarily methane) resources.

R. Potential ground-water contamination resulting from deep drilling for hydrocarbons would be the subject of another EIS. Potential ground-water contamination resulting from the presence of surplus reactor decommissioning wastes is discussed in Section 5.7 .

L003-CO1. The estimated natural background dose in the DEIS of $300 \mathrm{milli}$ rem/year per person is too large.

R. As stated in Section 4.4.3 of the DEIS, the source of this information is the report entitled Environmental Monitoring at Hanford for 1987, PNL-6464, which relied on the 1987 National Council on Radiation Protection and Measurements report, Ionizing Radiation Exposure of the Population of the United States. The latter report includes an exposure of $200 \mathrm{mill}$ irem/year per person from radon gas and its daughters, in addition to the approximately $100 \mathrm{millirem} /$ year from other natural sources.

L003-C02. The flood damage caused by a break in Grand Coulee Dam would not be as catastrophic as a break in Mica Dam, which would release much more water and result in higher flood elevations and longer flood time.

R. The impact of immersion of a single reactor in the Columbia River resulting from a severe flood is discussed in Section 5.7.3 of the DEIS. The impact of immersion of all eight reactors would be approximately eight times the impact of immersion of a single reactor. This is the maximum impact from flooding related to decommissioning. The maximum impact is independent of flood times and elevations.

L003-C03. Cost tables in Chapter 3 contain too many significant figures. 
R. As explained in the DEIS, costs are deliberately not rounded for computational accuracy. Costs are re-estimated in Appendix $K$ of the FEIS in 1990 dollars.

L003-C04. Was a cost estimate made for each reactor, or was an estimate made for a typical reactor and adjustments made for gross differences among the reactors?

R. Cost estimates were made for a typical reactor and adjustments were made for differences among reactors. As stated in Chapter 3 of the DEIS, these differences are not very significant for decommissioning purposes.

L003-C05. No mention is made in the DEIS of the need to decontaminate ground contaminated by leaks in effluent lines and retention basins and by deliberate releases of up to $20,000 \mathrm{gpm}$ of reactor effluent for long periods of time into cribs near the retention basins and into a natural sump south of $C$ Reactor.

R. These releases are outside the scope of this EIS, but are within the scope of the Tri-Party Agreement among the DOE, the EPA, and the WDOE. This Agreement covers the management of hazardous wastes at the Hanford Site and the cleanup of hazardous wastes, hazardous substances, and other pollutants and contaminants at the Hanford Site.

L003-C06. Appendix E, "Methods for Calculating Radiation Dose," is superfluous; a source document could be cited instead.

R. The decision to reproduce the material in Appendix $E$ rather than simply cite a source document was made because of the importance of this material and because the methodology continues to change and evolve.

L003-C07. Appendix F, "Radiologically Related Health Effects," is a rehash of extensive literature on radiological health effects. DOE should prepare a document stating health-risk factors to be used in EISs and then incorporate the document by reference.

R. Appendix $F$ is included for the same reasons that Appendix $E$ is included. L003-C08. It is ridiculous to assume that the Hanford Site would be abandoned after 100 years. 
R. This assumption was made in order to terminate costs at some point and in order to be consistent with DOE Order 5820.2A and with EPA guidance in 40 CFR 191.14. These documents contemplate loss of institutional control after 100 years following disposal of the waste (see Chapter 3 ). As noted in the DEIS, the DOE does not intend to abandon the Site and will maintain institutional controls as long as they are necessary. Also see response to L010-CO1.

L003-c09. It would be helpful to know if the actual doses would be less or greater than those shown in Table 1.2 .

R. The dose calculations are meant to be conservative (Appendix G). Therefore, the actual doses should not exceed the calculated doses shown in Table 1.2 .

L003-C10. (1) Does the population dose in Table 1.2 include the maximum well dose and any accident doses? (2) What is the significance of the well dose? Why single out the well dose and not talk about the other, much larger doses shown in Table 1.2? (3) How many wells would be drilled?

R. (1) No. The accident and well doses are doses to individuals rather than to populations. (2) The well dose is an individual dose from one well and would be delivered to very few persons. The "much larger" doses shown in Table 1.2 are population doses and represent small individual doses summed over large populations. (3) The number of wells is immaterial because the dose calculation is based on all of the contaminated water being withdrawn by a single well (Section G.1.3.1).

L003-C11. DOE should let each commenter know what the response was to each comment.

R. In this FEIS, DOE is responding to each comment on the DEIS. DOE will send a copy of the FEIS to each commenter.

L004-C01. Nuclear waste should be broken up into particles that will sink to great depths when dispersed over large areas of the ocean.

R. While ocean disposal of radioactive wastes is permitted under certain conditions under the Marine Protection, Research, and Sanctuaries Act, the United 
States adheres to a resolution of the London Dumping Convention calling for a moratorium on ocean disposal of radioactive wastes. Ocean disposal would increase the probability of processing and transportation accidents relative to disposal at Hanford.

L005-CO1. The EIS should treat the B Reactor separately from the other reactors in view of its eligibility for nomination to the National Register of Historic Places. The issue of historic preservation should be explored in more detail in the FEIS. For example, the EIS should evaluate the feasibility of removing only the most hazardous portions of the reactor and retaining in situ as much as possible of the reactor building, control room, mechanical and electrical systems, and any other features that are not a long-term health risk.

R. The DOE nominated the $B$ Reactor for inclusion in the National Register of Historic Places in accordance with the opinion of the Washington State Historic Preservation Officer and the provisions of 36 CFR 800, "Protection of Historic and Cultural Properties." On April 3, 1992, the National Park Service entered the $B$ Reactor in the National Register. Specific actions to mitigate the impact of decommissioning on the historic preservation of B Reactor will be determined later in accordance with 36 CFR 800 . Actions to preserve this historic resource may include extensive recordation by photographs, drawings, models, exhibits, and written histories, and may also include preservation of some portions of the B Reactor for display on or near its present location or at some other selected location.

L006-C01. The impacts of floods more severe than floods from a $50 \%$ break of Grand Coulee Dam should be evaluated.

R. See response to L003-CO2.

L006-C02. What assurance can DOE give that decisions made today will be carried out in 75 years and that money for decommissioning will be available?

R. Authorization and funding to carry out decommissioning at any time depend on congressional action. DOE's record of decision will be essentially a recommendation to Congress to authorize the necessary funding. 
L006-C03. What is the basis for the cost estimate?

R. The cost estimates were made by different persons and firms familiar with the tasks involved, as explained in Chapter 3.

L008-C01. The transport and hauling of all materials on state highways must comply with regulations and guidelines pertaining to safe transportation of those materials.

R. DOE does not contemplate the offsite shipment of any decommissioning wastes on public highways. However, should this occur, transportation regulations will be met, as noted in Section 6.5 of the DEIS.

L009-CO1. The definition of decommissioning used in the DEIS, Section 2.0, "to isolate securely any remaining radioactivity in a manner that will reduce environmental impacts to an acceptable level," is different from NRC's in 10 CFR 50.2, in which it is indicated that decommissioning means to "reduce residual radioactivity to a level that permits release of the property for unrestricted use and termination of license." No definition is given as to what constitutes acceptable radioactive levels.

R. The definition in Section 2.0 should have been the same as the definition in Section 1.2, specifically: "The purpose of decommissioning is to isolate any remaining radioactive or hazardous wastes in a manner that will minimize environmental impacts, especially potential health and safety impacts on the public." At the present time, DOE does not intend to release the Site for unrestricted use, only for other DOE use as noted in Section 1.5.10. Procedures for determining "acceptable" residual radioactivity levels for release of properties are defined in DOE 5400.5, should they be required. The DOE reactors are not licensed by the Nuclear Regulatory Commission (NRC). The EPA is proceeding with a rulemaking ( 40 CFR 194) that is intended to establish guidelines for "Radiation Protection Criteria for Cleanup of Land and Facilities Contaminated with Residual Radioactive Materials." DOE will revise its procedures as appropriate and implement the EPA regulations as guidelines, when they are promulgated. Also see response to L010-COl.

L009-C02. Information is not given in the EIS as to the basis for the use of 75 years for the safe-storage period. Note that the NRC 1 imits the 
Responses to Comments; Comments and Responses

safe-storage period in 10 CFR 50.82 (b)(1) to 60 years unless a longer period is needed to protect public health and safety. Factors to be considered in extending the safe-storage period include the unavailability of waste disposal capacity and other site-specific factors such as the presence of other nuclear facilities at the site.

R. The 75-year safe-storage period is intended to allow decay of cobalt-60 and cesium-137 in order to reduce worker dose. A different storage period could be chosen. Unavailability of disposal capacity and the presence of other onsite nuclear facilities are not factors in the choice. See also response to $\mathrm{LO10}-\mathrm{CO}$.

L009-C03. On page 3.2 it is indicated that the reactor is put into safe storage by securing all "smearable" radioactive contamination in the facilities. However, information is not given as to what type of smearable contamination is present in the reactors at this time.

R. This statement was intended to indicate that each reactor would be surveyed again for surface contamination from spills and releases in order to seal the contamination from possible air suspension during the safe-storage period. Specific information on existing smearable contamination is given in the letter report by $R$. A. Winship, "Radiation and Smear Survey Data," referenced in Appendix $A$.

L009-C04. NRC regulations do not permit "no action."

R. "No action" is included in the EIS as an alternative in order to satisfy the regulations of the Council on Environmental Quality (CEQ) implementing the National Environmental Policy Act in 40 CFR 1502.14(c) that require the inclusion of the no action alternative.

L009-C05. A detailed characterization of remaining radionuclides would be necessary for in situ decommissioning.

R. A detailed characterization of the radioactive inventory is given in the Miller and Steffes (1987) report and is summarized in Appendix A.

L009-C06. No information is given on costs, activities, or radiation doses after 100 years. 
Responses to Comments; Comments and Responses

R. The analyses of activities and costs do not extend past 100 years in order to be consistent with EPA guidance in 40 CFR 191 (Section 3.0). The analyses could be extended to any desired time. Long-term doses from radionuclide migration are given to 10,000 years.

L010-C01. Hanford should be cleaned up in 30 years. The site should be released to the public.

R. Thirty years presumably refers to the milestone in the Tri-Party Agreement among the DOE, the EPA, and the WDOE for the cleanup of the Hanford Site under CERCLA and RCRA. The Tri-Party Agreement specifically recognizes that certain activities related to decontamination and decommissioning may be subject to RCRA, and when those activities result in the generation of hazardous wastes, the treatment, storage, and disposal of those wastes will be subject to the Agreement. The safe-storage period of 75 years is based on an adequate time for decay of cobalt-60 (and partial decay of cesium-137), in order to reduce occupational radiation dose. For either of the safe-storage alternatives, the safe-storage period could be shortened or modified in order to make decommissioning consistent with time frames in the Tri-Party Agreement.

The broader issues of shoreline and land use planning are outside the scope of this EIS, except to note that Public Law 100-605, the Hanford Reach Study Act, provides for a study of the Hanford Reach of the Columbia River that will result in recommendations as to the future use and designation of the Hanford Reach. The reactor buildings are only a very small part of the 100 Areas. The 100 Areas, which include approximately 27 "operable units, "will require extensive investigation and remediation pursuant to the Tri-Party Agreement. Shoreline and land use planning will be a consideration in performing these investigations and remedial and corrective actions.

However, even though DOE has stated in the past that it intends to maintain institutional control of the Hanford Site in perpetuity and intends to do so for areas where radioactive materials are disposed of or where they are left in $\mathrm{place}$ above unrestricted release limits, it is possible that some other portions of the site could be released for public or private use. This possibility is being considered by DOE as part of its responsibilities under CERCLA. DOE has formed the Hanford Future Site Use Working Group (organizing 
committee) to assist in developing Hanford future site use alternatives. This organizing committee consists of representatives from the DOE Richland Field Office (RL), U.S. Environmental Protection Agency, States of Washington and Oregon, National Park Service, Yakima Indian Nation, Confederated Tribes of the Umatilla Indian Reservation, and Benton, Franklin, and Grant Counties. The organizing committee is considering six major steps in developing future Hanford use scenarios: 1) agree to charter and ground rules; 2) identify issues to be addressed; 3) identify individual "visions" of future site use; 4) gather information and examine issues and visions; 5) identify cleanup strategies to implement those visions; and 6) identify a list of alternatives for the Hanford Remedial Action Environmental Impact Statement that encompasses the visions of all participants. Final remediation and decommissioning decisions will be made through NEPA or CERCLA processes.

L012-C01. The Hanford Site should be cleaned up in 30 years and restored to public use.

R. See response to $\mathrm{LO10-COI}$.

L013-C01. Land use planning should be included in the EIS. Specifically, return of land to productive agriculture should be considered.

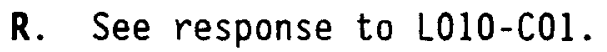

L014-C01. B Reactor should be developed as a visitor center and Hanford museum either separately or as a part of the decommissioning plan.

R. See response to L005-C01.

L016-C01. The remaining hazardous substances should be neutralized.

R. The remaining hazardous substances are lead and radionuclides. While organic materials can often be broken down into more simple and more benign forms such as carbon dioxide and water, the same is not true of an elemental inorganic substance such as lead, which is already in its simplest form. The lead might be converted into a less soluble compound, but this would involve isolating and processing the lead, which alone would increase worker exposure 
Responses to Comments; Comments and Responses

and hazardous waste volumes. Similarly, some radionuclides can be transmuted into stable nuclides by neutron irradiation, but not without worker exposure to radiation and further generation of waste.

L017-C01. The reactors should be decommissioned by in situ decommissioning following a 75-year safe-storage period.

R. While not evaluated specifically in the DEIS, the costs and impacts of this alternative can be easily derived from the costs and impacts of safe storage (no action) for 75 years and in situ decommissioning. This alternative was not considered in the DEIS since the safe-storage period would result in increased costs without significantly simplifying in situ decommissioning.

L018-C01. Leaving the reactors in their present location and burying them under a mound of dirt and gravel (and under an engineered barrier) is not a demonstrated technology. The EIS does not offer an estimate of how long the "engineered barrier" might last.

R. As stated in Appendix $H$ of the DEIS, the engineered barrier is not yet proven for the Hanford Site and will require at least 5 years of experimental work to demonstrate barrier performance. However, the design of the barrier is intended to provide long-term (10,000-year) protection from water infiltration and from inadvertent intrusion. In the event of failure of the engineered barrier in either the 100 or 200 Areas, the 1ong-term impacts are no greater than those of no action.

L018-C02. Hanford should be cleaned up within 30 years and the 1 and restored to public use.

R. See response to $\mathrm{LO10-CO1}$.

L018-C03. Immediate one-piece removal requires the least amount of 1 and to be barred from public access (see page 5.34).

R. As stated in Section 1.5.10 of the DEIS, DOE would restore the 1 and to other DOE use, not to public access (see also response to L010-CO1). 
Responses to Comments; Comments and Responses

L018-C04. DOE, EPA, and the State of Washington should develop a land use plan for the Hanford Site. The future use (and ownership) of the Hanford Site should be decided by the citizens of Washington and by the affected native American Indian tribes.

R. See response to $\mathrm{L} 010-\mathrm{CO} 1$.

L018-C05. Decommissioning should start with the reactor that has the lowest radiological inventory and proceed in order of increasing inventory.

R. The order of decommissioning will be decided on the basis of detailed engineering studies, which will include consideration of the inventories.

1018-C06. On page 3.27, there is an error in Table 3.7. The third "Deferred Removal" total for the DR Reactor is an error and should read $\$ 7,485.82$.

R. The error is in the D Reactor column and should read $\$ 7,448.82$ instead of $\$ 74,485.82$. In any event, the costs have been re-estimated in 1990 dollars in Appendix $K$.

1018-C07. There should be an explanation that the removal costs for deferred one-piece removal will probably be higher than those same costs for immediate one-piece removal due to inflation.

R. Costs were given in the DEIS in 1986 dollars for all alternatives without regard to the time period during which each activity might take place. This was done for comparison purposes. Future costs may vary with inflation, deflation, and changing technology. Costs are presented in Appendix $K$ in 1990 dollars.

L018-C08. The EIS does not provide an estimate of how long the engineered barrier will withstand erosion.

R. See response to L018-COI.

L018-C09. On page 5.3, DOE does not consider the possible breach of a contamination control envelope as an accident scenario.

R. The second accident (second bullet) on page 5.4 includes loss of the contamination control envelope (see Section 5.5.1.1). 
L018-C10. Accident calculations on page 5.6 should have been done using the KE Reactor rather than the F Reactor (which was chosen because it is closer to the population center); the KE Reactor inventory is larger than the $F$ Reactor inventory.

R. The KE Reactor inventory (in the $F$ Reactor location) actually was used for these calculations in order to provide the most conservative (highest impact) accident evaluation.

L018-C11. The accident calculations on pages 5.9-10 do not contain enough detail. There should be a description of the basic assumptions used in calculating the dose estimates, as well as a numerical expression of the range of uncertainty associated with the estimates.

R. The KE Reactor inventory in the F Reactor location was used for these calculations. Equations are presented in Appendix E. Uncertainties in the dose calculations arise from uncertainties in the source terms, meteorological conditions, transport models, and other assumptions. Note, for example, that the season in which the accident occurs makes a 40-fold difference in the dose to the maximally exposed individual and a 30-fold difference in the population dose in Table 5.1. These differences alone overshadow a difference in source terms between, say, KE Reactor and F Reactor.

L018-C12. DOE should consider the possibility that future users of the Hanford Site might not be able to comprehend warnings against intrusion.

R. Radiological impacts from both deliberate (ignoring the warnings) and inadvertent intrusion are discussed in Appendix $G$.

L018-C13. The DEIS does not state from which date the 100-year period of institutional control will be calculated.

R. For cost and dose calculations, the 100-year period begins in 1990 . L019-C01. The $\mathbf{N}$ Reactor should be included in the decommissioning plans.

R. As stated in the notice of intent to prepare this EIS, the $\mathbf{N}$ Reactor is outside the scope of this EIS. The $N$ Reactor is not now available for decommissioning. However, at an appropriate time, the $\mathrm{N}$ Reactor will be decommissioned and appropriate NEPA documentation will be prepared. 
Responses to Comments; Comments and Responses

L020-CO1. The $\mathrm{N}$ Reactor should be included in the decommissioning plans.

R. See response to L019-COI.

L021-CO1. The N Reactor should be included in the decommissioning plans.

R. See response to $1019-\mathrm{CO} 1$.

L022-CO1. B Reactor should be preserved intact at its present location and made accessible to the public.

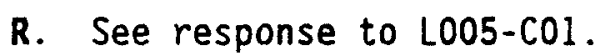

L026-C01. The Hanford Site should be returned to public use, including to individuals and Native American tribes who originally surrendered the 1 and.

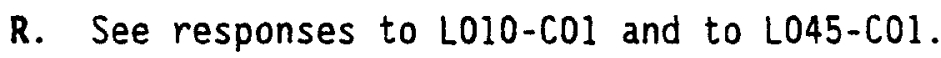

L027-CO1. The Hanford Site should be cleaned up within 30 years and as much land as possible returned to public access.

R. See response to $\mathrm{LO10-C01}$.

L028-C01. N Reactor should also be decommissioned.

R. See response to L019-COL.

L030-C01. DOE should establish an irrevocable trust fund for the safe storage and extensive recordation of $B$ Reactor for 75 years followed by one-piece removal.

R. See response to $\mathrm{LO05-CO1}$ and L006-CO2.

L031-C01. B Reactor should be preserved as a mode1, including the water treatment plant, in the Hanford Science Center.

R. See response to $\mathrm{LOO5}-\mathrm{CO}$.

1032-C01. What about the possibility of old radioactive fuel (storage basin) leaks under reactors other than KE?

R. The water level in these storage basins was always carefully monitored. While the possibility of a leak exists in any system containing water, the 
Responses to Comments; Comments and Responses

observed water loss in the other fuel storage basins was consistent with calculated evaporation losses. Cleanup studies under the Tri-Party Agreement should identify contaminants that may have been released from other basins. L032-C02. What about the possibility of erosion?

R. The impact of immersion of a reactor in the Columbia River caused by erosion under the reactor is discussed in Section 5.7 .3 of the DEIS.

L032-C03. Insufficient data are presented on the movement of Hanford ground water toward the water table and toward the Columbia River.

R. There is a very active effort to better characterize and understand ground-water movement, both vertical and horizontal, at the Hanford Site. Some of this work is ongoing through the site-wide ground-water monitoring program conducted by the Pacific Northwest Laboratory. This work will be expanded in order to carry out the terms of the Tri-Party Agreement. For the DEIS, the best available ground-water movement data were used in calculating impacts.

L033-C01. The B Reactor should be preserved intact at its present location and made accessible to the public.

R. See response to L005-C01.

L034-CO1. The B Reactor should be preserved intact at its present location and made accessible to the public.

R. See response to L005-CO1.

L035-C01. The B Reactor should be treated separately from the other reactors. Specifically, "continue present action" could be applied to B Reactor with the objective that public access and tours could be assured, consistent with safety requirements. If this option could not be allowed, alternative means should be provided for commemorating the reactor such as extensive recordation of written and photographic materials, a kiosk with displays of visual aids at the Vernita Rest Area, an obelisk at a point along Highway 240 from which the reactor site is visible, or a reconstruction of at least the reactor control room.

R. See response to L005-COL. 
Responses to Comments; Comments and Responses

L036-C01. The 100 Areas should be returned to the public domain. If that is not possible, then a nonnuclear use of the Site should be established such as power generation utilizing solar energy, wind, and/or fermented agricultural waste.

R. See response to $\mathrm{LO10-C01.}$

L038-C01. The B Reactor should be preserved intact at its present location and made accessible to the public.

R. See response to $\mathrm{L}_{005-\mathrm{CO}}$.

L041-C01. The FEIS should show the number of people involved versus estimated illnesses within the site and external to it for each of the five alternatives for the first 100 years, estimated illnesses for the same people for the same time period if Hanford did not exist, and the estimated illnesses for the remaining 9,900 years.

R. These numbers either appear in the DEIS or may be calculated from information presented in the DEIS, as follows. The number of persons within $80 \mathrm{~km}$ of Hanford is 340,000 (page 4.34). These persons receive approximately 100,000 person-rem annually from natural background radiation (page 5.39), or $10,000,000$ person-rem over 100 years. This 100-year population dose corresponds to 1,000 to 10,000 health effects (page F.13). The maximum dose from decommissioning in the first 100 years to the same group is the worker dose of 532 person-rem for the safe storage followed by deferred dismantlement alternative (there are no other population doses in the first 100 years). This population dose corresponds to a range of 0.05 to 0.5 health effects. Longterm health effects over 10,000 years are presented in Section 5.7.1.3.

L041-C02. Use of the term "no action" is confusing.

R. Evaluation of "no action" is required by the regulations of the Council on Environmental Quality. No action usually means not to carry out the proposed action. The proposed action in this case is decommissioning. No action, therefore, means either to do nothing further or to continue what is now being done. Both "no action" scenarios are discussed in this EIS. 
L041-C03. Future costs should take into account inflation and the future value of money.

R. Inflation and the future value of money were not included in order to avoid unnecessary confusion and speculation.

L041-C04. Why is no ground-water monitoring included under "continue present action" in Table 1.2?

R. "Continue present action" is the no action alternative required by the Council on Environmental Quality regulations. No action does not include any monitoring wells drilled especially for this alternative. There are, however, existing monitoring wells in the vicinity of each reactor that are and will continue to be sampled and tested regularly under the Hanford Site Monitoring Program. Also, DOE has an active surveillance and maintenance program to ensure the physical integrity of the reactors. These monitoring, survei1lance, and maintenance programs are part of the continue present action alternative.

L041-C05. People outside the scientific realm may be confused by "rem/yr," whereas in later chapters dosage is given in "mrem/yr." Consistency is recommended.

R. Definitions of the numerical prefixes are given in Chapter 8 . One rem is equal to 1,000 mrem.

L41-C06. The use of the word "conservative" in Table 5.3 is unfortunate. Such usage is not covered in most dictionaries and certainly not in politics. R. "Conservative" is defined in Chapter 8. For the purpose of the EIS, it refers to assumptions or choices that tend to overestimate rather than underestimate impacts.

1041-C07. Add the definition of "smear" or "smearable." Add the definitions of "stochastic" and "stochastic dose equivalent" as used in Section E.1.4.

R. Smearable means removable by wiping. In Section E.1.4, the phrases "stochastic dose limit" and "stochastic effective dose equivalent" are used. The first phrase should read "dose limit for stochastic effects," and the second should read "(stochastic) dose equivalent limit." "Stochastic" means 
Responses to Comments; Comments and Responses

that the probability of occurrence is proportional to dose. "Stochastic effects" are malignant and hereditary diseases for which the probability of an effect occurring, rather than its severity, is regarded as a function of dose without threshold.

L041-C08. Intruder scenarios in Section E.3.4.1 defy the imagination.

R. Intruder scenarios are included in order to show impacts on unsuspecting individuals if institutional control is somehow lost. Although these are not high-probability events, the scenarios are consistent with those used by the NRC to estimate doses to intruders.

L041-C09. The flow rate of the Columbia River of $1 \times 10^{4}$ liters per year on page E.38 is an obvious error.

R. The flow rate should be $1 \times 10^{14}$ liters per year.

L041-C10. A note of explanation should be added to Table 1.2 showing the population dose for the first 100 years.

R. The population dose (with the exception of worker dose) for the first 100 years for all alternatives is zero.

L042-C01. The in situ decommissioning and safe-storage alternatives may be severely impacted by RCRA regulations and the Washington State Dangerous Waste Regulations. The FEIS should more clearly identify and evaluate the potential regulatory requirements for these alternatives.

R. It is not yet clear that RCRA (or CERCLA) specifically applies to the decommissioning of the surplus production reactors or that a RCRA permit will be required. In order to fall under the purview of RCRA or the Washington State Hazardous Waste Management Act (HWMA), a substance must either be a listed waste or exhibit one of four hazardous characteristics (ignitable, corrosive, reactive, or toxic). The only substance in the reactors that might qual ify as hazardous under RCRA is lead. Lead is not a listed waste, but would be a characteristic waste if it fails the Toxicity Characteristic Leaching Procedure (TCLP). The TCLP measures the concentration of hazardous constituents in solution following dissolution of particles of the waste sample in a low pH extraction fluid. There is no low pH source at or near the 
reactors, the $\mathrm{pH}$ of the soils is approximately 8.0 , and the lead in the reactors is in large pieces (not small particles). Thus, even if it is determined that RCRA applies to the lead in the surplus production reactors, the lead may qualify for delisting.

EPA's land disposal restrictions (40 CFR 268) permit the land disposal of radioactive lead following encapsulation of the lead in a protective material that is intended to substantially reduce the surface exposure to potential leaching media.

It is not clear that while the reactors are being maintained in a safe-storage condition, the reactor materials would be classified as waste. The lead is firmly held in the thermal shields, inside the reactor block, above ground, dry, and not subject to dissolution or other release. The irradiated lead is part of the reactor block structure. Also, the enclosed buildings have never been used for the treatment, storage, or disposal of hazardous waste. The circumstances are unique in considering the applicability of RCRA and the Washington State Dangerous Waste Regulations. (Lead could be considered an extremely hazardous waste under the State's regulations.) For these reasons, the DEIS does not include any RCRA enhancements during the safe-storage period, and none are added in the FEIS.

For all decommissioning alternatives, the DEIS includes conceptual designs and cost estimates for ground-water monitoring, 1 iner/leachate collection systems (except for in situ decommissioning), intruder warning markers, and engineered barriers (Chapter 3 ). The liner/leachate collection system is omitted from the in situ alternative because of the difficulty of constructing such a barrier under the reactors, and al so because of the lack of efficacy of such a system. This lack of efficacy arises because release of the lead is expected to occur over a much longer period of time than is contemplated in the RCRA regulations for the liner/leachate collection system to function. The other systems are intended to meet the requirements of RCRA or CERCLA to mitigate the short-term and long-term potential for contamination migration into the ground water or the Columbia River. 
Responses to Comments; Comments and Responses

The Tri-Party Agreement recognizes that certain activities related to decommissioning of structures may be subject to RCRA. Whenever such activities result in the generation of hazardous wastes, the treatment, storage, and disposal of those wastes are subject to the Agreement.

Thus, while the specific applicability of RCRA is uncertain, enhancements have been added to the decommissioning alternatives that would essentially meet the technical requirements of RCRA. As stated in the DEIS, the DOE intends to continue discussions with the EPA and the WDOE to resolve the specific applicability of the particular requirements of RCRA or CERCLA to decommissioning.

L042-C02. The 1984 Hazardous and Solid Waste Amendments (HSWA) to RCRA contain provisions for corrective actions at permitted facilities. Consideration must be given in the EIS to the applicability of these provisions.

R. As a condition of any RCRA permit, HSWA require corrective action for any release of hazardous wastes and constituents. HSWA will not affect any decommissioning alternative because no release of lead has been observed. To the extent that hazardous substances from past reactor operations may have been released to surrounding soils, the clean-up studies to be performed under the Tri-Party Agreement will address the presence of such substances and any necessary remedial actions.

L042-C03. The Washington State Dangerous Waste Regulations (WAC-173-303) are more stringent than the federal RCRA regulations. For example, the state toxicity designation procedure in WAC-173-303-101 may designate the reactor cores as dangerous or extremely hazardous waste. The EIS should note that this may restrict alternatives.

R. Under the state's regulations, lead removed from the reactors as a waste would be classified as an extremely hazardous waste. Nothing else in the reactor blocks is known to be subject to this designation. Such material would be disposed of in a facility meeting the requirements of RCW 70.105.050. See also response to L042-CO1.

L042-C04. The safe-storage alternatives appear either to totally lack the appropriate ground-water monitoring or to severely underestimate what would be 
Responses to Comments; Comments and Responses

required. These alternatives should be reanalyzed to ensure that the appropriate ground-water monitoring programs are planned for and implemented over the possible 96-year safe-storage period.

R. See response to L042-C01. At the present time, DOE has an extensive program of monitoring, surveillance, and maintenance of the reactor facilities to ensure that there are no radiological or chemical releases to the environment. There are ground-water monitoring wells located in each of the 100 Areas as well as throughout the Hanford Site. Also, the lead in the reactors is dry, above ground, and not subject to leaching. Therefore, addition of a special ground-water monitoring system for safe storage would be both costly and redundant.

L042-C05. Should the B Reactor be nominated and eventually listed on the National Register of Historic Places, the EIS would need to evaluate a combination of alternatives, such as removal of the remaining seven reactors while decontaminating B Reactor. These discussions should be included in the FEIS.

R. See response to $L 005-C 01$.

L042-C06. The text on page 1.7 should clarify that irradiated lead is a mixed radioactive waste subject to regulation.

R. Irradiated lead, as a waste, would be a mixed hazardous radioactive waste if it fails the TCLP. The lead would be subject to regulation under RCRA and the radioactive impurities would be subject to regulation under the Atomic Energy Act of 1954 (see response to L042-CO1).

L042-C07. Thermal expansion and contraction plus past removal of metal channel liners resulted in powdered graphite (pages 1.22 and 5.4). Would graphite powders support combustion?

R. No. See Section 5.1.2.2 of the DEIS.

L042-C08. Columbia River flow alteration could be caused by factors in addition to climatic changes (page 3.57). The FEIS should describe erosion and accretion processes that could change the river channel and lead to immersion of the reactors. 
R. The processes of erosion and accretion are not relevant to the selection of the preferred alternative. Only the impacts of immersion of one (or more) of the reactors as a result of erosion are relevant. These impacts were evaluated in Section 5.7.3.

L042-C09. It would be helpful to have figures showing the extent of a probable flood resulting if $25 \%$ and $50 \%$ of Grand Coulee Dam were destroyed.

R. These floods will not reach the 200 Area. Elevations of the flood caused by a $50 \%$ failure of Grand Coulee Dam relative to the reactor elevations are given in Appendix B. The impacts of these floods with respect to decommissioning are evaluated in terms of immersion of one (or all) of the reactors in Section 5.7.3.

L042-c10. The text should include a comparison of recharge coming from artificial sources with recharge coming from natural sources and discuss how this pattern is expected to change over time (page 4.17).

R. Artificial recharge will not occur over the reactor disposal areas and therefore will not affect the rate at which substances from the decommissioned reactors enter or move vertically downward through the vadose zone. Artificial recharge will affect the level of the water table (mostly at the point. of recharge), the rate of horizontal movement of ground water, and the rate of horizontal movement of substances in the ground water to the Columbia River. Changes in artificial recharge will have little effect on long-term decommissioning impacts because the rate-controlling steps are the rates of downward movement of water, lead, and radionuclides and the rates of dissolution of the lead and radionuclides.

1042-C11. A review of University of Washington seismic data and reactor siting data indicates that deep seismic data are associated with known and inferred geologic structures (page 4.21).

R. The statement on page 4.21 refers to known geologic structures and does not include inferred structures. The authors of the DEIS are familiar with data from the University of Washington and believe that the pattern and 
Responses to Comments; Comments and Responses

distribution of earthquakes deeper than $8 \mathrm{~km}$ do not exhibit an obvious relationship to known folds or faults. See Section $\mathbf{5 . 7 . 3}$ for impacts of seismic events.

L042-C12. Current monitoring programs for leaking tanks are not refined enough to determine, with any degree of certainty, that leaks from waste tanks have or have not resulted in radiation exposure to the public (page 4.23).

R. Radiation monitoring programs at Hanford are not designed to establish a direct connection between any specific source and members of the public. Annual doses to members of the public are determined on the basis of measured releases, measured concentrations in air, soil, and water, measured dose rates at selected onsite and offsite locations, and on pathway analyses.

L042-C13. Have any of the well systems on the Hanford Site used for drinking water ever exceeded radiological drinking-water standards? If so, how did they come into compliance (page 4.25)?

R. Radiological drinking water standards apply, strictly from a regulatory standpoint, to water supplied by "community" drinking water systems. No community drinking water systems exist on the Hanford Site. However, in 1985, the average concentration of tritium in ground water used for drinking water at the FFTF was 22,000 picocuries per liter. The drinking water standard is 4 millirem per year; and an annual average drinking water concentration of 20,000 picocuries per liter of tritium is assumed to produce a total body dose of 4 millirem per yer ( 40 CFR 141.16). The average concentrations of tritium in 1986, 1987, and 1988 in a new, deeper replacement well drilled for drinking water purposes were $8,500,4,100$, and 8,500 picocuries per liter, respectively (R. E. Jaquish and R. W. Bryce, editors, Hanford Site Environmental Report for Calendar Year 1988, Pacific Northwest Laboratory, PNL-6825, May 1989).

L042-C14. The FEIS should explain how decisions could be influenced because RCRA applies to the hazardous component of radioactive mixed waste but not to the radioactive component of radioactive mixed waste (page 6.4).

R. This distinction does not affect the selection of the preferred alternative; it only affects the actions that the agency must take after an alternative is selected. 
Responses to Comments; Comments and Responses

L042-C15. Because masonite and transite are no longer in today's lexicon, the text should give a brief description of each product (page A.16).

R. Masonite is a Masonite Corporation trademark. Masonite is produced from byproduct wood chips that are reduced to fibers by high-pressure steam, which are then pressed into board without the use of chemicals. Transite is a Johns Manville Company tradename. Transite is a construction or insulating material made of asbestos fibers and Portland cement molded under hydraulic pressure. These definitions are added to the glossary as errata.

L042-C16. The FEIS should explain why certain facilities 1 isted in Table A.12 do not contain cadmium, while the text on page 3.4 states that cadmium is alloyed with lead.

R. Only $B, F$, and $H$ Reactors are known to contain cadmium. All of the cadmium inventory in these reactors (shown in Table A.12) is removable (see Miller and Steffes 1987). The cadmium in B Reactor is alloyed with lead. The cadmium in $F$ and $H$ Reactors is not alloyed with lead.

L042-C17. The DEIS understates the impact of RCRA and WAC 173-303 on in situ decommissioning and safe storage. The FEIS should more clearly describe the potential regulatory requirements for these alternatives.

R. See response to $\mathrm{LO42-CO1}$.

L042-C18. The FEIS should indicate that decommissioning will be done in accordance with the terms of the Tri-Party Agreement recently signed by the state and federal governments.

R. The Tri-Party Agreement, which was signed on May 15, 1989, recognizes that certain activities related to decommissioning may be subject to RCRA, and that whenever decommissioning activities result in the generation of hazardous wastes, the treatment, storage, and disposal of those wastes will be subject to the Agreement. None of the surplus production reactors are currently considered to be treatment, storage, or disposal facilities as defined by RCRA.

L042-C19. The B Reactor has an exceptionally strong association with the history of the U.S. atomic energy program and the development of the atomic 
bomb at the end of World War II. In view of its historic significance, the future interpretive value of the $B$ Reactor should be preserved, if it is technically, environmentally, and economically feasible. Varying degrees of interpretive value could be preserved by maintaining part of the facility in its present condition, construction of a replica at the site, displaying the control room at the Hanford Science Center or the Smithsonian Institution, or by providing extensive photographs and records at one of the sites. The FEIS should evaluate the environmental, cost, scientific heritage, and cultural impacts of each option listed above. Evaluations should address public accessibility and the ability to illustrate unique construction and operational achievements. Incremental costs associated with maintaining and monitoring the $B$ Reactor in place while the other seven reactor blocks are moved to the 200-West Area should be included in the FEIS. Of course, the historic register decision must not compromise protection of public health, safety, and the environment.

R. See response to L005-CO1.

L042-C20. The Washington State Shoreline Management Act (RCW 90.58) states that it is the policy of the state to provide for management of its shorelines by planning for and fostering all reasonable and appropriate uses. Although the DEIS assumes a time period of 100 years for active institutional control-with an intention to maintain institutional control of the site in perpetuity--there is no discussion about allowing reasonable and appropriate public use of the shoreline. Decommissioning of the reactors will remove a significant roadblock to opening major sections of the Hanford Reach shoreline to the public. If the reach is designated as a part of the National Wild and Scenic Rivers System, that portion of the river will remain open for boating and fishing but not for shoreline uses. Protection of historic, archaeological, and cultural properties together with yet-to-be-decommissioned sites would preclude opening of the entire Hanford Reach. However, the FEIS should articulate a federal policy of shoreline use during the period of institutional control. A phased approach would allow the public reasonable and appropriate use of the shoreline.

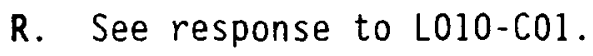


L045-C01. The Yakima Indian Nation requests that the Department of Energy consult with the Nation during planning, site characterization, cultural resource and archaeological site survey work, and implementation of the selected alternative to ensure the protection of numerous Indian cultural resource sites in the area (36 CFR 800, "Protection of Historic and Cultural Properties"). Such consultation must include onsite inspection by the Yakima Indian Nation.

R. It is DOE's intent to consult with Indian tribes during all phases of the planning, site characterization, cultural resource and archaeological site survey work, and implementation of the selected alternative as required under the $l$ aw and as is necessary to ensure protection of Indian rights under applicable treaties and other statutory and regulatory requirements. In addition, DOE will, on a regular basis, consult with Indian tribes with respect to potential impacts to Indian burial sites and cultural resources. Such consultation will include invitations for onsite visits by representatives of the affected Indian tribes.

L045-C02. The DEIS inadequately describes the treaty between the Yakima Indians and the U.S. government. Although mention is made of ceded land areas, no description is made of the legal status of this land. No mention is made of the DOE's trust responsibility to Indian tribes, as described in federal law and policy.

R. Section 4.6 .5 of the DEIS specifically acknowledges the treaty rights of the Yakima and Umatilla Indians. Also, Chapter 6 of the DEIS contains specific references to the National Historic Preservation Act, the Archaeological Resources Protection Act, and the American Indian Religious Freedom Act. Describing the terms of the treaty between the U.S. government and the Yakima Indian Nation is outside the scope of this EIS.

L045-C03. Description of cultural resource management of the Hanford Site in the DEIS, consistent with the National Historic Preservation Act and the American Indian Religious Freedom Act, is lacking. The DEIS makes mention of the fact that the 100 Areas have not been surveyed for cultural resources, but does not describe how the Yakima Indian Nation will be consulted during such surveys. 
R. DOE has a cultural resources $p l a n$ in place (Hanford Cultural Resources Management Plan, PNL-6942, June 1989) that was established to preserve and protect cultural resources. The plan applies to all new construction, decontamination and decommissioning, and CERCLA remediation. It is DOE's policy to ensure that tribal participation takes place during cultural resource survey work. This policy is carried out by the Site Management Division of the DOERichland Operations Office.

L045-C04. The Hanford Reach of the Columbia River is exceptionally significant to the Yakima Nation, in terms of the fishery, cultural and natural resource sites, and religious areas. The DOE must fully consider the impacts of its proposed actions on these resources when developing the FEIS.

R. See response to L045-C03.

L045-C05. The Yakima Indian Nation supports the goals of restoring the Hanford land.

R. See response to L010-CO1.

L045-C06. There is no doubt that the B Reactor is a significant historic site, but consideration of its protection should be weighed in the context of preservation of a record of thousands of years of human habitation and development in the same area. The DOE should place greater emphasis on preserving Indian cultural resources in the development of the FEIS.

R. See responses to L050-CO1, L010-CO1, and L045-C03.

L045-C07. As the environmental restoration of the land along the Columbia River goes forward, the federal government should consider means of returning access and use of this area to the Yakima Indian Nation, which maintains property rights at Hanford.

R. See responses to $\mathrm{LO10-COI}$ and $\mathrm{LO45-C03}$.

L045-C08. Many of the major federal environmental laws, including the Clean Water Act, Safe Drinking Water Act, and CERCLA, have been amended by Congress to specifically recognize the authority of Indian tribes to regulate the environment on tribal lands. This authority may extend off-reservation to ceded lands. The DOE should recognize in the FEIS that treaty rights and 
tribal jurisdiction are included in the statutory and regulatory requirements that apply to decommissioning the surplus production reactors.

R. The DOE is fully committed to meeting all tribal legal rights during the planning, engineering, and decommissioning of the Hanford surplus reactors.

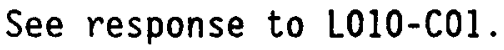

L045-C09. Section 1.6 of the summary should list the National Historic Preservation Act, the Archaeological Resources Protection Act, and the American Indian Religious Freedom Act.

R. These acts are discussed briefly in Chapter 6 . They were omitted from the DEIS summary for brevity, but have now been added to Section 1.6 of the Addendum.

L045-C10. The FEIS should explain how designation of the 100 Areas on the CERCLA National Priorities List and the Tri-Party Agreement among DOE, EPA, and Washington State will affect consideration of the DEIS alternatives and implementation of the chosen alternative.

R. The effect, if any, of these factors on final selection of the alternatives to be implemented will be discussed in DOE's record of decision. Implementation of the selected alternative ultimately will depend upon timely funding from Congress. See response to L042-C18.

L045-C11. Section 4.6.5, "Indian Tribes," should be placed under Section 6.0, "Statutory and Regulatory Requirements," with an equivalent change in the summary. Three specific changes should be made in this section. (1) Perhaps one-third of the enrolled Yakima Indian Nation members live off the Yakima Reservation. Thus the phrase on page 4.39, "who now live on nearby reservations," is incorrect and should be amended. (2) The sentence beginning at the top of page 4.41, "As part of their treaty agreements...," should be replaced (for the Yakima Indian Nation) with the following language from the Treaty of 1855 between the Yakima Indian Nation and the U.S. government: "The exclusive right of taking fish in all streams, where running through or bordering said reservation, is further secured to said confederated tribes and bands of Indians, as also the right of taking fish at all usual and accustomed places, in common with citizens of the Territory, and of erecting temporary 
buildings for curing them; together with the privilege of hunting, gathering roots and berries, and pasturing their horses and cattle upon open and unclaimed land." (3) The sentence on page 4.41 beginning "Consultation with Indian religious leaders may be necessary..." should be replaced by "Consultation with Indian religious leaders is required by law if the potential exists for abridgement of religious freedom, as set forth in the American Indian Religious Freedom Act of 1978."

R. The factual changes are made in the Errata (Appendix $N$ of the FEIS). Historic preservation acts and the American Indian Religious Freedom Act are added to the summary in Section 1.6 of the FEIS.

L048-C01. Any costs and health impacts that have already been incurred by the mothballed reactors should be included in the FEIS.

R. The purpose of the EIS is to evaluate the proposed action and its alternatives. Therefore, cost and health impacts are estimated for proposed future actions, not for past actions.

L048-C02. One-piece removal would permit releasing the 100 Areas to public use.

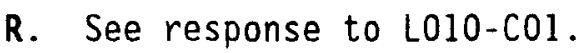

L048-C03. The reactors should be removed in order of increasing radioactive inventory.

R. The order of decommissioning will be decided on the basis of detailed engineering studies, which will include consideration of inventories.

L049-C01. The regulatory discussions on pages $1.7,6.5$, and 6.6 relating to CERCLA and RCRA need to be revised. The FEIS needs to be consistent with and reference the Tri-Party Agreement signed May 15, 1989.

R. See response to $\mathrm{L} 042-\mathrm{C} 18$.

L049-C02. On page 1.17, references need to be cited for all the information under the "Geology of the Site" and "Hydrology of the Site" headings.

R. References were purposely omitted from the summary for brevity. They appear in the corresponding sections in Chapter 6. 
Responses to Comments; Comments and Responses

L049-C03. On page 5.3, "routine release" needs to be defined. Does this include infiltration and migration of contaminants to ground water? If so, will there be a routine release of radionuclides to the ground water as a result of natural recharge?

R. "Routine release" means releases during decommissioning operations. The expression does not include long-term infiltration of water and migration of contaminants to ground water. The long-term release of contaminants caused by infiltration of rainwater through the engineered barrier is discussed in Chapter 5 and Appendix $G$ of the DEIS.

L049-C04. What are the "analyses" referred to in the first paragraph on page 5.18, and what is the "analysis" referred to in the second paragraph on page 5.18 ? What is meant by "infiltration rate" and by "recharge rate"?

R. The analysis/analyses refer to the calculation of the long-term impacts of the release of radionuclides and lead into the environment through the groundwater pathway. As stated in the text, infiltration rate refers to the downward movement of precipitation (net amount) through the engineered barrier, into the waste form, and downward to the ground water. Recharge rate refers to the downward movement of precipitation (the net amount outside of the engineered barrier) through the soil that supplies the ground water.

L049-C05. The last sentence in the third paragraph on page 5.18 implies that recharge from precipitation on the reservation (Hanford Site) is the sole source of water for the ground-water system under the Hanford Reservation. The ground-water system under the Hanford Reservation is not an isolated, closed system surrounded by ground-water divides. Water enters the area from outside the boundaries of the reservation and flows to the Columbia River. The ground-water model is constructed to simulate such flux; general statements made in other parts of the document should reflect this concept.

R. The language in paragraph 3 on page 5.18 was not meant to imply that the Hanford Site is a closed system. The discussion in Section 4.2.2 indicates that the Hanford Site aquifer system interacts with the Columbia and Yakima Rivers and receives water from sources such as the Cold Creek drainage system 
Responses to Comments; Comments and Responses

and from higher bordering elevations. Basalt ridges west and south of the Site do provide ground-water divides that act as site boundary conditions for water movement.

L049-C06. Estimates of human health effects of radionuclides in the Columbia River are very small (page 5.23). Would these same estimates apply to fish and aquatic life and to those who consume them?

$R$. The estimates of human health effects include the effects of eating contaminated fish. No estimate of the effects of these low levels of radiation on aquatic life was made for the purposes of this EIS, although concentrations of radionuclides in fish are routinely measured (Section 4.4.3).

1049-C07. In the last paragraph on page 6.5, it is unclear why the in situ decommissioning alternative would not need to include conceptual designs for the disposal site barriers.

R. The in situ decommissioning alternative includes conceptual designs for disposal site barriers, marker systems, and ground-water monitoring systems but does not include liner/leachate collection systems (Appendix H).

L049-C08. In the second paragraph on page C.1, the phrase "years per meter" should be "meters per year."

R. The phrase "years per meter" was deliberately chosen to reflect the very slow rate of downward movement of water through the vadose zone in the natural Hanford environment.

L049-C09. The discussion of ground-water movement on page C.I needs to be expanded to include vertical movement of water upward into the Columbia River.

R. Hydrologic modeling is discussed in Section C.3 and is more fully discussed in the Final Environmental Impact Statement, Disposal of Hanford Defense High-Level, Transuranic, and Tank Wastes, U.S. Department of Energy, DOE/EIS-0113, December 1987.

L049-C10. Page C.7, paragraph 3. Additional explanations of the water levels used for calibrating the model are needed here. What "computer routine"? This is a steady-state model, so specifically, what water levels were cal ibrated to? pre-liquid waste disposal? time-averaged? present day? If they 
Responses to Comments; Comments and Responses

were time-averaged, what are the time boundaries? This all makes a difference in light of the statement that the water levels were dropped to the pre-1945 levels.

R. The computer routine is a routine used by Cearlock et al. to calibrate the Variable Thickness Transient (VTT) Model on the basis of conditions in 1975 . This calibrated model then provided the basis for two postdisposal climatic conditions described in Section C.3.1 that also include no further liquid waste disposal.

L049-C11. Figure C.1 (ground-water contour map) should include Site boundaries and labels for the waste burial sites. If the map illustrates contour levels for the unconfined aquifer, this needs to be stated.

R. Boundaries and labels should be clear from other maps in the DEIS. The contours represent the top of the unconfined aquifer.

L049-C12. Ground-water effects should be clarified considering other water recharge rate estimates (page G.5). See H. H. Bauer and J. J. Vaccaro, Estimates of Ground-Water Recharge to the Columbia Plateau Regional Aquifer System for Pre-Development and Current Land-Use Conditions, Washington, Oregon, and Idaho, U.S. Geological Survey, 88-4108.

$R$. The basis for selection of the recharge rates $(0.5$ and 5.0 centimeters per year) is provided in Section 0.3 .2 of the Final Environmental Impact Statement, Disposal of Hanford Defense High-Level, Transuranic, and Tank Wastes, U.S. Department of Energy, DOE/EIS-0113, December 1987.

L049-C13. The description of the ground-water monitoring system on pages H.4 and $\mathrm{H} .5$ should be more complete, including location of the piezometers, a monitoring schedule, and a quality assurance plan for sampling and analysis procedures.

$\mathbf{R}$. The ground-water monitoring system will be designed and operated in consultation with the WDOE and EPA. Further details in the FEIS would be premature.

L049-C14. The following statement at the top of page H.5 needs clarification: "The 100- and 200-Area wells have different locations because the ground-water 
Responses to Comments; Comments and Responses

hydrology gradients are better known in the 200 Areas than in the 100 Areas due to the influence of the Columbia River on the 100-Area hydrology."

R. This sentence refers to other material in the same paragraph and is intended to explain why wells are arranged in a circular pattern around the waste form in the 100 Areas and why more wells are placed downgradient than upgradient of the waste form in the 200 Areas.

L050-C01. The Wanapum Band of Indians wishes to be informed about the method of decommissioning selected by DOE because the Band has burial sites, religious sites, medicines, herbs, and roots on the Hanford Site.

R. The DOE intends to honor this request.

L051-C01. The discussion of historic preservation of B Reactor should be clarified to explain exactly what inclusion in the National Register of Historic Places means and to distinguish among the different names assigned to different preservation statuses.

R. The National Register of Historic Places provides an authoritative list or guide to identify the nation's cultural resources and to indicate what properties should be considered for protection from destruction or impairment. It is designed to be administered as a planning tool. Federal agencies undertaking a project that may affect a listed or eligible property must provide the Advisory Council on Historic Preservation a reasonable opportunity to comment, pursuant to Section 106 of the National Historic Preservation Act. Procedures are outlined in 39 CFR 800 .

Ex05-C01. A comparison table should be included of the five alternatives versus the impacts of natural disasters such as flooding and earthquakes.

R. These impacts are covered in Section 5.7.3. A table was not thought necessary by the authors.

Ex05-C02. The estimate of employees on DOE-related work, given in Section 4.6 .1 , should be revised downward.

R. The number of employees on DOE-related projects in September 1989 was approximately 12,600 . 
Responses to Comments; Comments and Responses

Ex05-C03. Section 3.2 .5 recognizes that a major structural upgrade of the reactor foundation would be required for one-piece removal. It should also consider banding or otherwise securing the upper structure to prevent fissures during removal and transit.

R. While not mentioned in Section 3.2.5, the Kaiser Engineers Hanford report referenced in Section 3.2 .5 contains a statement with respect to reinforcing the reactor block during transit.

Ex05-C04. Section 5.3.1 addresses the block-drop accident. Two other accident scenarios, not as dramatic as the block drop but more probable, are the loss of synchronism of the four transporter drives while in transit and the jamming of the hydraulic mechanism, necessitating the sacrifice of the transporter in the pit at the 200 Areas.

R. These two accidents would increase the cost of one-piece removal, but would not likely increase accidental radiation doses, which is the subject of Section 5.3.1.

Ex07-C01. Preservation of $B$ Reactor will require consideration of public health and safety.

R. See response to L005-C01.

Ex08-C01. B Reactor should be preserved intact onsite and should be upgraded to provide relevant historical and educational displays and to provide public access.

R. See response to L005-C01.

Ex09-C01. What was the original congressional intent of taking and establishing the Hanford land area in carrying out the World War II secret Manhattan Project?

R. A discussion of the original congressional intent for Hanford is outside the scope of this EIS.

Ex09-C02. Did the 1942-1943 Congress and the Army Corps of Engineers evaluate their actions with knowledge that some portion or all of the Hanford Federal Reservation 1 and taken for this project would be contaminated and unsuitable 
for return to its previous use? In their deliberations, did they offer consideration to assess the ultimate plan for future generations?

R. A discussion of the original planning for use of all or part of the Hanford Site is outside the scope of this EIS.

Ex09-C03. What was the determination used in the amount of lands originally condemned for the Hanford Reservation in Benton, Franklin, and Grant counties? Is it planned by the federal government or yet to be determined that this portion of 1 and will be kept off of the tax rolls of Benton, Franklin, and Grant counties indefinitely? What land set aside is necessary to address the environmental impact containment of the eight surplus reactors?

R. Discussions of the amount of land originally condemned for the Hanford Reservation and of the impact of retaining this 1 and (thus kept off the tax rolls) are outside the scope of this EIS. The 1 and required for decommissioning purposes is discussed in Section 5.9.4.

Ex09-C04. Water allocation from the Columbia River for irrigation purposes has been conducted for a number of years. The resource of water combined with 1 and grows crops in ready abundance throughout the world. Recognizing that the Hanford Reservation was created in the middle of a vast agricultural plain, has the DOE considered the need to reserve water rights for future irrigation needs of the Hanford lands now held in its trust? If not, why not?

R. A discussion of consideration given to the need to reserve water rights for future irrigation of Hanford lands is outside the scope of this EIS.

Ex09-C05. With the original Hanford national mission now significantly declining, is DOE considering a future community impact plan? Does the DOE have any comparable environmental impact consideration plans for deactivation of any comparable facilities?

R. A discussion of future community impact planning, except for the action proposed in this EIS, is outside the scope of this EIS. See response to L010-CO1.

Ex09-C06. Land-use planning and socioeconomic impact need much more attention and emphasis than given in the DEIS. 
R. See response to L010-CO1. Socioeconomic impact of the action proposed in this EIS is covered in Section 5.8.

Ex10-C01. Alternative proposals should be considered in support of the nomination of B Reactor as a National Historic Landmark. Specific items that should be considered include an obelisk or information kiosks located at the Vernita Bridge rest area, enhancement of the B Reactor display currently located at the Hanford Science Center with a videotape, and access to the existing control room, either at the existing site or elsewhere.

R. See response to L005-C01.

Ex11-CO1. Land-use planning in the DEIS is inadequate and requires further consideration. Specifically, land that has not been adversely affected by radioactivity should be evaluated for return to productive agricultural use, including provisions for irrigation water systems that will deliver water to areas such as Cold Creek Valley adjacent to Highway 240. Reconsideration of the economic value of the Arid Lands Ecology Reserve should be included. If there is justification for keeping this land out of productive agriculture, consideration must be given to providing payment in lieu of taxes to units of local government, so that the adverse economic impact that now exists can be rectified.

R. See response to $L 010-\mathrm{COl}$.

Ex12-C01. N Reactor should be decommissioned along with the eight surplus production reactors.

R. Decommissioning of $N$ Reactor is outside the scope of this EIS. At an appropriate time, $N$ Reactor will be decommissioned and appropriate NEPA documentation will be prepared.

Ex12-C02. There should be some way in which the radionuclide tritium can be salvaged to preserve the usefulness of existing nuclear weapons.

R. While tritium exists within the carbon blocks, its removal would entail opening the reactors and performing an extraction procedure that could result in a greater worker radiation dose, a larger volume of radioactive waste, and a greater cost than estimated for any of the decommissioning alternatives. 
Responses to Comments; Comments and Responses

Ex13-C01. Concerning the leak under the KE fuel storage basin described in Chapter 3: 1) When did the leak occur? 2) How large was the leak? What is the radioactive inventory contained in the leak? 3) Is there a radioactive plume? 4) Could there be other undiscovered leaks? 5) Has liquid waste moved to the water table? 6) Could this liquid move to the water table in less than 260 to 880 years? 7) How much soil has been contaminated? 8) Is the river in danger? 9) When will DOE finish its characterization studies?

R. 1) The leak was first observed in 1974. 2) The leak is estimated to have been about 15 to 57 million gallons. The inventory of radioactivity contained in the leak is estimated to include cobalt-60, 3.6 curies; strontium-90, 1470 curies; cesium-137, 1050 curies; plutonium-238, 0.21 curies; and plutonium $239 / 240,1.3$ curies. 3) The extent of the radioactive plume has been partially characterized, and, as stated in Chapter 3 , will be fully characterized before decommissioning begins. 4) The possibility of an undiscovered leak always exists. However, the water level in the storage basins was always carefully monitored, and any losses (other than from the KE basin) were consistent with calculated evaporation rates. 5) Radionuclides and hazardous materials have been observed in the monitoring wells in the 100 Areas. Although the sources of these contaminants are not certain, characterization of the sources, their underground pathways, and the extent of contamination will be carried out as part of the Hanford Site RCRA/CERCLA cleanup under the Tri-Party Agreement. 6) Yes. 7) See item 3 above. 8) No. This response is based on the annual Hanford environmental monitoring reports. 9) Completion of these studies will depend on Congressional funding of activities to be carried out under the Tri-Party Agreement.

Ex13-C02. More information is needed on how DOE reached its conclusion on page 3.57, "Climatic changes that alter the flow of the Columbia River could result in long-term erosion under a reactor in the 100 Areas and eventual immersion of that reactor in the river."

R. This is not a conclusion. It is merely a supposition which allowed presentation of the impacts of immersion of one of the reactors in the DEIS. 
Responses to Comments; Comments and Responses

Ex13-C03. Different recharge rates (0.5 and 5.0 centimeters per year) produce different dose rates in the 200 Areas (page 5.19) due to dilution factors, but not in the 100 Areas. This requires clarification.

R. This is explained in Appendix C. Because the hydrology at the river is dominated by fluctuations of the river and not by recharge, different recharge rates do not matter.

Ex13-C04. On page C.1, the units "years per meter" should be replaced by "meters per year" in the sentence, "Water travels downward at rates measured in years per meter in the Hanford environment."

R. The phrase "years per meter" was deliberately chosen to reflect the very slow rate of downward movement of water through the vadose zone in the natural Hanford environment.

Ex13-C05. The DEIS on page C.6 discusses travel times downward through the vadose zone based on a water infiltration rate through the protective barrier of 0.1 centimeters per year. The 1987 Hanford Defense Waste EIS

(DOE/EIS-0113) also presents information based on infiltration rates of 0.0 , 5.0 , and 15.0 centimeters per year. The DEIS should include all available data.

$R$. The calculations for no action in Appendix $G$ include an infiltration rate of 5.0 centimeters per year. This infiltration rate bounds the long-term impacts for all alternatives at that rate (Section G.1.2). For no action, the impacts are the same at 5.0 and 15.0 centimeters per year (Section 5.7.1.1).

Ex13-C06. On page A.l, the DEIS states that a "liner/leachate collection system and leak detection system are omitted from in situ decommissioning because of the impracticality of installing these systems under the reactor blocks." Why is a detection system important away from the river (in the 200West Area) and not essential near the river?

R. The liner/leachate collection system and leak detection system were included in the DEIS for disposal alternatives in the 200-West Area solely to meet the requirements of RCRA based on the presence of lead in the reactors. A well-monitoring system was included to meet RCRA requirements for all disposal alternatives. In addition to the practical impossibility of installing 
such a system for in situ decommissioning, the liner/leachate collection system was omitted because of the lack of efficacy of such a system. This lack of efficacy arises because release of the lead is expected to occur over a much longer period of time than is contemplated by the RCRA regulations for the liner/leachate collection system to function (see L042-COI).

Ex13-C07. 1) The DEIS (in Appendix H) does not outline the long-term goals of well monitoring after decommissioning is complete. 2) What level of lead or radioactivity will require action? 3) Is there some plan to deal with elevated levels? 4) How long does monitoring continue? 5) Will failed seals in the monitoring wells be replaced? 6) Will the eventual deterioration of monitoring well seals allow an avenue of faster travel time to ground water?

R. 1) The goals of well monitoring are to determine whether or not lead or radionuclides from the decommissioned reactors have reached ground water.

2) The presence of lead or radioactivity, in wells downgradient of the monitored facilities, in concentrations that are statistically different from the historical record or statistically different from upgradient wells, will initiate an assessment of the nature, cause, and extent of the contamination. The result of the assessment will determine the response action. 3) Elevated levels will be handled in the same fashion as other Hanford ground-water cleanup. 4) Monitoring will continue until no longer required by the appropriate regulatory agency or until institutional control is lost. 5) The integrity of the monitoring well seal will be assessed by a continual review of the data from the well. If data indicate that the well seal is not functioning as designed and as required by the applicable laws, regulations, and DOE Orders, the well will be either remediated or abandoned in a manner to prevent contaminant movement through the well, including the well seal. 6) As stated in answer 5, the wells will be periodically monitored and the data assessed. Part of the data assessment will be an evaluation of well seal integrity. If data indicate that the well seal is not functioning as designed and as required by the applicable laws, regulations, and DOE Orders, the well will be either remediated or abandoned in a manner to prevent contaminant movement through the well, including the well seal. If DOE institutional control is transferred to another entity, either the new land administrator 
Responses to Comments; Comments and Responses

will assume responsibility for maintaining the wells and eventual well abandonment, or DOE will abandon the wells in accordance with applicable laws, regulations, and DOE Orders. Existing Washington State LaW (WAC-173-160) requires well abandonment to prevent water and contaminant migration.

Ex16-CO1. The DEIS does not discuss the case where failure of Grand Coulee Dam has occurred at the same time severe seismic activity has weakened the outer protective layer of riprap on the in situ mounds.

R. This case is equivalent to (or no worse than) complete immersion of one (or more) of the reactors, which is discussed in Section 5.7.3.

Ex17-CO1. The DEIS fails to acknowledge that the cleanup of the reactors must be done in accordance with federal and state environmental laws.

R. The following statement appears in Chapter 6 of the DEIS: "Decommissioning [of the surplus production reactors] will be carried out in accordance with DOE's environmental policy, which is 'to conduct its operations in an environmentally safe and sound manner...in compliance with the letter and spirit of applicable environmental statutes, regulations, and standards.'"

Ex17-C02. Federal and state environmental laws do not give the DOE the authority to make the fundamental decision as to the fate of the reactors. The State of Washington, the WDOE, and the EPA should be the fundamental decision-makers regarding these eight reactors, rather than DOE.

R. DOE is the responsible federal agency for decommissioning the reactors. As stated in the response to Ex17-CO1, DOE will comply with applicable environmental statutes, regulations, and standards.

Ex17-C03. The policies, procedures, and standards of RCRA and CERCLA are ignored by DOE in the DEIS.

R. The applicability of RCRA and CERCLA is discussed in Section 6.4. See also responses to $\mathrm{LO} 42-\mathrm{CO}$ and L042-C18.

Ex17-CO4. The DOE failed to consider the immediate dismantlement alternative, due to cost.

R. This alternative was considered and rejected in Section 3.6.1 because of the following disadvantages: a significant increase in occupational radiation 
Responses to Comments; Comments and Responses

exposure; increased costs of design and fabrication of special remote handling and viewing equipment; the necessity to use special contamination control equipment, water and other shielding, and water cleanup techniques; and the potential for increased public exposures from any transportation accident. The immediate one-piece removal alternative produces the same resuit with far less impact.

Tr-R26. B Reactor should be preserved in the form of a model that includes the front and rear faces and the horizontal and vertical control rods and safety systems.

R. See response to L005-CO1.

$\mathrm{Tr}-\mathrm{R} 47$. The potential future value of the irradiated materials in the reactor cores might be such that a method of access to the cores should be provided.

R. The very high costs involved in removing and processing irradiated materials in the reactor blocks make this possibility highly unlikely and too speculative to consider in this EIS.

Tr-P17. Why is $N$ Reactor not included in the DEIS?

R. $N$ Reactor is not available for decommissioning at the present time. DOE will prepare appropriate environmental documentation when $N$ Reactor does become available for decommissioning.

Tr-P19. If $B$ Reactor is preserved as an exhibit, the exhibit should include a visual display of the effects of the bombing of Nagasaki.

R. See response to L005-C01.

Tr-P20. How was the population dose of 50,000 person-rem for no action arrived at?

R. Population doses were calculated by means of radionuclide pathway analyses, which include calculations based on experimental data on the release of radionuclides (over 10,000 years) from the decommissioned reactors into water, on the movement of water and radionuclides through the ground to the columbia River, and on the ingestion of water and foodstuffs containing radionuclides by persons living downstream from Hanford. 
Responses to Comments; Comments and Responses

Tr-P21. Will persons in eastern Oregon or downstream from Hanford be affected by the 50,000 person-rem population dose from no action?

R. Yes. The 50,000 person-rem population dose is projected to result in 5 to 50 health effects over 10,000 years to persons downstream from Hanford.

Natural background radiation will produce 900,000 to 9 million health effects in the same population over the same time period.

Tr-P22. Where do the cost estimates come from?

R. Decommissioning cost estimates were made by various firms and individuals experienced both in decommissioning and in cost estimating.

Tr-P22. How safe is Hanford?

R. Radiological conditions at Hanford are monitored routinely. The results for 1987 are summarized in Section 4.4.3. These results show very small pub1 ic radiation doses (much below background) that can be attributed to Hanford. Tr-P37. Decommissioning of $N$ Reactor should be included in the EIS.

R. See response to $\mathrm{Tr}-\mathrm{P} 17$.

Tr-P39. Why is it essential to decommission the surplus production reactors?

R. As stated in Chapter 2, "Because the reactors contain irradiated reactor components and because the buildings that house the reactors are contaminated with low levels of radioactivity, the DOE has determined that there is a need for additional action to ensure protection of the public health and safety, and that decommissioning or continued surveillance and maintenance is necessary."

$\mathrm{Tr}-\mathrm{P41}$. Is there a technology for cleanup of ground water?

R. There are several technologies for cleanup of ground water, including technologies similar to those used to treat drinking water and domestic sewage. However, not all technologies are technically and economically viable for a given ground-water problem.

Tr-P42. Impacts from sludge in the storage basins seem to be omitted from the DEIS. 
R. Both short-term impacts to workers and long-term impacts to the public from sludge in the storage basins are included in Appendix G, Chapter 3, and Chapter 5 of the DEIS.

Tr-P43 and 44. The text discussing radiation dose calculations seems to contain many qualifying adjectives and adverbs, such as "possibly indicating," "quite probable," "approximately," "equivalent to about," etc.

R. This is true. To the extent possible, the dose calculations are based on experimental measurements. However, because the processes are so slow, the pathways so varied, and the time scales so long, experimental data must be extrapolated and often summed or averaged. Hence the qualifications.

Tr-Se57. EPA should have a strong involvement in decommissioning the surplus production reactors.

R. EPA's involvement in decommissioning is described in Chapter 6. EPA also participates (along with the WDOE) in the Hanford cleanup under the terms of the Tri-Party Agreement. See response to L042-C18.

$\mathrm{Tr}$-Se58. Would radioactive material in the surplus production reactors be classified as high-level or low-level waste?

R. All of the radioactive material that might be generated as waste in any of the decommissioning alternatives would be classified as low-level radioactive waste under the Low-Level Radioactive Waste Policy Act and under DOE 5820.2A. Tr-Se59. EPA has jurisdiction over decommissioning. If EPA chooses not to exercise its jurisdiction, then the WDOE has jurisdiction.

R. DOE is responsible for decommissioning the eight surplus production reactors. The authority of the EPA and the State of Washington is discussed in Chapter 6 (see also response to $\mathrm{Tr}-\mathrm{Se} 57$ ).

Tr-Se65. DOE does not have the right to decide what happens with respect to decommissioning. EPA, or whoever is in charge, must make the decisions.

R. See response to $\mathrm{Tr}-\mathrm{Se} 57$. 
Responses to Comments; Comments and Responses

Tr-Se66. DOE claims that the waste involved is low level, but if it must be left alone for 75 years before anybody can touch it, it must actually be very high level.

R. The terms "high-level radioactive waste" and "Tow-level radioactive waste" have specific meanings based on federal 1 aw and regulations. The material in the reactors would be characterized as low-level waste under the applicable laws and regulations. As noted in the DEIS, decommissioning can be conducted without waiting for 75 years, but worker radiation doses are lower if the radionuclides in the reactors are allowed to decay with time. 


\section{APPENDIX $F$}

ADDENDUM TO SECTION F.3 OF APPENDIX F: BIOLOGICALLY RELATED HEALTH EFFECTS 


\section{APPENDIX $F$}

ADDENDUM TO SECTION F. 3 OF APPENDIX F: BIOLOGICALLY RELATED HEALTH EFFECTS

Since the completion of the DEIS in early 1989, additional documentation on the potential effects of radiation on human health has become available. The U.S. Environmental Protection Agency, in development of the National Emissions Standards for Hazardous Air Pollutants (NESHAPs) for radionuclides, presented currently available information and adopted a fatal cancer risk factor associated with exposure to $1 \mathrm{SV}$ (sievert; $1 \mathrm{SV}=100 \mathrm{rem}$ ) of $39,000 / 10^{6}$ persons, or for 1 rem of about $4 \times 10^{-4}$ (EPA 1989). This evaluation was revisited in 1991 for the evaluation of National Primary Drinking Water Regulations for radionuclides, and retained (Federal Register 1991). Between these two evaluations, the Committee on the Biological Effects of Ionizing Radiation (BEIR) of the U.S. National Research Council published its recommendations in a report known as BEIR V (1990). On the basis of available evidence, this committee recommended use of a population-weighted average lifetime excess risk of death from cancer following an acute dose to the whole body of $0.08 / \mathrm{Sv}\left(8 \times 10^{-4} / \mathrm{rem}\right)$. However, they qualified this, in that extension of exposures "over weeks or months, however, is expected to reduce the lifetime risk appreciably, possibiy by a factor of 2 or more." If a conservative value of only two is used as a "dose rate reduction factor" applicable to the BEIR $V$ estimates, then the EPA and BEIR $V$ results are essentially the same. Both of these results are within the range estimated in Table F.4 of the DEIS.

If the EPA and BEIR $V$ estimates of fatal cancer are used, comparisons of the five alternatives of the DEIS in terms of cancer fatalities may be made. These are summarized in Table F.5. 
TABLE F.5. Comparison of Cancer Fatalities for the Disposal Alternatives

\begin{tabular}{|c|c|c|c|c|}
\hline Alternative & $\begin{array}{l}\text { Occupational } \\
\text { Doses } \\
\text { (person-rem) }\end{array}$ & $\begin{array}{c}\text { Occupational } \\
\text { Cancer } \\
\text { Fatalities } \\
\end{array}$ & $\begin{array}{l}\text { Population } \\
\text { Doses } \\
\text { (person-rem) }\end{array}$ & $\begin{array}{c}\text { Population } \\
\text { Cancer } \\
\text { Fatalities }\end{array}$ \\
\hline No Action & 24 & 0 & 50,000 & 20 \\
\hline $\begin{array}{l}\text { Immediate } \\
\text { One-Piece } \\
\text { Removal }\end{array}$ & 159 & 0 & 1,900 & 1 \\
\hline $\begin{array}{l}\text { Safe Storage } \\
\text { Deferred One } \\
\text { Piece Removal }\end{array}$ & 51 & 0 & 1,900 & 1 \\
\hline $\begin{array}{l}\text { Safe Storage } \\
\text { Deferred } \\
\text { Dismant Tement }\end{array}$ & 532 & 0 & 1,900 & 1 \\
\hline $\begin{array}{l}\text { In-Situ } \\
\text { Decommissioning }\end{array}$ & 33 & 0 & 4,700 & 2 \\
\hline
\end{tabular}

\section{ADDITIONAL REFERENCES}

U.S. Environmental Protection Agency (EPA). 1989. "Risk Assessment Methodology," Environmental Impact Statement on NESHAPS for Radionuclides, Background Information Document, Volume 1. EPA/520/1-89-005, Environmenta] Protection Agency, Washington, D.C.

56 FR 33050-33127. July 18, 1991. "National Primary Drinking Water Standards; Radionuclides." Federal Register. U.S. Environmental Protection Agency.

National Academy of Sciences Advisory Committee on the Biological Effects of Ionizing Radiation (BEIR). 1990. Health Effects of Exposure to Low Levels of Ionizing Radiation, BEIR $V$. Commission on Life Sciences, National Academy of Sciences--National Research Council, Washington, D.C.2222 
APPENDIX $K$

DECOMMISSIONING COSTS 
APPENDIX K

\section{DECOMMISSIONING COSTS}

Updated estimates (in 1990 dollars) for the cost of decommissioning the eight surplus production reactors at the Hanford Site, Richland, Washington, are presented in this appendix (see Chapter 3.0 for previously described costs). Appropriate factors for adjusting costs from the 1986 base to the 1990 base were used to facilitate this update. These factors are based on an analysis of cost indices and other measures of projected cost escalations over the period of interest (Konzek 1989). The purpose of these cost estimates, to provide a basis of comparative analysis among the decommissioning alternatives, remains unchanged by this update.

The general conditions and assumptions applied during this re-evaluation are unchanged from those given in Chapter 3.0, except that estimated costs are given in constant 1990 dollars. The order of decommissioning will be determined on the basis of detailed engineering studies. However, for cost estimation purposes, it was assumed that $F$ Reactor would be decommissioned first. The contingency allowances contained in various reports by others (individuals and firms) that were used to develop the decommissioning cost estimates in Chapter 3.0 were reviewed for reasonableness. This review of contingency allowances determined that 1) they were in compliance with DOE guidelines contained in DOE-RL 5700.3, and 2) they covered onty the scope of decommissioning work as it was originally conceived in the parent document(s). DOE-RL 5700.3 delineates the contingency requirements for Hanford projects, primarily construction projects; however, for the purpose of this cost update, these contingency requirements are assumed to be equally applicable to "deconstruction"/decommissioning projects as well. As a result of this review, no adjustments were necessary in the various contingency allowances previously provided by others.

The estimated costs of decommissioning the eight surplus production reactors using each of the five postulated alternatives are summarized in 
Section K.1. The detailed cost estimates supporting the summary information are contained in Section K.2 for no action, Section K.3 for immediate onepiece removal, Section K.4 for safe storage followed by deferred one-piece removal, Section K. 5 for safe storage followed by deferred dismantlement, and Section K.6 for in situ decommissioning.

\section{K.1 COST COMPARISON OF THE ALTERNATIVES}

A cost comparison of the alternatives is presented in Table K.l to show the separate costs of safe storage, active decommissioning, barrier construction and waste site modifications, and subsequent monitoring. An overall evaluation of the five alternatives is presented in Chapter 3, Section 3.7, and is not repeated here.

\section{K.2 NO ACTION}

Consideration of no action is required by the regulations of the Council on Environmental Quality that implement the National Environmental Policy Act (NEPA). No action has two possible meanings: either to discontinue present actions and do nothing further, or to continue present actions indefinitely.

\section{K.2.1 No Further Action}

With no further action, the facility would be closed and all related activities would be discontinued. Although this alternative has no cost, it is not reasonable because it does not properly isolate the facility's remaining radioactivity from the environment, does not provide for any maintenance or repair of the structures, and does not make any other provision for protection of human health and safety. No further action would result in deterioration of the reactor buildings, potential release of radionuclides to the environment, potential human exposure to radioactivity by intrusion, and potential safety hazards to intruders. No further action is not the DOE's interpretation of no action. Therefore, this alternative is not analyzed in greater detail. 
TABLE K.1. Costs of Decommissioning Alternatives(a)

\begin{tabular}{|c|c|c|c|c|c|}
\hline Activity & No Action & $\begin{array}{l}\text { Immediate } \\
\text { One-Piece } \\
\text { Removal } \\
\end{array}$ & $\begin{array}{l}\text { Safe Storage } \\
\text { Followed by } \\
\text { Deferred } \\
\text { One-Piece } \\
\text { Removal } \\
\end{array}$ & $\begin{array}{l}\text { Safe Storage } \\
\text { Followed by } \\
\text { Deferred } \\
\text { Dismantlement }\end{array}$ & $\begin{array}{l}\text { In Situ } \\
\text { Decommissioning }\end{array}$ \\
\hline Safe storage & 43.5 & -- & 35.9 & 38.0 & -- \\
\hline Mound/barrier & -- & -- & -- & -- & 61.9 \\
\hline Burial site/barrier & -- & 46.6 & 46.6 & 15.9 & -- \\
\hline $\begin{array}{l}\text { Construct ground-water } \\
\text { monitoring wells }\end{array}$ & -- & 1.6 & 1.6 & 1.6 & 2.1 \\
\hline Ground-water monitoring & -- & 38.1 & 8.8 & 10.3 & 101.6 \\
\hline $\begin{array}{l}\text { Other decommissioning } \\
\text { costs }\end{array}$ & -- & 142.0 & 142.0 & $\underline{\underline{245.5}}$ & $\underline{27.4}$ \\
\hline TOTALS & 43.5 & 228.3 & 234.9 & 311.3 & 193.0 \\
\hline
\end{tabular}

(a) Costs are for 100 years, in millions of 1990 dollars. 
Decommissioning Costs; Immediate One-Piece Removal

\section{K.2.2 Continue Present Action}

The continue present action alternative consists of comprehensive surveillance, monitoring, and maintenance. These activities are the same as those required during the safe-storage period of the safe storage followed by deferred decomissioning alternative. The annual (or unit) costs and radiation doses are similar. Initial repairs are estimated to cost about $\$ 975,200$ per reactor; major building repairs are estimated to cost about $\$ 248,500$ per reactor every 20 years; minor repairs are estimated to cost about $\$ 78,000$ per reactor every 5 years; and routine surveillance, monitoring, and maintenance activities are estimated to cost about $\$ 23,200$ per reactor annually. For 100 years of continued present action, the cost is estimated to be $\$ 43.5 \mathrm{mil}$ lion in 1990 dollars, including a $20 \%$ contingency.

Throughout this EIS, continue present action is subsequently referred to as the no action alternative.

\section{K.3 IMMEDIATE ONE-PIECE REMOVAL}

The immediate one-piece removal alternative involves the removal of the surplus production reactors (in one piece) from their existing sites, along with their respective spent-fuel storage basins. This would include all piping, equipment, components, structures, and wastes having radioactivity levels greater than those permitted for the sites to be available for other DOE use. Immediate one-piece removal entails the following activities: 1) removing each reactor block (graphite core, surrounding shielding, and support base) in one piece and transporting it on a tractor-transporter over specially constructed haul roads to a DOE-owned burial location in the 200West Area; 2) dismantling and removing the remaining contaminated materials, equipment, and soils; and 3 ) reuse or disposal of all noncontaminated equipment and structures.

\section{K.3.1 Costs of Immediate One-Piece Removal}

A summary of estimated costs for immediate one-piece removal is given in Table K.2. The costs shown are for movement of the eight intact reactor blocks by tractor-transporter overland to the 200-West Area burial ground and 
TABLE K.2. Summary of Estimated Costs for Immediate One-Piece Removal of the Eight Surplus Production Reactors (thousands of $1990 \$)^{(a)}$

\begin{tabular}{|c|c|c|c|c|c|c|c|c|c|}
\hline \multirow{2}{*}{ Cost Category } & \multicolumn{8}{|c|}{ Reactor } & \multirow[b]{2}{*}{ Totals } \\
\hline & $165-F$ & $105-\mathrm{H}$ & $105-0$ & $105-\mathrm{DR}$ & $165-B$ & $105-C$ & 195-KE & $105-\mathrm{KW}$ & \\
\hline $\begin{array}{l}\text { abor } \\
\text { quipnent/materials } \\
\text { ervice charge (25\%) }\end{array}$ & $\begin{array}{r}3,462 \quad 20 \\
69244 \\
1,038 \quad 66 \\
\end{array}$ & $\begin{array}{r}2.764 \quad 66 \\
69244 \\
864 \quad 28 \\
\end{array}$ & $\begin{array}{r}2,764 \quad 66 \\
69244 \\
864 \quad 28 \\
\end{array}$ & $\begin{array}{r}2,764 \quad 66 \\
69244 \\
864 \quad 28 \\
\end{array}$ & $\begin{array}{r}2.80903 \\
70089 \\
87746 \\
\end{array}$ & $\begin{array}{r}2.80963 \\
70080 \\
87746 \\
\end{array}$ & $\begin{array}{r}2.76466 \\
69244 \\
86428 \\
\end{array}$ & $\begin{array}{r}2.76466 \\
69244 \\
86428 \\
\end{array}$ & $\begin{array}{r}22,90356 \\
5,55624 \\
7,11498 \\
\end{array}$ \\
\hline abtotal & 5,19330 & 4.32138 & 4,32138 & 4,32138 & 4,38729 & 4,38729 & 4,32138 & 4,32138 & 35,57478 \\
\hline he plece removal & $\underline{17}_{1}^{09504}{ }^{(\mathrm{b})}$ & $4,567 \quad 35$ & $4,556 \quad 83$ & $4.368 \quad 65$ & $4,488 \quad 22$ & $4,304 \quad 36$ & 4,54278 & $4,361 \quad 64$ & $48,284 \quad 81$ \\
\hline jubtotal & $22,288 \quad 34$ & 8,88873 & 8,87821 & $8,690 \quad 03$ & 8,87551 & 8.69159 & $8,864 \quad 16$ & 8,68302 & 83,8595 \\
\hline ont ingency $(20 \%)$ & $4,457 \quad 67$ & $1,796 \quad 75$ & $1.794 \quad 64$ & $1,757 \quad 01$ & $1,794 \quad 10$ & $1,757 \quad 32$ & 1,79183 & 1.75561 & $16,904 \quad 9$ \\
\hline Subtotal & $26,746 \quad 01$ & 10.68548 & 10,67285 & 16.44764 & 10,66961 & 18.44891 & 10.65599 & $16,438 \quad 63$ & 100,7645 \\
\hline $\begin{array}{l}\text { Building removal }(c) \\
\text { Road construct ion } \\
\text { Ground-water monitor } 1 \mathrm{pg}\end{array}$ & $\begin{array}{r}2.93412 \\
16,77175\end{array}$ & $\begin{array}{l}2,36050 \\
2,17250\end{array}$ & $\begin{array}{r}2.36050 \\
56488\end{array}$ & $\begin{array}{r}2.36050 \\
56488\end{array}$ & $\begin{array}{r}2,36050 \\
43450\end{array}$ & $\begin{array}{r}2,36050 \\
43450\end{array}$ & $\begin{array}{r}2,36050 \\
43450\end{array}$ & $\begin{array}{r}2.36050 \\
43450\end{array}$ & $\begin{array}{l}19,457 \quad 62 \\
21.812 \quad 81\end{array}$ \\
\hline $\begin{array}{l}\text { system and operation } \\
\text { Burial ground }\end{array}$ & $\begin{array}{r}4,96194 \\
5,821,87 \\
\end{array}$ & $\begin{array}{r}4,96194 \\
5,821 \quad 87 \\
\end{array}$ & $\begin{array}{r}4,96194 \\
5.82187 \\
\end{array}$ & $\begin{array}{r}4,96194 \\
5,821 \quad 87 \\
\end{array}$ & $\begin{array}{l}4,96194 \\
5,821,82 \\
\end{array}$ & $\begin{array}{r}4,961 \quad 94 \\
582187 \\
\end{array}$ & $\begin{array}{r}4,96194 \\
5 \quad 821 \quad 87 \\
\end{array}$ & 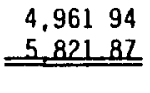 & 39,69552 \\
\hline FOTAL COSTS & 7.23569 & .09229 & $1,382 \quad 04$ & .15623 & .24842 & 1.02772 & 4.23480 & 1.01744 & 28,384 \\
\hline
\end{tabular}

(a) Notes 1) shipping and burial costs are based on disposal at Hanford, 2) no salvage credit is taken, and 3) water flushes, high-pressure water lance, concrete scarfing, and selected manual techn iques are the decontamination methods assumed to be used Costs are deliberately not rounded for computational accuracy

(b) Includes total cost of transporter

(c) Adapted from Kaiser (1983) report, and includes $36 \%$ cont ingency as well as selected adjustment factors for a fixed-price contractor

(d) Includes $25 \%$ cont ingency

(e) Includes $20 \%$ cont ingency

(f) Includes $12 \%$ cont ingency 
Decommissioning Costs; Immediate One-Piece Removal

for the dismantlement and removal of the remaining components and structures. In all cases, shipping and burial costs are based on disposal at Hanford in the low-level burial site in the 200-West Area. The estimated costs do not include any additional allowance for inflation to account for either the work not beginning immediately or for the work extending over several years. This method of presenting the cost estimate permits useful comparisons to be made among the costs of all alternatives.

The total estimated cost for immediate one-piece removal of all eight surplus production reactors is about $\$ 228$ million in 1990 dollars. This estimate includes a $25 \%$ service charge on labor, equipment, and materials; a $20 \%$ contingency allowance on dismantlement costs and construction of monitoring we $11 \mathrm{~s}$; a $30 \%$ contingency allowance on building removal; a $25 \%$ contingency allowance on road construction; and a $12 \%$ contingency on burial-ground costs. The $25 \%$ service charge on labor, equipment, and materials is standard practice at Hanford for obtaining these services internally. The $20 \%$ contingency on dismantlement costs is based on the Kaiser (1985) report. The $20 \%$ contingency on monitoring wells is based on the Smith (1987) report. The $25 \%$ contingency on road construction activities is based on and consistent with the Kaiser (1986) report. The $30 \%$ contingency on building removal is based on the Kaiser (1983) report. The $12 \%$ contingency on burial-ground costs is based on conceptual designs developed for this EIS.

Reductions in planning and preparation costs are estimated for the second and subsequent reactors to account for the elimination of some planning activities that do not need to be repeated and for reduced site-preparation costs when two reactors are located at the same site. Haul-road construction costs are greatest for the $F$ Reactor because it was assumed for cost estimation purposes that $F$ Reactor would be decommissioned first and because it is farthest from the 200-West burial ground. Short haul-road extensions that tie into the main haul road would be constructed for subsequent reactor-block transport operations as required, resulting in significantly lower haul-road construction costs for these latter reactors. Fuel storage basin decontamination 
Decomissioning Costs; Immediate One-Piece Removal

costs are higher for the $B$ and $C$ Reactors than for the other six reactors because contaminated sludge must be removed from the fuel-storage transfer pits of these two reactors.

Estimated costs (in 1990 dollars) for immediate one-piece removal of a "typical" reactor are shown in Table K.3. Average costs per reactor are used when estimating costs of radioactive waste packaging and disposal, building removal, engineering, and road construction. However, other costs such as the tractor-transporter are one-time costs starting with the first reactor and cannot be accurately represented by averaging. Still other costs, such as satisfying regulatory requirements and developing work plans and procedures, are greatest for the first reactor and are substantially less for subsequent reactors.

The estimated costs for the planning and preparation activities that precede actual decommissioning operations are included in Table K.3. In addition, costs are included in the table to account for such functions as supervision, radiation monitoring, and engineering support.

The Kaiser estimate (Kaiser 1986) for the tractor-transporter (see Chapter 3 and Section K.3.3 for details) has been revised to reflect 1990 cost base values. In 1990 dollars, two transporter units are estimated to be purchased for $\$ 12.53$ million.

\section{K.3.2 Waste-Site Costs}

The 200-West Area waste-site costs for the reactor blocks are presented in Table K.4. The table summarizes the costs associated with using protective barrier and warning marker systems and a liner/leachate collection system, but does not include the costs of road construction to the 200-West Area burial site from the individual reactor sites.

\section{K.3.3 Transporter Shipment of the Reactor Blocks}

As discussed in Chapter 3, Section 3.2.5, the following two studies were conducted to determine the feasibility of moving a reactor block in one piece:

- a study by Rockwell (1985) to develop preliminary cost estimates of route preparation and burial of the surplus production reactors 


\section{TABLE K.3. Estimated Costs for Immediate One-Piece Removal of a Typical Reactor}

\begin{tabular}{|c|c|}
\hline Acturtty & $\begin{array}{c}\text { Cost } \\
\text { (thousand } \\
\text { of } 1990 \text { S } 1 \text { (a) }\end{array}$ \\
\hline 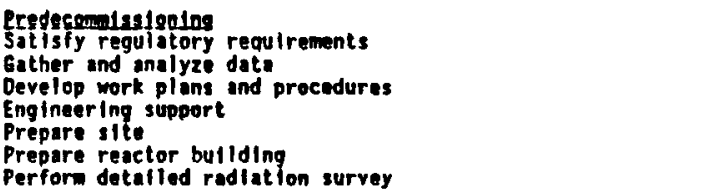 & $\begin{array}{l}76.70(b) \\
47.75(b) \\
115.51(b) \\
253.61 \\
300.10(b) \\
121.78 \\
3.90\end{array}$ \\
\hline 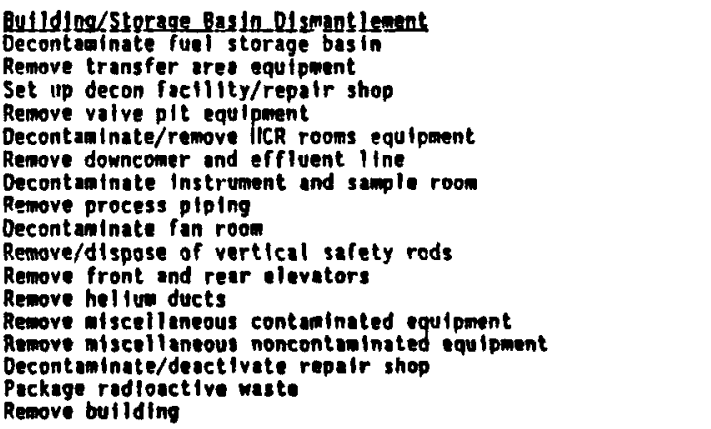 & $\begin{array}{r}251.90 \\
35.93 \\
152.45 \\
51.89 \\
332.01 \\
229.11 \\
245.70 \\
708.11 \\
265.08 \\
338.74 \\
342.90 \\
29.50 \\
675.52 \\
34.10 \\
77.96 \\
565.68(b) \\
2,432.20(b, c)\end{array}$ \\
\hline 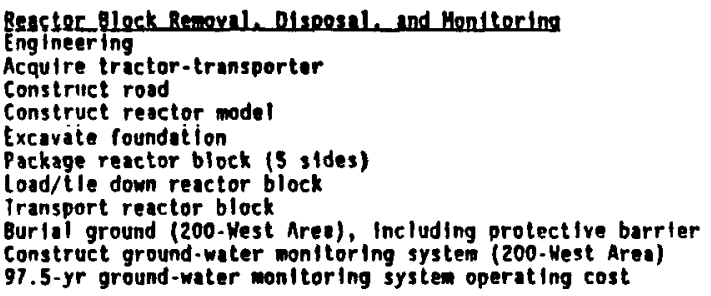 & $\begin{array}{l}79.60(b) \\
1,565.80(b) \\
2,181.20(b) \\
19.55 \\
1,278.63(b) \\
22.25 \\
71.83 \\
35.15(b) \\
5,198.10(b) \\
164.26(b, d) \\
3,970.69(b, d)\end{array}$ \\
\hline 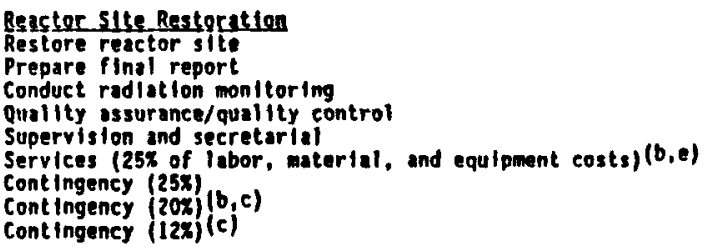 & $\begin{array}{r}27.18 \\
46.83 \\
307.07 \\
108.05 \\
526.03 \\
889.37 \\
545.26 \\
2.940 .11 \\
623.21\end{array}$ \\
\hline TOIAL & $28,592.36$ \\
\hline
\end{tabular}

(a) Includes labor, equipment, waste disposal, and contractor costs for

(b) inch netiviey.

(b) This cost is a calculated fractional allocation of about one-elghth the totel cost of this task for ell elght reactors.

(c) The $20 \%$ contingency applies to all activity costs in the table except buliding removil, road constructlon, and birlal-ground work. The first of these three activitles utllizes $30 \%$ contingency as well as other adjustment factnrs adapted From KEll-R-63-14 (Kalser 1983), and these costs are Included in the activity cnst presented in the toble. Based on the Rockweil llanford operallons (1985) In the table. Based on the Rockweil Manford aperallons (1985) Burlai-qround work activity utilizes $12 \%$ cont ingency, based on the Adans (1981) report. The costs estlmated in these reports were escalated to 1990 cost base.

(d) Based on a cost estimate by Sfith (1987) escalated to a 1990 cost base.

(e) Services include Items obtalned from other ons lte contractors, such as Iaundry, utlitties, fire protection and patrol, transportation, medical aid, ete. 
Decommissioning Costs; Immediate One-Piece Removal

TABLE K.4. Estimated Construction Costs for Burial of Reactor Blocks with Liner/Leachate Collection System in the 200-West Area(a)

\begin{tabular}{|c|c|c|}
\hline & Costs (tho & of 1990 \$ \\
\hline Item & Per Block & $\underline{8}$ Blocks \\
\hline $\begin{array}{l}\text { Direct Costs: } \\
\text { Excavation } \\
\text { Foundations } \\
\text { Hauling of soils/sand/gravel } \\
\text { Installation of soil/clay mix } \\
\text { Installation of geotextile } \\
\text { Installation of geomembrane } \\
\text { Backfilling } \\
\text { Revegetation } \\
\text { Installation of subsurface markers } \\
\text { Installation of surface markers } \\
\text { Contractor overhead and markup }\end{array}$ & $\begin{array}{r}491.3 \\
363.8 \\
301.8 \\
911.2 \\
223.0 \\
194.0 \\
783.4 \\
6.1 \\
50.0 \\
325.8 \\
517.1 \\
\end{array}$ & $\begin{array}{r}3,930 \\
2,910 \\
2,414 \\
7,289 \\
1,784 \\
1,552 \\
6,267 \\
49 \\
400 \\
2,606 \\
4,137 \\
\end{array}$ \\
\hline Total construction & $4,167.5$ & 33,338 \\
\hline $\begin{array}{l}\text { Construction management } \\
\text { Contract management } \\
\text { Engineering design and inspection } \\
\text { Escalation } \\
\text { Contingency }(12 \%)\end{array}$ & $\begin{array}{l}317.1 \\
317.1 \\
396.4 \\
0 \\
623.8 \\
\end{array}$ & $\begin{array}{r}2,537 \\
2,537 \\
3,171 \\
0 \\
4,990 \\
\end{array}$ \\
\hline TOTALS & $5,831.9$ & 46,573 \\
\hline
\end{tabular}

(a) From Adams (1987), except as noted otherwise; escalated to 1990 cost base.

(b) Adapted from Rockwell (1985), Table 2; escalated to 1990 cost base.

- a study by Kaiser (1986) to determine the structural feasibility of moving the surplus production reactor blocks intact from the ir present locations in the 100 Areas to permanent, low-level burial grounds in the 200-West Area.

For the purpose of determining the total decommissioning costs associated with the various decommissioning alternatives described in this EIS, costs in both of these studies have been escalated to 1990 dollars.

The transport of each of the eight surplus production reactors at Hanford from their present locations near the Columbia River to the 200-West Area burial grounds is estimated to cost an average of about $\$ 2.8$ million 
Decomissioning Costs; Immediate One-Piece Removal

(see Table K.5), not including demolition of surrounding building structures, construction of roadways for transporting the reactor blocks, cost for transport to the burial site, or preparation of the 200 -West Area burial site.

\section{K. 4 SAFE STORAGE FOLLOWED BY DEFERRED ONE-PIECE REMOVAL}

The safe storage followed by deferred one-piece removal alternative includes three distinct operational phases: preparation for safe storage, the safe-storage period, and deferred one-piece removal. Additional details associated with this decommissioning alternative are presented in chapter 3 , Section 3.3 .

\section{K.4.1 Costs of Safe Storage Followed by Deferred One-Piece Removal}

A summary of estimated costs for safe storage followed by deferred onepiece removal is given in Table K.6. The storage costs shown are corrected for the safe-storage period that varies from 75 to 84 years. The deferred removal costs shown in the table are for removal of the eight intact reactor blocks by tractor-transporter overland to the 200-West Area burial ground and the dismantlement and removal of the remaining components and structures. In all cases, shipping and burial costs are based on disposal at Hanford in the low-level burial site in the 200-West Area. The total estimated cost for safe storage followed by deferred one-piece removal is about $\$ 235$ mil1ion in 1990 dollars.

The application of a $25 \%$ contingency on road construction costs is based on the Kaiser (1986) report. The $12 \%$ contingency on burial-ground construction costs is based on the Adams (1987) report. The $30 \%$ contingency applied to building removal costs is based on the Kaiser (1983) report. The estimated costs do not include any additional allowance for inflation, either to account for the work not beginning immediately or to account for the work extending over several years. This method of presenting the cost estimate allows useful comparisons to be made among the costs of all alternatives.

Reductions in planning and preparation costs are estimated for the second and subsequent reactors to account for the elimination of some planning activities that do not need to be repeated and for reduced site-preparation 
Decommissioning Costs; Immediate One-Piece Removal

TABLE K.5. Summary of Costs for Transporters and Removal of Eight Surpius Production Reactors ${ }^{(a)}$

Cost Category

Transporters, two (2)

Tax at $7.8 \%$

Total Transporter Cost

CPAF $^{(b)}$ construction:

Direct construction cost

- Excavation and concrete removal

- Pressure grout holes

- Steel supports

Total Direct Construction Cost

Indirect Costs:

General overhead ${ }^{(c)}$

- Sma17 tools at 2.5\% 1abor

- Contractor indirects and fees at $18 \%$ of 1 abor

- Radiation and health protection at $3 \%$ of 1 abor

Technical services

General requirements

Subcontractor administration

Bid package plus badging

Constructability review

Subtotal Indirect Cost

TOTAL
Estimated

Costs (1990 \$)

$11,620,000$

906,360

$12,526,360$

$7,857,440$

158,900

890,100

$8,906,440$

3,860

27,830

4,640

41,830

35,730

$1,172,770$

15,400

20,540

$1,322,600$

$22,755,000^{(d)}$

(a) Based on Kaiser (1986), Appendix A, and escalated to 1990 cost base. The cost estimate is for construction only and does not include engineering or contingency.

(b) Cost plus award fee.

(c) The estimated cost of each subcategory is the product of the total labor cost $(\$ 155,000$ in 1990 dollars) times the percentage given for that item (Kaiser 1986).

(d) Total cost is rounded to the nearest $\$ 1,000$. 
TABLE K.6. Summary of Estimated Costs for Safe Storage Followed by Deferred One-Pjefe Removal of the Eight Surplus Production Reactors (thousands of 1990 \$) (a)

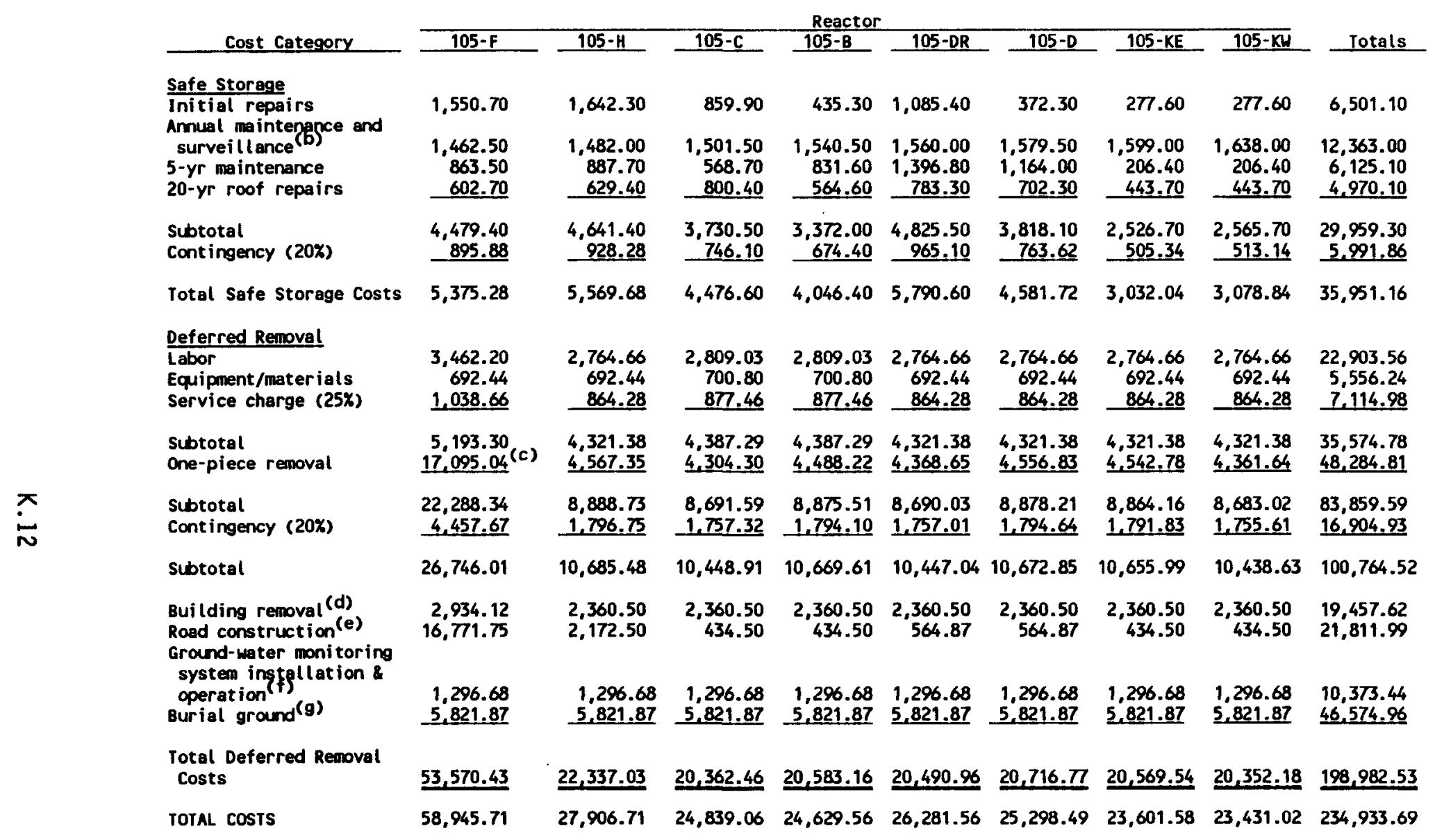

(a) Notes: 1) shipping and burial costs are based on disposal at Hanford; 2) no salvage credit is taken; and 3) water flushes, high-pressure water lance, concrete scarfing, and selected manual techniques are the decontamination methods assumed to be used. Costs are del iberately not rounded for computational accuracy.

(b) Based on letter report by Hughes (1986).

(c) Includes totol cost of tractor-transporter.

(d) Adapted from Kaiser (1983) report and includes $30 \%$ contingency as well as selected adjustment factors for a fixed-price contract, escalated to 1990 cost base. The higher removal cost for the 105-F Reactor includes the cost of a mabile crane that would also be used for demolition of the other seven reactors.

(e) Includes $25 x$ cont ingency.

(f) Includes $20 \%$ contingency.

(g) Includes $12 x$ contingency. 
Decommissioning Costs; Safe Storage Followed by Deferred One-Piece Removal

costs when two reactors are located at the same site. Haul-road costs would be greatest for the $F$ Reactor because it was assumed for cost estimation purposes that it would be decommissioned first and because it is farthest from the 200-West Area burial ground. Short haul-road extensions that connect with the main haul road would be constructed for subsequent reactor-block transport operations as required, resulting in significantly lower haul-road construction costs for these latter reactors. In addition, fuel storage basin decontamination costs would be higher for the $B$ and $C$ Reactors than for the other six reactors because contaminated siudge must be removed from the fuel storage transfer pits of these two reactors.

Estimated costs (in 1990 dollars) for deferred removal of a "typical" reactor are the same as those shown previously in Table K.3 for immediate onepiece reactor block removal. Average costs per reactor are used when estimating costs of radioactive-waste packaging and disposal, building removal, engineering, and road construction. However, other costs, such as the tractor-transporter, are one-time costs starting with the first reactor and cannot be accurately represented by averaging. Based on the estimate by Kaiser (1986), the tractor-transporter (see Section K.3.3 for details on escalation of the Kaiser cost estimate to 1990 cost base) could be purchased for $\$ 12.53$ million. Still other costs, such as satisfying regulatory requirements and developing work $\mathrm{plans}$ and procedures, are greatest for the first reactor and are substantially less for subsequent reactors. Nevertheless, the total cost given in Table K.3 is intended to be representative of decommissioning a typical reactor by deferred one-piece removal.

The estimated costs for planning and preparation activities that precede actual decommissioning operations are also included in Table K.3. Work requirements are included in the table to account for such functions as supervision, radiation monitoring, and engineering support.

\section{K.4.2 Waste-Site Costs}

The 200-West Area waste-site costs for safe storage followed by deferred one-piece removal are the same as for immediate one-piece removal (Table K.4). 
Decommissioning Costs; Safe Storage Followed by Deferred Dismantlement

\section{K.5 SAFE STORAGE FOLLOWED BY DEFERRED DISMANTLEMENT}

The safe storage followed by deferred dismantlement alternative comprises three distinct operational phases: preparation for safe storage, the safe-storage period, and deferred dismantlement. Routine surveillance operations are postulated for safe-storage periods that vary from 75 to 96 years for the eight reactors. Piece-by-piece dismantlement of the first reactor would begin after 75 years of safe storage, but dismantlement of the eighth reactor would not begin until 21 years after the start of dismantlement of the first reactor. This results in a 96-year safe-storage period for the eighth reactor. Deferred dismantlement of a single reactor is postulated to require approximately 6.5 years for completion. When dismantlement of one reactor has progressed to the stage that piece-by-piece dismantlement of the reactor block can begin (approximately 3 years into the dismantlement schedule), work on a second reactor would begin. This staggered dismantling would result in efficient use of personnel and equipment resources. Additional details associated with this decommissioning alternative are presented in Chapter 3, Section 3.4.

\section{K.5.1 Costs of Safe Storage Followed by Deferred Dismantlement}

Estimated costs for safe storage followed by deferred dismantlement of the eight surplus production reactors, corrected for the safe-storage period that varies from 75 to 96 years, are summarized in Table K.7. The total cost for all eight reactors is about $\$ 311$ million. Estimated costs for deferred dismantlement of the first reactor, shown in Table K.8, are assumed to be typical of the remaining seven reactors.

Reductions in planning and preparation costs are assumed for the second and subsequent reactors to account for the elimination of some planning activities that do not need to be repeated and for reduced site-preparation costs when two reactors are located at the same site. Fuel storage basin decontamination costs are higher for $B$ and $C$ Reactors than for the other reactors because the contaminated sludge must be removed from the fuel storage transfer pits of these reactors. Waste-disposal costs are higher for KE and KW Reactors than for the other reactors because their reactor blocks are 
TABLE K.7. Summary of Costs for Safe Storage Followed by Deferred Dismantlement for Eight Surplus Production Reactors (thousands of 1990 \$)

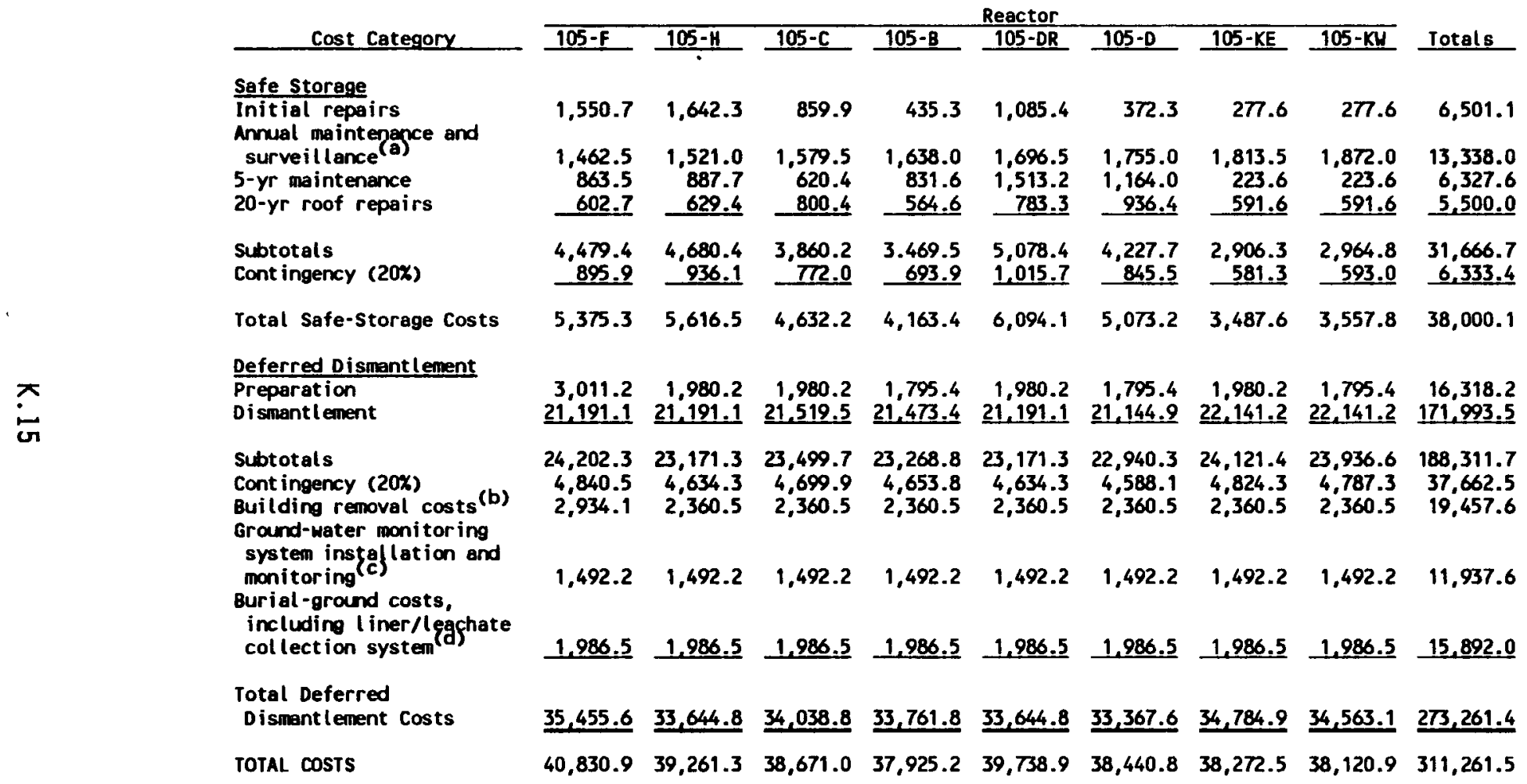

(a) Besed on letter report by Hughes (1986); escalated to 1990 cost base.

(b) Adapted from Kaiser (1983) report and includes $30 \%$ contingency as well as selected adjustment factors for a fixed price contract; escalated to 1990 cost bese. The higher removal cost for the $F$ Reactor includes the cost of a mobile crane that is subsequently utilized for demolition of the other seven reactors as well.

(c) Includes $20 \%$ contingency based on a 1987 cost est imate supplied by Smith (1987); escalated to 1990 cost base.

(d) Includes $12 X$ contingency; see Adams (1987) for details; escalated to 1990 cost base. 
TABLE K.8. Estimated Costs for Deferred Dismantlement of a Surplus Production Reactor

\begin{tabular}{|c|c|}
\hline Activity & $\begin{array}{c}\text { Cost } \\
\text { (thousands } \\
\text { of } 1990 \text { s) (a) }\end{array}$ \\
\hline $\begin{array}{l}\text { Predecomissioning } \\
\text { Satisfy regulotory requirements } \\
\text { Gather and analyze dota } \\
\text { Develop work plans and procedures } \\
\text { Design/procure/test speclal equipment } \\
\text { Prepare site } \\
\text { Prepare reactor butiding } \\
\text { Repair rail spur } \\
\text { Decontaminate fuel storage bas in } \\
\text { Establish decon/repair shop }\end{array}$ & $\begin{array}{r}76.7 \\
139.0 \\
336.2 \\
468.5 \\
369.7 \\
424.7 \\
668.1 \\
201.6 \\
154.6\end{array}$ \\
\hline 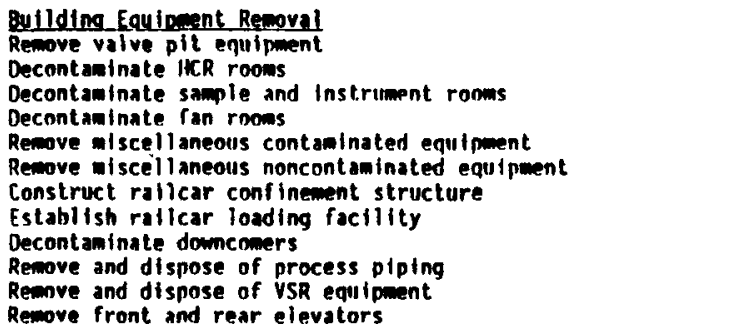 & $\begin{array}{r}54.0 \\
332.4 \\
229.6 \\
262.3 \\
461.6 \\
38.6 \\
643.3 \\
175.8 \\
244.3 \\
1.228 .6 \\
313.3 \\
343.0\end{array}$ \\
\hline 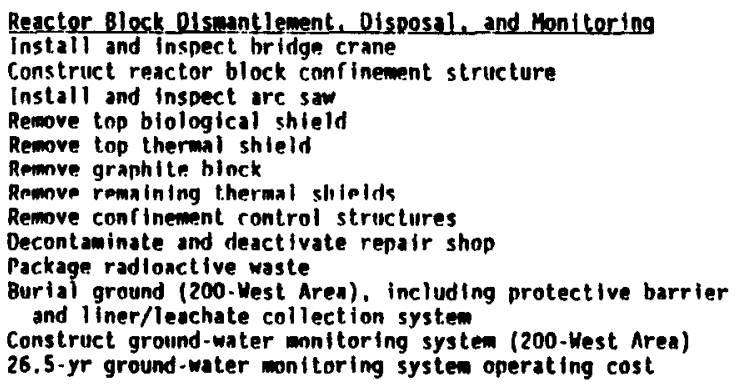 & $\begin{array}{r}438.5 \\
54.2 \\
534.0 \\
738.7 \\
116.7 \\
3,615.3 \\
356.0 \\
187.6 \\
78.0 \\
1,223.2 \\
1,986.5(b) \\
164.3 \\
1,079.2\end{array}$ \\
\hline Butlding Der.solition/Restoration & \\
\hline $\begin{array}{l}\text { Demolish reactor base } \\
\text { Dewolish bullding and bullding foundation(c) } \\
\text { Restore site }\end{array}$ & $\begin{array}{r}667.2 \\
2.432 .2 \\
34.0\end{array}$ \\
\hline $\begin{array}{l}\text { Generic Activities } \\
\text { Engineering support } \\
\text { Radiation monitoring } \\
\text { Quality assurance/quality control } \\
\text { Supervisjgg and secretarial } \\
\text { Services } \\
\text { Final report }\end{array}$ & $\begin{array}{r}1,263.2 \\
767.7 \\
270.1 \\
1.315 .1 \\
2.613 .9 \\
46.8 \\
\end{array}$ \\
\hline $\begin{array}{l}\text { Subtotals } \\
\text { Cont Ingency }(20 x)(e)\end{array}$ & $\begin{array}{r}29,864.5 \\
5,089.2\end{array}$ \\
\hline TOTAL COST FOR OEFERRED DISNW & $34,953.7$ \\
\hline
\end{tabular}

(a) Includes labor, equipment, waste disposal, and contractor costs for each activity.

(b) This activity includes a 127 contingency (Mdans 1987), and the contingency is included in the activity cost presented in the table.

(c) The activity utillzes $30 x$ conitingency as well as other adjustment factors adopted from KEH R-83-14 (Kolser 1983): these costs are included In the activity cost presented in the tabie.

(d) Services Include Itews obtained from other onsite contractors such is laundry, utllities, fire protection and patrol, Iransportation, is laundry, Ittilitid, ete.

(e) The $20 x$ contingency applies to all activity costs in the table except bullding demolishing and removal and burial-ground costs; see also footnotes (b) and (c). 
larger (see Chapter 3, Tables 3.10 and 3.11 for details); thus, deferred dismantlement costs are higher for the KE and KW Reactors.

\section{K.5.2 Waste-Site Costs}

The 200-West Area waste-site costs for the dismantled reactor blocks are presented in Table K.9. The table summarizes the costs associated with constructing a protective barrier, a warning marker system, and a 1 iner/leachate collection system.

\section{K.6 IN SITU DECOMMISSIONING}

Decommissioning of a surplus production reactor by in situ decomissioning is the least complex of the proposed decommissioning alternatives. The specific activities associated with the in situ decommissioning alternative are discussed in detail in Chapter 3 , Section 3.5, and are not repeated here.

The original analyses presented in Section 3.5 were based on three separate estimates, adjusted to a 1986 cost base: 1) the Kaiser (1985) report; 2) the Adams (1987) report; and 3) a report by Smith (1987). The detailed estimates developed by Kaiser and Westinghouse Hanford (Adams 1987) were averaged over all reactors to obtain values for each task for the "average" reactor.

\section{K.6.1 Costs of In Situ Decommissioning}

The estimated costs of in situ decommissioning are summarized in Table K.10. The costs shown in the table are based on the three separate costs estimates mentioned previously, escalated to a 1990 cost base. The total cost at the bottom of the table includes site support services (25\% of staff 1 abor, materials, and equipment) and contingencies (20\% of all costs, except $12 \%$ on placement of earth, gravel, and seeding). The total cost for in situ decommissioning of all eight reactors is estimated to be $\$ 193 \mathrm{million}$.

Individual and collective reactor burial mound costs (in 1990 dollars) are presented in Table K.11. The table summarizes the costs associated with 
Decormissioning Costs; In Situ Decommissioning

TABLE K.9. Estimated 200-West Area Burial-Site Costs Associated with Burial of the Dismantled Reactor Blocks

\begin{tabular}{|c|c|c|}
\hline & Costs (tho & of $1990 \$ 1$ \\
\hline Item & Per Block & 8 Blocks \\
\hline $\begin{array}{l}\text { Direct Costs: } \\
\text { Excavation } \\
\text { Hauling of soils/sand/gravel } \\
\text { Installation of soil/clay mix } \\
\text { Installation of geotextile } \\
\text { Installation of geomembrane } \\
\text { Backfilling } \\
\text { Revegetation } \\
\text { Installation of subsurface markers } \\
\text { Installation of surface markers } \\
\text { Contractor overhead and markup }\end{array}$ & $\begin{array}{r}125.3 \\
137.3 \\
391.3 \\
107.8 \\
77.1 \\
164.6 \\
2.5 \\
22.8 \\
217.2 \\
175.7 \\
\end{array}$ & $\begin{array}{r}1,002.4 \\
1,098.4 \\
3,130.4 \\
862.4 \\
616.8 \\
1,316.8 \\
20.0 \\
182.4 \\
1,737.6 \\
1,405.6 \\
\end{array}$ \\
\hline Total construction & $1,421.6$ & $11,372.8$ \\
\hline $\begin{array}{l}\text { Construction management } \\
\text { Contract management } \\
\text { Engineering design and inspection } \\
\text { Escalation } \\
\text { Contingency }(12 \%)\end{array}$ & $\begin{array}{r}108.3 \\
108.3 \\
135.5 \\
0 \\
212.8 \\
\end{array}$ & $\begin{array}{r}866.4 \\
866.4 \\
1,084.0 \\
0 \\
1,702.4 \\
\end{array}$ \\
\hline TOTALS & $1,986.5$ & $15,892.0$ \\
\hline
\end{tabular}

(a) From the Adams (1987) report; escalated to 1990 cost base.

using a protective barrier and warning marker system but without using a liner/leachate collection system.

\section{K.6.2 Waste-Site Costs}

With in situ decomissioning, each reactor facility would be left in place. No wastes would be removed and transferred to another disposal location; therefore, no separate costs would be incurred for activities at another waste site. 
TABLE K.10. Estimated Costs for In Situ Decommissioning of an "Average" Surplus Production Reactor

\begin{tabular}{|c|c|}
\hline Activity & $\begin{array}{l}\text { Cost } \\
\text { (thousands } \\
\text { of } 1990 \$ \text { ) } \\
\end{array}$ \\
\hline $\begin{array}{l}\text { Predecommissioning } \\
\text { Satisfy regulatory requirements } \\
\text { Perform detalled radiation survey } \\
\text { Develop drawings for demonstration, } \\
\text { etc. ( } 1 / 8 \text { share) } \\
\text { Prepare work plans and procedures } \\
\text { Procure concrete batch plant, etc. } \\
\text { ( } 1 / 8 \text { share) } \\
\text { Assemble mobilization/training team } \\
\text { Construct ground-water monitoring } \\
\text { system }\end{array}$ & $\begin{array}{r}76.7 \\
5.2 \\
135.1 \\
51.7 \\
73.9 \\
27.8 \\
217.2^{(a)} \\
\end{array}$ \\
\hline Subtotal & 587.6 \\
\hline $\begin{array}{l}\text { Decommissioning } \\
\text { Fix contamination } \\
\text { Fill below-grade voids } \\
\text { Fill above-grade voids } \\
\text { Remove roofs and superstructures } \\
\text { Demolish shielding walls } \\
\text { Remove concrete block } \\
\text { Mound/gravel/seed } \\
\text { Engineering survetllance and } \\
\text { closeout (1/8 share) } \\
\text { Radiation monitoring } \\
\text { Supervision } \\
\text { QA } \\
\text { Support services (25\% of staff } \\
\text { labor, materials, equipment cost) }\end{array}$ & $\begin{array}{r}568.5 \\
174.5 \\
207.4 \\
536.0 \\
13.1 \\
127.6 \\
6,910.9 \\
43.2 \\
75.8 \\
98.8 \\
54.1 \\
474.8 \\
\end{array}$ \\
\hline Subtotal & $9,284.7$ \\
\hline $\begin{array}{l}\text { Postdecommissioning } \\
97.5-y r \text { monitoring system } \\
\text { operating cost }\end{array}$ & $10,584.4^{(a)}$ \\
\hline Subtotal & $20,456.7$ \\
\hline $\begin{array}{l}\text { State sales tax (at } 7.8 \% \text { on purchased } \\
\text { materials/equipment usage, etc.) } \\
\text { Contingency }(20 \%) \text { (b) } \\
\text { Contingency }(12 \%)(b)\end{array}$ & $\begin{array}{r}106.2 \\
2,730.4 \\
\quad 829.3 \\
\end{array}$ \\
\hline $\begin{array}{l}\text { TOTAL AVERAGE COST FOR IN SITU } \\
\text { DECOMMISSIONING }\end{array}$ & $24,122.6$ \\
\hline $\begin{array}{l}\text { (a) Based on a cost estimate by Smith } \\
\text { escalated to } 1990 \text { cost base. } \\
\text { (b) This contingency applies only to } \\
\text { gravel/seed activity. }\end{array}$ & $\begin{array}{l}\text { (1987); } \\
\text { he mound/ }\end{array}$ \\
\hline
\end{tabular}


Decommissioning Alternatives; References

TABLE K.11. Estimated Burial-Site costs for the In Situ Decommissioning Alternative ${ }^{(a)}$

Item

Direct Costs:
Hauling of soils/sand/gravel
Installation of riprap
Installation of soil/clay mix
Installation of geotextile
Revegetation
Installation of subsurface markers
Installation of surface markers
Contractor overhead and markup
Total construction
Construction management
Contract management
Engineering design and inspection
Escalation
Contingency (12\%)

TOTALS

Costs (thousands of $1990 \mathrm{~S}$ )
$\begin{array}{ll}\text { Total for } \\ \text { Per Block } & 8 \text { Blocks }\end{array}$

$1,115.2$

659.3

972.8

357.7

0.9

7.6

$1,737.6$

688.1

$5,539.2$

422.1

422.1

527.5

0

829.3

8,922

5,274

7,782

2,862

7

61

13,901

5,505

44,314

$7,740.2$

61,922

(a) Estimates made specifically for this EIS; escalated to 1990 cost base.

(b) Totals have been rounded to the nearest thousand.

\section{K.7 REFERENCES}

Adams, M. R. 1987. Conceptual Designs and Cost Estimates for Reactor Disposal Alternatives (Letter Report). 8752228, West inghouse Hanford Company, Richland, Washington.

DOE-RL 5700.3. March 1985. Cost Estimating. Analysis, and Cost Standardization. U.S. Department of Energy, Richland Operations Office, Richland, Washington.

Hughes, M. C. 1986. Cost Estimate for Annual Surveillance and Maintenance of the Eight Shutdown Hanford 100 Area Reactors (Letter Report). UNC Nuclear Industries, Richland, Washington. 
Kaiser Engineers Hanford Company (Kaiser). 1983. Preliminary Engineering Study, Cocooning of 105 F Reactor. KEH R-83-14, Kaiser Engineers Hanford Company, Richland, Washington.

Kaiser Engineers Hanford Company (Kaiser). 1985. Decommissioning Conceptual Study for In Situ Decommissioning of Eight 105 Reactor Buildings in the 100 Areas. KEH R-84-9, Kaiser Engineers Hanford Company, Richiand, Washington.

Kaiser Engineers Hanford Company (Kaiser). 1986. Reactor Block Removal Study (Letter Report). KEH-86-22, Kaiser Engineers Hanford Company, Richland, Washington.

Konzek, G. J. 1989. Development of Cost Escalation Factors for Updating 1986 Decommissioning Costs of Eight Surplus Production Reactors at Hanford to a 1990 Base (Letter Report). Pacific Northwest Laboratory, Richland, Washington.

Rockwell Hanford Operations (Rockwe11). 1985. Preliminary Cost Estimates of Route Preparation and Burial of 100 Area Reactors and Listing of Applicable Environmental Regulations (Letter Report). R85-4910, Rockwe11 Hanford Operations, Richland, Washington.

Smith, R. M. 1987. RCRA Compliance--Ground-Water Monitoring for the SPRD EIS and Revision to RCRA Ground-Water Monitoring Design, SPRD EIS (Letter Reports). PNL-6562 and PNL-6562 Rev. 1, Pacific Northwest Laboratory, Richl and, Washington. 


\section{APPENDIX L}

SUPPLEMENTAL INFORMATION ON THE RELEASE RATES OF

RADIONUCLIDES FROM THE GRAPHITE MODERATOR BLOCKS 
APPENDIX L

\section{SUPPLEMENTAL INFORMATION ON THE RELEASE RATES OF \\ RADIONUCLIDES FROM THE GRAPHITE MODERATOR BLOCKS}

As noted in Appendix $D$, very little data were available on which to base the estimates of release rates of radionuclides from the reactor-block materials. Subsequent investigations have provided additional information on the release (leaching) rates of carbon-14 and chlorine-36 from irradiated graphite, including graphite retrieved from one of the surplus production reactors at the Hanford Site. The purpose of this Appendix is to discuss the supplemental information and the implications of that information in regard to the estimated release rates of carbon-14 and chlorine-36 from the graphite moderator blocks of the surplus reactors.

\section{L.1 RESULTS OF SUBSEQUENT STUDIES}

Gray and Morgan (1988) measured the leach rates of carbon-14 and chlorine-36 from samples cut from a graphite bar that had been irradiated in the $Y$ Test Hole in the Hanford $C$ Reactor during the entire time that $C$ Reactor was in operation. For various reasons (Gray and Morgan 1988), the radionuclide inventory in this bar is not considered to be typical of that in the graphite moderator bars of $C$ Reactor, or in the moderator bars of other Hanford reactors. The relative leach rates, however, are thought to be independent of the radionuclide concentrations. Moreover, because this graphite bar was manufactured for use in construction of one of the Hanford reactors and was irradiated in one of the Hanford reactors, the leach rate data should be more directly applicable than should data obtained from graphites manufactured under other conditions and irradiated in other reactors.

The following general observations can be noted in regard to the data presented by Gray and Morgan (1988):

- The ratios of the initial release rate of chlorine-36 over the initial release rate of carbon-14 from the same sample were consistently higher than the ratio predicted for long-term leaching. 
Supplemental Information; Results of Subsequent Studies

- The initial release rate of carbon- 14 from the samples leached at $20^{\circ} \mathrm{C}$ was about $20 \%$ of the rate predicted using Equation (D.2); however, the decrease in leach rate with time was less pronounced than that reported by White et al. (1984).

- The initial release rate of chlorine-36 from the samples leached at $20^{\circ} \mathrm{C}$ was higher than predicted; however, the measured leach rate rapidly decreased to less than the predicted long-term rate.

- At the end of 8 weeks, the leach rates at $20^{\circ} \mathrm{C}$ were in reasonable agreement with the predicted rates for both isotopes.

- At higher temperatures $\left(50^{\circ} \mathrm{C}\right.$ and $\left.90^{\circ} \mathrm{C}\right)$, both initial and final leach rates for both isotopes were lower than the predicted rates.

In a subsequent study, Gray and Morgan (1989) measured the release rates of carbon-14 and chlorine-36 from three irradiated graphite samples obtained from the moderator block of the $\dot{G}-2$ Reactor at Marcoule, France. The source of the raw materials used to manufacture this graphite, the process used to purify the moderator bars, and the environmental conditions to which the graphite was exposed during operation of the reactor represent major differences between these samples and those obtained from $C$ Reactor at Hanford. Because of these differences, the leach rate results from the French graphite should not be assumed to apply, a priori, to the Hanford moderator graphites.

The results obtained by Gray and Morgan (1989) from their leach rate studies (at $20^{\circ} \mathrm{C}$ ) using irradiated graphite from the G-2 Reactor can be summarized as follows:

- The ratios of the initial release rate of chlorine-36 over the initial release rate of carbon-14 from the same sample varied by two orders of magnitude (one order of magnitude higher and one order of magnitude lower, for different samples, compared to the ratios measured for the samples from ( Reactor).

- The initial release rates of carbon-14 from the three samples were higher than predicted using Equation (D.2); moreover, the release rates decreased very slowly as a function of time, averaging about two orders of magnitude higher than the predicted rate at the end of the 13-week study. 
- In contrast to carbon-14, the release rates of chlorine-36 decreased rapidly with time. However, at the end of the 13-week study, the release rates were still about one order of magnitude higher than the predicted long-term release rate.

\section{L.2 IMPLICATIONS OF NEW RESULTS}

As discussed in previous publications (Morgan 1985; Gray and Morgan 1988), the carbon-14 and chlorine-36 may exist in more than one chemical (and physical) state in irradiated graphite. Furthermore, one can expect that each chemical state would exhibit a unique leach rate, with the measured (gross) removal rate being the sum of the individual rates times the relative concentrations of the isotope in each state. By postulating the existence of only two chemical states for each isotope, one can explain the general features and the differences in leaching behavior that have been reported to date. A more comprehensive analysis of the data will be required to determine if more than two chemical states are needed to adequately describe the details of the observed leaching behavior. Additional studies will also be required to characterize the different chemical states, the concentrations of radioisotopes in each state, and their relative distributions within the moderator graphite.

At the present time, however, a "best estimate" for the long-term release rates of carbon-14 and chlorine-36 from the graphite in the moderators of the surplus Hanford reactors is that they will not exceed the predicted release rates given in Appendix D. Therefore, there is no need to alter previous estimates of long-term leach rates for either isotope based on these new data concerning leach rates. Doses calculated for leaching of graphite are unchanged with inclusion of the new data. 


\section{L.3 REFERENCES}

Gray, W. J., and W. C. Morgan. 1988. Leaching of ${ }^{14} \mathrm{C}$ and ${ }^{36} \mathrm{Cl}$ from Hanford Reactor Graphite. PNL-6769, Pacific Northwest Laboratory, Richland, Washington.

Gray, W. J., and W. C. Morgan. 1989. Leaching of ${ }^{14} \mathrm{C}$ and ${ }^{36} \mathrm{Cl}$ from Irradiated French Graphite. PNL-6989, Pacific Northwest Laboratory, Richland, Washington.

Morgan, W. C. 1985. "Migration and Availability of Carbon-14 from Irradiated Graphite." In A Compilation of Carbon-14 Data, R. A. Paasch, ed., UNI-3499, pp. 1-18. UNC Nuclear Industries, Inc., Richland, Washington.

White, I. F., G. M. Smith, L. J. Saunders, C. J. Kaye, T. J. Martin, G. H. Clarke, and M. W. Wakerley. 1984. Assessment of Management Modes for Graphite from Reactor Decommissioning. EUR-9232, Commission of the European Communities, Luxembourg. 
APPENDIX $M$

ACCIDENT SCENARIOS 
APPENDIX M

\section{ACCIDENT SCENARIOS}

The DOE has continued to review the accident scenarios presented in the DEIS. The following information is provided to supplement the discussions in Chapter 5 of the DEIS.

1. Regarding the dose calculations for the bounding accident scenario for the two one-piece removal alternatives, the assumption was made that less than 8 hours would be required to immobilize a small pile of cold, broken-up graphite, because work crews (emergency response crews) would accompany the reactor at all times during its transport (see Section 5.1.2.1). The reason why the reactor would fall off the tractor was not discussed, but it was assumed in the DEIS that this event would not immobilize the work crews.

While it could be argued that a release period greater than 8 hours should have been used, the application of the 8-hour release was particularly conservative. The analys is assumed that the "maximally exposed individual" remained in the plume of radioactively contaminated air emanating from the accident site for the full 8 hours. The atmospheric dispersion model used to calculate the resulting dose to the individual (see Section E.3.3.4) is based on providing a 1-hour average airborne contaminant concentration that will not be exceeded 95 percent of the time. Using an 8-hour exposure period in the model is conservative because there is a high probability that the wind direction and turbulence would change in that length of time. Thus the calculated dose conservatively assumes an 8-hour release, a stable wind pattern for the entire release period, and that the individual remains in the air path for the entire release.

2. Regarding a potential transport accident scenario involving a flammable liquid (e.g., gasoline) and the reactor graphite in the two one-piece removal al ternatives, such a potential scenario was not considered for four reasons. First, the haul road would be a special, single-use road that avoids high traffic areas of the Hanford Site. Second, the rate of travel of the tractors that carry the reactor blocks would be slow enough that ample time would be available for establishing suitable roadblocks at road crossings. Third, the graphite would still be encased in the heavy biological shield and would not be affected by the fire. Fourth, even if the fire were to breach the shield, significant quantities of the graphite within would not burn (see Section 5.1.2.2). 
3. Regarding a potential railcar accident scenario involving a collision at a railroad crossing between a railcar containing 3 percent of the total reactor graphite and a vehicle carrying a flammable liquid (e.g., gasoline) that could occur during the deferred dismantlement alternative, the following assumptions were made in the analysis:

i. The 30-minute fire would bound the radiological impacts.

ii. The fire would be limited to 30 minutes.

iii. The impact forces would crush only 1 percent of the graphite shipment into fine powder.

iv. Only 1 percent of the powder (i.e., 0.01 percent of the graphite shipment) during the fire would result in resuspensions that would determine the source term (atmospheric release) from this accident.

These assumptions are conservative for the following reasons:

$i$ and $i j$. As discussed in the above analys is of potential accidents for the one-piece removal alternatives, the reactor graphite is not combustible under this accident condition and therefore the duration of the fire is not a significant factor. The fire was utilized in this scenario to provide a means for resuspending the graphite powder in the accident. The important factors used to define how much graphite powder is assumed to be resuspended are discussed below.

iii. The assumption that the impact forces would crush only 1 percent of the graphite to a fine powder is an engineering estimate. Based on past experience at Hanford with handling reactor graphite, very minor amounts of dust are generated when the graphite is fractured. One percent is considered conservative but no formal study was used to develop the value. Although 1 percent is considered conservative, an increase in the release fraction by a factor of five would still not result in a likelihood of a health effect.

iv. The assumption that 1 percent of the graphite powder would be resuspended is derived from two documents referenced in the DEIS (see Sections 5.3.1 and 5.5.1.2) and other sources in the literature. A review of these sources reveals that resuspension rates can vary from as high as 10 percent to less than 0.00001 percent depending on the resuspension mechanism and particulate. One percent was selected as a reasonable yet conservative value.

4. Regarding the in situ decommissioning alternative, DOE concluded that there are no credible accidents that would result in the release of radioactive materials. DOE believes that this conclusion is valid after considering the potential impacts of adverse weather conditions and the 
loss of integrity of temporary structures during the demolishing and burial stages of this decommissioning alternative. As indicated in the DEIS (see Section 5.3.1), the bulk (a 10-to-1 peak-to-average ratio was assumed) of the radioactive inventory is in the interior part of the reactor block, which remains sealed in the in situ alternative. The graphite would never be exposed and is therefore not available for resuspension. Potential areas of contamination on the outside would be immobilized with surface coatings before any exterior structure would be removed. Therefore, the quantity of radioactive material potentially available for resuspension would be insignificant. 
APPENDIX N

ERRATA 
APPENDIX N

\section{ERRATA}

This section contains errata for the DEIS. Errata are listed by page number $(p$.$) and line number (L)$ or by page number, table number $(T)$, and line number, as appropriate.

Location

p. $1.6, \mathrm{~L} 6$

p. 1.7, L 24

p. 1.13, L 7

p. 1.14, T 1.1, L 7

p. $1.14, \mathrm{~T} 1.1, \mathrm{~L} 12$

p. $1.15, \mathrm{~T} 1.2, \mathrm{~L} 11$

p. $1.15, \mathrm{~T} 1.2, \mathrm{~L} 16$

p. $2.1, \mathrm{~L} 12$

\section{Change}

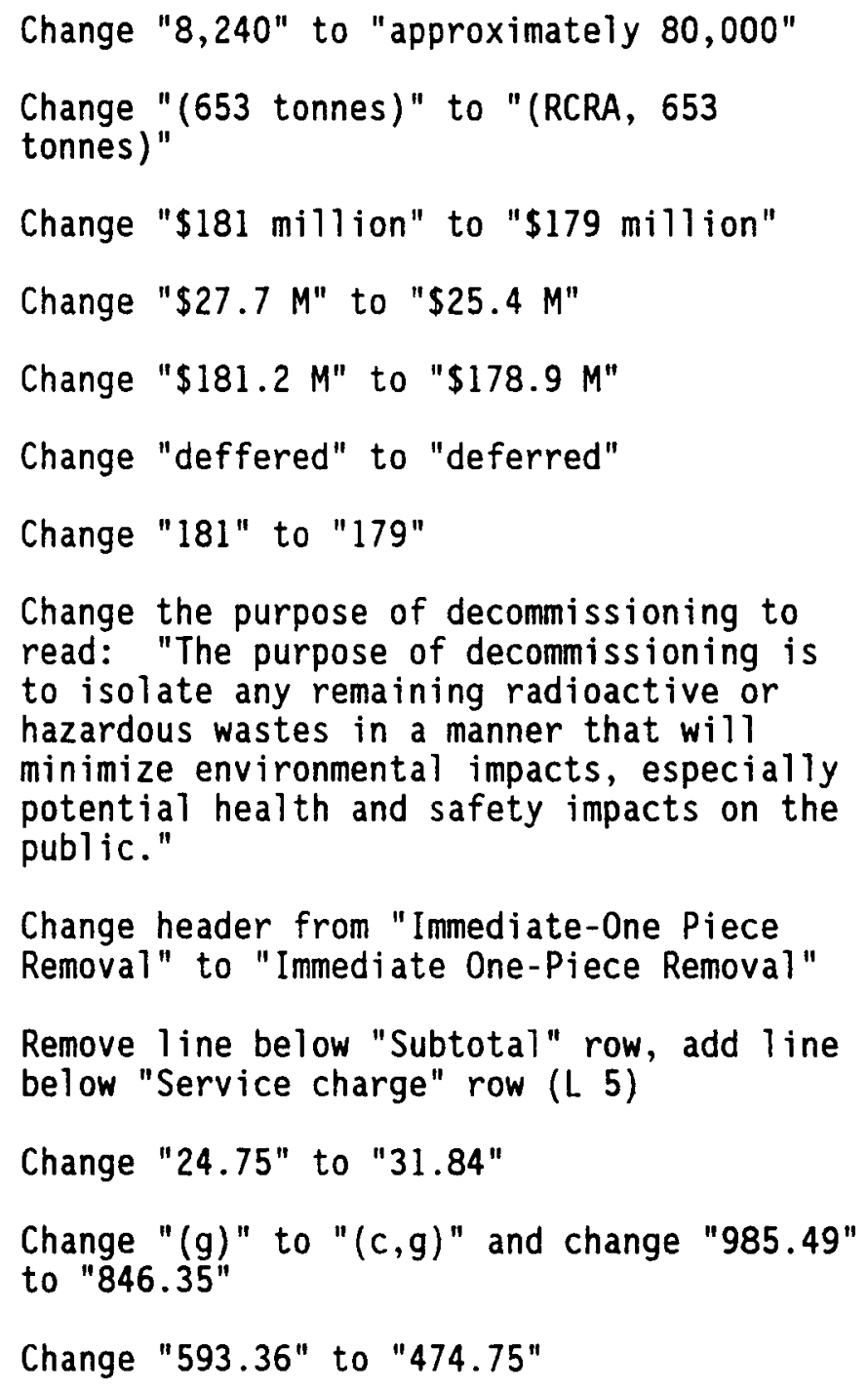

Change header from "Immediate-One Piece Removal" to "Immediate One-Piece Removal"

Remove line below "Subtotal" row, add line below "Service charge" row (L. 5)

Change "24.75" to " 31.84 "

Change "(g)" to " $(\mathrm{c}, \mathrm{g})$ " and change "985.49" to "846.35"

Change "593.36" to "474.75" 


\section{Location}

p. 3.13, T 3.3, L 52

p. $3.13, \mathrm{~T} 3.3, \mathrm{~L} 61$

p. $3.18, \mathrm{~T} 3.6, \mathrm{~L} 20$

p. $3.27, \mathrm{~T} 3.7, \mathrm{~L} 14$

p. $3.27, \mathrm{~T} 3.7, \mathrm{~L} 17$

p. $3.27, \mathrm{~T} 3.7, \mathrm{~L} 18$

p. $3.27, \mathrm{~T} 3.7, \mathrm{~L} 20$

p. 3.27, T 3.7, L 28

p. 3.34, L 24

p. $3.38, \mathrm{~T} 3.8, \mathrm{~L} 32$

p. $3.46, L 1$

p. $3.46, L 6$

p. $3.47, \mathrm{~T} 3.13, \mathrm{~L} 39$

p. $3.47, \mathrm{~T} 3.13, \mathrm{~L} 42$

p. $3.47, T 3.13, \mathrm{~L} 50$

p. $3.52, \mathrm{~T} 3.15, \mathrm{~L} 16$

p. $3.55, \mathrm{~T} 3.18, \mathrm{~L} 10$

p. 3.55, T 3.18, L 11

p. 3.57
Change

Change "22,606.18" to "23,877.38"

Between "(Kaiser 1983)" and the period, insert "and these costs are included in the activity cost presented in the table"

Change "2,900" to "32,900"

Change "Equipment materials" to "Equipment/ materials"

Change "12,855.50" to " $12,856.50 "$

Change "17,815.36" to $17,815.35 "$

Change "74,485.82" to "7,448.82"

Change "6,722.74" to "16,722.74"

Delete sentence beginning "Safe-storage costs..."

Change citation from "Westinghouse 1987" to "Adams

$1987^{\prime \prime}$

Change "Kaiser (1987)" to "Kaiser (1985)"

Change "\$181 million" to "\$179 million"

Change "2,800.2" to "2,519.6"

Change "22,647.3" to "22,366.7"

Add footnote (d) as follows: "(d) This contingency applies only to the mound/gravel/seed activity."

Change "181" to "179"

Change "27.7" to "25.4"

Change "181.2" to "178.9"

Add the underlined word to the last sentence in the first paragraph: "No significant short-term adverse ecological, socioeconomic, or resource impacts were identified for any alternative." Add the following sentence at the end of the second paragraph: "No significant long-term adverse ecological impacts were identified for any alternative." 
Location

p. 4.33, L 27

p. 4.39, L 27

p. 4.41, L 3

p. $4.41, \mathrm{~L} 8$

p. 5.35

p. $7.1, \mathrm{~L} 16$

p. 8.1

p. 8.7
Change

Change "About 13,000 persons are" to "In September 1989 , about 12,600 persons were"

Replace "who" with "many of whom"

After "places." insert "For example, the Treaty of 1855 between the Yakima Indian Nation and the U.S. Government states that 'The exclusive right of taking fish in all streams where running through or bordering said reservation, is further secured to said confederated tribes and bands of Indians, as also the right of taking fish at all usual and accustomed places, in common with citizens of the Territory, and of erecting temporary buildings for curing them; together with the privilege of hunting, gathering roots and berries, and pasturing their horses and cattle upon open and unclaimed land."

Delete sentence beginning "Consultation..." and substitute "Consultation with Indian religious leaders is required if the potential exists for abridgement of religious freedom, as set forth in the American Indian Religious Freedom Act."

Add the following paragraph to Section 5.10.2: "The use of standard industrial protective work procedures will minimize any impacts to workers from the handling, recycling, storage, or disposal of friable asbestos, mercury, polychlorinated biphenyls, lead, or cadmium."

Following J. V. Robinson, insert: "Editorial assistance was provided by V. L. Harrison, K. A. Parnell, and P. L. Novak."

Add the following definitions: "smearable removable by wiping; stochastic - probability of occurrence is proportional to dose; stochastic effects - malignant and hereditary disease for which the probability of an effect occurring, rather than its severity, is regarded as a function of dose without threshold"

Add the following definition: "Masonite - a trademark of the Masonite Corporation that refers to a board produced from byproduct wood chips that are reduced to fibers by high-pressure steam, and then pressed into board without the use of chemicals." 


\section{Location}

p. 8.12

p. B.3, T B.2, L 1

p. C. $5, L 22$

p. E.7, L 9 and 10

p. E.32, T E.11, L 20

p. E.38, L 21

p. F.13, T F.4

\section{Change}

Add the following definition: "Transite - a tradename of the Johns Manville Corporation that refers to a construction or insulating material made of asbestos fibers and Portland cement molded under hydraulic pressure."

Move "Reactor" to Column 2 from Column 3

Change "3.3" to "C.3"

Change "stochastic dose limit" to "dose limit for stochastic effects" and change "stochastic effective dose equivalent" to "(stochastic) dose equivalent"

Change "during 1982 and 1983" to "from 1976 through $1983^{\prime \prime}$

Change " $1 \times 10^{4}$ " to " $1 \times 10^{14 "}$

No change. The health-effect risk factor range used in the DEIS (100 to 1,000 health effects per million person-rem) encompasses new cancer risk factors published in BEIR $V$ (National Academy of Sciences, Committee on the Biological Effects of Ionizing Radiation. 1990. Health Effects of Exposure to Low Levels of Ionizing Radiation, BEIR V.)

Add Index to DEIS (pages N.5 and N.6) 


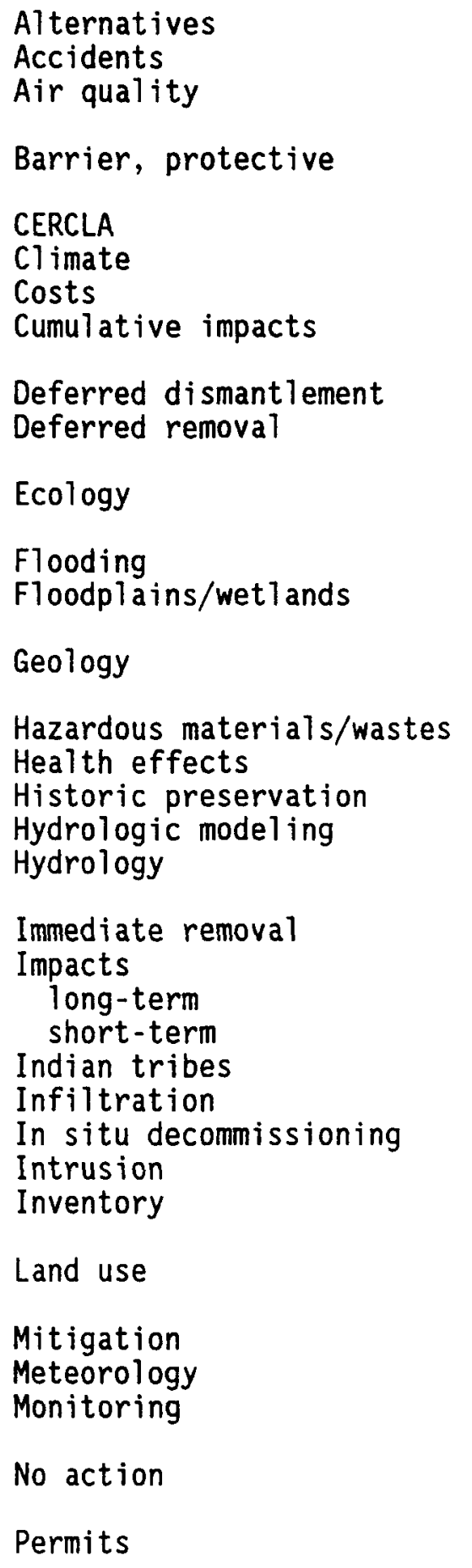

$1.3,3.1$

$5.8,5.11,5.12,5.15$

$1.19,4.21$

G.6, H.1

6.5

$1.18,4.17$

$3.10,3.26,3.37,3.45$

$1.25,5.37$

$1.11,3.31$

$1.10,3.22,3.31$

$1.20,4.26$

G.35, G.37

B. 1

$1.17,4.7$

1.23, A. 27

F.1

4.38, J. 1

C.5

$1.17,4.11$

$1.9,3.8$

$1.22,5.1,5.16$, G. 1

$1.22,5.1$

4.39

G.1, H.1

$1.12,3.42$

5.26, G.27, G.30, G.31

A. 16, A. 29

$5.34,5.36$

5.36

$1.18,4.17$

$1.19,4.24$

$1.7,3.6$

$1.25,6.1$

Index-1

(N.5) 
INDEX (contd)

$\begin{array}{ll}\text { Radiation dose } & 1.22,3.16,3.30,3.40,3.48,5.8, \\ \text { Radiation dose calculations } & 5.11,5.12,5.15,5.16,5.39 \\ \text { Radioactive wastes } & \text { E.1 } \\ \text { RCRA } & 3.14,3.29,3.37,3.48 \\ \text { Recharge } & 6.5 \\ \text { Regulations } & G .4 \\ \text { Release rates } & 1.25,6.1 \\ \text { Resource requirements } & C .2, D .1 \\ \text { Riprap } & 5.32 \\ \text { Safe storage } & H .5 \\ \text { Seismology } & 1.10,1.11,3.22,3.31 \\ \text { Socioeconomics } & 1.18,4.20, G .39 \\ & 1.21,1.23,4.33,5.31,5.38 \\ \text { Threatened and endangered species } & 4.29,1.1 \\ \text { Transportation } & 1.22,4.41 \\ \text { Transporter } & 3.17 \\ & \\ \text { Water quality } & 1.19,4.22\end{array}$


APPENDIX 0

LETTERS, TRANSCRIPTS, EXHIBITS 


\section{LETTERS}

L001A

D'Arcy P. Banister

U.S. Department of the Interior

L001B

Alton Haymaker

L002

Dennis R. Arter

$L 003$

J. R. Young

L004

Roger C. Gibson

L005

Jacob E. Thomas

Washington Historic Preservation

officer

L006

Lourdes Fuentes-Williams

Coalition Organizing Hanford Opposition

$\llcorner 007$

June A. Sawyer

L008

Richard L. Larson

Washington Department of Transportation

$L 009$

John T. Greeves

U.S. Nuclear Regulatory Commission

L010

Dr. and Mrs. Michael Berg

L011

H. Dale Hellewell

$\mathrm{L} 012$

Ora Mae and Floyd Orton

L013

Dennis D. Skeate

Benton County Management Team

L014, L015

M. J. Szulinski

L016

Beulah L. Sumner

$\llcorner 017$

Beth D. Marsau

L018

Jim Thomas

Hanford Education Action League

L019

J. Ross and Lois H. Adams

L020

Stephen J. Doyle 
Bonnie Tucker Doyle

Johnson

Mr. and Mrs. M. W. Bradshaw

L025

The Honorable Max E. Benitz Washington State Senate

Barbara Richardson

Theresa Potts

Alan Richards

Barbara Harrah

Lantz Rowland

Thomas M. Clement

L032

Colleen Bennett and Adele Newton League of Women Voters of Oregon

The Honorable Brad Fisher

Kennewick City Council

The Honorable Ed Hendler

Pasco City Counci]

Hans C. F. Ripfel

Tri-Cities Technical Council

Tom Lande

David E. Clapp

Washington Department of Health and Human Services

The Honorable Robert Drake Benton County Board of Commissioners

Richard J. Leaumont Lower Columbia Basin Audubon Society 
L041

L042

L043

L044

L045

L046

L047

Network

L048

L049

L050

L051

L052

L053
T. H. MCGreer

Christine 0. Gregoire

Washington Department of Ecology

J. Ernesto Baldi

Michael R. Cummings

Ray 01ney

Yakima Indian Nation

[duplicate of L045]

Tom Wynn

Trail and District Environmental

Michael Gilfillan

Kootenay Nuclear Study Group

Ronald A. Lee

U.S. Environmental Protection Agency, Region 10

Rex Buck, Jr. Wanapum Tribe

Laurel Kay Grove

The Honorable Dean Sutherland Washington State Senate

C. M. Conselman

Columbia Section, American Society of Civil Engineers 
$$
\text { . }
$$ 


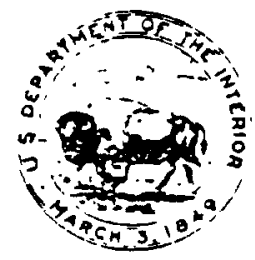

\title{
United States Department of the Interior
}

\author{
BLREAU OF MINES
}

WESTERN FIELD OPERATTONS CENTER

EAST 360 3RD AVENUE

SPOKANE, WASHINGTON $99202-1413$

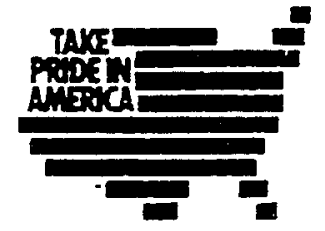

April 21, 1989

Mr. Tom Bauman

U.S. Department of Energy

Richland Operations office

RE: SPFE-DRAFT EIS

P.O. Box 550

Fichland, liashington 99352

Dear Mr. Bauman:

The draft document on decomissioning eight reactors at the Hanford Site is incomplete as concerns possible distant future mineral or energy resource exploration and development.

The document addresses the possibility of human intrusion as the result of shallow water-ivell drilling, but does not address mineral or energy resourres that may exist at the site or possible environnental consequences of future exploration in search of sich resources. No mention is made cf the possibilit: of ground-water contamination resulting from deep drilling in search of hydrocarbon (primarily methane) resources. K. S. Lingley, Jr., and T. J. Walsh, in Issues Relating to Petroleum Drilling lear the Proposed High-Level haste Repository at Hanford (Washington Geologic Newsletter, hashington State Department of Natural Resources, Olympia, v. 14, No. 3, Ausust, 1986, pp. 10191, suggest that possible petroleum reserves in the Hanford area range bet:ieen 40 billion and 1 trillion cubic feet of methane per trap.

It is imperative that the Department of Energy address these possible resources and the environmental effects that may result from exploration or extraction of them.

Thank you for the opportunity to review this draft document.

Sincerely,

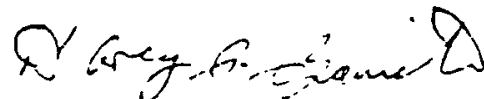

D'Arcy 'P. Banister, Supervisor

Mineral Issue Involvement Section

Branch of Engineering and Economic Analysis 
Lo01B

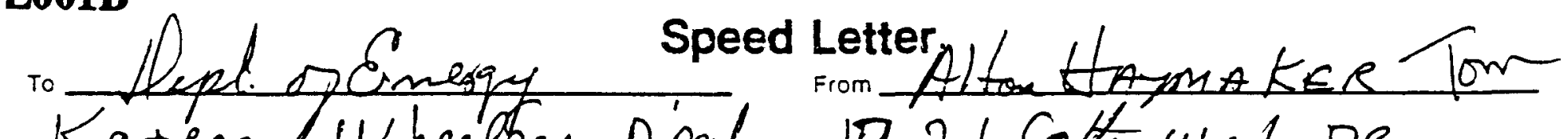
Karen/Wheelsos, DiReto 1721 Cottor ubod DR.

Rechlaud Wo Pasco Wa 9930/ subect Decommissioning of exght revetors.

Hessar haven Whules,

Thank you for including my name on receving E 1 s droft. 40 yean ago 1 was muech younger and a hatorating technicin at $100 \mathrm{~F}$ Thoevere interesting times in my life.

REPLY

dwiel make an effot to let the thet. now of ony conkernes. 1S. Plespe étchóes.

Wilsonjones

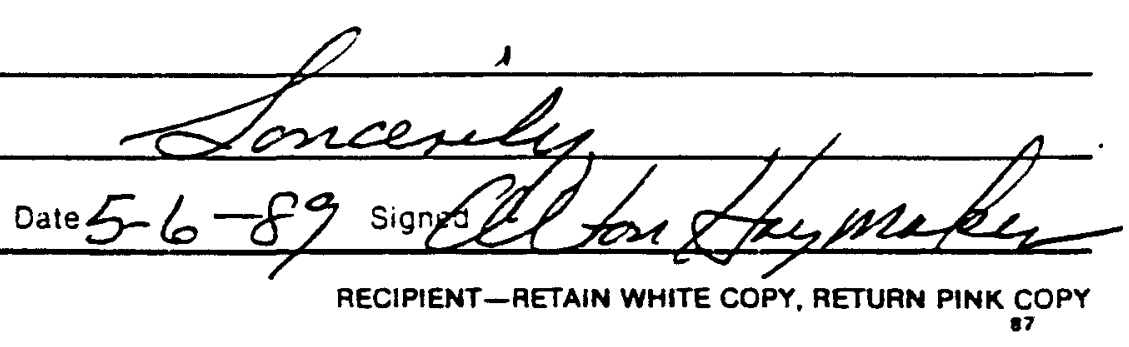

Columbia River Cherries

Alton \& Joan Haymaker

1721 Cottonwood Drive

Pasco, WA 99301

(509) 266-4629

0.6 


\section{Dennis R. Arter, P.E.}

TICOMP

116 N. Fifth

Pasco, WA 99301

$509 / 547-1243$

May 26, 1989

Tom Bauman

US Dept of Energy

P.O. Box 550

Richland, WA 99352

Decommissioning of Eight Surplus Production Reactors

Draft DOE/EIS-0119

Thank you for providing me with a copy of the draft document for review. I have examined the contents and find it to be well prepared, comprehensive and adequately documented. I have no comments of an adverse nature.

Please request your contractor to change their records to reflect my correct mailing address, as shown above. I moved from the Sylvester Street location three years ago.

Yours truly,

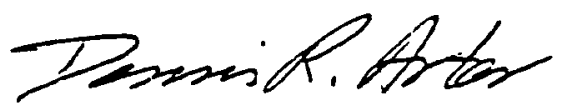

Dennis R. Arter 
9021 W. Sagemoor Road

JUN 16 ERg

Pasco, WA 99301

June 13, 1989

Ms. Karen J. Wheeless

Office of Commurications, Ricinland Cperations Cifice

U. S. Department of Energy

Richland, 'NA 99352

Dear Ms. Wheeless:

Tharis gou for the opportunity to comment on DOE/EIS-0119D, the draft EIS on deccmmissioning of the eight surplus production reactors at the Hanford site. I have nine comments and suggestions.

1. Grossly Overestinated Backsround Radiation Dose

Throughout this report the natural background radiation dose received annualig by an everage individual living near Hanford is stater to be about $300 \mathrm{mr}$. This is ifive times as large as the actual background radiation cose of about $60 \mathrm{mr}$ (For example, see pages 4.4 to 4.6 of PNI 6120). Since it is inconceivable that either nCB or the authcrs of this report do not know the background radiation cose, this gross exaggeration appears to be a deliberate attempt to exaggerate the health effects of the background radsation to make the already trivial effects of the decomissioning appear even more trivial. ivo wonder the public coes not trust IOE to turn cut a correct or unbiased anzijsis!

2. Linerestimated Catastrophic Flood Damage

The accident scenarios mention the effects of a catastrophic 50\% failure of Grand Coulee Dam and the resultant flood elevations. Because Coulee is a concrete gravity dam, the only reasonable cause for such a failure is an erems attack. Any eneny capable of such an aitack probably wouidn't attack Coulee. They would probably attack kica Dam and crobably near the height of a spring flood. This would release many times as muci water and probably would result in higher flood elevations and a rach longer flood time.

\section{Insignificant Ligit Crerioill}

lost tables suca as Table 3.8 contain as many as 8 significant digits for preliminary order-of-masnitude cost estimates that contain about $25 \%$ contingency and such gross assumptions as the $K$ Reactors having about the same costs as the smaller reactors. Such tables showing the breakdowns of costs for the individual reactors should be eliminated because they inely that detailed cost estimates were made for each reactor (which presumably did not occur) or the tables should be simplified by elininating the details and/or rounding down to no more than 3 significant digits.

It is also suggested that another bullet item be added to section 3.0 that states whether detailed cost estinates were made for each reactor or an estimate was made for a tjpical reactor and adjustinents were made for gross differences among the reactors.

4. Contaminated Ground Decomissioning

Possibly it is considered outside the scope of this EIS, but there is no mention of the need or lack of need for decontaminating the square miles of ground that were contaminated by leaks in the effluent lizes and retention basins and by doliberato 
release $=$ of to to $20,000 \mathrm{gpm}$ of reactor effluent for lors periocs of time into cribs near tice retention basins and into a natural sump south of 1050 .

5. Superfluous APPajDIX E Educaticnal Haterial

Wuch of this appendix is simply a description of the methociologies used (for example, Sections $\mathrm{E} .2$ and $\mathrm{E} .3$ ) and could be covered by a sinole statement that the rethocologies used are those in tine appropriate references. EISs are not supcosed to be ecucational documents loaded up with great quantities of information copied out of the literature to inpress the roaders with the grept technical expertise of the authors.

\section{Poor Image Created by ADPE:DD F}

AP:E:DIX F is a renash of the extensive literature on radiological health effects and ICE's conclusions (apoarentIy only for this EIS) as to wiat method will be used to evaiuate those effects. This leaves the reader with the impression that "Ye Gads! DOE and the other goverment agencies have stent many jears and millions of dollars studying this subject and still do not have a standard set of mules or assuppions that should be used for every U.S. Gorerment EIS!"

DOE and the other govermment agencies coutd inorove their inages (and probably save millions of dollars) br issuing a document that states the health-risk factors that should be used and then simolJ referming to it when they write an EIS.

\section{Fantasyland Iose Calculations}

The radiation dose estimates are based on the assumption that the Hanford site would be abandoned after 100 gears. First of all, this assumetion ices not agree irith the siatement on 2. 5.1 that accident conditions chosen describe the most serious incidents thint cculd be reasonably costulated to occur. It is completely ridiculous, based on the current social and Iegal clinate, to assime tinat the site would be abancioned when we kncw that it contains a major radioactite waste disposal site.

Then, the radiation dose scenarios contain the "Iantaryland" inplied assumctionthat after the site is abandoned, all records and remories of und happened at ientord would be lost! This would be expected to occur only ip there were scme global catastrophe that destroyed all written records, and presumably at the sare time essentialls all humar. Iije. Then, majestically, within 10,000 years the hunan race is rejurenated and its technology adrances so fast that this new human race has well drills that can drill througi many incines of steel reactor shield (see page G.28) withcut even slowing down the drill enough that the operator might notice thet it is no longer drilling through sand, gravel, and rock! I again refer you to the staterent that accident conditions chosen describe the nost serious incicents that could be reasonably" postulated to occur. ine sure don't have anj sell or geological drills no:s that have that amazing drilling capability, and it is unreasonable to expect arpody to ever use such a sophisticated drifl when there is no reasonable reason to have one. Anybody with the teohnology to have well drills can also be reasonably expected to have enough sense to stop driliing and try to figure out what they hit and what the nature of it is before they blithely drill on and spread radioactivity around.

8. Need for Reescnable Lons-term Imoact Estimate

The most reasonable long-term inpact scenario for this IIS is the one based on the assuription that the site will not be abandoned after 100 years. It is not apparent as to whether that alternative was actually evaluated and then described in the surmary, particularly in Table 1.2. That table should either contain cost and cose data for the two alternatives for abandoment and non-abandonnent or it should have a footnote (or text statement) that states wich of those two alternatives is described by that table and what the difference would be (if any) for the other alternative.

Also, section 1.3.7, that refers to Table 1.2 contains no information on the quality of the data in that tablo. It whuld be helpful to have a statement in tiat section stating your belief as to whether the actial doses would be less than shcwn in that table, or larger.

Also, does the population dose in Table 1.2 inclute the maximm well dose and ang 


\section{$\mathbf{L 0 0 3}$}

accident doces? ihat is the significance of the well dose? inf single it out and not talk about the source of the other, mucin larger, dosas sincin in that table? Fow many wells wolld be drilled? You need more discussion of the contents of that tibie.

9. Sugzested Recoonse Prosedure for Corrents

DCE shoula let eacn comentor know unat the response was to each coment.

It is rerg frustrating to have DCE ackmorledge your coments, but not tell you what the resconse rres, partieularly if the final inpact statement contains najor revisions wen comparec to the drait siatenent.

It is alsuestad tinat $X X 2$ number each comment and then state on an attached comment disposal sheet what the response was, including the page nimbers winere the resaonse occurs or the reason that no cirange was made in the document.

Thank jou, agiz, for this cycortunity to comsent.

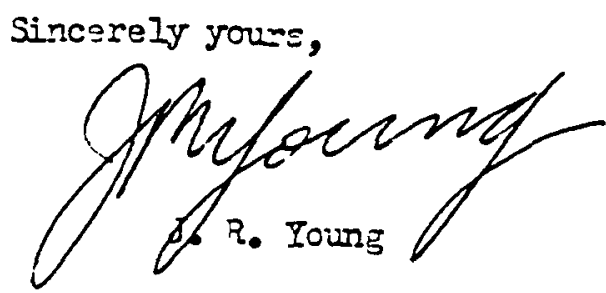


HANFORD SURPLUS PRODUCTION REACTOR DECOMMISSIONING

DRAFT ENVIRONMENTAL IMPACT STATEMENT

TO: United States Department of Energy

Richland Operations Office

FROM: Haj. Roger C. Gibson(Ret.)

P. 0. B0X 992

Date: June 15, 1989

Seattle, if $98111-0992$

(Please print/type name, address and zip code clearly)

I would like to make the following comments on the DRAFT Surplus Production Reactor Decommissioning Environmental Impact Statement:

The following is a suggestion for the disposal of nuclear radioactive waste: Nuclear waste should be broken up into fine particles that will sink to great deoths when dispersed over Large areas of the ocean where there is no or very lit+le arwatic life, and ocean currents are minimal or oon-existent. The crushing, pulverization. choopins uo of the waste most likely cauld be performed on land more conveniently than at sea, and then be disDersed with special machiner that would ensure wide dispersal By Dlacins nuclear waste on land in storase depats, these depots autoratically become targets in a war. It is my understanding that the Soviet government is continuine with nuclear reactor programs because they would be military targets in war, and thus they act as a deterrent to war.

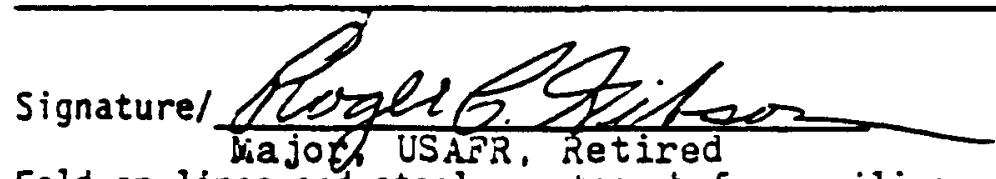

Fold on lines and staple or tape before mailing. Include postage. 


\section{. LOOD}

C.HILA Clakhi

Direntor

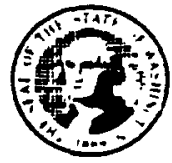

JUN 16 EES

STATE OF WASHINCTON

DEPARTMENT OF COMMUNITY DEVELOPMENT

OFFICE OF ARCHAEOLOCY AND HISTORIC PRESERVATION

111 liest Twenty-First Avenue. KL-11 - Ohmpla. W'ashington 98504-5411 • (206) 753-4011 • SC+11 234-3111

June 14,1989

Mr. Tom Bauman

U.S. Dept. of Energy

Richland Operations office

P.O. Box 550

Richland, WA 99352

Log Reference: 1275-F-DOE-09

Re: Decommissioning of Eight

Surplus Production Reactors at

the Hanford Site, Richland, Washington

Dear Mr. Bauman:

We have reviewed the U.S. Department of Energy draft Environmental Impact Statement, Decommissioning of Eight Surplus Production Reactors at the Hanford Site, Richland, Washington (DOE/EIS-0119D), March 1989 and would like to offer the following comments.

Appendix $J$ of the EIS, National Historic Preservation Act Requirements, evaluates only two options with respect to the Hanford 105-B Reactor, which has been determined eligible for the National Register of Historic Places. The options identified are the no action alternative, which the EIS concludes is unacceptable for health and human safety reasons, and the "recordation" alternative, which would involve the production of measured drawings and written documentation prior to dismantling.

In view of the extraordinary historic significance of the 105-B Reactor, we believe that it should be treated separately from the remaining seven reactors in determining the options for its decommissioning. One additional option that should be carefully considered is the feasibility of removing only the most hazardous portions of $105-8$ and retaining in situ as much as possible of the reactor bullding, control room, mechanical and electrical systems and any other features that are not a long term health risk. Although this approach may present technical problems, we believe that the future interpretive value of 100-B should be preserved in the decommissioning process if it is feasible and prudent. 
Mr. Tom Bauman

June 14, 1989

Page 2

As the world's first large scale production reactor, 105-B represents a watershed in the history of science and technology. Although access to the site is now restricted, $105-B$ is still one of the most compelling and thought provoking historic landmarks in the United States. This issue should be explored in greater detail in the EIS.

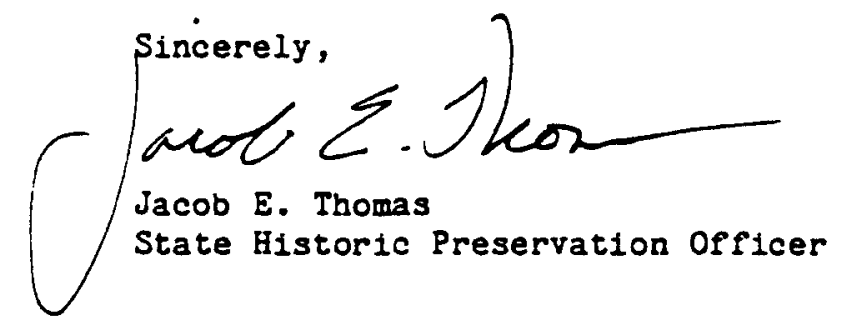

mr 
\% W2122 Dean - Spokane. WA 99201

June 12,1989

Lourdes Euentes-Williams

P.O. Box 422

Coeur d'Alene, ID 83814

Tom Bauman

US DOE/Richland Opertions

PO Box 550

Richland, WA 99352

On behalf of Coalition Organizing Hanford Opposition (COHO) I request that the following comments be entered into the record for the US Department of Energy's (DOE) Draft Environmental Impact Statement for the "Decommissioning of Eight Surplus Reactors at the Hanford Site."

COHO supports the Immediate One-Piece Removal Alternative for all 8 reactors (including $B$-Reactor) for the following reasons:

1) The safest thing that can be done with the reactors is to move them away from the Columbia River. Given DOE's worse case scenario of a 50\% failure in Grand Coulie Dam the flood waters would not reach the 200-West Area but would reach several of the 100-Area reactors if left on site. More severe scenarios were not examined by DOE because "catastrophic floods, would in themselves have such overwhelming environmental impact as to obliterate or obscure any impact from waste they might release." COHO feels this is an invalid assumption. Imagine if the floods last year in Bangladesh would have taken with then 8 nuclear reactors!

2) Given DOE's estimate that the cost of all the alternatives are conparable, it is unfair to place the financial burden of deferred clean-up on future generations.

3) Even though the 200-West Area has born the brunt of DOE's waste since the start of chemical processing operations, it is preferable to consolidate the waste rather than leaving it spread along the shore of the Columbia River.

4) To defer removal of the reactors for 75 years has numerous other serious problems and leaves many unanswered ethical and technical questions. For example, what assurance can DOE give that a decision made today will be carried out 75 years in the future? DOE projects a $\$ 198$ million cleanup. What basis do you have for this estimate? Clearly, the economic conditions and technical capabilities 75 years in the future cannot be predicted with any degree of certainty. Even if DOE is correct about the cost of cleanup, what assurance can you give that the necessary funds will be appropriated when needed?

COHO urges the DOE to initiate the Immediate One-Piece Remoral Alternative without delay and, furthermore, to allow the land to heal, - that do new DOE projects be permitted on the sites.

$$
\text { For } \mathrm{COHO} \text {, }
$$

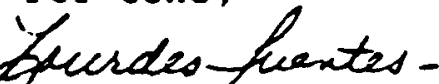




\section{L007}

JUN $19 \$ 89$

HANFORD SURPLUS PRODUCTION REACTOR DECOMMISSIONING

DRAFT ENYIRONMENTAL IMPACT STATEMENT

$\rightarrow$

TO: United States Department of Energy

Richland Operations Office

FROM:

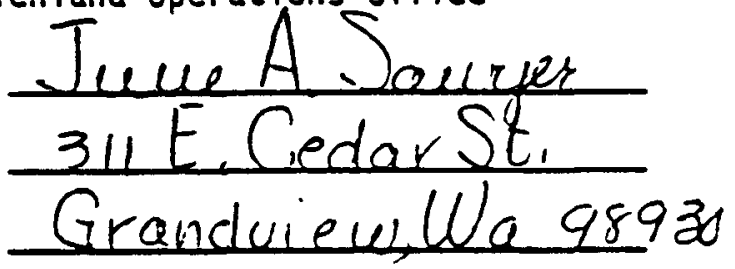

Date: $8 / 2 / 89$

(Please print/type name, address and zip code clearly)

I would like to make the following comments on the DRAFT Surplus Production Reactor Decommissioning Environmental Impact Statement:

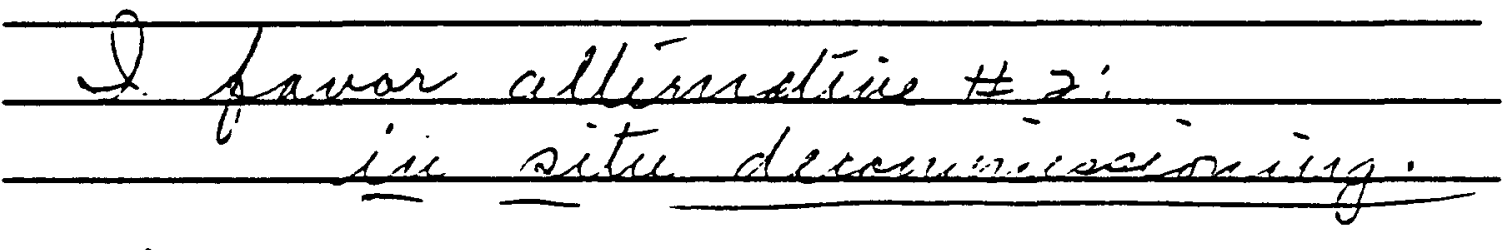

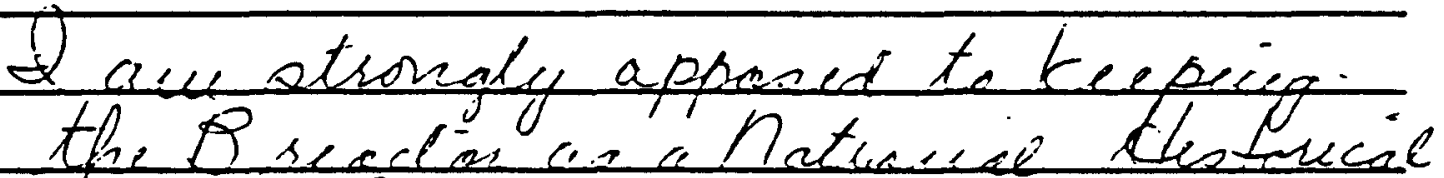

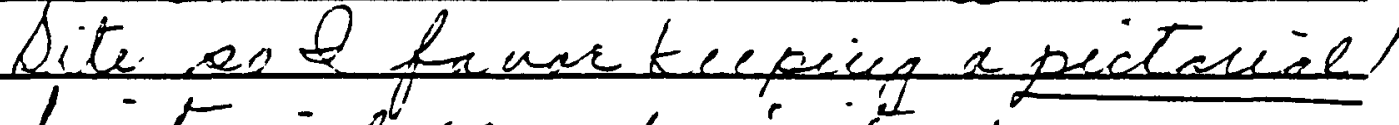

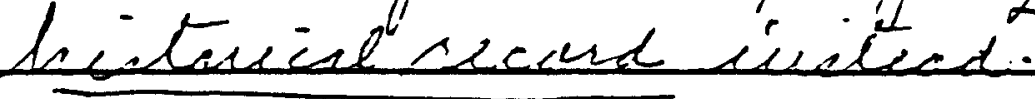

signaturel dees Leenet

Fold on lines and staple or tape before mailing. Include postage. 
Distrat 5

2809 Rudkin Road. Union Gap

P.O. Box 12560

Yakima Washington 98909-2560

(509) $575-2510$

June 29,1999

U.S. Department of Energy

P.O. Box 550/A7-75

Richland, WA. 99352

Public Hearing DEIS

Reactor Decommissioning

Hanford Reservation

We have reviewed the Notice of Public Hearing on the Draft Environmental Impact Statement (DEIS) on the Decommissioning of Eight Surplus Production Reactors at the Hanford Reservation. We offer the following comments.

We are concerned about the transport and hauling of the decommissioned reactors on State highways. The transport and hauling of all materials on State highways must comply with all regulations and guidelines pertaining to the safe transportation of those materials. If spillage or accident occurs, the developer and/or transporter would be responsible for any cleanup and damage to the State highway caused by the spillage or accident.

We would request advanced notice, two weeks or more, of any transport or hauling of the decommissioned reactors on State highways. Adequate notice should include the proposed routes, dates, and times. Notice should be made to this office.

Thank you for the opportunity to review and comment on this proposed project.

Sincerely,

RICHARD L. LARSON, P.E.

District Administratpr
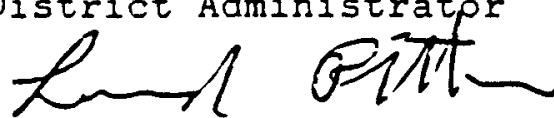

By: LEONARD PITTMAN, P.E. Assistant District Project Development Engineer

GRB : eps 
UNITED STATES

NUCLEAR REGULATORY COMMISSION

WASHINGTON, D. C. 20555

JLL 5 IS\&9

Mr. Tom Bauman

Office of Communications

JUL 1,1000

Richland Operations office

U.S. Department of Energy

P.O. Box 550

Richland, Washington 99352

Attn: SPRD Draft EIS

Dear Mr. Bauman:

This letter is in response to the notice in the Federal Register appearing at 54 FR 18325 in which DOE requested comments on the Draft Environmental Impact Statement (DOE/EIS-0119D), "Decommissioning of Eight Surplus Production

Reactors at the Hanford Site, Richland, Washington." Our comments on the EIS are contained in the Enclosure.

If you have any questions please contact Frank Cardile, of my staff, on (301) 492-0171.

Sincerely,

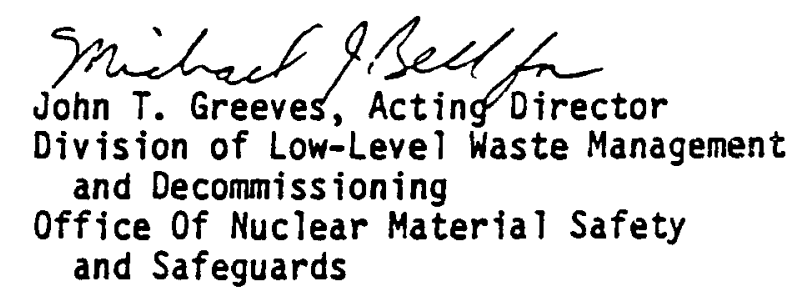

Enclosure: As stated 


\author{
HRC/NMSS COMMENTS ON THE DEPARTMENT OF ENERGY'S \\ DOE/EIS-0119D "DECOMMISSIONING OF EIGHT SURPLUS PRODUCTION REACTORS \\ AT THE HANFORD SITE, RICHLAND WASHINGTON"
}

1. The definition of decommissioning used in the EIS Section 2.1, "to isolate securely any remaining radioactivity in a manner that will reduce environmental impacts to an acceptable level", is different than NRC's in 10 CFR $\$ 50.2$ in which it is indicated that decommissioning means to "reduce residual radioactivity to a level that permits release of the property for unrestricted use and termination of license." While this difference may be reasonable because there are different circumstances, nevertheless it means that two Federal agencies are using the same word to mean different things with resulting potential for confusion. Furthermore, information is not given in the EIS as to what criteria are used for establishing acceptable radioactive levels.

2. The EIS indicates that certain of the alternatives will use a 75 year or greater storage period prior to completion of decommissioning. Information is not given in the EIS as to the basis for the use of 75 years for the safe storage period. Hote that NRC 1 imits the safe storage period in 10 CFR $\$ 50.82(b)(1)$ to 60 years unless a longer period is needed to protect public health and safety. Factors to be considered in extending the safe storage period would include unavailability of waste disposal capacity and other site specific factors such as the presence of other nuclear facilities at the site.

3. On pg. 3.2 it is indicated that the reactor is put into safe storage by securing all "smearable" radioactive contamination in the facilities. However, information is not given as to what type of smearable contamination is present in the reactors at this time.

4. DOE defines "No Action" as continuing surveillance indefinitely, (i.e., for up to 100 years). NRC's regulations do not permit a surveillance mode involving lengthy delays in the completion of decommissioning without a commitment on the time frame in which the decommissioning would be completed. The NRC requires commercial reactors to submit a decommissioning plan within two years of permanent cessation of operations.

6. DOE defines "in-situ decommissioning" as essentially converting the reactor site to a low-level waste burial site. The analysis of this conversion to a LLW burial site appears insufficient. A detailed 
characterization of remaining nuclides would be necessary. Also it is indicated that the monitoring costs are substantial and would continue for 100 years (the time assumed for institutional control), however no information is given as to costs, activities, or radiation doses after that time. 
TO: United States Department of Energy Richland Operations Office

from: H.DALE HELLEWELL 70 SE 11 ROAD DTHELO WA, 99344

(Please print/type name, address and zip code clearly)

I would like to make the following comments on the DRAFT Surplus Production Reactor Decommissioning Environmental Impact Statement:

in Situ decommissioning Appears to re THe Most Cost effectuve Methoo \& CAN Be Accompoushed In THE LEAST AmOUNT OF IIME.

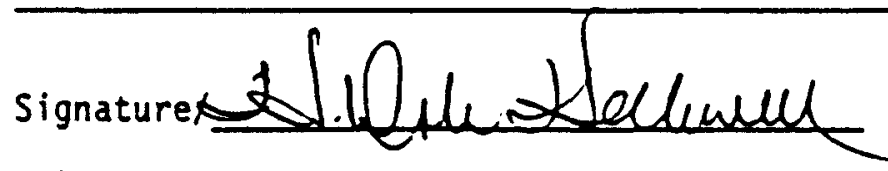

Fold on lines and staple or tape before mailing. Include postage. 
L012

Grely 11,1989

Fom Bauman

U. A. Depty Energy

Q.O. By 550

Richeand, HA. 99352

He enterce the moveff entendiated reactow way from the Colentie hives in the OnePrece Removel Opteón.

the believe thie more usel favos greates asurarce thet the reactore will not be forgottea as yease pew and tarfored hisl be clearud up and the lene cer Fe restored for public use. Thir wiel mabe it possible for the entiv thenfod mese to Tecleared ifp witheri the thisty yes aysement.

Tinerely.

Ara the Eld Floyd Ortow W, 3210 Velirew Dr Hpoteree, Wa. 99208

0.22 


\section{BENTON COUNTY}

Ms. Karen J. Wheeless

Office of Communications

Richland, Operations Office

U. S. Department of Energy

Richland, Washington 99352

RE: Draft Environmental Impact Statement -- Decommissioning of Surplus Production Reactors at the Hanford Site.

Dear Ms. Wheeless:

This ietter is being prepared on behalf of the Benton County Management Team, who adopted a motion at yesterday's team meeting. The management team includes all of the Benton County elected officials and appointed directors and their deputies.

The motion, adopted unanimously, requests the Department of Energy to include land use planning as part of the environmental impact statement on the decomissioning of eight surplus production reactors at the Hanford Site.

The land, once required for public safety and isolation, is no longer needed for that purpose. The return of this land to productive agriculture should be considered where practicable and possible. Reasons for not returning the land to agriculture should be identified and justified.

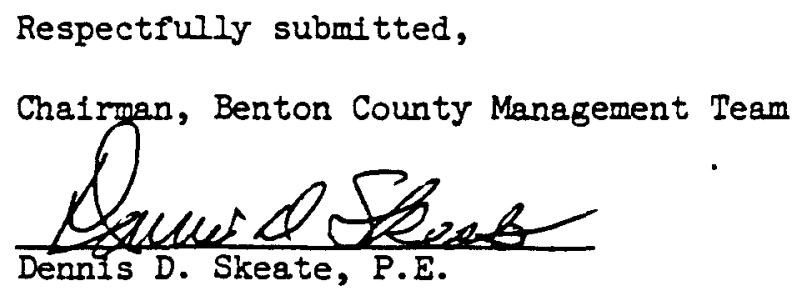


Benton County Management Team

July 13,1989

Page Five

Decommissioning of 8 Surplus production Reactors:

Department Head/Elected officials: Ray asked if they could get support from the management team, supporting the land use planning. It was suggested a letter of support could come from the management team.

*** Motion was made by Sheriff Kennedy; seconded by Sue Tanska. that a letter be sent, requesting DOE to include land use planning as part of an environmental impact statement on decommissioning of eight surplus production reactors at the Hanford Site, as they may be affected by said decommiss ioning. Motion passed unanimously.

Team members would like a copy of what is sent to DOE. 
July 28,1989

Mr. Emmett Moore

Pacific N. W. Laboratory

P. O. Box 999

Richland, Washington 99352

Dear Mr. Moore:

Replying to your phone call, this morning, concerning the Management Team (I.e. Benton County's) letter concerning the decommissioning of surplus production reactors at the Hanford Site.

I have included a copy of the top of Page Five, of the Management Team Minutes for July 13th, when the motion mentioned in the letter of July 14, was adopted.

It is not very formal, but is a record of how the motion was adopted.

If there are any questions please give me a call. Thanks.

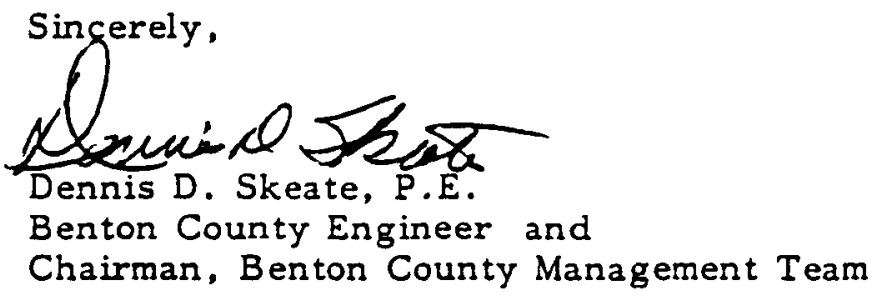


July 14,1989

Tom Bauman

U.S. Department of Energy

P.O. Box 550

Richland, WA. 99352

COMMENT: Eight Reactors Decommisioning

The Tri-City Herald reports that at a recent meeting discussing the Draft EIS for decommissioning the eight reactors, preservation of $B$ Reactor as a national monument was discussed. Tri-Dec (John Burnham) recommended that the reactor be preserved but not developed as a tourist attraction. He proposed that instead of developing a tourist attraction the money be spent in financing further development studies.

This is a very short-sighted viewpoint and would be penny-wise and pound-foolish.

Developing $B$. reactor as a Hanford showpiece and visitor center could do much to attract visitors to the Tri-Cities.

I feel strongly that $B$. reactor should be developed as a visitor center and Hanford Museum either separately or as a part of the decommissioning plan.

I would appreciate it if this letter could be made a part of the meeting record.

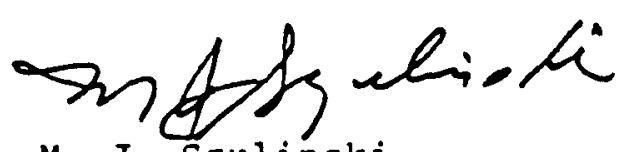

M. J. Szulinski

1305 Hains Street

Richland, WA. 99352

cc/ J. Burnham

J. Stoffel 
JUL 181989

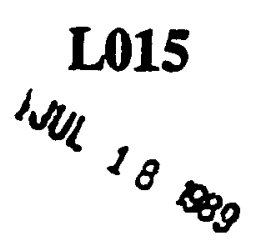

July 14,1989

Tom Bauman

U.S. Department of Energy

P.O. Box 550

Richland, WA. 99352

COMMENTS: Decommissioning Eight Reactors

Document No. DOE/EIS - 0119D

The facts support no action above the lowest cost.

It is recognized that the objectives of anti-nuclear groups within the State and Environmental Groups may not be rational. The DOE should resist all efforts to expand the action beyond basic requirements.

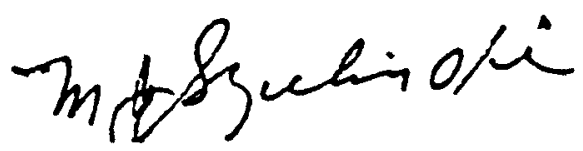

M. J. Szulinski

1305 Hains Street

Richland, WA. 99352 
L016: Gur 14, 1989

JUL 181989

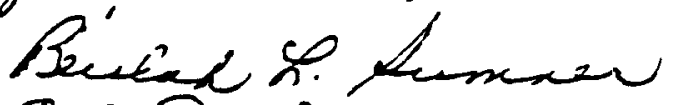

906 Tweip

Comlze Nam, MF 9 G116

Fox Bunsear

Office of Onswuricitios

is Appitment of bxeryy

Parset550

Aichlex, IA 99352

Neas Ai,

Grear of the nilline of dollase Yopenes to diesnextle Starlow installation to prevert "lewther radistion, eto. And priti still Luve radioactive reactors to hide somewhere.

Thaw suistict, made thew things When they were sueder. Hry cait scienticts wot ox a way to reutraline any and all of thi offexdix meaterial, exw if it Lots a lot, it wowld be better the burying it of dispersing of of were it wowld have to be dealt with liter.

In all thet lie kal about thi

0.28 
L016

2. protikn, orky once heve o kaed that a sciertist said the material Could be neutrabijes.

Put some of our best equiged people on this prodlin anduce pone of that Norey beiry wark jint thixking about it.

Sixicerely,

Bevad L Lewnew

0.29 
Mr. Tom Bauman

U. S. Dept. of Energy

P.O. Box 550

Richland, WA 99352

RE: Draft EIS, decomissioning eight surplus reactors

Dear Mr. Bauman:

I have read the EIS draft regarding decomission of eight nuclear reactors on the Hanford site.

Given the five alternatives, I recomend in situ decomissioning as a first choice, with the safe-storage of 75 years as an added option.

Environnmental protection is of primary concern. Once an accident occurs, the safety of our future is threatened. Padioactive equipment and waste whould not be dismantled or transported because the risks for contamination are too high. Even a small accident or leak would cause harm to someone.

100 Areas land has already been destroyed by the construction and operation of these nuclear reactors. Please contain this mistake at site. But before you seal and bury the reactors, I recommend the 75-year surveilance and storage for two good reasons:

1) by maintaining surveilance of the site, safety factors such as corrosion and geological changes can be checked and contrclled. Valuable research can also be made available.

2) by allowing a 75-year pre-burial state, we allow our future citizens to improve technology and, perhaps revise the EIS options to allow for either a safer decomissioning or a safe recomissioning of the plants.

If you choose one of the 75-year storage and surveilance options, I hope you will allow our future citizens the flexibility of choice.

Beth D. Marsau 6162 Aquarius Ferndale, WA 98248
Sincerely,

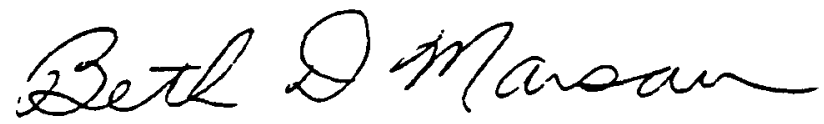

Mrs. Beth D. Marsau 
Tom Bauman

Department of Energy

MS: A7-75

P. O. Box 550

Richland, WA. 99352

Dear Mr. Bauman.

The following are HEAI's written comments on the Draft EIS on the "Decomissioning of Eight Surplus Production Reactors at the Hanford Site, Richland, Washington."

Hral endorses the Imediate One-Piece Removal option for all eight reactors, including the B reactor.

The main reasons HEAL supports the Immediate One-Piece Rerroval option are:

1. It moves the reactors, which are still radioactive, aray from the Columbia River.

The reactors should be buried away from their present location near the Columbia. By being along the river, the reactors rould remain too accessible by the general public. The option of leaving them in their present location and burying them under a mound of dirt and gravel is not a demonstrated technology. The EIS does not even offer an estimate of how long the "engineered barrier" might last before allowing the contaminated reactor blocks to be exposed to the environment.

2. By doing the job immediately, citizens have a greater assurance that the reactors will not be forgotten, that Hanford will be cleaned up, and that the federal government will restore the land to public use. It will also make it possible to keep the entire Hanford mess within the thirty-year cleanup agreement.

In answer to a series of questions by HEAL on the EIS. the Department of Energy responded in part that the "(s)tart of the decomissioning vill depend on the availability of funding and on the priorities established by the Department." Again we apparently have a case of the Department not respecting the vill of the citizens it is supposed to serve. On numerous ocoasions over the past several years the citizens of the Northrest bave made it abundantly clear that re want Hanford to be oleaned up imediately. 
We now have the greatest iikeiinood of obtaining tide necessary funding and skilled rorkforce to safely dispose of these atomic age relics. If re rait for 75 years as is proposed by tro of DOE's options, we run a very high risk of not being able to complete the job of decommissioning.

3. This option requires the least amount of land area to be barred from public access (see p. 5.34--all page references are to those in the draft EIS).

HFAI has repeatedly raised the point that there is no overall government strategy for minimizing the amount of land at Hanford which will have to be off-limits for centuries, and in some cases, millennia. He again call upon the state, EPA and the DOE to develop a plan which will limit (to the greatest extent possible) the amount of land at Eanford which will be fenced off and in effect, turned into a national sacrifice zone. Before such a plan is in place, it is only common sense to pursue those cleanup options which require the least amount of area that will be left contaminated.

There is one other point which should be addressed. At various places throughout the EIS, the DOE states that once the reactor areas are cleaned up, they will be available for "other DOE use." The EIS goes so far as to say that "federal ornership and the presence on the Hanford Site is planned to be continuous." Nowhere does the Energy Department stipulate the basis for its claim to Eanford. HEAL strenuously objects to the Department's regal attitude. The future use of Hanford is a decision which the citizens of Washington and the affected Native American tribes should and must make (refer to pages 3.51 and 5.27 ).

The following are additional coments which are more technical in character.

The decomissioning of the reactors should start with the reactor which has the lowest radiological inventory (DR) and rork on the one with the greatest radiological inventory last (KE). HFAL recomends the folloring sequence, based on the decay of Cobalt-60 (compare rith Eigure 3.2 on p. 3.10 ):
1. $D R$
2,200 curies in 1990
2. $\mathrm{H}$
2,300
3. $\mathbf{F}$
2,600
4. D
1,960 curies in 1995
5. B
2,300
6. C
2,600
7. $K W$
1,850 curies in 2001
8. $K E$
2,900

On page 3.27, there is an error in Table 3.7. The third "Deferred Removal" Subtotal for the DR reactor is an obvious error and should read $\$ 7,485.82$. 
On page 3.27, there should be an explanation that the removal costs for deferred one-pice removal will probably be higher than those same costs for imediate one-piece removal (due to inflation of costs), or at least that there is more certainty with those costs associated with the immediate option.

Concerning the mound designed to withstand erosion without exposing any radioactive material from the reactors (page 3.56 ), the EIS is deficient in not providing an estimate for how long the engineered barrier vill vithstand erosion.

On page 5.3, the Department does not consider the possible breach of a "contamination control envelope" as an accident scenario. The other postulated scenarios may not adequately bound the consequences that might result from such a breach of the contamination control envelope under the deferred dismantlement alternative.

On page 5.6, the calculations rere done using $F$ reactor. DOE chose $F$ because it is the closest to Richland. However it is more appropriate to use $K E$ reactor in order to have a truly conservative estimate because $K E$ has more than three times the radiological inventory than $F$ and it is only $4 \mathrm{~km}$ more distant. The $\mathrm{KE}$ reactor should be used in these calculations (including the inverse square lar) to accurately bound the estimated consequences of a possible accident.

On pages 5.9-10, there is not enough detail regarding the calculation of the dose estimate. There should be a description of the basic assumptions used in calculating these dose estimates, as rell as a numerical expression of the range of uncertainty associated with the estimate.

On page 5.17, the EIS refers to certain people as "those who ignore rarnings." DOE should also consider the possibility that future users of Hanford might not be able to comprehend the rarnings (no matter how hard we might try to communicate the danger underlying Hanford).

On page 5.27 (and elsewhere), the DEIS does not state from which date the 100-year period of institutional control will be calculated. The Energy Department should stipulate whon this 100-year period will begin.

Thank you for considering these comments in the preparation of the final EIS. If you have any questions concerning the above coments, please contact me.

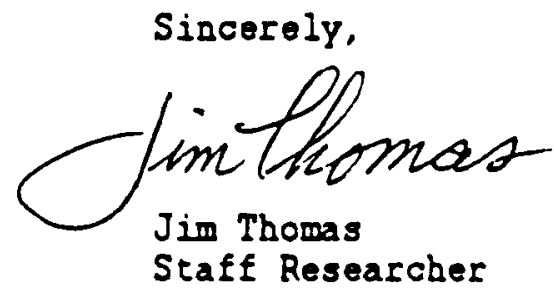




\section{are 2000}

1020 Grand ive.

Astoria, OR 97103

July $18,19,89$

Vr. Tom Eauran

Office of Communications

U. S. DOE

Richland́s overations office

P. 0 . Eox 550

RichIand, :A 99352

Dear Ur. Bauman

Re: Decommissioning plans for

Hanford reactors

iie believe as foliows:

1. Option 3, Imsediate Cne-Piece Removal, should be chosen as the preferred decommissioning plan. It is urent that the reactors be roved ayay from the Columbia River as soon as nossible.

2. The N-Reactor should be included in the decomeissioning pians.

3. The E-Seactor should not be made into a lational Fistorical Site.

Te also believe that tre cublic hearirgs on these matters should be heli at other olaces in addition to Portland, Seattle, Sicisland, and S pokane.

Very truly yours,

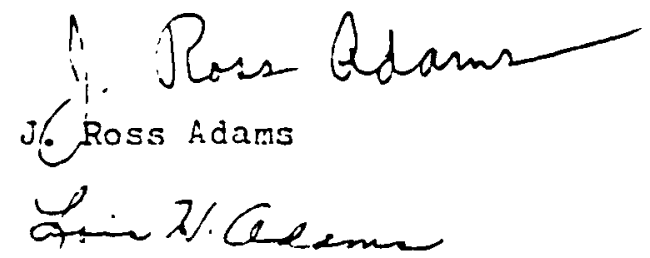

Lois H. Adams 


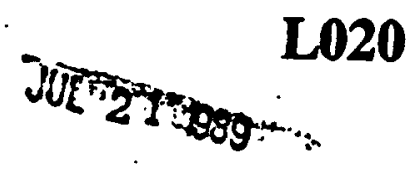

july 17, 1989

2314 SE 24 AVPenue

Portland, OR 97214

Tom Bauman

Office of Communications

J.S. DOE

Richland Operations Office

PO BOX 550

Richland, WA 99352

Dear Mr. Bauman:

It has come to $\mathrm{my}$ attention that hearings are being held regarding the decommissioning of Hanford's Nuclear Reactors.

I suggest that the DOE should select option - 3, IMMEDIATE ONE-PIECE REMOVAL, as the preferred cecommissioning plan. These reactors should be moved away from the Columbia River as soon as possible. Additionally, the $\mathrm{N}$-Reactor should also be included in the decommissioning plans and the B-Reactoy should notoe made into a National Historic Site.

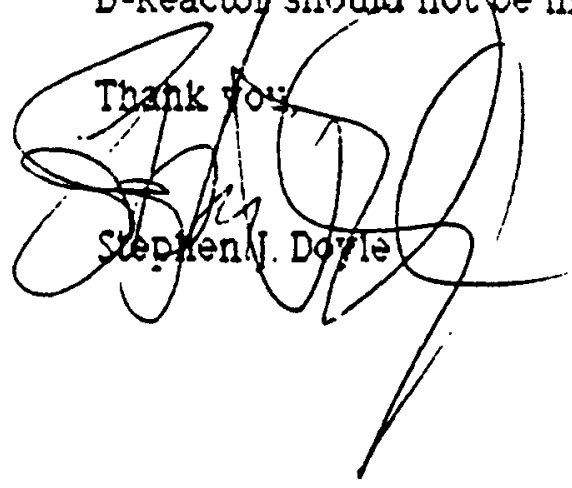


Jul 17, 1989

2314 SE 24 Avenue

Portland, OR 97214

Tom Bauman

office of Communications

U.S. DOE

Richland Operations Office

PO BOX 550

Richland, WA 99352

Dear Mr. Bauman:

It has come to my attention that hearings are being held regarding the decommissioning of Hanford's Nuclear Reactors.

I suggest that the DOE should select option *3, IMMEDIATE ONE-PIECE REMOVAL, as the preferred decommissioning plan. These reactors should be moved away from the Columbia River as soon as possible. Additionally. the $N$-Reactor should also be included in the decommissioning plans and the B-Reactor should not be made into a National Historic Site.

Thank you,

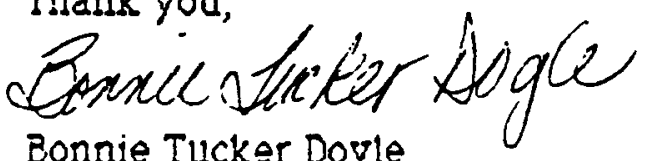

Bonnie Tucker Doyle 


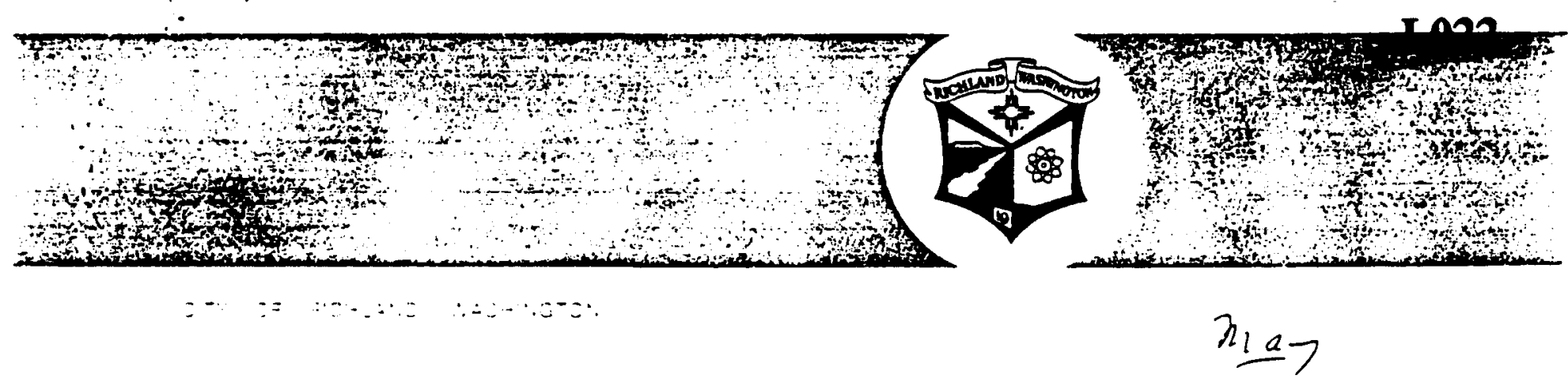

July 18,1989

Mr. Tom Bauman

Office of Communications

U.S. Department of Energy

Richland Operations office

P.0. Box 550

Rlchland. WA 99352

Dear Mr. Bauman:

Enclosed is a copy of Resolution No. 49-89 which expresses the City of Richland's support of the preservation of the $B$ Reactor as a national historic site.

The Resolution was passed by the Richland Clty Council on July 17, 1989.

Sincerely,

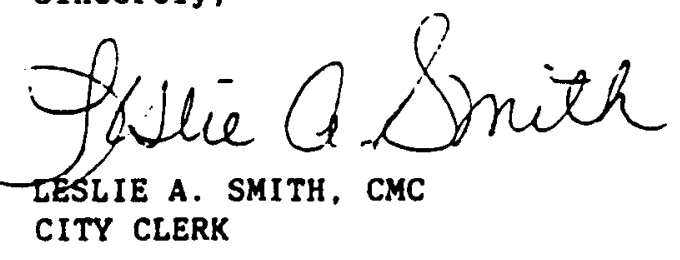

Encl : 


$$
\begin{aligned}
& \text { RESOLUTION NO. } 49-89 \\
& \text { A RESOLUTION supporting the } \\
& \text { preservation of B Reactor. }
\end{aligned}
$$

WHEREAS, the B Reactor at Hanford was constructed and first operated during World War II as part of the Manhattan Project; and WHEREAS, the $B$ Reactor produced the plutonium for the first man-made nuclear explosion (the Trinity test) and for the bomb that ended World War II: and

WHEREAS, the U. S. Department of Energy is considering alternatives for decommissioning the $B$ Reactor: and

WHEREAS, the U. S. Department of Energy and the Washington State office of Archaeology and Historic Preservation have determined that the $B$ Reactor is eligible for nomination as a National Historic Site; and

WHEREAS, the $B$ Reactor, if publicly accessible, would be a significant asset to the tourism industry of Richland and Benton County.

NOW, THEREFORE, BE IT RESOLVED by the City of Richland, acting by and through its Council, that the City of Richland supports:

1. The $B$ Reactor at Hanford as a National Historic Site.

2. The preservation of $B$ Reactor intact at its present location.

3. The upgrading and staffing $B$ Reactor as needed to allow tours by the general public.

4. The provision of a public vehicle access road from state highway 240 . 


\section{L022}

PASSED by the City Council of Richland at a regular meeting on the 17 th day of July, 1989.

\section{/s/ John Poynor JOHN POYNOR \\ Mayor}

APPROVED AS TO FORM:

/s/ Thomas 0 . Lampson THOMAS 0 . LAMPSON

City Attorney 
L023

Get on with it, using best available tech to ReDUCE General a WORKER RAD DOSE.

(You people ate pathetic. You hold puranc

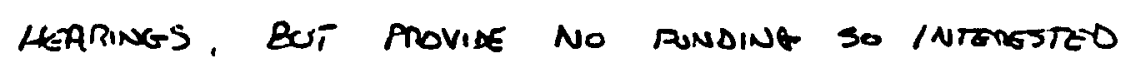
parties can research issue hud attend. No wonder no one shows up. A sham, I say. Horse youth enjoying vul exDouse account.)

Jensen

POS 451

Nerttrint, WA. 99/5)

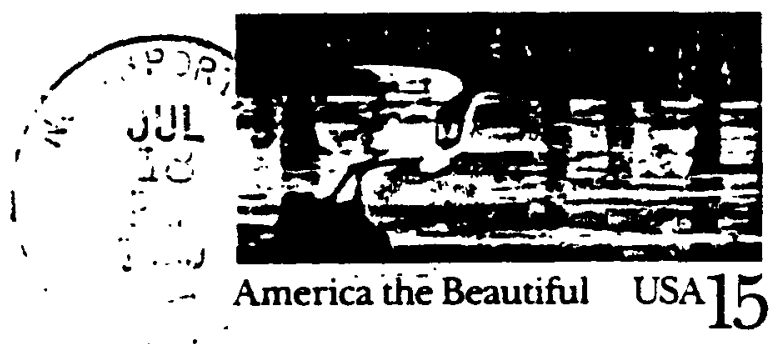

TOM BATMAN

DOE

Po Box 550,

Richland. WA. 99352

0.40 


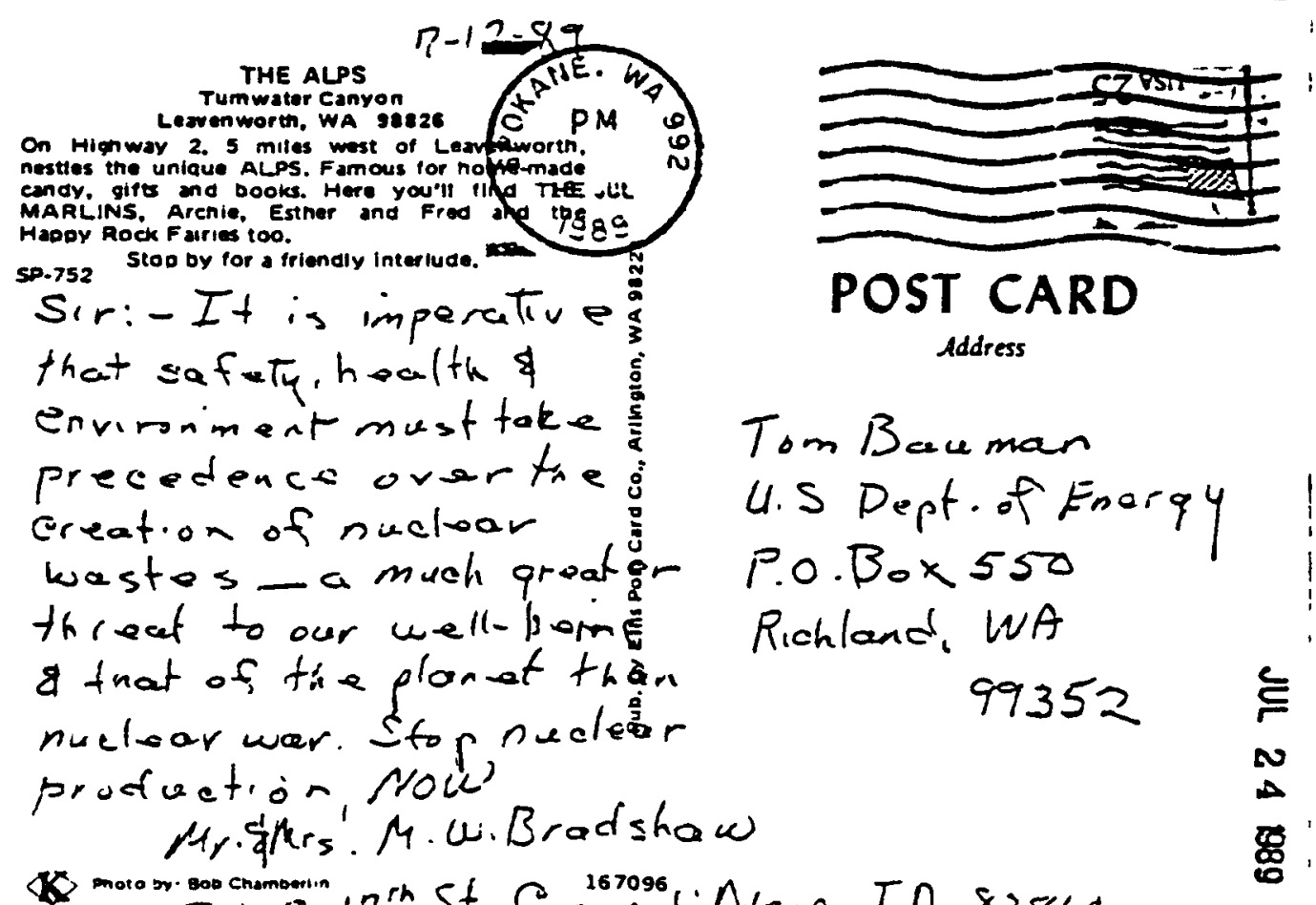


Tom Bauman

U.S. Department of Energy

Richland Operations office

RE: SPRD-DRAFT EIS

P.O. BOX 550

Richland, WA 99352

Dear Mr. Bauman:

I am writing with comments relating to the Draft Environmental Impact statement on decommissioning the Eight surplus production Reactors at Hanford. These reactors have gained a measure of public interest due to their size and proximity to the columbia River.

My comments fall into two areas: factors to consider in determining the preferred alternative, and the future of the $B$ Reactor.

All five options for the reactors appear to present very low risks to the general public in terms of radiation. Therefore, I would suggest that worker safety is given major consideration when choosing an alternative.

Some people have argued that in the event of a catastrophic flood of the Columbia River, water could reach one or more of the reactors and become contaminated. A close examination of the facts does not substantiate major concern over these fears. In the extremely unlikely event of a major catastrophic flood, people are going to have a lot more to worry about than some water contacting several surplus reactors. In reality, a major flood could wipe out substantial portions of the Tri cities residential community, as well as major areas in vancouver, Washington and Portland, oregon. The reactors will not be a major health hazard in such an event. 
I would like to be on record as supporting the efforts to place the B Reactor on the National Register of Historic Places. The B Reactor not only has a solid place in history for helping to end a deadly war, it has also been frequently described as an engineering miracle. After touring the structure and knowing the history of its early operators, it is clear that the structure should be saved. The B Reactor can serve as a monument to the need for a strong defense to ensure peace.

It is my understanding that since the B Reactor is located on federal land, USDOE has the initial opportunity to nominate the site for the national register. However, if USDOE decides against nominating the site, I plan on making the nomination.

Thank you for consideration of these comments.

sincere regards,

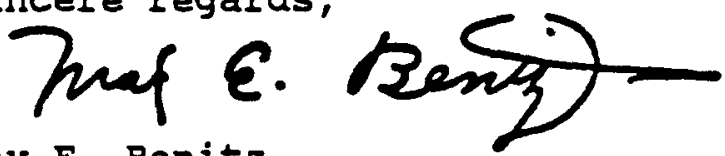

Max E. Benitz

Chairman 


$$
\text { July 2C, 198y }
$$

Dear DCE,

I did not testify at the EIS hearing regarding disposal options for the old reactors at Hanford because $I$ heard of the public hearing too late. Faving considered the several options, I think the Immediate Cne-Fiece Removal would be wisest as it would move the reactors away from the Columbia River.

I also see, as an eventual plus, the retum of these lands to public use. The individuals and Native American tribes who originally surrendered the land understocd that this was a temporary agreement for war-time necessity. They should be rewarded for their patriotism by a careful clean-up and return of their lands.

Sincerely,<smiles>C#CCCOc1ccccc1</smiles>

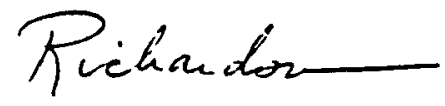

Sarbara Eichardson iv. 18,6C7 Dartford Rd. Colbert, WA $990 \mathrm{CC}$ 
L027

Fin 24

Dear me. Bowman.

A Am responding to the E Is regarding

the disposal options you the eight old nuclear production reactors ar ftantod.

I would like to see the renctass disposed ling dismantling the surrounding tenildingo and removing the reactor Core block en its entirety. this would remove the rester Away frow the Columbia hive and get th you completed right Away. It would require the lest amount of hond ane to the tarred from public access. It would also make it passible to pup the entice stanford mess within the 30 yes cleanups. agreement.

Sinculy, There a Poos 4103 Arrowhead Ed Count Aline, bf. 83814

0.45 
FM: ALAN RICHARDS / HCR 78 BOX 559 / NASELLE WA 98638 206/484-7119

L028 TO: TOM BAUMAN / OFFICE OF COMMUNICATIONS / US DOE

RICHLAND OPERATIONS OFFICE / PO BOX 550 / RICHIAND WA 99352

RE: HANFORD CLEANUP / REMOVAL OF REACTOR BLOCKS B, C, D, DR, F, H, KE, KW DT: $07 / 20 / 89$

Please add my comments to your file. I am unable to attend any of the public hearings, but I would like my opinion to be noted.

I believe that it is VERY important for DOE to select

DRAFT EIS OPTION 3 -- ONE-PIECE REMOVAL

as the decommissioning plan. I feel that the ancient reactors should be moved as far from the Columbia River (or any other body of water) as soon as possible. In addition I hope that you will strongly consider

\section{DECOMMISSION OF THE N-REACTOR VERY SOON}

as well. Finally, I feel it is in very poor taste to even consider making a national monument of the B-reactor, a place which made it possible for one group of humans to kill, maim, and horrify hundreds of thousands of other humans. It seems to me that you should

\section{DECOMMISSION THE B-REACTOR IN THE SAME MANNER}

as the others.

I am pleased to see some efforts in beginning to clean up the mess at Hanford. I think this is a challenge of which we should all be as fully aware as possible so that we may all work together to achieve safe and reasonable solutions.

The problem belongs to all of us; the solution must come from all of us.

I request that you keep me informed of all events relating to the decommissioning process, as well as to other cleanup components. Please add my name to your mailing list, so that I may be informed in a timely manner of future hearings on these matters. Thank you!

sincerely,

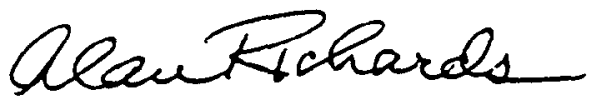

Alan Richards

CC: NEA, Adams, Gorton, Hadley, Hudson, Unsoeld 


\section{Jut 2.4-2009:}

P.0. Box 2119

Gearhart, OR 97138

July 20, 1989

Mr. Tom Bauman

Office of Comminications

U.S. Department of Energy

Richland Operations office

P.0. Box 550

Richland, WA 99352

Dear Mr. Bauman:

I would like the DOE to select option 3 , the immediate one-piece removal decomissioning plan for Hanford's nuclear reactors. It seems this option would be safest for the population.

Thank you for your consideration.

Sincerely,

ixubaracteruah

Barbara Harrah 
L030

HANFORD SURPLUS PRODUCTION REACTOR DECOMMISSIONING DRAFT ENVIRONMENTAL IMPACT STATEMENT

TO: United States Department of Energy Richland Operations office

FROM: Lent Rowland

9255 Greenwood Ave $N \# 1$

Seattle, wA 98103-3009
NULL 24 LESS

Date:

(Please print/type name, address and zip code clearly)

I would like to make the following comments on the DRAFT Surplus Production Reactor Decommissioning Environmental Impact Statement:

- I would like to complement you re beth your Summary Draft and the brochure "Facts about tan food', I lookslat the Draft at the U.jW and went back to the samar i brochure.

- While your reports wire very clear they downplay one factor that $I$ make ${ }^{\prime}$ lining on; the advance in technologive Mv reccommadations modify your proposals in that light.

- Establish an irrevocable trust, fund for safe storage of Hanford's $B$ reactor, with budget for extensive "recordation" over 75 years followed by One -Piece Removal Alternative. I would want the trust fund fixed so that this budget can never be cut: I would add one instruction to the conservative trustee sta one million bellow budget aver 75 years to find sell the public, that could keep the react o- in place with population dose Q1400, person -rem per 10000 yrs.

Regrading reactors $C, D, D R, F, H, K E, W W I$ am in favor of the Immediate one-jiece removal plan paid foo . tunstading 6600000 for a 30 day study every 2.5 years re technology to reduce occupational radiation doseguithin setfoudget. Thanks? Signature/

Fold on lines and staple or tape before mailing. Include postage.

0.48 


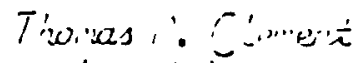

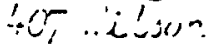

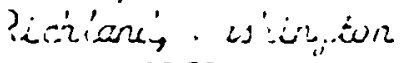

$$
\begin{aligned}
& \text { 1935? }
\end{aligned}
$$

'ízen 'j. ': zesiess, Directur

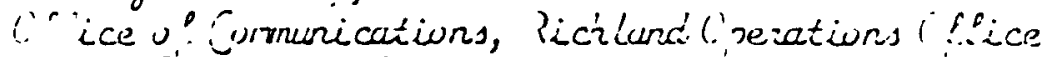

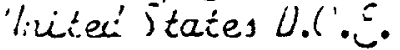

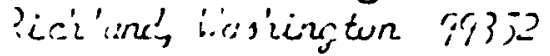

Cin:Ts:

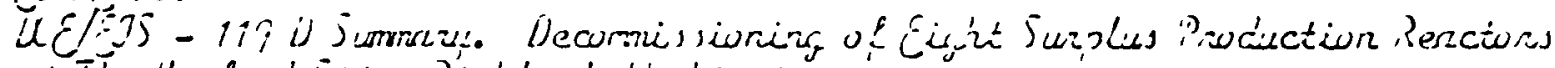

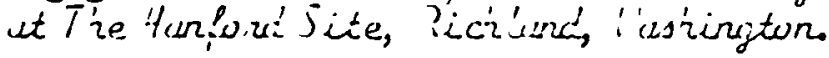

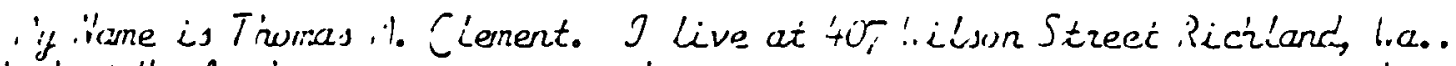
I wuried at hinfund as an enjineer and a manager in varivus caxicities in the 100 ireas from 19't't until retirement in 1782. I a'so wried for two swimer. 1983 and 190, on tize Decurnisswning and Vemo lition irwject witi 3ub ?casch.

$I$ attended tir Pu'lic llesining meeting on Fu'y 11, 19,89 held in tize Federal 3ridding, Ricriand at 10:00 am. I have alsi real tirwugh tie Sunnay of $10 \mathrm{C} / \mathrm{C}=019 \mathrm{O}$ - 019.

1 wuld lise to ouncur with tie coments giver by Gordon iugers at the

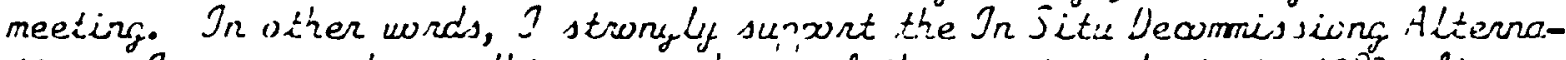

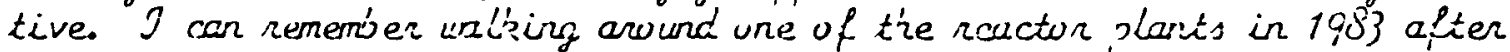
realing a re'ort recommending tire reactor b 6 c'rs be moved to 200 trea for burial and thirizing that that action wuld be a tremena'wus weste of homan expoure and money. The reactor srielding is in place at the site and is backed us bif three fiot thich cuncrete walls. I wrote a letter at that time reoumnending In Situ Vecomnissioning.

The preservation of the " $3^{\prime \prime}$ reactor as a Vational Histurical "onoment wisla' be a rice gesture, hut wuld be cost'j. I t'rin's t'ut a replica of ". 3 " plant in Tire Science Center wult be nore to the puint and none infunnative as to hw the plant acturlly wried. The wher plant portion of "3" area could je

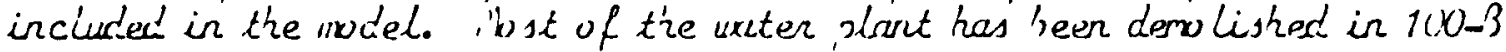
arer.

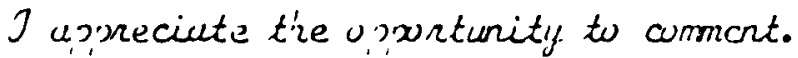

\section{Sincerely,}

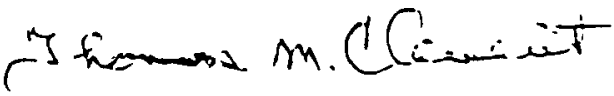


July 19.1989

Karen Wheeles, Director Office of Communications Richland Operations Office U.S. Department of Energy Richland, WA 99352

\section{Comments on DEIS: Surplus Reactors}

The League of Women Voters of Oregon has taken an active interest in Hanford radioactive waste since 1979 . We published a study, Nuclear Update in 1980. The League of Women Voters of the United States published Nuclear Primer in 1980, which described types and extent of nuclear waste in the U.S. During the last year the LWVUS has held seminars on military nuclear waste in Atlanta, Denver and Seattle.

A number of our members have toured the Hanford Reservation. and we are interested in the deposition of the eight old reactors. We recommend that USDOE selected DEIS Option 2 -- Immediate one-Piece Removal of the old reactors and fuel basins. We make this recommendation because of the significant leak which has contaminated earth under one of the fuel basins. Although we knew of other contaminated earth at Hanford, we did not know of this particular leak until the DEIS.

Our members are very concerned about contamination of the Columbia River. We believe that technical uncertainties must be planned for and publicly recognized. We are not satisfied with the data presented on movement of water under Hanford toward the water table and toward the Columbia River. What about the possibility of old radioactive fuel leaks under the other reactors and the possibility of erosion? 
In-site decommissioning would not be acceptable because of weakness in the leak detection system and lack of a specified action system in response. Removal after 75 years cannot be supported because of the lack of information on hydrology and ground water contamination. Option 2. removal to higher ground, would also eliminate flood danger.

The League supports a state consultation and concurrence process and consideration of environmental impacts of military nuclear waste sites. We believe in the effective involvement of state and local governments and citizens in siting proposals for treatment, storage, disposal and transportation of radioactive wastes.

Sincerely,

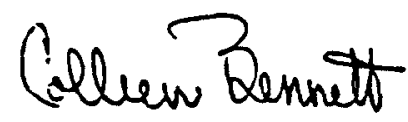

Colleen Bennett

President

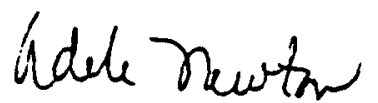

Adele Newton

Energy Chair 


\section{L033}

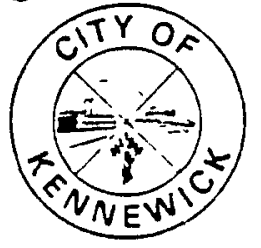

\section{CITY OF KENNEWICK WASHINGTON}

CIVIC CENTEA

[BOS) SEG-4191 / SCAN-SEG-2z37

210 WEST SIXTH AVENUE/PO. BOX 6108/KENNEWICK. WASHINGTON 99336-0108

July 25, 1989

Mr. Tom Bauman

office of Communications

Department of Energy

Richland Operations office

P. O. Box 550

Richland, Washington 99352

Dear Mr. Bauman:

Enclosed is a copy of Resolution 89-36, supporting the preservation of B Reactor, which was adopted by the city council at its meeting of July 18, 1989 .

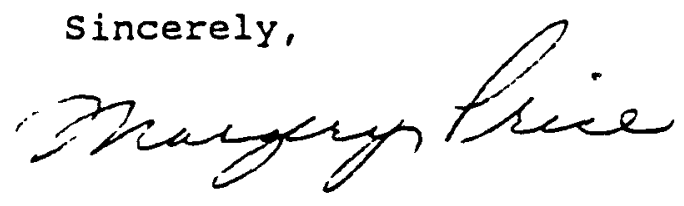

Margery Price, CMC

city clerk

CC: $\mathrm{CM}$ 


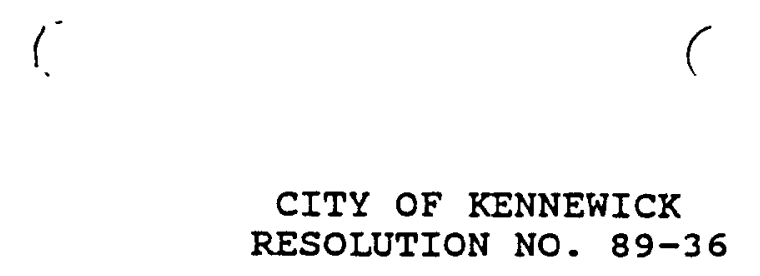

\section{A RESOLUTION SUPPORTING THE PRESERVATION OF B REACTOR}

WHEREAS, The B Reactor at Hanford was constructed and first operated during World War II as part of the Manhattan Project; and

WHEREAS, The B Reactor produced the plutonium for the first man-made nuclear explosion (the Trinity test) and for the bomb that ended World War II; and

WHEREAS, The U. S. Department of Energy is considering alternatives for decomissioning the B Reactor; and

WHEREAS, The U. S. Department of Energy and the Washington state office of Archaeology and Historic Preservation have determined that the B Reactor is eligible for nomination as a National Historic Site; and

WHEREAS, The B Reactor, if publicly accessible, would be a significant asset to the tourism industry of Richland and Benton County, NOW, THEREFORE,

BE IT HEREBY RESOLVED BY THE CITY COUNCIL OF THE CITY OF KENNEWICK, WASHINGTON, that the City of Kennewick supports the B Reactor at Hanford as a National Historic Site; the preservation of $B$ Reactor intact at its present location; the upgrading and staffing of $B$ Reactor as needed to allow tours by the general public; and the provision of a public vehicle access road from state Highway 240 .

PASSED BY THE CITY COYNCIL OF THE CITY OF KENNEWICK, WASHINGTON, this 182,1 day of 1989 , and signed in authentication of its passage this lexiday of Pey 1989.

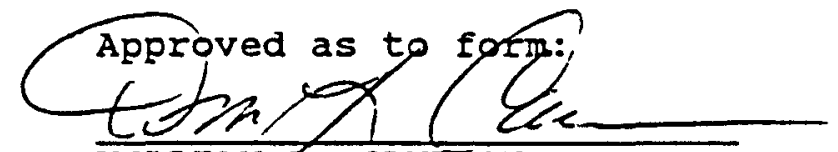

WILLIAM L. CAMERON

City Attorney

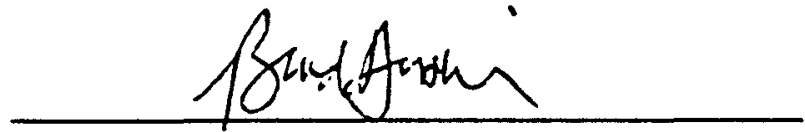

BRAD FISHER, MaYor

Attest:

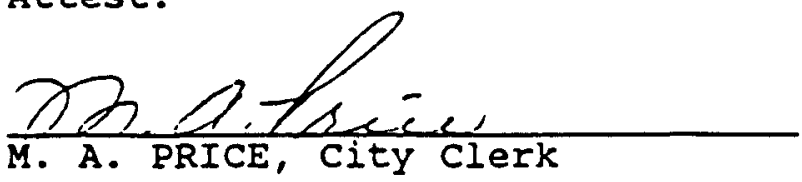


RESOLUTION NO. 1880

A RESOLUTION supporting the preservation of $B$ Reactor

WHEREAS, the 8 Reactor at Hantord was constructed and first operated during World War 11 as part of the Manhattan Project: and

WHEREAS, the $B$ Reactor produced the plutonium for the first man-made nuclear explosion (the Trinity test) and for the bomb that ended World War 11: and

WHEREAS, the U. S. Department of Energy is considering alternatives for decommissioning the $B$ Reactor: and

WHEREAS, the U. S. Department of Energy and the Washington State Office of Archaeology and Historic Preservation have determined that the B Reactor is eligible for nomination as a National Historic Site: and

WHEREAS, the $B$ Reactor, if publicly accessible, would be a significant asset to the tourism industry of the general Tri-Cities area: NOW. THEREFORE.

BE IT RESOLVED by the City of Pasco, acting by and through its Council. that the City of Pasco supports:

1. The B Reactor at Hanford as a National Historic Site.

2. The preservation of $B$ Reactor intact at its present location.

3. The upgrading and staffing $B$ Reactor as needed to allow tours by the general public.

4. The provision of a public vehicle access road from State Highway 240. July

PASSED by the City Council of the City of Pasco this . 1989.

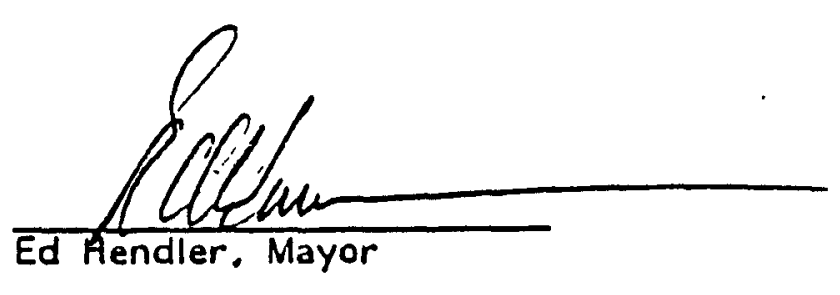

ATTEST:

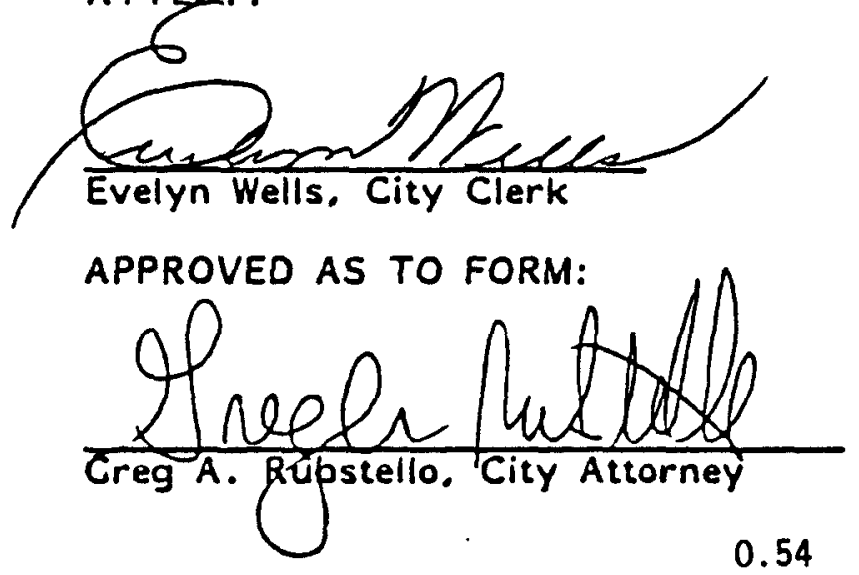




\section{TRI-CITIES TECHNICAL COUNCIL P.O. Box 1483 \\ Richlond. Voshington 99352}

July 19,1989

Mr. Tom Bauman

US. Department of Energy

P.0. Box 550 Richlend. V1 99352

Dear Mr. Baumen:

The Tri-Cities Iochnical Council is an organization thase members are the representat ves or 21 proressional. engineering and technical societies having sections or chepters in this region. As local residents and citizens vitally concerned Fith assuring the conunued healthrul en vironmental fearures of the area, ve vish to offer the folloving comments on the drant Environmental Impact Statement for decommisioning the eight surplus production reactors, incluting possible preservation of the B Reactor as a Rational Historic Site.

Ve vould support either "Continue present actions" or "In situ decommissioning" on the basts that these are the lovest cost options and they toth have negligible en vironmental impacts. Hovever. ve believe the in situ decommissioning is vorth the extra cost in that it provides a more permonent solution in the shortest time.

Ve strongly oppose the options in volving removal or dismanuement. The bigher corts, longer times to complete, adbed risk of unpleasent surprises, and the very small reduction in estimated total radiation exposure make any of these options very poor choices.

Vo strongly recommend that $B$ Reactor be designated as a National Historic Site. As you are atrare. B Reactor has been designated as an Historic National Engineering Landmark of the American Society of Mechanical Engineers. The brass plaque signifying this honor is mounted in the Hanford Science center. Our preference is that the Continue present actions" option be applied to B Reactor; vith the objective that public access and tours could be assured, consistent vith current sarety requirements. If this option cannot be alloved for any reason, ve request that allernative means for commemorating the reactor be provided; for example vith extensive recordation of vritten and photographic materials, a kiosk vith displats of vistal aids at the Pernita Rest Area on otelisk at a point along High way 240 at a point where the reactor site is visible, of a reconstruxtion of at least the reactor control room.

Ve appreciate the opportunity to offer our vievs on this subject. The above comments have been approved by the Council's Executive Board. Ve vould velcome the opportunity to provide information or assistance to DOE in the course of your preparation of the final EIS.

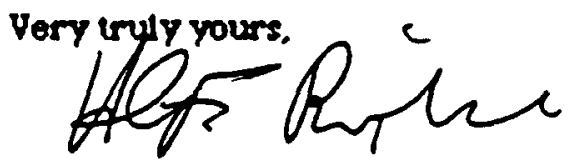

Bens CF. Ripfol, Chairmen 
Tow Eauman

Cifice of Dommunications

US DOE

Dear Mr. Bauman,

I attended the meeting in Spokane on the draft EIS for the decomiaionsing of 8 surplus reactora at the Hanford sito. I read the $m_{M}$ terisis provided, 1 istened to one person testify, and spoice for atime with a fellow from the Battolle corpo It jocame clear the immediate one-piece removal the the 200 area is preferable. The time factor may indeed ween thet there is more Cesium 137 and Cobalt 60 present duriag removal. However, the overriding factor is that these reactors need to be removed frow the immedigte vicinity of the Columbia River before the curront generation of of workers and supervisors dies of old age. Anything can happen in 75 or 100 yoars time; that includes oconowic collapse, political change, groat climatic changes, and, ate very least, retirewent and death of Il the people who began the frocess. The possibilities for great change, in 75 or 100 yoars time, is frightening. Also, in situ decommisioning ia unacceptablo bocause tho reactor bulldingedrill ramain too close to the river; given abight cisangeis in the course of the Colunbia rivertid and otnor climatic changes ovor

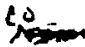
meny centuries - radiogicelly active fission by-products and some heavy metals may become part of tine Columbit.

The "B" reactor is a symbol of death and destruction to moat of the world: Fif certain people who consider theoselvas patriots want to retain that bulding for itg hiotorical volue; but I and f ladead, most other people worldwioe are regulsed at the ijea of colebrating the wartime use of aisclear weapona. If nuclear weapons wo were forover banned from use, it would bo a different story; but that is far from being the case.

Once the reactor bulldigs ere romoved I'd Iike you to conslder roturaing the "100" sites to the public domain. Berring that, a non-nucleartuse of the area (ospeciolly utillsing oolar and wind power and forwented agicukural wate) 
would be apprecitod by all - except, perhaps, Tri-Citios rosidonta and emploes of DOE and their contractors.

Thank you for the opportunity to share these views with you. The draft EIS and your sparsely attended heoring seomed quite open. Howerer, I st1ll ramin sceptical as to the intont of tine DOE - that it might well do what it rants to do no wattor what viow are expreesed that run counter to 1t. The history of the DOE, unfortunately, is of low regard for human lifo and well-being in the face of "Bationl security" neods. In fact, that seexs to be all the wore reason to proceed with dismontlement as soon es possible before some distant future lendersinip can decide to do something ol se with those reactor busidings.

youss,

Tom Lando

W. 14158 th Ar.

Spoknno Spreme, WA 99204 
Tom Bauman

Office of Communications

Richland Operations office

U.S. Department of Energy

P.O. Box 550

Richland, Washington 99352

Attention: "SPRD Draft EIS"

Dear Mr. Bauman:

We have reviewed the Draft Environmental Impact statement (DEIS) for "Decommissioning of Eight Surplus Production Reactors at the Hanford Site, Richland, Washington." We are responding on

behalf of the U.S. Public Health Service. Since this EIS contains significant radiological health considerations, we have requested review assistance from the Office of Health Physics, Food and Drug Administration (within the Public Health Service).

Our major concern in this DEIS is the selection of the alternative which provides the highest level of protection of worker safety and health. Toward this end, two of the

alternatives are preferred: 1) immediate one-piece removal, and 2) safe storage followed by one-piece removal. These two alternatives appear close in cost while minimizing impacts on air and water quality, ecology, socioeconomics, and resource commitments. From a radiological health standpoint, we strongly recommend immediate one-piece removal as the preferred removal method.

Thank you for sending this document for our review. Please insure that we are included on your mailing list for future documents with potential public health impacts which are developed under the National Environmental Policy Act (NEPA).

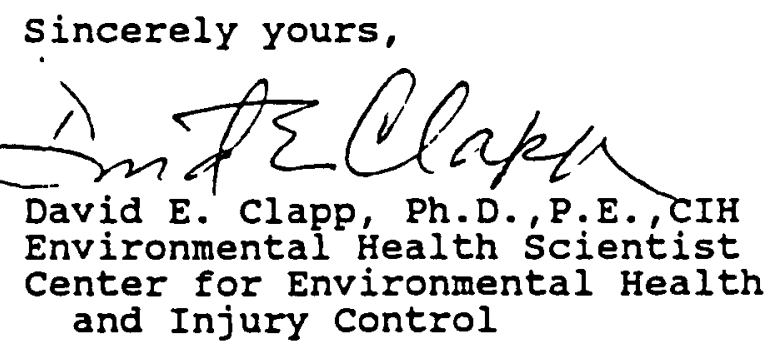




\section{RESOLUTION}

89249

\section{BEFORE THE BOARD OF COMMISSIONERS OF BENTON COUNTY, WASHINGTON:}

IN THE MATTER OF SUPPORTING THE PRESERVATION OF B REACTOR

WHEREAS, the B Reactor at Hanford was constructed and first operated during World War II as part of the Manhattan Project, and

WHEREAS, the B Reactor produced the plutonium for the first man-made nuclear explosion (the Trinity test) and for the bomb that ended World War II, and

WHEREAS, the U. S. Department of Energy is considering alternatives for decomissioning the B Reactor, and

WHEREAS, the U.S. Department of Energy and the Washington State Office of Archaeology and Historic Preservation have determined that the $B$ Reactor is eligible for nomination as a National Historic Site, and

WHEREAS, the 8 Reactor, if publicly accessible, would be a significant asset to the tourism industry of Benton County,

NOW, THEREFORE, Be it resolved that the Board of Benton County Commissioners supports

1) The designation of the B Reactor at Hanford as a National Historic Site;

2) The preservation of $B$ Reactor intact at its present location;

3) The upgrading and staffing of $B$ Reactor as needed to allow tours by the general public; and

4) The provision of a public vehicle access road from State Highiway 240.

Dated this ....24th ......... day of .... July. .

Board of County Commissioners

Benton County Courthouse

P. O. Box 190

Prosser, Washington 99350

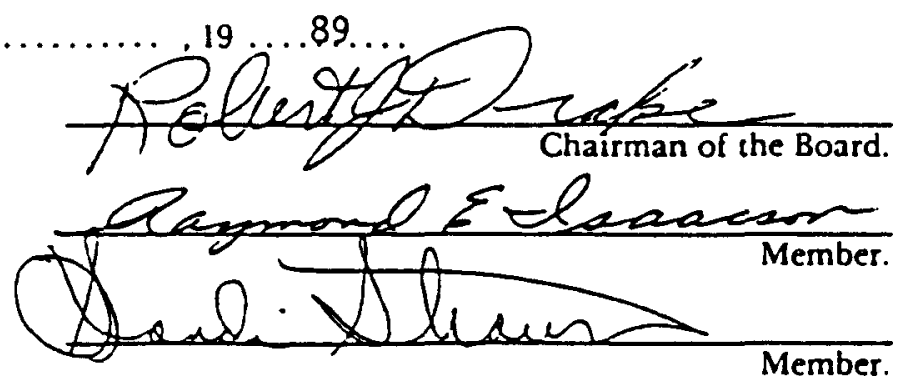

Constituting the Board of County Commissioners of Benton County. Washington.

Heintz 


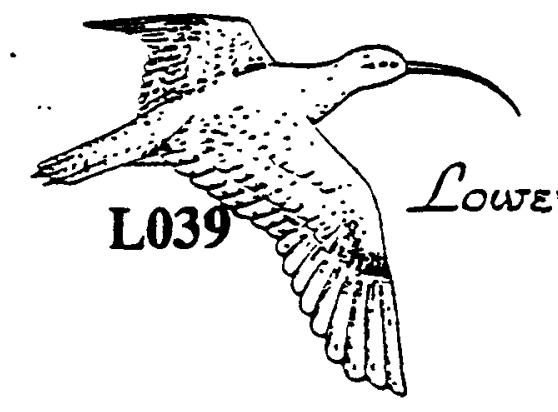

Columbia Basin Audubon Socisty

A BRANCH OF the NATIONAL aUdUgON SOCIETY 9517 W. R1chardson

Pasco, Wa. 99301

July 27,1989

Raren J. Wheeless, Director

Office of Communications, Richland Operation office

U.S. Department of Energy

Richland, Washington 99352

Dear Ms. Wheeless:

I am witting to comment on the Draft Environmental Impact Statement concerning Decommisstoning of Eight Surplus Production Reactors at the Ganford Site, Richland, Washington.

We recommend adoption of the Immediate One-Piece Removal Alternative. This alternative would not only provide for decomissioning the reators but would also do a great deal towards restoring the shoreline of the Columbia to its natural state. This alternative would enhance the scenic values of the Columbia's Hanford Reach which are currenty uncer study by the National Park Service.

Adoption of this alternative would provide an imediate positive impact on the local economy which has grlevously suffered from cutbacks at the Hanford site.

The costs of this alternative at $\$ 190.8$ million is exactly in the middle of the five alternatives. The No Action alternative would cost only $\$ 41.0$ willion and is the cheapest yet least desirable. The other four alternatives range from $\$ 181.1$ million to $\$ 216.6$ million. Imediate One-Piece Removal appears to be a cost effective solution.

Again we encourage your adopiton of the Imediate One-Pfece Removal Alternative as a wise, cost-effective method for decommissioning these reactors whlle enhancing the environment and scenic and wildife resources of the Columbia River. Thank you!

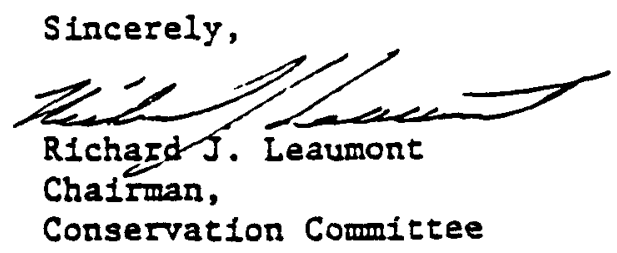




\section{Columbia River Conservation League}

\section{W. Richardson Pasco, WA 99301 July 27,1989}

Karen J. Wheeless, Director

Office of Communications, Richland Operations Office

U.S. Department of Energy

Richland, Washington 99352

Dear Ms. Wheeless:

I am writting to comment on the Draft Environmental Impact Statement concerning Decomissioning of Eight Surplus Production Reactors at the Hanford Site, Richland, Washington.

We recommend adoption of the Immediate One-Piece Removal Alternative. This alternative would not only provide for decommissioning the reactors but would also do a great deal towards restoring the shoreline of the Columbia to its natural state. This alternative would enhance the scenic values of the Columbia's Hanford Reach which are currently under study by the National Park Service.

Adoption of this alternative would provide an immediate positive impact on the local economy which has grievously suffered from cutbacks at the Hanford Site.

The costs of this alternative at $\$ 190.8$ million is exactly in the middle of the five alternatives. The No Action alternative would cost only $\$ 41.0$ million and is the cheapest yet least desirable. The tpther four alternatives range from $\$ 181.1$ million to $\$ 216.6$ million. Immediate One-Piece Removal appears to be a cost effective solution. ;

Again we encourage your adoption of the Immediate One-Plece Removal Alternative as a wise, cost-effective method for decommissioning these reactors while enhancing the environment and scenic and wildlife resources of the Columbia River. Thank you!

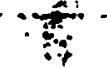

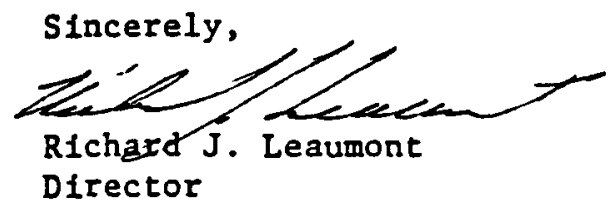

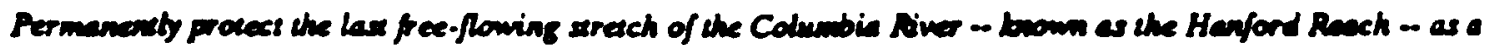

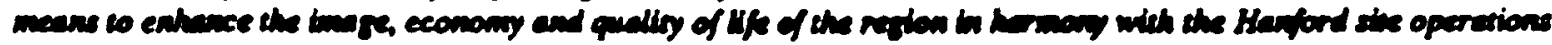

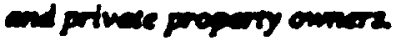


T. H. MCGreer

3389 Cherry Drive

Hood River, Oregon 97031

Karen J. Wheeless, Director

office of Eommunications, Richland Operations office

U. S Dapartment of Enerjy

Pichland, Nashington 99352

Subject: DOE/EIS 01190

Dear Ms Wheeless:

I commented orally at the recent meeting in Portland with ragard to the above Environamental Impact Statement. I am adding further cominents in the attached report I am a retired engineer with dormant registrations as a professional engineer in Illinois, California and Oregon. I served as an electrical engineer for six years during the construction and initial operation of the ZGS accelerator at Arjo ne National Labjratory at Argonne, Illinois and a total of eight years during the design, construction at the =erni National Laboratory at Batavia, Illinois.

Please add ny hane to your mailing list of interested persons receiving copies of reports and comments on this subject.

very truly yours,

$r . x$. $m$ over

T. H. McGreer 
COMMENTS ON THE DRAFT ENVIRONMENTAL IMPACT STATEMENT DOE/EIS-01190 DECOMUISSIONING OF EIGHT SURPLUS PRODUCTION REACTORS AT THE HANFORO SITE, RICHLANO, WASHINGTON.

\section{Introguctory Comments}

The Jraft report is quite complete and should suffice for a final decision by DOE and EPA with only a few corrections J chanjes. It is inevitable that a report on a situation such as the Ha.zford raactors will contain much scientific jargon. When reviewing the summary chapter of the draft rept the authors should make every effort to write each sentence with the lay persons in mind. Many of the decisionmakers are laymen in the matter of nuclear reactors.

In particular a two or three page discussion in the simplest possible language should be included in the summary chapter to show the number of people involved versus illnesses within the site and external to it for each of the five alternatives. The time period of 100 years would be rost useful. Estimated illnesses for the same people for the same time period that would be suffered if Hanford did not exist. An explanation that the figures are at best ediszated guesses nould be helpful. If necessary a similar discussion of health effects for the remaining 9900 years could be included.

General Comments from a Taxpayersstandpoint

Taxpayers are, at this time, adamant that tax rates shall not be icreased. 3oth the Executive and the Legislative branches of federal and state governments are quite aware of this. Just as evident are the demands made on governmental agencies.

Every project is, therefore in competition for taxpayer money, Unfortuneatly, every locality is also demanding equal treatmentso that a total budget is 50 to 100 times that for the Hanford decommissioning Hopefully we taxpayers will engage 
in the piocess so that our priorities are met.

As $a$ niาimum Hanfor $\mathrm{m}\lrcorner s t$ be kept safe. Beyond the saving of lives and protection of health there is no incentive for spending money on the obsolete reactors in area 100 . Ne urje those in the Department of Energy wh participate in bujget decisions to select an alternate that gives us the most for our noney. Onze that selection is made, place it in relative priority with other DOE activities that have to do with the common welfare.

Beyond the Doe budjet the demands upon the Federal budget are mush greater than the ceiling we taxpayers have and will establish. Therefore the Hanford decommissioning must and shouldiawperte host of other concerns. Of course we will want to be good stewards and provide a safe and decenthanford area. Further than that, the time and method of decommissioning should be competitive with other uses of our money.

The competition is great. The minimum annual reactor budget item for safe storage is about $\$ 500,000$. Immediate decommissioningwould cost about $\$ 15,000,000$. for 12 years. The difference is $\$ 14.5$ million per year. A conseientious

Congressman will ask whether that amount of money might be better spent on some other concern such as the following: Repair or replacement of bridges that are becoming dangerous.

Repair or replacement of dams that show signs of breaking. Reduction of air polution estimated as causing 50,000 deaths per year.

Salvaging pəople who face death because of addiction to drugs, alcohol or tobacco.

The list could be continued for pages.

In comparison, delayed decommissoning is guessed to cause less than a thousand deaths in 10,000 years! 


\section{joecific Comments on the EIS}

Page $v$, Line 5 "No action alternative"

using this term for the title of the altefiative is confusing and misleading and has required explanation is several places in succeeding pages. A much better title is shown in parenthesis under 1.3.1, "Continue Present Action". If "Safe Storage" means the same as "No Action", why not use "Safe Storage for 75 Years" as the title for the first alternative?

Page 1.14, 1.3.7, Evaluation of Alternatives.

When evaluating cost of a project to be done far in the future versus one to be completed immediately, both should be present-valued. Certainly a program delayed 75 years is much less costly to the taxpayers than one completed and paid for in 12 years.

Since no specific cost of money or inflation rates are predictable, it is common practice to assume a difference between inflation rate and interest rate. The difference tends to be more stable. Presently this would be about $4 \%$ per year. Anotheribay of looking ${ }_{\lambda}^{i}$ the cost comparison is to compute the amount of money placed at $4 \%$ interest compounded annually to equal 1 million dollars in 75 years; $\$ 52,784$. If present-valued, all costs shown in Tablel.2 would be. reduced. In order to accomplish this an annual budget estimate for each alternative for 100 years using 1986 dollars is required. Even if not present-valued, such a tabulation would be of great value to decision makers. Page 1.22 , 1.5.1 Invironmental Cośnequences

The truck driver would not much care whether the box car was filled with plutonium or potatoes.

Dage 3.1

"Continue Present Action" is not "No Altion".

Page 3.3 .

A discussion of Present-valuing should be added. 
Table 3.1

Why is no monitoring required snder continued present action?

Table 1.2

Peopla outside the saientist'raaln may be confused by "rem/yr" whereas in later chapters dosage is given in mrem/year. Consistency is recommended.

Tále 5.2

Same 3:s for Table 1.2 above.

5.7 Assessment of Long Term Impacts

Even after 10 years in this democracy the rules may change. To assume that our descendents will be careless about their health is rather insulting to them. Actually they will know. where we guess about low level radiation effects. Probably sone janius will find a way to decontaminate radionuclides that we do not even entertain in our dreams. Private enterprise will probably find a way to profit from such materials as carbon 14.

The use of the word "sonservative" is unfortunate. Such usage is not covered in most dictionaries and certainly not in politics. Table 5.3

Same zominent as zisure

Section 5.7.2 EPA's Philosophy Page 5.27

If the EPA philosophy really is "that active institionaltontrols are not to be relied upon........for more than 100 years after disposal." Then EPA assumes that we will learn nothing more in the next 100 years, safety laws and practices will be relaxed and that stupid people will abound. As to the utter nonsense of such a philosaphy look back 100 years and imagine what rules we would be followingnow that were promulgated in 1889. Even Thomas Edison less than 100 years ago thought that high voltage alternating current power distribution should be outlawed because of public danger. 
6.6 Standards for Protaction of the Public

Since these standards use millirem, the EIS should use millirems where dosing is tabulated throughout.

8.10 Glossary

Add the definition of smear, smearable as it applies in the EIS. Add the definition of stochastic and "stochastic dose equivalent"as used Page E.7, E 1.4 .

Page E.35, E.3.4.1 Intruder Scenario

That the regulating agencies representing the populace would abandon all responsibility and :- permit an individual to foolishly dig a basanent and live in a house in the worst possible location, using all of the contaminated water from the worst reactor for drinking and irrigating his own food supply, defies inajication.

Honever, one hundred years from now, after all data is in on Chernobyl and other pertinent information becomes available, there is a possibility that many controls can be sensibly relaxed. Trust our Jescendents!

age $E .38$

An obvious error in Columbia River flow rate.

Table F.2 Appendix F

Refarring bazk to Tabla 1.2 The 50000 person-rem far the socalled "ivo action" apparently assumes that the site will be abandoned in 100 years and left willy-nilly to the following 9900 years.

A note of explanation should be added to Table 1.2 showing the exposure forthe first 100 years This would put the alternative into better perspective. 
RECOMMENDATION

1. Since tbe EIS is written to show technical icomparisons of various ways of decommissioning for those who must make the final decision it has been free of actual recommendations. The authors have done this in a commendajle fashion and deserve our congratulations. On the basis of the facts as presented, I recommend that the third alternate "Safe Storage followed by One Piece Removal" be adopted for the following reasons.

a. The radiation dasage is far below the maximum considered to be safe.

b. It allows future administrators and budget ina'k 35 freejom of choice as additional nonitoring makes present estimated radiological effects either confirmed or altered. $=$. It allows state of the art of people protection to be utilized.as new facts and new methods devalop.

d. The timing ar removal, dismantlement or in situ discommissioning to be chosen at any time in the next 10,50 , 100 , or 1003 J years ascording to the judgment of people living at that time. e.Jur money can bz spent on projects more effective for the promotion our health and welfare or even to reduce the budget deficit.

f. It is the least expensive since the removal expense is deferred for naרy years. The expectation that the removal of the reactors in 75 years is reasonable for cost estimating purposes.

2. Even though neither $00 \equiv$ nor SPA include it in their instructions for the preparation of the EIS, I recomnend tat additional cost estimates include the effect on annual budgets and an evaluation of present worth of deferred costs.

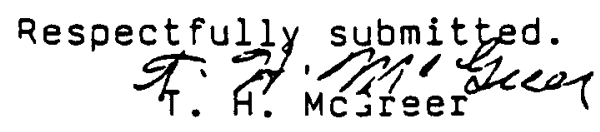


STATE OF WASHINGTON

\section{DEPARTMENT OF ECOLOGY}

Mal Slop PV-11

Olympia. Washington 98504-8711 •

(206) $459-6000$

July 27, 1989

Ms. Karen J. Wheeless, Director

United States Department of Energy

Office of Communications

Richland Operations Office

Richland, Washington 99352

Dear Ms. Wheeless:

Thank you for the opportunity to comment on the Draft Environmental Impact Statement on Decommissioning of Eight Surplus Production Reactors at the Hanford Site, Richland, Washington. The Department of Ecology is responsible for coordinating the state agencies' review of federal documents issued under the National Environmental Policy Act.

Consistent with this responsibility, we circulated information on the Draft Environmental Impact Statement to other state agencies, and received responses from the of fice of Archaeology and Historic Preservation. Their comments, along with Governor Gardner's July $\mathbf{2 0}$ hearing testimony and comments from Ecology are enclosed, and represent the comments and concerns of the state of Washington.

We strongly support the United States Department of Energy's effort to move ahead with this key element of Hanford cleanup and we look forward to working with you on this most important project.

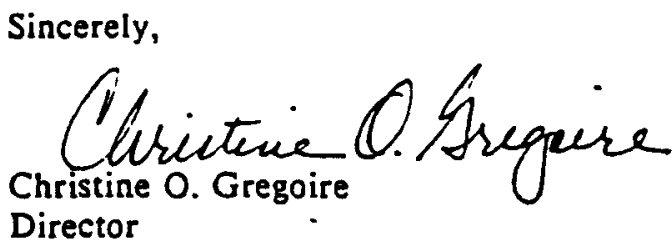

COG:dp/tgj

Enclosures

cc: Terry Husseman

Mike Palko 


\title{
STATE OF WASHINGTON, DEPARTMENT OF ECOLOGY, COMMENTS ON DRAFT ENVIRONMENTAL IMPACT STATEMENT, DECOMIMISSIONING OF EIGHT SURPLUS PRODUCTION REACTORS
}

\author{
AT THE HANFORD SITE, RICHLAND, WASHINGTON
}

July 27,1989

The following comments refer specifically to RCRA and state Dangerous Waste Regulations.

1. Section 6 discusses the various regulatory authorities which may need to be considered during D\&D activities. Section 6.4 is specific to RCRA and CERCLA requirements. In part, this section states that the EIS is not intended to resolve specific regulatory requirements. This is proper, however the EIS does need to discuss the impacts of these regulations on the proposed alternatives. Specifically, in situ decommissioning and safe storage alternatives may be severely impacted by RCRA regulations and the state Dangerous Waste Regulations (WAC 173-303). The final EIS should more clearly identify and evaluate the potential regulatory requirements for these alternatives.

2. The 1984 amendments to RCRA, commonly known as Hazardous and Solid Waste Amendments (HSWA), contain provisions which allow for corrective actions at permitted facilities. As the Hanford Site will be permitted under provisions of WAC 173-303, consideration must be given to the applicability of HSWA provisions. Specifically, the reactor sites in question may be considered Solid Waste Management Units (SWMUs) under HSWA and therefore would need to be addressed in the site permit. Although this regulatory question may not be resolved in the EIS, it should be discussed as it may severely affect any alternative.

3. Section 6.3 discusses the various regulations governing solid waste. The third bullet identifies WAC 173-303 as the state regulatory program for hazardous waste. This is correct, however, it should also point out that these regulations are considerably more stringent than the federal counterparts (RCRA). These differences may restrict alternatives. Of immediate interest is the state Toxicity Designation procedure (WAC 173-303-101) which may designate reactor cores as dangerous or extremely hazardous waste. Similarly, it should be pointed out that Ecology is pursuing authorization for implementing the HSWA provisions and this may occur prior to any activities being completed for this project, thereby subjecting these activities to state oversight.

4. The safe-storage alternatives apear to either totally lack the appropriate groundwater monitoring, or severely underestimate what would be required (see comments 1 and 2 above). This alternative should be reanalyzed to ensure that the appropriate groundwater monitoring programs are planned for and implemented over the possible 96 year safe-storage period. 
5. Appendix $\mathrm{J}$ discusses the National Historic Preservation Act requirements and invites comment on potential impact. Should the B Reactor be nominated and eventually listed on the National Register of Historic Places, the EIS would need to evaluate a combination of alternatives, such as removal of the remaining 7 reactors while decontaminating $B$ Reactor. These discussions should be included in the final EIS.

The following are specific comments on the remainder of the DEIS.

Page 1.7 - The text should clarify that irradiated lead (653 tonnes) is a mixed radioactive waste subject to regulation.

Page 1.22 - Thermal expansion and contraction plus past removal of metal channel liners resulted in powdered graphite. Would graphite powders (see page 5.4) support combustion?

Page 3.57 - Columbia River flow alteration could be caused by factors in addition to climatic changes. The final EIS should describe erosion and accretion processes which could change the river channel and lead to immersion of reactors.

Page 4.12 - It would be helpful to have figures showing the extent of a probable maximum flood and flooding resulting if $25 \%$ and $50 \%$ of Grand Coulee Dam were destroyed. An example is enclosed.

Page 4.17 - The text should include a comparison of recharge coming from artificial sources with recharge coming from natural sources and discuss how this pattern is expected to change over time.

Page 4.12 - A review of University of Washington seismic data and reactor siting data indicates that deep seismic data is associated with known and inferred geologic structures.

Page 4.23 - Current monitoring programs for leaking tanks are not refined enough to determine, with any degree of certainty, that leaks from waste storage tank have or have not resulted in radiation exposure to the public.

Page 4.25 - Have any of the well systems on the Hanford site used for drinking-water ever exceeded radiological drinking-water standards? If so, how did they come into compliance?

Page 6.4 The final EIS should explain how decisions could be influenced because RCRA applies to the hazardous component of radioactive mixed waste but not to the radioactive component of radioactive mixed waste.

Page A.16 - Because masonite and transite are no longer in today's lexicon, the text should give a brief description of each product.

Page A.28 - The final EIS should explain why certain facilities listed in Table A.12 do not contain cadmium but on page 3.4 it states cadmium is alloyed with lead. 


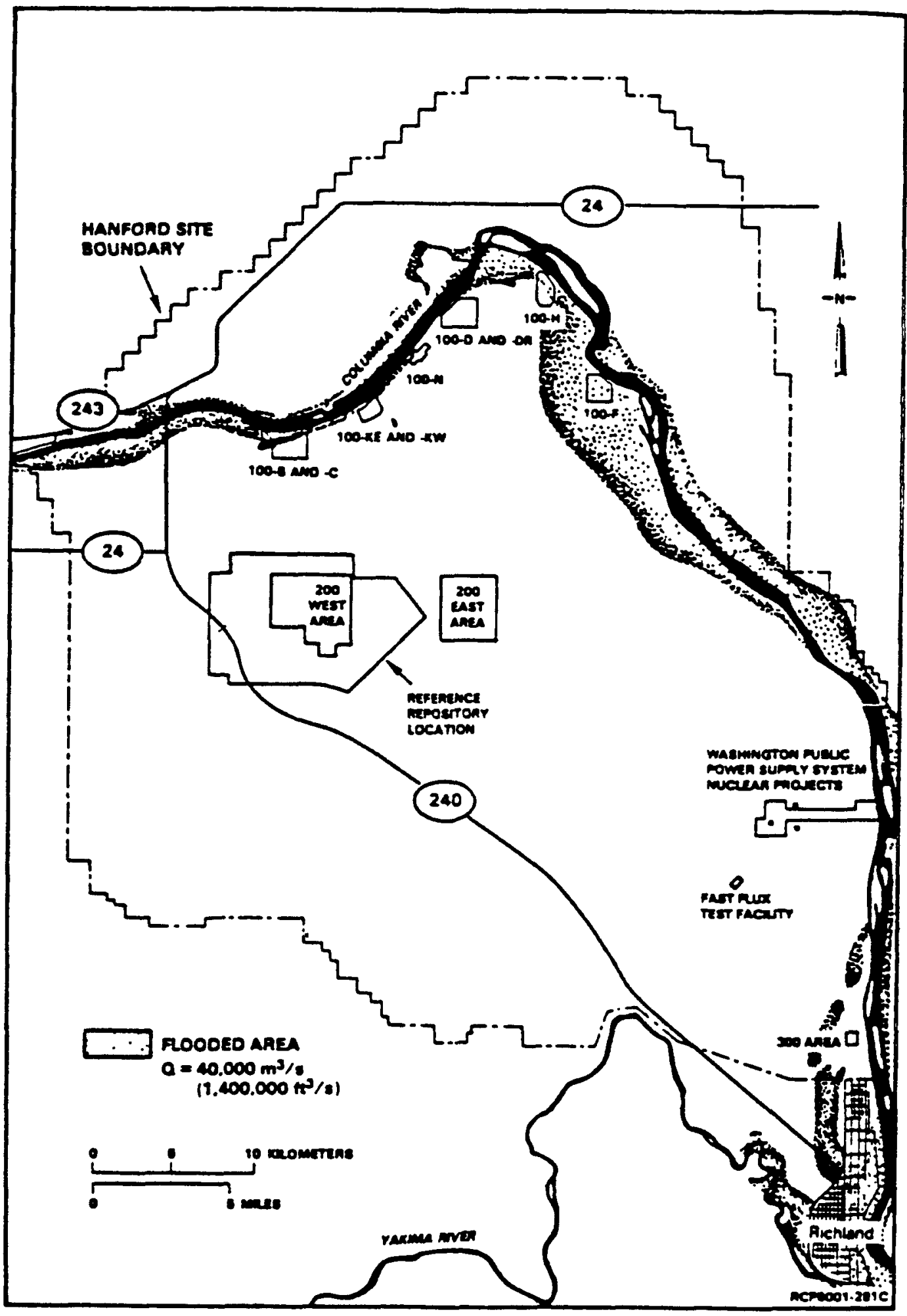

E1gure 3-27. Flooded area for the probable maximum flood (after ERDA, 1976). 


\section{TATE OP WASEIMGTON COYMEATS ON DRAFT EATIRONDCWMAI IYOPACT BTATEMENT, DECOMYI88IONING OF EIGHT 8URPLOS PRODUCTION REACTORS EANTORD BITE, RICHIAND, WASEIMGTON}

JULY 20,1989; BEATTLE, WASEINGTON

Thank you for the opportunity to comment on the draft envizonmental impact statement (DEIS) on Decommissioning of Eight Surplus production Reactors at the Hanford site in Richland. My name is Dan Silver. I am Governor Gardner's Special Assistant on Hanford.

My comments will focus on broad public policy issues involved with decommissioning of the reactors. Detailed comments will be submitted before the public review period ends on July 28 .

Governor Gardner and the citizens of Washington applaud the U.S. Department of Energy (USDOE) decision to move ahead with decomissioning of the surplus reactors, and we look forward to working with you on this most important project. 
The Governor regards decommissioning to be our responsibility. We should not pass this nuclear waste problem down to citizens three or four generations hence. Accordingly, he believes that decommissioning of the reactors must not be delayed for 75 more years.

His preference is that all eight of the reactors be buried in the plateau of the 200 West Area, well away from the Columbia River. This will provide the maximum protection to the public and to the environment from natural catastrophe or human error.

Although the DEIS briefly discusses the various regulatory authorities which may need to be considered during decommissioning activities, the document understates the impact of the Resource Conservation and Recovery Act (RCRA) and the Washington Administrative Code 173-303 on in situ decommissioning and safe storage. The final draft should more clearly describe the potential regulatory requirements for these alternatives. The final draft should also indicate that the decommissioning will be done in accordance with the terms of the Tri-party Agreement recently signed by the state and the federal government.

The B Reactor has an exceptionally strong association with the history of the U.S. atomic energy program and the development of the atomic bomb at the end of World War II. In view of its 
historic significance, the future interpretive value of the $B$ Reactor should be preserved, if it is technically, environmentally, and economically feasible. Varying degrees of interpretive value could be preserved by maintaining part of the facility in its present condition, construction of a 105-B representative at the site, displaying the control room at the Hanford Science Center or the Smithsonian Institute, or by providing extensive photographs and records at one of the these sites.

The final EIS should evaluate the environmental, cost, scientific heritage, and cultural heritage impacts of each option listed above. Evaluations should assess public accessibility and the ability to illustrate unique construction and operational achievements. Incremental costs associated with maintaining and monitoring the B Reactor in place while the other seven reactor blocks are moved to the 200 West Area should be included in the final EIS. Of course, the historic register decision must not compromise protection of public health, safety, and the environment.

The Washington State Shoreline Management Act (chapter 90.58 RCW) states that it is the policy of the state to provide for management of the shorelines of the state by planning for and fostering all reasonable and appropriate uses. Although the DEIS assumes a time period of 100 years for active institutional 


\section{L042}

control -- with an intention to maintain institutional control of the site in perpetuity -- there is no discussion about allowing reasonable and appropriate public use of the shoreline. Decomissioning of the reactors will remove a significant roadblock to opening major sections of the Hanford Reach shoreline to the public. If the reach is designated as a part of the National wild and Scenic Rivers System, that portion of the river will remain open for boating and fishing but not for shoreline uses. Protection of historic, archaeological, and cultural properties together with yet to be decommissioned sites would preclude opening of the entire Hanford Reach. However, the final EIS should articulate a federal policy of shoreline use during the period of institutional control. We recommend a phased approach which would allow the public reasonable and appropriate use of the shoreline.

In conclusion, Governor Gardner strongly supports USDOE's effort to move ahead on this key element of Hanford cleanup. 


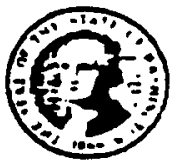

STATE OF WASHNCTON

\section{DEPARTMENT OF COMMUNITY DEVELOPMENT OFFICE OF ARCHAEOLOCY AND HISTORIC PRESERVATION}

111 H'est Twentyfirst Avenue. N2-17 - Ormpia, Washing:on 98504-5411 - 206) 753-4011 : SCAV 234-4111

$$
\text { Juge 14, } 1989
$$

Mr. Tom Bauman

D.S. Dept. of Energy

Richland Operations orfice

P.O. Bor 550

Rlctuand, WA 99352

Log Reference: 1275-E-DOE-09

Be: Decomisstoning of Elght

Surplus Production Reactors at the Eanford Site, Ricbland, Vashington

Dear Mr. Beuman:

We have reviewed the $0 . S$. Department of Eoergy draft Eoviroamental Impact Statement, Decommissioning of Eight Surplus Production Reactors at the Eanford Site, Bichland, Washington (DOE/EIS-0119D), March 1989 and would ilke to offer the following coments.

Ippendix J of the EIS, Nat1onal Eistoric Preservation Act Requirements, evaluates only two options with respect to the Banford 105-B Reactor, which has been determined eligible for the National Register of Bistoric Places. The options 1deatified are the no action alterative, which the EIS concludes 19 unacceptable for bealtb and human safety reasons, and the "recordat1on" altermative, which would 1nvolve the production of measured drawings and written documentation prior to dismantling.

In view of the extraordinary b1storic sigalflcance of the 105-B Reactor, we believe that it should be treated separately frow the remaining seven reactors in determining the options for its decomissioning. One additional option that sbould be carefully considered is the feasibility of removing only the nost bazardous portions of 105-B and retaining in situ as ach as possible of the reactor bullding, cootrol room, mechanical and electrical systems and any otber features that are not a lons term bealeb risk. Lltbougb tbis approach ay present technical problems, we believe that the future 10terpretive value of 100-B sbould be preserved in the decomassioning process if it is feasible and prudent. 


\section{L042}

Mr. Tom Baumao

June 14, 1989

Page 2

Is the world's first large scale product100 reactor, 105-B represents a watersbed in the historg of scleace and technology. Litbough access to the site $1 \mathrm{~s}$ now restricted, $105-\mathrm{B}$ 1s st111 one of the most compell1ag and thought provokiag histor1c landmarks in the On1ted States. Th1s 1ssue sbould be explored in greater detall in the EIS.

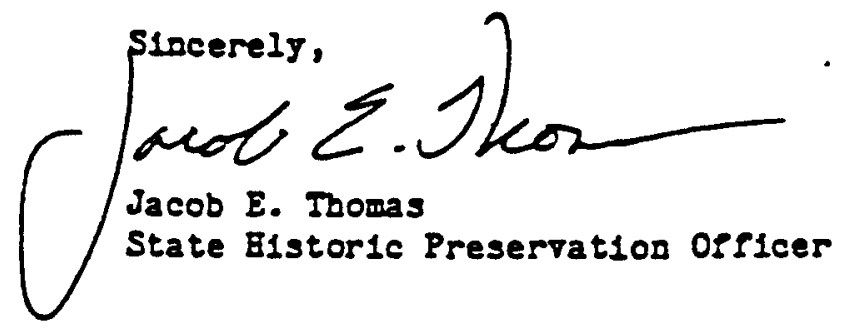

m 
' JUL 31989

L043

Karen V. Wheedles, Director.

Office ot Communications

Richtaul operation Others

U.S. Opportmant of Energy

July 28,1989

Richard, washing ton, 99352

Dear th wheelers

Z wish to male my comments port of the effieal record regarding the Draft Enivronmental Impact Statement concerning Decomissioning of Eight Surplus Production Reactors at the Hanford Site, Rich loud, Wuilingtor.

After reviewing the Draft EIS I believe the best alternative would be the Immediate One Piece Removal. I Rove been

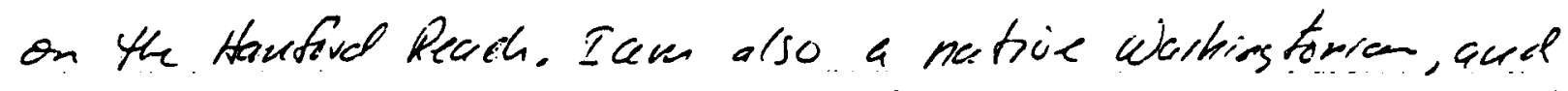
I desire to keep this beautiful place know as the tri-lities economically heathy and a great location to raise a family. This action of Immediate One-Piece Removal will provide a positive impart for the local economy while en hanging the scenic values of the Hanford Reach which is currently under study as a Wild and Sonic River.

the cost of this alternative appears to be nectevate in comparison of othovoptions, but inexpensive ow pr the by period. while protecting the environment and quality of the Columbia River.

Again, I encourage your acloptom of the Immediate EnePiece Removal Alternations.

Sincerely

RI COMMITISENT CONTROL

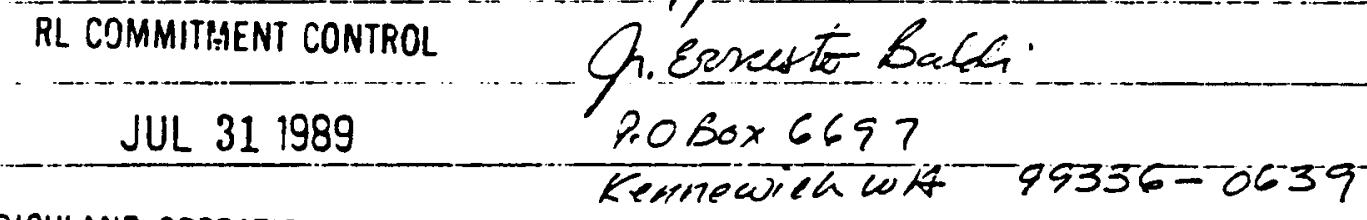

RICHLAND_OPERATIONS_OEFICE

0.79 


\section{Michael R. Cummings, M.D.}

Pathologist

805 South Auburn Street

P.O. Drawer 5898

Kennewick, Washington 99336

July 27,1989

Karen J. Wheeless, Director

Office of Communications, Richland Operations Office

U.S. Department of Energy

Richland, WA 99352

Dear Ms. Wheeless:

As a member of the Columbia River Conservation League I would like to herein comment on the Draft Environmental Impact Statement concerning decomissioning of eight surplus production reactors at the Hanford Site, Richland, Washington.

In an effort to create a more esthetically pleasing enviroment and yet one which is econcmically feasible when considered with the other proposed alternatives we recamend adoption of the Immediate One-Piece Renoval Alternative. This choice would enhance the scenic values of the Columiaia River's Hanford Reach which are currently under study by the National Park Service.

Too, this alternative would provide for a positive impact on our local econamy which has received setbacks with the recent cuts at the Hanford site.

The costs of this alternative at $\$ 190.8$ million is in the middle of the five alternatives. We feel that the Immediate One-Piece Removal appears to be a cost effective solution.

We encourage your adoption of this alternative as representing a safe, cost effective method for decamissioning the reactors while enhancing the esthetic attributes and wildlife resources of the Columbia River. Your attention will be most appreciated. Thank you.

sincerely,

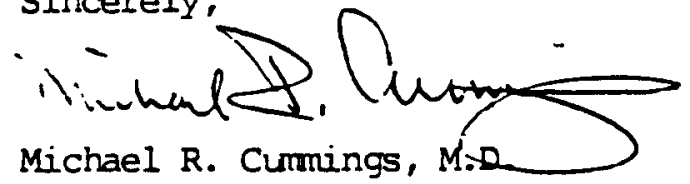

MRC/rre

RL COMMITAENT CONTROL 
July 28,1989

Mr. Tom Bauman

U.S. Department of Energy

Richland Operations of fice

Richland, Washington 99352

RE: YAKIMA INDIAN NATION COMMENTS ON THE DRAFT ENVIRONMENTAL IMPACT STATEMENT, DECOMMISSIONING OF EIGHT SURPLUS PRODUCTION REACTORS AT THE HANFORD SITE, RICHLAND, WA.

Dear Mr. Bauman:

Enclosed are the comments of the Yakima Indian Nation concerning the U.S. Department of Energy's (DOE) Draft Environmental Impact Statement (DEIS) on decommissioning eight surplus production reactors at the Hanford site.

As you will note, the Yakima Indian Nation supports DOE actions which minimize or eliminate future environmental damage at the Hanford Nuclear Reservation. Therefore, the Yakima Nation supports the Immediate OnePiece Removal alternative described in the DEIS, which would require removal of the reactor block assemblies to the 200 West Area, along with facilities and equipment contaminated with radioactivity. This alternative provides the maximum environmental, health, and safety protection of the alternatives decribed in the DEIS.

The Hanford Nuclear Reservation rests on land ceded to the U.S. Government in the Treaty of 1855; the Yakima Nation retains rights to this land and to the Columbia River fishery. The Yakima Indian Nation urges the DOE to take into full consideration the protection of the Columbia River fishery and developing the final EIS.

Sincerely,

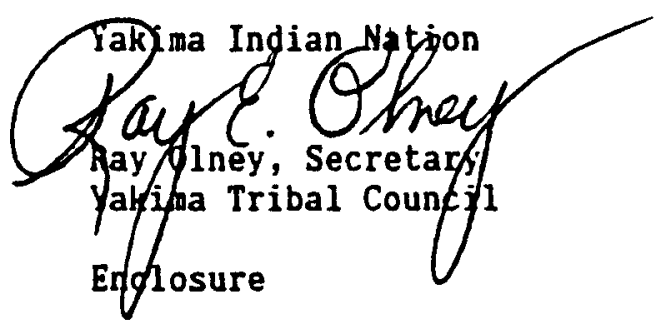

cc: Carroll Palmer, Deputy Director, Natural Resources Dept. Delano Saluskin, Environmental Protection Program Mgr. 


\title{
L045
}

\author{
YAKIMA INDIAN NATION \\ COMMENTS ON THE \\ DRAFT ENVIRONMENTAL IMPACT STATEMENT \\ DECOMMISSIONING OF EIGHT SURPLUS PRODUCTION REACTORS \\ AT THE HANFORD SITE, RICHLAND, WASHINGTON
}

JULY 28, 1989

\author{
Submitted to: \\ Mr. Tom Bauman \\ U.S. Department of Energy \\ P.O. Box 550 \\ Richland, Washington 99352 \\ Submitted by: \\ Yakima Indian Nation \\ P.O. Box 151 \\ Toppenish, Washington 98948
}


TABLE OF CONTENTS

I. SUMMARY OF COMMENTS . . . . . . . . . . . . . . . . . . 1

A. PROPOSED ALTERNATIVE . . . . . . . . . . . . . . . 1

B. GENERAL AND SPECIFIC COMMENTS . . . . . . . . . . . 1

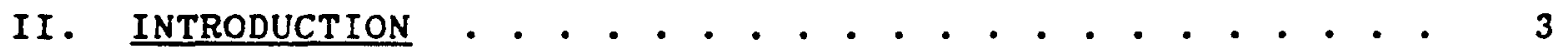

A. TREATY OF 1855 . . . . . . . . . . . . . . . . 3

B. MANHATTAN PROJECT . . . . . . . . . . . . . . . 3

C. YAKIMA INDIAN NATION TRADITIONAL USE $\quad . \quad \cdot \quad . \quad . \quad . \quad . \quad 4$ AT HANFORD AND RESERVED RIGHTS

III. GENERAL COMMENTS ON DRAFT ENVIRONMENTAL IMPACT • • • • 6 STATEMENT
A. PROPOSEd Alternative . . . . . . . . . . . . . 6
B. NATIONAL ENVIRONMENTAL POLICY ACT (NEPA) • . . . . 7
C. FEDERAL POLICY AND STATUTORY REQUIREMENTS . • . . 8
D. NATIONAL HISTORIC PRESERVATION ACT (NHPA) • • . . 9

IV. SPECIFIC COMMENTS ON DRAFT ENVIRONMENTAL IMPACT . . . $\quad 10$ STATEMENT 


\section{SUMMARY OF COMMENTS}

\section{A. PROPOSED ALTERNATIVE}

The Yakima Indian Nation supports the Immediate One-Piece Removal alternative considered in the DEIS. This alternative provides the greatest protection to the health and safety of people in the area, and minimizes potential impacts to the Columbia River. However, the Yakima Nation requests that the Department of Energy consult with the Tribe during planning, site-characterization, cultural resource and archaeological site survey work, and implementation of the selected alternative to ensure the protection of numerous Indian cultural resource sites in the area. Such consultation must include on-site inspection by the Yakima Indian Nation.

The Yakima Nation continues to rely on the fishery of the Columbia River system, and measures which lead to the long-term environmental protection of the fishery are in concurrence with Tribal goals. Though the surplus reactors appear to pose little immediate danger to the river relative to other inactive waste sites, the immediate removal of the reactor blocks to the 200 West Area, along with facilities and equipment contaminated with radioactivity, would provide maximum protection for the environment.

The Immediate One-Piece Removal alternative presented in the Draft EIS best supports the trust responsibility of the Federal government to the Yakima Indian Nation, by minimizing further damage to the natural resources in this area of the ceded land.

\section{B. GENERAL AND SPECIFIC COMMENTS}

The Draft EIS is lacking in terms of describing the Treaty between the Yakima Indian and the U.S. government. Though mention is made of ceded land areas, no description is made of the legal status of this land. No mention is made of the Department of Energy's trust responsibility to Indian tribes, as described in Federal law and policy.

Description of cultural resource management of the Hanford site in the Draft EIS, consigtent with the National Historic Preservation Act and the American Indian Religious Freedom Act, is lacking. The Draft EIS makes mention of the fact that the 100 Areas have not been surveyed for cultural resources, but does not describe how the Yakima Indian Nation will be consulted during such surveys. 


\section{L045}

The Hanford Reach of the Columbia River is exceptionally significant to the Yakima Nation, in terms of the fishery, cultural and natural resource sites, and religious areas. The Department of Energy must fully consider the impacts of its proposed actions on these resources when developing the Final EIS. 


\section{INTRODUCTION}

\section{A. TREATY OF 1855}

Under Article III of the Treaty of 1855 , signed by the Yakima Indian Nation and the United States government, the following provisions were agreed to and now form part of the supreme law of the land:

"The exclusive right of taking fish in all streams, where running through or bordering said reservation, is further secured to said confederated tribes and bands of Indians, as also the right of taking fish at all usual and accustomed places, in common with citizens of the Territory, and of erecting temporary buildings for curing them; together with the privilege of hunting, gathering roots and berries, and pasturing their horses and cattle upon open and unclaimed land." (12 Stat. 951, June 9, 1855).

The ceded land referred to in the Treaty is of utmost importance to the Yakima Indian Nation. This is the land which constituted the domain of the Yakima Native people since time immemorial. The Yakima Nation is still reliant on the natural resources of the ceded land area. Of particular relevance to the decommissioning of the Hanford reactors is the protection of the fishery of the Columbia River system, other natural resources dependent upon an uncontaminated environment, and the cultural resources in the area which are an integral part of present day Yakima life.

\section{B. MANHATTAN PROJECT}

At the inception of the Manhattan Project in 1943 , the Yakima Indian Nation continued to exercise its Treaty rights in the Hanford area, as enumerated in the above passage. Further, those rights not specifically enumerated in the Treaty were, and are, held to be reserved by the Yakima Indian Nation.

The Manhattan Project of the U.S. Army Corps of Engineers arose from a national security emergency, in what was determined at the time to be a race between warring powers to develop an atomic weapon. The first three of the eight reactors described in the Draft Environmental Impact statement (105-B, 105-D, and 105-F) were constructed under the urgency of wartime by the Manhattan Project, beginning in early 1943. 
The 105-B reactor first began producing weapons grade plutonium 15 months from the time of initial construction. The second atomic weapon dropped on Nagasaki, Japan was built with plutonium produced at the 105-B reactor. Although there cannot be an absolute determination, it is widely believed that use of atomic weapons in the war against Japan helped to shorten the war relative to the probability of an extended conventional war.

In this context, it is important to note that the Yakima Indian Nation has contributed to every war effort and conflict engaged in by the United States since the signing of the Treaty. The Yakima Indian Nation considered the condemnation of the Hanford land by the U.S. government to be a temporary measure to further the war effort. Although private landholders at Hanford were compensated when the Hanford site was secured by the U.S. government, it is unclear whether any formal communication occurred between the U.S. government and the Yakima Indian Nation regarding reserved Treaty rights in the area.

\section{YAKIMA INDIAN NATION TRADITIONAL USE AT HANFORD AND RESERVED RIGHTS}

The Hanford land holds special significance for the Yakima Indian Nation as part of its ceded area. This land was the traditional wintering area for the Yakima people. For thousands of years, the Yakima people made Hanford their winter home when snow began descending into the valleys from the crest of the Cascades. The low elevation and resulting mild winter temperatures, abundance of wildlife, and the confluence of three major rivers were factors which made the Hanford region a site of rich natural resources. Over thousands of years of habitation the Hanford area assumed great cultural, religious, and traditional significance for the Indian people. This significance remains today, and is the basis for concerns regarding further alteration of the land along the Columbia River.

Nuclear material production activities at Hanford, commencing in 1943 have profoundly altered the land. Construction activities have altered physical features, and nuclear and chemical production operations have contaminated land, air, and water with radioactive and chemical waste. It is now estimated that over $\$ 50$ billion will be required to contain, isolate, and dispose of such waste at Hanford. Some waste isolated and immobilized at the Hanford site will remain hazardous for thousands of years. From the Yakima Nation's perspective, however, a thousand years is not such a long time, and represents only another page in history. 
The Yakima Nation supports the goals of restoring the Hanford land. The future health and safety of the people living near Hanford depends on conscientious and responsible remediation of inactive waste sites, as well as revision of current waste management activities to minimize or eliminate discharges to the environment. Characterization and remediation of inactive waste sites at Hanford poses an unprecedented challenge, and many economic, social, and technical tradeoffs must be weighed during the lengthy cleanup process.

The Yakima Indian Nation, as a sovereign government, will continue to exercise its rights and responsibilities at Hanford. of great concern to the Yakima Nation, as regards the reactor decommissioning process, is the attention given to protection of cultural resources, traditional use areas, and religious sites. The Draft Environmental Impact statement makes note of the potential listing of the $B$ Reactor in the National Register of Historic Places (36 CFR 60$)$. There is no doubt that the $B$ Reactor is a significant historical site, but consideration of its protection should be weighed in the context of preservation of a record of thousands of years of human habitation and development in the same area.

Placing the Hanford reactor decommissioning in a historical context helps to explain the Yakima Indian Nation perspective regarding future actions in this area. The reactors were built specifically to further the war effort in the early 1940's, a time when many Yakima people lived by hunting, fishing, and gathering traditional foods and medicines in the Hanford area. When the decision was made to drop atomic weapons on Japan, Hanford's initial mission in support of national security was realized. The end of World War II, however, did not result in the re-opening of this land for the Yakima people.

In 1943, the Yakima people lost a great traditional and natural resource for the cause of national defense; during this era the Yakima Nation also contributed soldiers to the war effort. The Yakima Nation has not been compensated for the land, cultural sites, and fishery which it lost during World War II. As the environmental restoration of the land along the Columbia River goes forward, the Federal government should consider means of returning access and use of this area to the Yakima Indian Nation, which maintains property rights at Hanford. 
III. GENERAL COMMENTS ON DRAFT ENVIRONMENTAL IMPACT STATEMENT

\section{A. PROPOSED ALTERNATIVE}

The Yakima Indian Nation supports the Immediate One-Piece Removal alternative considered in the DEIS. This alternative provides the greatest protection to the health and safety of people in the area, and minimizes potential impacts to the Columbia River. However, the Yakima Nation requests that the Department of Energy consult with the Tribe during planning, site-characterization, cultural resource and archaeological site survey work, and implementation of the selected alternative to ensure the protection of numerous Indian cultural resource sites in the area. Such consultation should include on-site inspection by the Yakima Indian Nation.

The No Action alternative, as described in the DEIS, would result in deterioration of the reactor buildings, potential release of radionuclides to the environment, potential human exposure to radioactivity by intrusion, and potential safety hazards to intruders. The No Action alternative is unacceptable.

The Safe Storage Followed by Deferred One-Piece Removal alternative is inadequate because it would cost more than the Immediate One-Piece Removal alternative, and provide only limited reduction in occupational radiation doses. In addition, this alternative increases the risk of contamination to the environment during the storage interval.

The Safe Storage Followed by Deferred Dismantlement alternative is inadequate because it also entails a greater cost, results in greater occupational radiation doses, and increases the potential for release of radionuclides to the environment over the Immediate One-Piece Removal alternative.

The In Situ Decommissioning alternative is grossly inadequate. This scenario would save only a marginal amount in terms of overall cost when compared to the other plausible alternatives (about five percent less than the Immediate OnePiece Removal alternative). Though decommissioning on-site would result in the lowest occupational radiation doses of the plausible alternatives considered, it would yield the greatest impacts to the environment and to cultural resource sites significant to the Yakima Nation. In addition, this alternative would yield the greatest radiation population dose over 10,000 years. 
The Yakima Indian Nation supports the objectives cited in Section 2.0, "Purpose of and Need for Action":

"The purpose of decommissioning is to isolate securely any remaining radioactive or hazardous wastes in a manner that will reduce environmental impacts to an acceptable level, especially potential health and safety impacts on the public."

The Yakima Nation continues to rely on the fishery of the Columbia River system, and measures which lead to the long-term environmental protection of the fishery are in concurrence with Tribal goals. Though the surplus reactors appear to pose little immediate danger to the river relative to other inactive waste sites, the immediate removal of the reactor blocks to the 200 West Area, along with facilities and equipment contaminated with radioactivity, would provide maximum protection for the envi ronment.

The Immediate One-Piece Removal alternative presented in the Draft EIS best supports the trust responsibility of the Federal government to the Yakima Indian Nation, by minimizing further damage to the natural resources in this area of the ceded land.

\section{B. NATIONAL ENVIRONMENTAL POLICY ACT (NEPA)}

The Draft Environmental Impact Statement on Decommissioning of Eight Surplus Production Reactors at the Hanford Site, Richland, Washington was prepared under the authority of the National Environmental Policy Act (NEPA) of 1969 (Public Law 91190). Section 4331 of the Act states, in part, that:

"In order to carry out the policy set forth in this chapter, it is the continuing responsibility of the Federal

Government to use all practicable means, consistent with other essential considerations of national policy, to improve and coordinate Federal plans, functions, programs, and resources to the end that the Nation may --

(1) $\ldots$

(4) preserve important historic, cultural, and natural aspects of our national heritage, and maintain, wherever possible, an environment which supports diversity and variety of individual choice ..." 
Because the Hanford Nuclear Reservation has been closed to public access since 1943, many of the cultural resources directly associated with Yakima presence are still intact at Hanford. In other regions of the ceded land, pothunters and amateur archaeologists have irretrievably damaged such resources. The NEPA clause cited above is a clear indication of Congressional intent to preserve cultural aspects of the national heritage. Enough archaeological research has been completed at Hanford to demonstrate the richness and diversity of cultural resources left by Indian people. The Department of Energy should place greater emphasis on preserving these cultural resources in the development of the Final EIS.

\section{FEDERAL POLICY AND STATUTORY REQUIREMENTS}

The DEIS states that decommissioning will be carried out in accordance with DOE's environmental policy. It continues:

"Environmental regulations and standards of potential relevance to decommissioning are those promulgated by the EPA under the Atomic Energy Act (AEA), the Clean Air Act (CAA), Clean Water Act (CWA), Safe Drinking Water Act (SDWA), Resource Conservation and Recovery Act (RCRA), and the Comprehensive Environmental Response, Compensation, and Liability Act (CERCLA). State environmental regulations have also been promulgated under the authority of some of these federal statutes. Regulations of the U.S. Nuclear Regulatory Commission do not apply to the decommissioning of the surplus production reactors."

Current United States administrative policy is to recognize Treaty rights, and to interact with tribes on a government-togovernment basis. In addition, the Environmental Protection Agency (EPA) has a policy of treating federally recognized tribes as it does states. Further, many of the major federal environmental laws, including the Clean Water Act, Safe Drinking Water Act, and CERCLA have been amended by Congress to specifically recognize the authority of Indian tribes to regulate the environment on tribal lands. This authority may extend offreservation to ceded lands. The DOE should recognize in the Final EIS that Treaty rights and tribal jurisdiction are included in the statutory and regulatory requirements which apply to decommisgioning the surplus production reactors.

In addition, regulations which will affect decommissioning alternatives but not listed above are those derived from the National Historic Preservation Act, the Archaeological Resources Protection Act, and the American Indian Religious Freedom Act. These laws should be included in section 1.6 , STATUTORY AND REGULATORY REQUIREMENTS. Please refer to section 6.5. 


\section{NATIONAL HISTORIC PRESERVATION ACT (NHPA)}

The DEIS refers to the eligibility of the 105-B reactor for inclusion in the National Register of Historic Places. Section 106 of the National Historic Preservation Act (NHPA) requires Federal agencies to take into account the effects of their actions on historic propertieg and to afford the Advisory Council on Historic Preservation a reasonable opportunity to comment on such undertakings. The Advisory Council has issued regulations ( 36 CFR Part 800) on how agencies are to comply with the NHPA; when the regulations were revised in 1986 , special attention was given to ensuring that Indian tribes and other Native American groups were provided full opportunity to participate in the review of Federal undertakings under Section 106.

These regulations encourage Federal agencies to "be sensitive to the special concerng of Indian tribes in historic preservation issues, which often extend beyond Indian lands to other historic properties." This language refers to the historical fact of complete and total Indian ownership of lands prior to migration of Indo-European settlers to North America.

In addition, the regulations require a Federal agency which is identifying historic properties impacted by its actions to "seek information in accordance with agency planning processes from... Indian tribes... likely to have knowledge of or concerns with historic properties in the area" ( 36 CFR Sec. $880.4(a)(1)(i i i))$. Further, when an undertaking reviewed under the regulations will affect Indian lands, the regulations require that the Federal agency responsible for the undertaking "invite the governing body of the responsible tribe to be a consulting party and to concur in any agreement" (36 CFR Sec. $800.1(\mathrm{c})(2)(\mathrm{i} i \mathrm{i}))$. 


\section{SPECIFIC COMMENTS ON DRAFT ENVIRONMENTAL IMPACT STATEMENT}

\section{COMMENT 1, Section 1.3, Page 1.7}

The Final Environmental Impact Statement (Final EIS) should explain how designation of the 100 Areas on the CERCLA National Priorities List (NPL) would affect timetables for action on decommissioning. Also, in May of 1989, the U.S. Department of Energy (DOE), Washington State Department of Ecology (WaDOE), and U.S. Environmental Protection Agency (EPA) signed a Federal Facilities Agreement and Consent Order regarding waste management and environmental restoration activities at Hanford. The Final EIS should explain how this agreement will affect consideration of Draft EIS alternatives as well as implementation of the chosen alternative.

COMMENT 2, Section 1.4.6, Page 1.21

The Draft EIS states that:

"Preoperational surveys at proposed borrow-pit sites and around the reactors will be conducted in advance of any decommissioning operations to ensure that no cultural resource or archaeological site is inadvertently impacted or disturbed."

The Nuclear Waste Policy Act (NWPA) of 1982 mandated affected Indian tribe participation in DOE's high-level nuclear waste repository program, as a recognition of potential impacts on reserved Treaty rights on the ceded land. During the period from 1983 to 1988, the Yakima Indian Nation was extensively involved in review of technical, socioeconomic, and cultural resource data generated by DOE. The data and information generated by DOE on Indian cultural resources at Hanford was consistently identified by the Yakima Indian Nation as lacking on technical and academic merits. The National Historic Preservation office has also seriously criticized DOE cultural resource management planning.

The Yakima Indian Nation recommends that DOE develop a policy for ensuring Tribal participation during cultural resource survey work. 
COMMENT 3, Section 1.4 .6 , Page 1.21

The statement in the Draft EIS,

"The Hanford Site is located on lands ceded to the U.S. government by the Yakima and Umatilla Indians and is near lands ceded by the Nez Perce Indians",

should be made under Section 1.6 , STATUTORY AND REGULATORY REQUIREMENTS. Ceded land rights have little relevance to socioeconomic considerations, but are in the domain of legal powers exercised by governments.

COMMENT 4, Section 1.5.12, Page 1.25

The Draft EIS states that:

"Sites used for the acquisition of dirt and gravel will be surveyed for archaeological resources and endangered species, and will be rehabilitated when no more material need be acquired from the site".

Please refer to COMMENT 2 .

COMMENT 5, Section 4.6.3, Page 4.38

The Draft EIS gtates that:

"Three National Register Archaeological Districts, one listed site, and numerous as-yet unevaluated sites are located near the 100 Areas. A detailed description of some of these sites can be found in Rice 1985 and ERDA 1975. The 100 Areas themselves have not get been surveyed for cultural resources."

The Yakima Nation was contacted by DOE in December, 1987 regarding possible remedial action near the $116-K-2$ Trench, an area adjacent to the 105-KE reactor and typical of the land around the other reactors. The issue of concern was potential impacts to Indian burial gites at the site of remedial action. Referring to the archaeological literature, including Rice, DOE produced maps which clearly indicated a lack of adequate information concerning location of the burial sites. Following consultation and on-site inspection by the Yakima Nation the remedial action was approved.

The Yakima Nation recommends that similar consultation by the Department of Energy, including on-site inspection, occurs during cultural resource surveys at the surplus production reactors. 
COMMENT 6 , Section 4.6 .5 , Page 4.39

The section in the Draft EIS entitled "Indian Tribes" is completely inadequate, and contains more misinformation than factual material.

The first sentence of the section reads:

"The Hanford Site is located on lands ceded to the U.S. government by the Yakima and Umatilla Indians, who now live on reservations near the Hanford Site (DOE 1987)."

Perhaps one-third of enrolled Yakima Indian Nation members live off the Yakima Reservation. Stating that the Yakima and Umatilla Indians now live on reservations is comparable to stating that Department of Energy employees live in Richland.

The Draft EIS further states:

"As part of their treaty agreements, the Yakima and Umatilla Indians were generally assured of the right to fish at all their usual and accustomed places."

This sentence is an inadequate paraphrase of the actual Treaty language. Refer to the comment INTRODUCTION, PART A., Treaty of 1855 .

Finally, the Draft EIS states:

"Consultation with Indian religious leaders may be necessary if the potential exists for abridgement of religious freedom."

This sentence should be changed to read, "Consultation with Indian religious leaders is required by law if the potential exists for abridgement of religious freedom, as set forth in the American Indian Religious Freedom Act of 1978 (P.L. 95-341)."

The entire Section 4.6.5 entitled "Indian Tribes" should be placed under section 6.0, "STATUTORY AND REGULATORY

REQUIREMENTS". Indian Tribes are sovereign governments whose rights have consigtently been upheld in the highest courts, whose powers are derived from a treaty between governments. Consideration of Indian tribes under a section entitled "SOCIOECONOMICS OF THE AREA SURROUNDING THE SITE" denotes a fundamental misconception of tribal legal standing by the Department of Energy. 
Trail and District Environmental Network

c/o Local 480, USWA

910 Portland Avenue

Trail, B.C.

July 27,1989

Mr. Tom Bauman

US DOE

P.O. Box 550

Richland, WA 99352

U.S.A.

Dear Mr. Bowman:

The Trail \& District Environmental Network is a recently formed group who have come together over a common concern for the environment. It has come to our attention that the DOE is asking for public response to the document titled "Decommissioning of the Eight Surplus Production Reactors at the Hanford Site", which is a draft EIS.

We have had an opportunity to review this DEIS and would therefore respectfully wish to make comment as a group whose concern and focus is the environment.

of the options listed the immediate one piece removal to the $200 \mathrm{~W}$. area would seem to us most likely to achieve the goal of least impact.

Removal to the $200 \mathrm{~W}$. area for final disposal seems obvious to us as the risk of flood waters reaching the higher elevations are less likely. A disaster of this kind would have a much greater impact if the entombment areas were reached by the water.

It would also seem obvious that whatever action is taken should begin right away; deferment to some future date and administration, in an unknown economic climate, is risky at best. It is also another example of mortgaging the future.

Also, corsolidation of the wastes in one place has mure appeal than spreading it over a wider area. There is already low level waste disposal in the $200 \mathrm{~W}$.; cleaning up the 100 area would allow for its release for public use.

We would like to thank you for this opportunity to express our views and we wish you a speedy and safe completion of the decontamination process.

Sincerely,

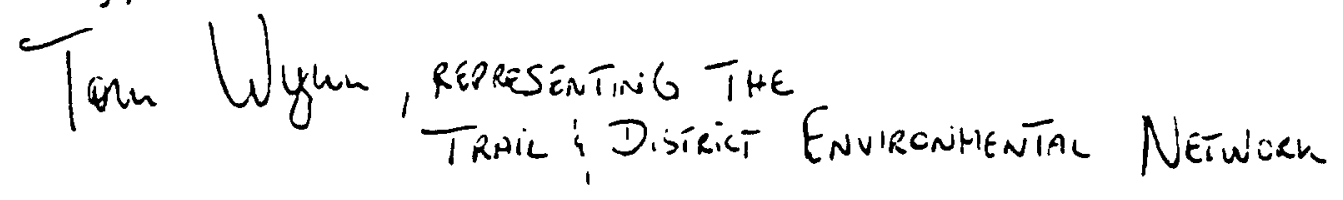




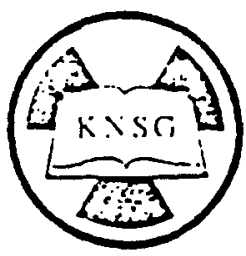

\section{Kootenay Nuclear Study Group}

July 27,1989

Tom Bauman

US DOE/PO BOX 550

Richland, WA 99352

Dear Mr. Bauman,

The KNSG agrees with the decision of the DOE to decommission the 8 mothballed reactors referred to in the DEIS. We have long realized that whatever one's belief about "things nuclear", final disposition of waste generated by the operation of nuclear facilities must be dealt with. We regard this as a step in that direction.

There are problems associated with the disposal of these reactors regardless of the method chosen. These methods are unproven, so whatever is done will be an experiment. Unforseen remedial action may be necessary at some time in the future, the health and economic costs of which are not and in fact can not be dealt with now. Also, it seems that some health and economic costs that do not appear in the DEIS have already been incurred by these mothballed reactors. We would urge that all these costs be added to the estimates contained in the DEIS to give a truer picture of the total cost of producing plutonum for bombs from the mine site to the disposal site. This will give the public better information on which to base their choices in these matters.

Having considered the options discussed in the DEIS, the KNSG has with some reluctance picked option 2 as the best of a lessthan satisfactory lot. The sad history of Hanford with the lack of experience in the area of proper disposal and lack of government funding to carry on with the chosen option are reasons why we consider the options less than satisfactory; however; given that retroactive action is not possible, we cannot offer: better alternatives. We may only hope that future projects will be influenced by what must now be done.

Immediate one piece removal to the 200 West Area is preferred for the following reasons: 
1. The higher elevation and increased distance of the 200 Area makes it better situated for the safe disposal of these wastes than is the 100 Area.

2. We feel the wastes will be safer especially in the future, if consolidated in one spot. It makes the affected area easier to look after.

3. By removing the reactors to the 200 Area and cleaning up the vacated sites in the 100 Area, this land could be released for public use.

4. We believe it to be of prime importance that any delays to implementation be avoided, hence our rejection of the deferred options. It is unlikely that any deference would be acceptable to those who have been pushing for clean up at Hanford for so long. This would be seen as a delaying tactic, and the public must believe that Hanford will be cleaned up. Immediate action also avolds the possibility of an accident involving one or more of the reactors during the $75 y$ tsafe storage period.

For the purpose of worker safety, we feel that the reactors should be removed in the order of least "radiologal inventory" first, to the greatest last (based on the decay of cobalt 60).

The KUSG thanks you for soliciting and considering our comments on this matter.

Sincerely,

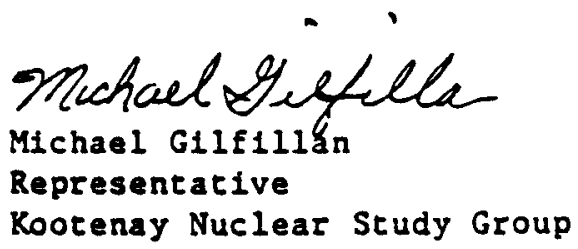

MG : db 


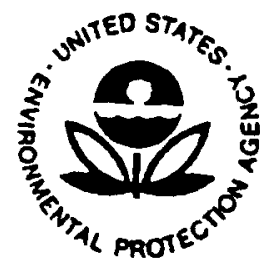

RTPLY 10 ATI 0 :
REGION 10 1200 SIXTH AVENUE

SEATTLE, WASHINGTON 98101

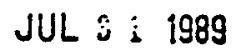

AUG 2

L049

Karen Wheeless, Director

Office of Communications

Richland Operations Office

U.S. Department of Energy

Richland, Washington 99352

Dear Ms. Wheeless:

In accordance with our responsibilities under the National Environmental Policy Act and Section 309 of the Clean Air Act, we have reviewed the Draft Environmental Impact Statement (draft EIS) for the Decommissioning of Eight Surplus Production Reactors at the Hanford Site, Richland, Washington.

Eight of the nine water-cooled, graphite-moderated plutonium production reactors constructed between 1943 and 1963 at the Hanford Site have been declared surplus and are available for decommissioning. Five decommissioning alternatives are examined in the draft EIS. A preferred alternative is not identified.

Based on our review we have rated the draft EIS LO (Lack of Objections). Our review has not identified any potential environmental impacts that would require any significant changes to the analysis. The enclosed specific comments need to be addressed for clarification.

In particular, regulatory discussions relating to the Comprehensive Environmental Response, Compensation, and Liability Act and Resource Conservation and Recovery Act need to be revised. The final EIS needs to be consistent with and reference the Hanford Federal Facility Agreement and Consent Order signed on May 15, 1989. This Agreement is significant as it is designed to ensure that the environmental impacts associated with past and present activities (including decommissioning) are thoroughly investigated and. appropriate response action taken as necessary to protect the public health, welf are and the environment.

Thank you for the opportunity to review this draft EIS. Please contact Wayne Elson at (FTS) 399-1463 for any questions concerning our comments.

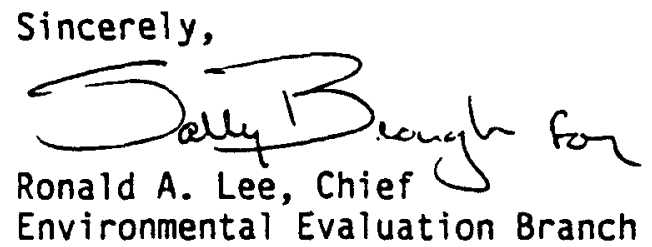

Enclosure

CC: Carol Borgstrom, U.S. Department of Energy

Roger Stanley, Washington Department of Ecology 
U.S. Environmental Protection Agency Specific Comments on the

Draft Environmental Impact Statement for the

Decommissioning of Eight Surplus Production

Reactors at the Hanford Site, Richland, Washington

Page 1.1--We agree with the goal to decommission these reactors safely.

Pages $1.7,6.5$, and 6.6 - The regulatory requirement discussions are inaccurate and need to reflect the Hanford Federal Facility Agreement and Consent Order signed by the U.S. Environmental Protection Agency, Washington Department of Ecology, and the U.S. Department of Energy. Section 3.1 of the Action Plan for this Agreement specifically addresses decontamination and decommissioning activities.

Page 1.17--References need to be cited for all the information under the "Geology of the Site" and "Hydrology of the Site" headings.

Page 5.3. First paragraph under "Routine and Accidental Releases"-"Routine release" needs to be defined. Does this include infiltration and migration of contaminants to ground water? If so, will there be a routine release of radionuclides to the ground water as a result of natural recharge? That needs to be stated here, even though it is discussed later in the report.

Page 5.18--What are the "analyses" referred to in the first paragraph? Likewise for the "analysis" referred to in the second paragraph.

Third paragraph: Need to discuss the difference between

"infiltration rate" and "recharge rate." These are defined later

in the report but really need to be defined here, where they are

first discussed.

Also in the third paragraph: The last sentence is incorrect. The statement implies that recharge from precipitation on the

Reservation is the sole source of water for the ground-water system under the Hanford Reservation. The ground-water system under the Hanford Reservation is not an isolated, closed system which is surrounded by ground-water divides as is alluded to. Water enters the area from outside the boundaries of the reservation and flows to the Columbia River. The ground-water model is constructed to simulate such flux, and thus, general statements made in other parts of the document should reflect this concept.

Page 5.23--Estimates of human health effects of radionuclides in the Columbia River are very small. Would these same estimates apply to fish and aquatic life and those who consume them?

Page 6.5. last paragraph--It is unclear why the in situ decommissioning alternative would not need to include "conceptual designs for disposal site barriers." This needs to be clarified. per year...".

Page $c .1$. second paragraph--"...years per meter..." should be "...meters
ar...". 


\begin{abstract}
Also in the same paragraph, the discussion on ground-water movement under the Reservation needs to be expanded to include a discussion on vertical movement of water upward into the Columbia River.
\end{abstract}

Page C.7, third paragraph--Additional explanations of the water levels used for calibrating the model are needed here. What "computer routine"? This is a steady-state model, so specifically, what water levels were calibrated to?... Pre-liquid waste disposal, time-averaged, present day? If they were time-averaged, what are the time boundaries? This all makes a difference when they say that the water levels were dropped to pre-1945 levels.

Page C.9. map--This map needs to include the Hanford Reservation boundaries and have the burial sites labeled. The study area boundary needs to be delineated because, as depicted, it looks as if the "Basalt Above Water Table" follows straight lines. We assume that this map is illustrating water level contours of the unconfined aquifer. This needs to be stated in the map description.

Page G.5--Ground-water effects should be clarified considering other water recharge rate estimates. See the U.S. Geological Survey report on the Columbia Basin Recharge Model: Estimates of Ground-water Recharge to the Columbia Plateau Regional Aquifer System, for Pre-development and Current Land Use Conditions. Washington, Oregon, and Idahe, Bauer, H. H., Vaccaro, J. J., Water Resources Investigation Report 88-4108.

Page H,4-H,5. GROUND-WATER MONITORING--There needs to be a more complete description of the monitoring network, including the vertical location of the base of the piezometers. We suggest installing several piezometers at various depths at each monitoring well site. At least 6 of the 12 monitoring sites at the 100 Area should consist of these multiple piezometers. A monitoring schedule (i.e., how many times a year) should be included in the final EIS. Will a Quality Assurance/Quality Control plan be developed for the sampling and lab analyses procedures? We suggest that one be developed.

Page H.5. first paragraph--The following sentence needs clarification: "The 100- and 200-Area wells have different locations because the ground-water hydrology gradients are better known in the 200 Area than in the 100 Area, due to the influence of the Columbia River on the 100-Area hydrology." The 100and 200-Area are at different locations spatially, so the wells are of course in different locations. This needs clarification or a different way of explaining what is meant. 
Mr. Rex Buck Jr.

Wanapum Tribe

P.O. Box 275

Beverly, WA 99321-0275

July 31,1989

Mr. Tom Bauman

U.S. Dept. of Energy

P.O. B.ox 550

Richland, WA 99352

Dear Mr. Baunan:

I am sorry for the delay in replying to the Environmental

Impact statement. I hope that you can accept my apology.

On behalf of the Wanapum Band of Indians, the feeling is whatever method is chosen for the decomissioning of the reactors from hanford by the majority of the people, is fine with is. Our concern is that we will be made aware of the method for we have burial sites, religious sites, medicines, herbs, and roots on the hanford reservation. we are an indigenous band of people.

Thank you for letting us make our comment. Please send us the final draft. Again, I am sorry for the delay.

$$
\text { sincerely, }
$$

Rex Buck Jr.

Wanapum

$R B J: 16$ 
AU6. 10 P89.

L051

\author{
1532 Thayer \\ Richland WA 99352 \\ 8 August 1989
}

Tom Bauman

U.S. Department of Energy

P.0. Box 550

Richland WA 99352

Dear Mr. Bauman:

In regard to the EIS on decommissioning reactors at the Hanford Site, I would like to make one comment as both an archeologist and a technical

communicator. People are going to be confused by the discussion of nomination of the B Plant to the National Register of Historic Places. I have already heard some who assumed that meant it would become a museum or National Monument or that a plaque would be placed on it. To prevent such confusion, I recommend adding a short discussion of exactly what inclusion in the National Register means. The current discussion is correct, but people not involved in historic preservation are unlikely to distinguish among the different names assigned to different preservation statuses, and their inevitable confusion could create misunderstandings over what in fact is a nonissue.

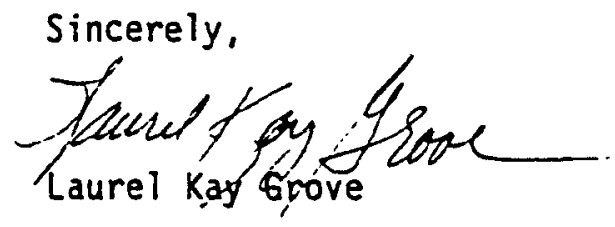




\section{SENATOR DEAN SUTHERLAND}

AlĜ̣ 14 ISb̆

\section{$\mathrm{LO52}$}

August 11, 1989

Tom Bauman, Office of Communications

Richland operations office

U.S. Department of Energy

P.O. Box 550

Richland, WA 99352

Dear Mr. Bauman:

I am writing to comment on the proposed action by the Department of Energy on the Eight Surplus Production Reactors at the Hanford site. As a state senator, I represent an area which includes over 150 miles of Columbia River shoreline.

I want to thank the Department for the opportunity to comment on the Draft Envirommental Impact Statement (DEIS) on the reactors. The release of the DEIS is a productive early milestone in dealing with this issue. It is better to address this issue now than to delay decisions and burden future decision makers.

I wish to state my preference for the disposal alterrative which entails inmediate one-piece removal of the reactors to the 200-West Area. This appears to be the most conprehensive and fastest way to dispose of the reactors.

With the exception of the "no action" alternative (which I find unacceptable) the cost of immediate one-piece removal is comparable to or lower than the costs of the other options.

Thank you for consideration of these conments. I will be very interested in the release of the Final Erviromental Inqact Statement next year.

Sincerely,

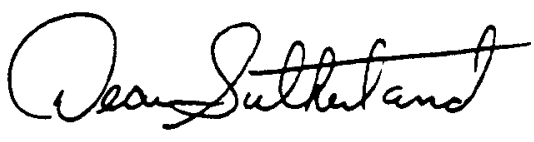

DEAN SUTHERIAND

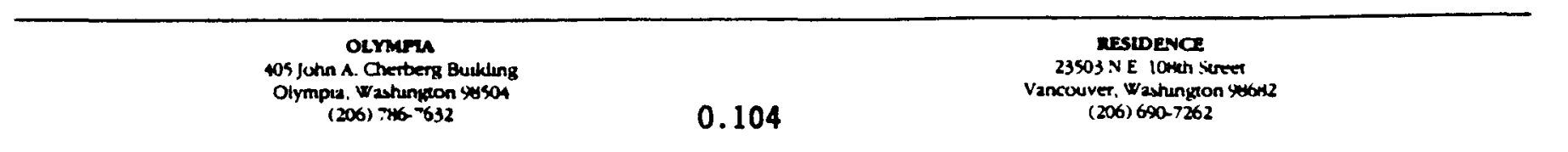


October 9, 1989

Mr. Jim Goodenough

U.S. Department of Energy

Richl and Operations Office

Post Office Box 550

Richland, Washington 99352

Dear Mr. Goodenough

SUBJECT: HISTORIC PRESERVATION OF B-REACTOR

Reference: DOE/EIS-0019D, Draft Environmental Impact Statement, "Decommissioning of Eight Surplus Production Reactors at the Hanford Site, Richland, WA"

The Columbia Section of the American Society of Civil Engineers (ASCE) recommends that there be consideration given to historic preservation of the B-Reactor at the Hanford Site. We recognize that we have missed the formal comment period on the referenced document, but request that you consider our recommendation in preparing your Record of Decision.

The Columbia Section represents about 250 civil engineers in the Yakima, Tri-Cities, Walla Walla, and Pendleton Area. Our national society, which represents over 120,000 civil engineers nationally and internationally, has a historical preservation task group for recognizing and preserving major civil engineering achievements. We feel that the B-Reactor construction falls within this category. We have members of our society who would welcome the opportunity in assisting the Department of Energy in developing plans and detailed recommendations on how to preserve the significance of B-Reactor.

We support some of the recommendations that were made by the Columbia Basin section of the American Society of Mechanical Engineers in their comments on the subject document. We believe that the civil engineering significance could also be effectively recognized without undue cost to the United States tax payers. Specifically, the following, as a minimum, are recommended:

- Information Kiosk at the Vernita Bridge rest area on Washington State Highway 240. It should point out the construction achievements and innovations, as well as the national significance.

- Enhanced photography display of construction. This could also be placed at the Vernita Bridge roadside rest, the Hanford Science Center, or as part of a traveling display.

- Enhanced audio-visual display at the Hanford Science Center. A portion of this should discuss the civil engineering achievements. 


\section{L053}

Mr. Jim Goodenough

Page 2

October 2, 1989

- Preservation of the reactor structure, if possible. The sheer size of the structure would be difficult for many to visualize. If possible, we would prefer seeing the reactor structure preserved, and possibly cleaned up to the point that engineering students and other interested groups could occasionally tour the facility.

Please contact me on $376-5053$ (days) if you would be interested in having some of our members pursue a more detailed proposal for preserving this engineering achievement.

Sincerely,

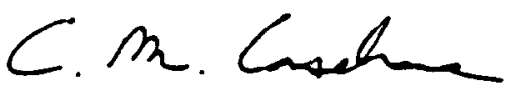

C. M. Conselman, President

Columbia Section, ASCE

did

cc: Tom Bauman, DOE-RL

Del Ballard, ASCE 


\section{IRANSCRIPTS}

Richiand

$\operatorname{Tr}-\mathrm{R} 17$

Alton Haymaker

$\operatorname{Tr}-\mathrm{R} 20$

John Burnham

Tri-Cities Industrial Development Council

$\operatorname{Tr}-\mathrm{R} 24$

Gordon Rogers

$\operatorname{Tr}-\mathrm{R} 27$

Jim Stoffels

$\operatorname{Tr}-\mathrm{R} 29$

The Honorable $\mathrm{Claude} 01$ iver Benton County Treasurer

$\operatorname{Tr}-\mathrm{R} 38$

Harry Brown

Columbia Basin Section

American Society of Mechanical

Engineers

$\operatorname{Tr}-\mathrm{R} 43$

Dick Hammond

$\operatorname{Tr}-\mathrm{R} 45$

Milton Lewis

Tr-R49

Eleanor Finkbeiner

$\operatorname{Tr}-\mathrm{R} 53$

The Honorable Raymond Isaacson

Benton County Commissioner

Spokane

Tr-Sp16

Jim Thomas

Hanford Education Action League

$\operatorname{Tr}-\operatorname{Sp} 22$

Mary Wieman

Portland

Tr-P16

Eugene Rosalie Northwest Environmental Advocates

Tr-P20

T. H. McGreer

Tr-P22

Ruth McGreer

Tr-P24

David Stewart-Smith

Oregon Department of Energy

$\operatorname{Tr}-\mathrm{P} 36$

JoAnn Oleksiak 
Tr-P39

$\operatorname{Tr}-\mathrm{P} 47$

Tr-P50

Tr-P52

Seattle

$\operatorname{Tr}-\mathrm{Se} 15^{(\mathrm{a})}$

$\operatorname{Tr}-\mathrm{Se} 24$

$\operatorname{Tr}-\mathrm{Se} 48$

$\operatorname{Tr}-\mathrm{Se} 48$

$\operatorname{Tr}-\mathrm{Se} 52$

$\operatorname{Tr}-\operatorname{Se} 55$

$\operatorname{Tr}-\mathrm{Se} 60$

$\operatorname{Tr}-\operatorname{Se} 65$

$\operatorname{Tr}-\operatorname{Se} 68$
Martha Odom

Bill Jones

Eugene Rosalie Northwest Environmental Advocates

Kathieen Maloney

Dan Silver

Washington State Governor's Office

Barbara Zepeda

Washington Democratic Councit

Sharon Gann

Frank Hammond

Sierra Club, Cascade Chapter

Mark Bloome

Heart of America Northwest

Brendon Mahaffey

Donna Bernstein

Heart of America Northwest

Russ Childers

Mark Bloome

Heart of America Northwest

(a) These comments repeat those of L042, and are recorded under L042. 


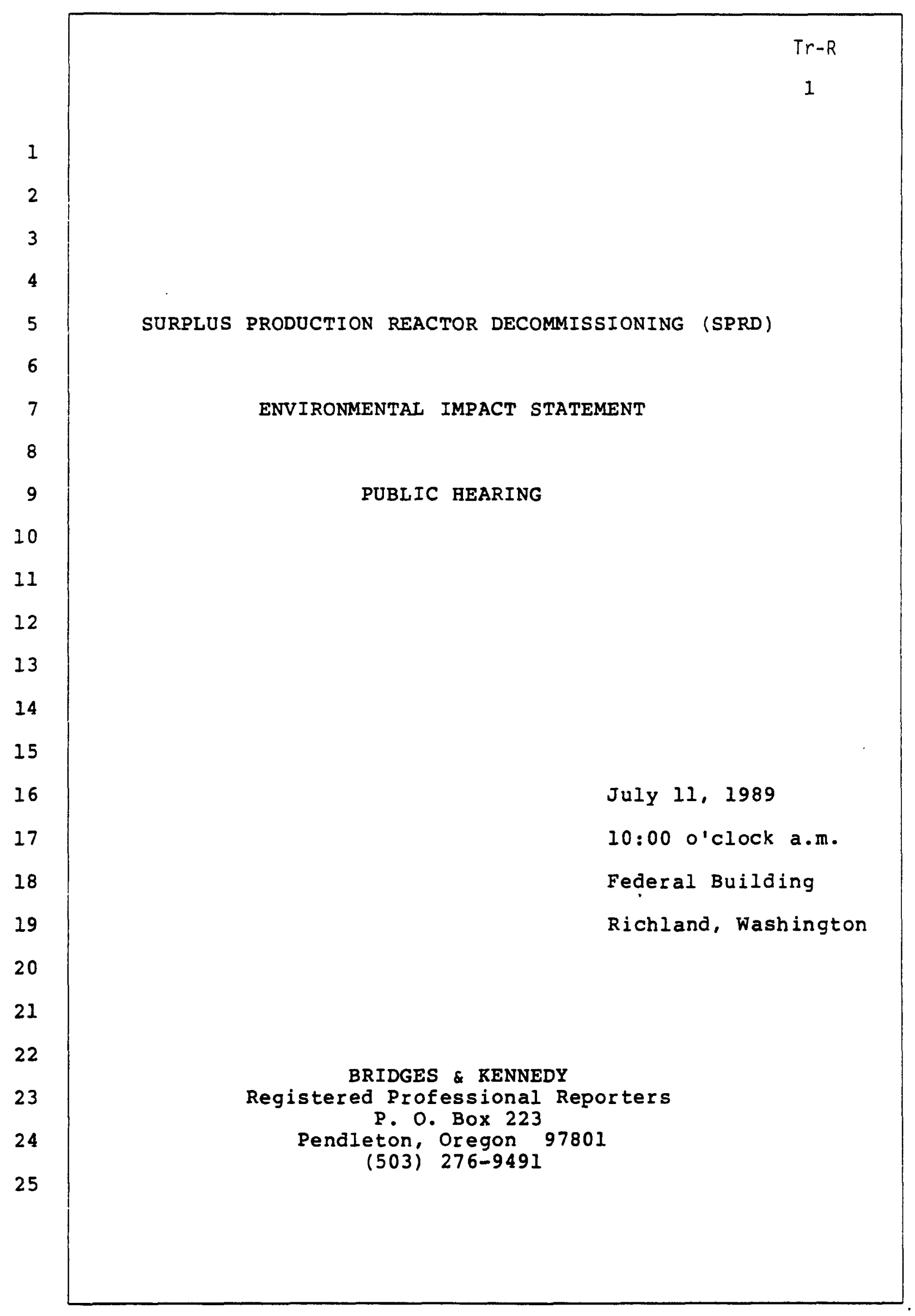




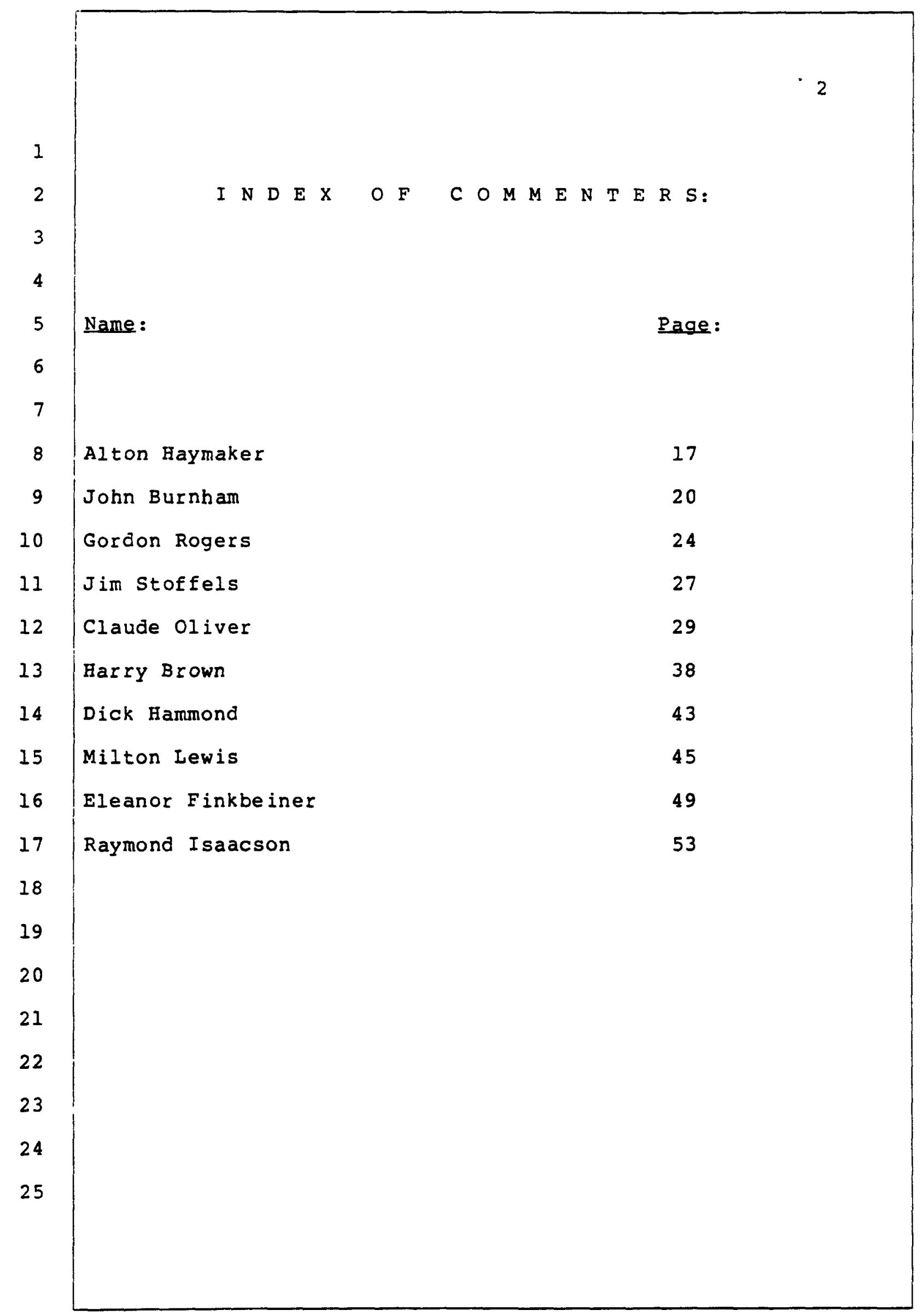


MR. ROY EIGUREN: Good morning, ladies and gentlemen. At this time I will formally open this morning's public hearing.

This is the United States Department of Energy proceeding number DOE EIS 0119-D. This is being held on the llth day of July, 1989 in Richland, Washington, for the purpose for receiving public comment regarding the Draft Environmental Impact statement prepared to analyze potential environmental impacts of decommissioning the eight surplus production reactors located at the Department of Energy Hanford Site located near Richland, Washington.

This EIS when finalized will provide environmental information to decision makers regarding selection of the decommissioning alternative for these reactors.

My name is Roy Eiguren, and I'm an attorney in private practice with the law firm of Lindsay, Hart, Neil \& Weigler, which has offices in Portland, Oregon; Boise, Idaho; Seattle, Washington; San Francisco, California and Washington, D.C. My practice and that of our law firm is heavily concentrated in energy, environmental and natural resources law.

I personally have had over 11 years experience in conducting and participating in hearings of this type, first as special assistant to the Administrator of the Bonneville Power Administration within the Department of Energy, as 
Senior Deputy for the Attorney General for the State of Idaho, and in private practice.

I have conducted NEPA hearings and meetings for the Department of Energy for more than three years throughout the United States.

I have been retained by the Department of Energy as an independent Hearing Officer to help assure that all the interested persons and organizations have the opportunity to accomplish two things here at this hearing.

Number one, that all members of the public are given the opportunity to obtain information concerning the Department of Energy's proposed decommissioning of the eight surplus production reactors, with a particular emphasis on the key environmental issues that have been identified relative to the Project. And I will be presenting this information on this particular matter in a few moments.

And secondly, to allow members of the public the opportunity to comment on all significant issues for additional environmental evaluation and analysis, in the development of the Final Environmental Impact statement associated with the SPRD Decommissioning Project.

In my role as a Hearings Officer, I do not serve as an advocate for or against the proposed action in this proceeding. My sole purpose at this hearing is to provide that all interested persons have a fair and equal opportunity 
to comment, on the record, concerning the issues of concern relative to the potential environmental impacts of the proposed decommissioning action.

At this point, I would like to introduce the senior representative representing the Department of Energy who is seated with me at the table at front, as the official hearing panel to receive your comments. Mr. James Goodenough, who is the chief of Environmental Restoration Branch here at the Richland Operations.

I would like to indicate at this point that this is not an interactive hearing, that is to say, those of us on the hearing panel will not be responding specifically to comments or questions that are made by members of the public today .

The purpose of this hearing is to receive public comment for the record about the proposed action of the Department of Energy. I would, however, point out that members of the hearing panel may ask our commenters today clarifying questions to make sure that the full import of what you're saying is fully understood for the record.

I would like to briefly discuss at this point the federal environmental decision-making process that's applicable to this particular project. The National Environmental Policy Act of 1969, or NEPA as it's commonly known, requires that the potential environmental impacts of 
major Federal decisions be assessed by Federal agencies and that the public be given the opportunity to consider and comment on those impacts.

This process is accomplished through the EIS's, which in turn are made available to the public for review and comments.

Hearings, such as the one we are conducting here today, are held to receive public input on the document. The Environmental Impact statement development process is governed by Council on Environmental Quality regulations, that Council being an agency within the executive office of the President of the United States, as well as the Department of Energy guidelines that define the type of procedures and policies the Department of Energy will follow in conducting and developing these types of documents.

These guidelines and regulations in their entirety have been previously marked by me as Exhibit Number 1 and have been submitted for the record of the proceeding.

Publication of the notice in the Federal Register, which in this case was entitled Notice of Intent to Prepare an EIS and Decomissioning the eight Shutdown Production Reactors located at the Hanford Site near Richland, Washington, dated May 16th, 1985, initiated the Environmental Impact Statement process that we're in. The May 16th, 1985 Notice of Intent 
began a 30 day comment period during which interested parties were provided with an opportunity to comment on alternatives and issues to be considered in the preparation of the Draft Environmental Impact statement.

35 comment letters were received in response to the Notice of Intent and were considered in preparing the DEIS. I have marked and included as Exhibit Number 2 in the record of this proceeding a copy of the Federal Register notes, which is labeled 50 Federal Register 20489.

The Department of Energy announced the Notice of Availability of this Draft Environmental Impact Statement for the SPRD on April 28th, 1989. That was in 54 Federal Register 18325. The publication of the Notice of Availability of the DEIS marked the beginning of the 90 day comment period during which all interested parties may provide input concerning the Draft Environmental Impact Statement. The comments that we received at these hearings will be considered in preparing the Final EIS. I have marked and included as Exhibit Number 3 in the record of this proceeding copy of the Federal Register notice announcing the availability of the Draft EIS.

Receipt of public comments on the Draft EIS is the purpose of the hearing. To assure that all parties potentially interested in commenting on this Draft Environmental Impact statement were informed of its preparation and availability and afforded the opportunity to 
provide input on it, the Department of Energy conducted a significant number of public involvement and public information activities in advance of these hearings. These activities included issuing news releases, fact sheets, the conduct of individual and group news media interviews and the display of decommissioning exhibits at 12 locations in eight Northwest communities. A comprehensive list of these public involvement activities has been marked and included by me as Exhibit Number 4 in the record of this proceeding.

This hearing is a part of the public comment process in that it provides another opportunity for interested parties to provide input on the draft. Both oral and written comments received at this hearing will receive equal consideration along with written comments submitted throughout the entire comment period, which will close on the 28 th day of July, 1989. Comments received after the $28 \mathrm{th}$ day of July will be considered, to the extent practical. Additional public hearings on this Draft EIS have now been scheduled in spokane, Washington, for Thursday of this week; Spokane, Washington, July 13th; Portland, Oregon, on July 18 th and Seattle, Washington, on July 20 th.

Those of you who are here today but not prepared to make an oral statement today but wish to submit written comments, may do so by either submitting the written comments to me as the Hearing officer or in the alternative, you may 
mail them to Mr. Tom Bauman, the office of Communications, at the Richland Operations office. We do have the exact mailing address on a card out at the registration table if you rould like to obtain it.

Federal environmental decision-making process. After reviewing the record that we're developing at these public hearings, as well as the written comments that will be received for the record, the Department of Energy will consider the comments in finalizing the EIS. The Department will also as it may -- excuse me, the Department may also choose to modify, supplement or reissue the Draft Environmental Impact statement prior to issuing a Final EIS.

$$
\text { Following the issuance of the Final EIS, tentatively }
$$
scheduled for the summer of 1989, a Record of Decision, or ROD, will be issued which will identify the environmentally preferred alternative chosen by the Department, along with any practical means to avoid or minimize environmental harm from the alternative selected. It will also be issued no sooner than 30 days following the issuance of the Final EIS. So to put it differently, the document that will ultimately emanate out of this series of proceedings will be a Final EIS and the Record of Decision which will define the alternative that is the most preferred by the Department. Before discussing the procedures that we are going 
to follow at these hearings, I would like to outline the Department's proposed action and the alternatives that are considered in this Draft EIS.

From 1943 to the mid 1950 's, eight nuclear reactors were built at the Hanford Site. These reactors were used in various times through 1971 for the production of plutonium for the nation's defense program. The last of these reactors operated in 1971, in the 1970's and early 1980's they were declared surplus by the government.

The action proposed in the Draft EIS is to decommission these eight reactors.

The purpose of the Draft EIS is to provide the environmental information that will assist the Department of Energy in deciding which alternative action is the most appropriate.

The scope of the Draft EIs includes the reactors, their associated fuel storage basins and the buildings that house these facilities.

The fuel slugs were removed from these reactors in the 1960's and early 1970 's. A ninth reactor, the N-Reactor, began operating in 1964 and operated through early 1987. The N-Reactor currently is in "wet layup" and is not included in the scope of this EIS.

The scope also does not include the cribs, burial grounds and settling basins associated with the eight 
reactors. These facilities were evaluated in the Final Environmental Impact Statement entitled Hanford Waste Management Operations, Hanford Reservation, O. S. Energy Research and Development Administration. ERDA 1538, 1975.

Further, the Department of Energy is presently re-evaluating these facilities as part of DOE's responsibilities under the Comprehensive Environmental Response, Compensation, and Liability Act of 1980, or CERCLA as it is commonly known.

The purpose of decommissioning is to reduce the potential environmental, health, and safety impacts of the contaminated facilities, which may include the stabilization, reduction, or removal of radioactive and hazardous materials or the demolition of facilities.

\section{Because the reactors contain irradiated reactor} components and because the building that housed the reactors are contaminated with low levels of radioactivity, the Department of Energy has determined that there is a need for action to ensure the long term protection of the environment and public health and safety.

The alternative actions considered in this Draft Environmental Impact statement include the following:

Number one, immediate one-piece removal of the reactor-block assembly to a low-level waste burial ground in the center of the Hanford site and the dismantlement and 
removal of the contaminated equipment and components of the fuel storage basins and reactor building.

The second alternative is safe storage followed by deferred one-piece removal. That is, continuation of current maintenance activities for approximately 75 years followed then by one-piece removal.

The third option is safe storage followed by deferred dismantlement and removal to the burial ground of the reactor-block assembly and other contaminated-components.

The fourth option is in-situ decommissioning, that is, the demolishing and sealing and burial under engineered protected mounds of the reactor facilities at their present locations.

And, finally, the mandated no action alternative, which is continued present surveillance, monitoring and maintenance.

Because the reactors are located along the Columbia River, it is necessary to evaluate the effects of any decommissioning actions with respect to flood hazards, floodplain management, and wetlands protection.

In accordance with Executive Order Number 11988, which is Floodplain Management, Executive Order 11990, which deals with Protection of Wetlands and DOE regulations 10 CFR 1022, which deals with the compliance with floodplain and wetlands Environmental Review Requirements, DOE has prepared a 
floodplain wetlands assessment for decommissioning of the surplus production reactors, and this is contained in Appendix B of the Draft Environmental Impact Statement. No reactor is in a wetland or the 500 year critical action floodplain as defined by the regulations, is within that area. Let me state that again. No reactor is in a wetland or within the 500 year critical action floodplain as defined by these regulations. As a part of the review of the Draft EIS and in compliance with executive orders and regulations regarding floodplain management and wetlands protection, the DOE solicits public and agency comments on these determinations.

The Department of Energy and the Washington State Historic Preservations officer have determined that the B-Reactor is eligible for inclusion in the National Register of Historic Places according to the procedures in 36 CFR 800, protection of Bistoric and Cultural Properties, and the criteria in 36 CFR 60 , which deals with criteria for inclusion in the National Register of Historic Places.

These findings are discussed in Appendix $J$ of the Draft Environmental Impact Statement.

Department of Energy solicits public and agency comments on whether or not the B-Reactor should be nominated for inclusion in the National Register of Historic Places on the potential impacts of decommissioning on the inclusion of the B-Reactor in the National Register and on means identified 
to mitigate potential impacts of the decommissioning action.

That concludes my preparation relative to the

Federal environmental decision making that is applicable to this particular proceeding.

At this time I would now like to turn to the procedures that we're following in this as well as all of the other public hearings that we're conducting in this series.
We have developed a series of procedures in consultation with the Department of Energy and these procedures which were developed for the purpose of maximizing public input are available at the registration table, if you so desire. The procedures are fairly straight forward. First, all participants of these hearings will be Iisted in the official record as will the comments they present orally. To the extent that any of you have prepared written comments and would like to submit them as a supplement to your oral comments here today. I have requested that you would bring them forward when you testify and give them to me or to the court reporter for inclusion in the record. We'Il mark them as exhibits and include them as received. Once again, I would like to indicate that written comment will receive the same weight in the record as oral comment.

Second, as I have previously mentioned, comments 
received by July 28 th, 1989, will be assured consideration in preparation of the Final EIS. So to the extent that you would like to provide written comment but do not have written comment with you today, you may mail them to the address that any elected federal, state and local officials, as well as designated spokesmen for Indian Tribes, and following that we will begin receipt of comments from members of the public. minutes within which to offer their comments. We do have a will be considered, provided they are mailed by the 28 th day of July. We do have comment forms also at the registration table on which you can write your written comment.

\section{Following my remarks, we will receive comment from} set of signal lights here at the podium to assist you in determining where you are at in your allocated five minutes. After the elapse of four minutes, the green light goes on. At the end of five minutes, the red light goes on. Given the fact that we have a relatively large -- or excuse me, a relatively small number of commenters at this hearing, we are going to be somewhat liberal in the use of the five minute rule. That is to say, we are going to give you a

24 little bit more than five minutes within which to make your comments if you need that. 
Any of those who have pre-registered for comments at this hearing will come to the podium first. Following that we will receive comments from any folks who have signed up at the registration table for the purpose of commenting here at this public hearing.

I would indicate that as a Hearing Officer, I'm not going to limit the scope or the content of any comments received from the public. I would like to emphasize, however, that in my opinion and that of the Department, those comments that are related to the proposed decommissioning of the eight surplus production reactors are relevant to the EIS process. Other comments are not.

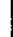

Finally, I want to stress that this is a formal proceeding under the National Environmental Policy Act and accordingly it is a recorded proceeding. That is to say, everything that is said at this as well as the other public hearings in this proceeding will be recorded and a full transcript will be made. Copies of the transcript will be made available to the public at a later time for review. The Department's decision making in this proceeding will be based upon the record that we develop at these public hearings. So accordingly, it is imperative that when you do provide your comment, particularly oral comment, that you speak very clearly into the microphone so that our court reporter here can pick up all of your comments and that prior 
to giving your comment, you give us your name and address for the record.

At this point I would be glad to respond to any questions you might have on procedure. If there are any questions on procedure, I will respond to those at this point, and then following that we will go ahead and begin the receipt of public comment. Any questions?

Very well. Then I will go up to the table there and we'll start the receipt of public comment. Again, we would ask, when your turn comes to comment, you would step forward to the podium here and give us your name and address and go ahead and begin your comment.

Our first scheduled commenter this morning is Mr. Larry Caldwell. Mr. Larry Caldwell.

I would indicate for the record that in the event we call a name and there is no response, we will call these names later in our hearing and make sure that we have not missed anybody.

Our next pre-registered commenter is Mr. Alton Haymaker.

MR. ALTON HAYMAKER: Good morning. I am Alton Haymaker. 1721 Cottonwood Drive, Pasco, Washington, and I'm a Franklin County farmer and orchardist.

I have been a down-winder since 1954 and I'm presently living at the same farm location. I would like to 
comment -- or rather compliment the DOE for the preparation they have made with regards to the text. I'm a farm boy. I'm not going to probably use the language that would be appropriate.

But certainly the language that was used in the text was one that I could understand and somewhat relate to. So my compliments to DOE in the way that they have presented this and especially the material I picked up this morning, which is a very nice job of summation.

I feel in somewhat of an ego situation, but I do want to kind of present a little background so that you appreciate the fact that I am here for probably some reasons that others are not.

I think this is a technical issue. It's not an emotional issue. And so therefore those people that are uncomfortable in the areas of technical portion or the aspects, I should say, of the reactors I am sure are not here for that reason. So I apologize for those, and especially my Earming community, that perhaps are not comfortable in being here to discuss this with you.

Between 1944 and ' 46 I was with the Navy as a Seabee. In 1974 I was a member of the participating group that moved a 120 pound -- or a 120 ton barracks from the Pasco Naval Base to North Richland.

1974 to 179 I was with the General Electric lab. 
I had the good fortune of having a Chicago chemist teach me my -- re-teach me my high school chemistry. That was a nice experience. I was a water analyst in the 100-F before I decided to leave and go to California, Santa Monica Tech, where I spent two years in college and two years on-the-job training.

At that time I received in 1952 my journeyman papers from the International Association of Machinists.

I returned then to the Hanford Project and from 1952 to 1968 I worked for Kaiser General Electric, J.A. Jones, Boeing and the Corps of Army Engineers. I took a one year withdrawal from the International Machinists in 1968.

Okay. I will submit my brief letter and it reads as follows: I understand from the report that the eight reactors are basically structurally sound. I am proud to say that I was a member of the technoligical team. I support "continued present action," page 3.7, which I believe is in the best interest of the national budget. I believe that -- excuse me. I believe with the present rate of scientific advancement worldwide that the eight reactors may prove to be a research asset rather than the present thought of a liability. Sincerely, Alton Haymaker. Thank you.

Are there any questions? MR. ROY EIGUREN: I have none. Thank you, Mr. Haymaker. 
We'll go ahead and include your letter as Exhibit Number 6 in the written record.

For the purpose of keeping the record straight, Exhibit Number 5 was a set of written comments that were submitted to us prior to the commencement of our hearing this morning, Exhibit 5 will be the written comments of Ivan M. A. Garcia of P. O. Box 682, Richland, Washington.

Also I would like to make a correction for the record. I misspoke earlier. The Final EIs for this particular project will be available in the summer of 1990 as opposed to this summer, 1989.

Our next scheduled commenter is John Burnham. MR. JOHN BURNHAM: My name is John Burnham, 371 Quailwood Place, Richland, Washington.

I would like to speak for the Hanford Division, the Tri-Cities Industrial Development council of the Tri-Cities.

I have 40 years of experience, working the nuclear industry. My work has included $r$ isk analysis and preparation of Environmental Impact statements. Now I work with the Hanford Division of TRIDEC.

We're interested in preserving the Hanford site and developing site activities.

I'm pleased to see the Department of Energy come out with this EIS on the site's retired production reactors. 
The government has a responsibility to move forward with a permanent, safe disposal of these reactors and the low-level waste contained in the reactor blocks.

Implementing one of these decommissioning options along with the actions taken as a part of the Tri-Party Agreement is evidence of the Department's interest in cleaning up the Hanford Site efficiently and completely.

We are certainly interested in seeing that the reactors are decommissioned properly. This means the decommissioning work must ensure worker safety, community safety and environmental safety. The decommissioning must be technically sound as well.

The Draft EIS compares four alternatives, taking into account cost and health impacts. I am particularly interested in the health impacts, as safety is a prime consideration. The characteristics of the reactor blocks must be considered.

since the shutdown of the last reactor in 1971. 95 percent of the radionuclides are contained within the blocks, each block is protected by 20 to 25 centimeters of cast iron thermal shielding, plus a biological shield of alternating layers of steel plate and masonite, which are 100 to 200 centimeters thick.

This shielding provides excellent confinement so 
that there's no imminent danger of low-level waste moving into the environment. Reeping the block in tact with its protective shielding is important. Because the radionuclides are contained within the block, the less direct interaction required with the block is the better.

Because of this, DOE should not seriously consider dismantlement options which means moving of the reactor blocks to the 200 Area. Once the protected shielding of the reactor-block is breached, the risk of exposure to workers and ultimately the public and the community is greatly increased.

$$
\text { As the EIS points out, there is a far greater }
$$
opportunity for exposure to workers with these options. Common sense tells us that there are also practical risks in moving 9,000 to 11,000 ton blocks several miles inland. These risks need to be carefully weighed against the environmental benefit of moving the blocks to a higher elevation and a few miles from the Columbia River. It is all to easy to confuse present sure exposure to workers with hypothetical future exposure to the public. This error must be avoided.

Once DOE determines the best option, it is important that decommissioning work receive adequate levels of funding. I encourage DOE and the Congress to continue to work for the funding necessary to implement the decommissioning option on a 
meaningful schedule.

DOE has also asked for comments on the designation

of B-Reactor as a national historic site. I support this.

B-Reactor has been an important site in the

evolution of the U.S. history, in ending World War II, and

certainly in the history of the nuclear industry.

The B-Reactor was constructed in 1944, just 45 years

ago. That is a few short years in the scope of history.

An appreciation of the historical significance of

this first full scale defense reactor will grow over the years. to give the public an opportunity to share in the historical

B-Reactor should be preserved as much as possible significance. and to make it more available to the public, health and safety must also be considered.

In summary, we support the Department of Energy's effort to move forward in decommissioning the surplus reactors on the Hanford site as part of the total cleanup effort. The final option the DOE chooses must make the best engineering and scientific sense. And it must take into account the total risk to workers and the public.

TRIDEC supports DOE's activities and cleanup efforts at Hanford. On behalf of TRIDEC, thank you for this 
opportunity to suppress our views.

MR. ROY EIGUREN: Thank you very much. We will take your written comments and include those in the record as Exhibit Number 6. I am sorry. Exhibit Number 7.

Next scheduled commenter is Mr. Gordon Rogers.

MR. GORDON ROGERS: Good morning. My name is Gordon Rogers. 1108 Road 36 in Pasco.

I have been a resident of the $\operatorname{Tr}$ i-City area since 1947 and during my 38 year career on the Hanford Project I had occasion to be significantly involved both with the upgrades at one time of the old reactors and various improvements to their safety while they were still operating. I have a great affection for them, as having an important place in my prior work history.

I would also commend the DOE for an extremely thorough and comprehensive Environmental Impact statement assessing the impacts of decommissioning of these eight old plants.

I think for me the most important information in the entire EIS is the absolutely trivial and insignificant health risks from any of the decommissioning alternatives examined for these plants. This is both due to the remaining low-level radioactive waste in the plants and for the chemical constituents that are also involved there.

In the case of the radioactivity, the health impacts 
are absolutely insignificant compared to those due to natural background radiation. And it's also of interest that for the chemical wastes, hazards to anyone downstream using the Columbia River water are practically non-existent. All releases are well within drinking water standards.

If it were my own money and we had some other political climate in this country other than the, I'll call it demagoguery, for lack of a better term, regarding almost anything with the word nuclear in it, I would favor the action, to continue the present action of decommissioning alternative. However, we have to recognize facts as they are.

In line with the nationwide effort to clean up existing waste sites and as part of the cleanup of the wastes on the Banford Reservation, these old reactors are a significant low-level radioactive and chemical waste hazardous site.

So from the realities, I strongly urge the Department to pursue the decommissioning in place alternative. I can't believe the cost estimates, that this is almost as expensive as hauling the reactors in one block several miles inland for disposal in the 200 Areas, but I certainly support the comments offered by Mr. Burnham, that dismantling or even moving intact the blocks is inherently a much more unsatisfactory way of handling this problem than 
decommissioning them in place.

This alternative is, according to the facts of the DOE, the next least expensive and I strongly support that as a taxpayer. It also permits the completion of the cleanup action in the shortest time. And that has a psychological advantage, if no other, in today's climate of action for waste cleanup.

You also request comments respecting the preservation of $B$-Reactor as a national historic site.

My personal recommendation is that the DOE take action to preserve major amounts of information concerning the B-Reactor. They have mentioned photographic and written records. I would also suggest perhaps a Hollywood type stage set model of certain of the features that could be seen by a visitor to the reactor, such as the front face and the rear face and perhaps the horizontal, vertical rod systems. I think this could be done at a reasonable cost and would still give a visitor some feeling for the immense and interesting features of this historic plant.

In reality, B-Reactor, important as it is locally, is only one of a very large number of unique complex plants that were built under absolutely extraordinary circumstances and which had a major part in bringing World War II to a speedy and successful conclusion. 
to B-Reactor also, but preserve the information concerning it in other ways.

Thank you very much for the opportunity to present

MR. ROY EIGUREN: Thank you, Mr. Rogers. Our next registered commenter this morning is $\mathrm{Mr}$. Jim Stoffels.

MR. JIM STOFFELS: My name is Jim Stoffels. I live at 1219 Del Mar Court in Richland.

Ladies and gentlemen, were you ever in a place that made you tingle with a combined sense of awe, excitement and eeriness?

I was two years ago when I toured Hanford's first plutonium production reactor, the historic B-Reactor. I felt awe, excitement, and eeriness.

Awe at seeing that huge reactor face, massively scaled up in just a matter of months from Enrico Fermi's first critical pile. Excitement that must have been felt back then by the participants in the Manhattan Project. The excitement of a race, a deadly race for the survival of a free world.

Eeriness. As if the ghosts of Fermi and his co-workers still inhabited that empty control room.

The war that gave birth to the Manhattan Project, to Hanford, and to the B-Reactor, was one of the great human 
tragedies of our lifetime. The bistorical facts are that B-Reactor produced the plutonium for the first manmade nuclear explosion, the Trinity test, and for the bomb that destroyed much of the city and people of Nagasaki.

By the grace of God our need for nuclear weapons is rapidly disappearing. And era, the era of nuclear weapons, is passing. And while we cannot yet see the end of that era, we have already seen the beginning of the end. This hearing on the decommissioning of the Hanford reactors is evidence of that hopeful reality for our future. And Hanford has a role in that future.

I believe that part of Hanford's future lies in its past. Not in the preservation of its original mission, but in the preservation of its history.

I want to see B-Reactor preserved as a permanent monument to that passing era. Because of the wartime secrecy in which the Manhattan Project was born, many Americans of the present do not know the history of the atomic bomb. This will be even more true of future generations, unless we save some of the relics, such as B-Reactor, for their immense historic and educational value.

Therefore, I urge that the Hanford B-Reactor be preserved intact on site as a national historical monument and museum, that it be upgraded with relevant historical and educational displays and that it be provided with public 
vehicle access from State Highway 240. With these steps accomplished, many other Americans and neighbors from around the world can visit that historic place and tingle with awe, excitement and eeriness for the past, and with hope for a future of peace. Thank you.

MR. ROY EIGUREN: Thank you.

Our final pre-registered commenter for our hearing this morning is Mr. Claude oliver:

The written comments of Mr. Jim Stoffels will be included as Exhibit Number 8 in the record of this proceeding.

Exhibit Number 9 will be the written comments of Mr. Claude Oliver.

MR. CLAUDE OLIVER: Good morning. I'm Claude Oliver, Benton County Treasurer for eight years, previously serving this area as a state Representative for four years, eight years as a commercial loan officer with a financial institution, working in all three communities, Pasco, Richland and Rennewick.

I'm offering public comment, response to the Environmental Impact Statement as offered by the Department of Energy for public hearing as of this date, July 11, 1989.

At this time of public input on the $U$. S. Department of Energy's planning process to de-activate eight nuclear production reactors, we should reflect on the original Hanford 
mission. What was the intent of Congress and President Franklin Delano Roosevelt when they created and activated this vast federal facility of over 350,000 acres in Benton, Franklin and Grant Counties?

National forces driven by the urgency of World war II against the background of a legitimate question of national survival compelled the United States to produce the ultra secret, the Manhattan Project.

Even after detalls of perhaps the greatest World War II secret became known, the late 1940's and '50's ushered us into an era of the cold war standoff between the United States allies and the Soviet Union.

In order to understand where we are today, it is important to clarify the activities of the federal government in our area as they occurred in an era which was largely void of public knowledge or involvement.

From a national, state and local government objectives, it is important that we give a definition to original intent for Hanford startup in order to properly plan conclusion for these facilities and lands.

The 1940 federal census gave Benton County 12,053 people. With World War II activity, it became necessary to provide a special census which was taken in 1944, which revised Benton County's total to 70,987 people. This six fold increase in population totally overwhelmed our local education 
systems, county roads deteriorated without funds to repair or replace them, and county courts and offices were sent reeling with totally unexpected and unplanned service demands.

Though Benton County property values increased from nine million dollars to twelve million dollars during this time, county taxes were being levied at the maximum 10 mills allowed under state law. It was necessary in addressing one emergency in 1946 to receive $\$ 76,000$ from Washington state for Benton County operations for war time unreimbursed expenses of the previous year.

The courthouse journals evidence one financial impact after another on the people of this county. The people of Benton, Franklin and Grant Counties, however, rallied to the war effort and the national policy of essential war victory gladly, and, in fact, recognized the need to make national sacrifices as an accepted practice of the day. Thus, Hanford was created.

So that we can now proceed to address resource use of the land and its impact on the people of Benton, Franklin and Grant Counties, please answer the following:

Number one: What was the original Congressional intent of taking and establishing the Hanford land area in carrying out the World War II secret Manhattan Project? Number two. Did the 1942-1943 United States Congress and the Department of Army Corps of Engineers 
evaluate their actions with knowledge that some portion or all of the Hanford Federal Reservation land taken for this project would be contaminated and unsuitable to return to its previous use? In their deliberations, did they offer consideration to assess the ultimate plan for future generations that are now in the genesis of this Environmental Impact statement on our communities?

Number three. What was the determination used in the amount of lands originally condemned for the Hanford Reservation in Benton, Franklin and Grant Counties? Is it planned by the federal government or yet to be determined that this portion of land will be kept off the tax roles of Benton, Franklin and Grant Counties indefinitely. What lands set aside is necessary to address your environmental impact containment of the eight idled reactors?

Number four. Water allocation from the Columbia River for irrigation purposes has been conducted for a number of years. The resource of water combined with land grows crops in ready abundance throughout the world. Recognizing that the Hanford Reservation was created in the middle of a vast agricultural plane has the U. S. Department of Energy given consideration for the need to reserve water rights for future irrigation needs of the Hanford lands now held in its trust? If not, why not?

Number five. With the original Hanford national 
mission now significantly declining, what consideration is being given by the U. S. Department of Energy for future community impact plan? Does the U. S. Department of Energy have any comparable environmental impact consideration plans for deactivation of any comparable facilities? 30 percent of Benton County's tax base, 16,000 acres in Franklin County and 25,000 acres of Grant County lands have been left off the tax roles since 1944, the main community and the U. S. Department of Energy missions of World Peace Through Strength, though not conducted without incidence, have certainly worked. We could all pray that nuclear genie of atomic war was not out of the bottle, but it is. We also do recognize the full value of the peaceable use and continuing development of the atom that has and will significantly benefit mankind.

The people of Benton, Franklin and Grant Counties have played proud roles these past 45 years. Their contributions to future endeavors by the U. S. Department of Energy, both known and unknown in origin, will be significant and valued as future generations will evidence.

However, we now must address a legacy to one chapter of the cold war and a community that has accepted responsibility without hesitation. Let us adequately explain the basis of our genesis so that we can arrive at the best intelligent assessment of where we came from, so that we can truly plan for our future wisely. 
Recent national policy changes by the U. S. Department of Energy to de-emphasize production and emphasize safety is indeed refreshing and highly professional.

Though we live in a world that could be considered vast and boundless, we certainly must recognize that responsible limitations for living standards and future generations can only be best maintained and enhanced if we are willing to preserve them.

In this regard, land use planning and socio-economic impacts need much more attention and emphasize than is given in the March, 1989 Draft Environmental Impact Statement. Answers specific to the issues enumerated above, especially item five, are respectfully requested.

Thank you for taking this public comment. MR. ROY EIGUREN: Thank you, sir. We will mark your written comments as Exhibit Number 9 and include those in the record, and give those to the gentleman in the blue shirt there. Thank you for coming.

Ladies and gentlemen, that concludes our list of pre-registered commenters for our public hearing today.

I would ask if there is anybody in the room who has not had the opportunity to comment that would like to do so.

There being no one in that category, then, what we are going to do under the procedures of this hearing is go 
into recess until the hour of 3:00 p.m. at which time we have another pre-registered commenter. In the event that we should have other walk-in registered commenters for this public hearing, we will go back on the record as necessary.

We will be in recess until the hour of 3:00 p.m. Thank you very much.

(Recessed at 11:00 a.m.)

MR. ROY EIGUREN: It is now 3:02 p.m. on July 11, 1989. This is a resumption of the United States Department of Energy proceeding, DOE 0119-D. It is a public hearing being held in Richland, Washington, for the purpose of receiving public comment regarding the Draft Environmental Impact statement prepared to analyze the potential environmental impacts of decommissioning eight surplus production reactors located at the Department of Energy's Banford Site located near Richland.

This EIS, when finalized, will provide additional environmental information to decision makers regarding selection of a decommissioning alternative for these particular reactors.

We commenced this public hearing this morning at 10:00 a.m. this is the first in a series of four public hearings being held on this Draft Environmental Impact statement. As I mentioned, we began the hearing at 10:00 this morning. We had six individuals who were pre-registered to 
come and who did come at that time. We went into recess at approximately 11:15 a.m. until the hour of 3:00 p.m. for the purpose of receiving comment from additional individuals who either were pre-registered to comment this afternoon or who were registered at the door to present comments at this public hearing.

In my introductory comments this morning I indicated that my name is Roy Eiguren. I'm an attorney in private practice with the law firm of Lindsay, Hart, Neil \& Weigler, which has offices in Portland, Oregon; Boise, Idaho; Seattle, Washington; San Francisco, California; and Washington, D. C. I have been a retained as an independent third party as a Hearing officer to conduct these public hearings to make sure that all interested citizens have the opportunity to provide their comment in a fair and equal way on the record relative to the environmental impacts or potential environmental impacts relative to the proposed federal action. With me here in front of the room is Mr. Roger Freeberg who is the Chief of the Environmental Restoration Branch of the Department of Energy's Richland Operations office. The two of us constitute the hearing panel that's receiving public comment on this Draft Environmental Impact statement.

The rules of this proceeding provide that interested members of the public who wish to comment on the Draft EIS may 
1 do so/either pre-registering or registering at the door to provide their comment during the hearing.

For this afternoon's session, we have one individual who pre-registered who will be speaking first and then following that individual we have two additional individuals who have registered at the door who would like to comment here this afternoon.

The rules provide that all interested parties do have the opportunity for five minutes of comment for the record. Given the fact that we have a very limited number of individuals who are testifying at this public hearing, however, we are being somewhat liberal in the application of the five minute rule and so you have a bit more than five minutes if you would like to take a bit more than five minutes to present your remarks.

What I will do is at the conclusion of four minutes of testimony time, I will turn on a little green light at the podium that indicates that we have a minute remaining. The red light means that five minutes has elapsed. Once you see the red light, I would ask that you would begin the process of bringing your comments to a conclusion.

\section{I have also stressed earlier that written comment} receives equal consideration in the record as does oral comment, and so if you do have oral comment with you -- excuse 
me, written comment with you, we would like to have you present that to me as a part of the record, or for inclusion in the record as an exhibit. The close of comment for this particular proceeding is July $28 \mathrm{th}$, and so if you don't have written comment with you but would like to present written comment for the record, we would ask that you would send those written comments to the Department by that date at an address that we would provide to you at the registration table outside the hearing room.

So with that, we will begin now the receipt of public comment for those of you who have registered to comment this afternoon. Our first registered commenter is Mr. Harry Brown.

Mr. Brown, we would ask that you step forward to the podium here, sir. We would like to have your name and address for the record and go ahead and begin your comment.

MR. BARRY BROWN: My name is Harry Brown. My address is 1507 South Tweedt Court in Kennewick. I'm here today to speak on behalf of the Columbia Basin Section of the America Society of Mechanical Engineers. And I'd Iike to read a position paper which we have prepared for the Section.

This is a proposal for special treatment for the Hanford B-Reactor during the subsequent decommissioning to preserve and commemorate its historical status, submitted as 
comment to the Environmental Impact statement, document DOE EIS 0119-D by the Columbia Basin Section of the America Society of Mechanical Engineers. Respectfully submitted by Janet Hibbard, Chairman.

EIS Document DOE/EIS 0119-D describes alternate methods of decommissioning the currently shutdown Hanford production reactors constructed beginning in 1943 for the production of plutonium for the first atomic bombs. The America Society of Mechanical Engineers, ASME, a nationally and internationally recognized technical society, acknowledges the historical significance of these reactors to the future nuclear industry by certifying the Hanford B-Reactor as a national historic mechanical engineering landmark in 1976. ASME supports of safe decommissioning of nuclear facilities, including total demolition and site restoration, where necessary.

However, in the case of historic landmarks such as the B-Reactor, ASME believes that steps should be taken to preserve and commemorate the landmark and retain some degree of its historic status.

For the Hanford B-Reactor, various alternatives are offered by way of comment on the EIS. The historical background of the reactor and the ASME history and heritage program are also described briefly to provide a frame of reference for the ASME proposals. 
2.0 The historical background and significance of the Hanford B-Reactor.

The Hanford B-Reactor was the first plutonium production reactor to be placed in operation. Its startup followed successful operators of three test scale reactors, including the Chicago pile and the Hanford test reactor which proved that all of the physics calculations and engineering decisions required for the construction of the graphite pile and cooling system, were correct and within proper limits to sustain a controllable chain reaction.

From an engineering standpoint, the significance of the B-Reactor lies in achieving the results of the startup after designing the mammoth production reactor based on the data from the much smaller test reactors.

For example, the B-Reactor moderating pile alone contains 2,000 tons of graphite blocks, penetrated by over 2,000 aluminum process tubes. The pile, as high as a four story building, was surrounded by a skin of cast iron ten inches thick and a shield of masonite, steel and concrete four feet wide. The B-Reactor complex is said to contain more concrete than Alonzo Stagg Stadium under which the Chicago pile operated. However, outside of its contribution to the defense of the United States, the full significance of the B-Reactor startup was realized in later years with the development of the domestic nuclear industry. 
Thus, the successful operation of the Hanford B-Reactor was a major milestone for the Manhattan Project and made possible the subsequent development of commercial atomic energy ultilization.

The research, engineering and planning required to make the reactor operate should be included in history as one of man's most brilliant scientific and advanced engineering achievements.

Historically B-Reactor began as part of the Manhattan Project in 1942 with the breaking of ground in April, 1943, for support facilities. Construction of the reactor started in June, 1943 and was completed during September, 1944. This was followed in rapid succession by fuel loading and startup during the same month. Three months later, on Christmas day, 1944, the first irradiated fuel was discharged from the reactor.

The facility operated intermittently until it was shut down permanently in 1968 .

$$
3.0 \text { The designation of B-Reactor as a national }
$$
historic landmark.

The ASME historic landmarks program is an outgrowth of a relationship between ASME and the Smithsonion Institute. ASME contributes historical material particularly related to mechanical engineering to the U. $S$. National Museum of $\mathrm{History}$ and Technology in Washington, 
D.C.

In 1971 ASME established its history and heritage program for the society, and the landmarks program was added in 1973.

A national landmark is a mechanical engineering achievement with national or international significance, one associated with persons or events that have contributed to the general development of mankind. All nominations are approved by the ASME national history and heritage committee. Once a nomination is approved, a history brochure and bronze plaque are prepared and presented to an appropriate organization for display in the vicinity of the monument being dedicated.

The Hanford B-Reactor plaque is displayd in the Hanford Science Center. Hanford B-Reactor was nominated for landmark status in 1975 by the Columbia Basin Section, ASME. This nomination was subsequently approved by the history and heritage committee, which cited the B-Reactor as a technical achievement and because much of the reactor core, cooling system, shielding, and auxiliary support systems were designed by mechanical engineers, although many different types of scientists and engineers contributed to the ultimate success. 4.0 The preservation of B-Reactor as a historic landmark.

Alternative proposals described below are offered to support the belief by the Columbia Basin section, that 
the B-Reactor represents as a significant achievement that continued recognition of the facility as a historic landmark is warranted.

The proposals are intended to be consistent with requirements of the decommission mode selected based on the EIS.

I'm not going to describe each of these, but I will mention the five alternative -- or four alternative methods that we had proposed.

One is an information kiosk to be installed at a rest area such as the Vernita rest area; an enhanced audio $v$ isual display to accompany the plaque here at the Banford Science Center; a reactor memorial such as an obelisk which would be placed on State Highway 240 near the B-Reactor as a historical landmark; and facility access, withholding a part of the B-Reactor from decommissioning and putting it on display to the public.

Thank you very much.

MR. ROY EIGUREN: Sir, we will take your written comments and include that in the record as Exhibit Number 10. Next call Mr. Hammond.

MR. DICK HAMMOND: Dick Hammond, 1522 Haines, Richland, Washington. Thank you, Eiguren and Mr. Freeberg and the Department of Energy for the opportunity to talk about this subject matter. 
As a past person interested in and active in the

field of mechanical engineering, I would like to second all

the information provided by Mr. Brown, for the ultimate activity on B-Reactor.

As far as action on the old reactors are concerned, $B, C, D, D R, F, H, K E$, and $K W$, built in that order, the first mentioned objective, no action, with continuing present action, seemed to me to be the most logical of the several provided in your EIS analysis.

There are objectives and benefits to the other possible alternatives, as well. But I see no action one, continued present action, is the logical one, from my standpoint.

And my standpoint is a person who has worked at B-Reactor for some six years in engineering, as well as the other - all the other eight older reactors for a period of some 30 years, and perfectly familiar with the engineering details as well as the operational details, maintenance and that sort of thing. So that I would accept your data on comparison of alternatives by costs and environmental impact as probable. The least cost action being the no action, present action, is obviously going to save the taxpayers a lot of money over the long haul.

The other feature, the population over 10,000 years in person-rem is much higher than some of the others. 
However, it's divided under, I'm certain, many thousands of additional people who would be exposed, so that per person, I'm sure that it would be a very small figure, too, as

I think Tom Dunn must be congratulated for having the forethought to give extra attention to B-Reactor. I certainly agree that because of a strong association over the history of the United States, nuclear program, that we should indeed give the extra attention which Harry Brown has described. Thank you.

Any questions from you, by the way? MR. ROY EIGUREN: Thank you, Mr. Hammond. Next we will call Mr. Milton Lewis. MR. MILTON LEWIS: My name is Milton Lewis, 2600 Harris street in Richland.

I, too, would like to support the in-situ decommissioning alternative for two reasons.

One of those reasons was stated this morning. I'd like to support that. That is, that in the first alternative, the in-situ decommissioning, we have a known radiation dosage 
that would be experienced by the population, since we know very well what the current situation is, radiation-wise, in the reactors where they stand. Any movement of the blocks could result in a larger, much larger radiation dosage in the event of an accident in the movement operations, and so there's some unknown really radiation dosage that would be accompanied by such a movement.

Even though as mentioned by Mr. Hammond, the figures show a higher population dose over 10,000 years for that first in-situ decommissioning, the footnote I believe is significant. It says the same population would receive nine billion person-rem over the 10,000 years from natural radiation.

So any of the alternatives is insignificant by comparison with what the natural radiation to the population will be over that period of time.

So mainly my point there is that let's not trade some unknown radiation dosage by moving the blocks for some well known, well defined radiation dosage by leaving them where they are.

My second point was not mentioned earlier today, and I'm not sure what it's value is, but let me mention it. Those reactor cores consist of thousands of tons of the purest graphite ever known to mankind. In addition to that, they consist of probably thousands of tons also of 
aluminum and steel. All of these materials having been irradiated to very high nutron exposures.

It is conceivable that sometime in the future there would be a new use or a discovered use for the long life radio isotopes that exist in those materials. I don't know what it is. But it may develope perhaps not within our lifetime, but at some time in the future.

I would like to see the cores preserved in such a way that those materials could be removed if desired at some future date.

So the point I would like to make is that the future value of those irradiated core materials might be such that we should provide a method of access so that they could be mined out at some future date, perhaps hundreds of years from now, but there is no other such supply of those materials.

So on the basis of that, then, to sum up, I strongly urge that the Department of Energy consider the in-situ decommissioning rather than the moving of the blocks. MR. ROY EIGUREN: Thank you, Mr. Lewis. Ladies an gentlemen, that completes our list of commenters for this afternoon. I would ask if there's anybody in the room who has not had an opportunity to comment who would like to do so at this point?

There being no one in that category, we'll go ahead and once again recess this public hearing until the hour of 
7:00 p.m. this evening at which time, pursuant to Federal Register notice, we are scheduled to recommence this heating. I would note for the record at this juncture that we do not have any pre-registered commenters for this evening, but as required per the Federal Register notice, we will once again reconvene at 7:00 o'clock and remain here as long as necessary to take any at-the-door commenters who might wish to go on the record.

So with that we'll stand in recess until the hour of 7:00 p.m. Thank you.

(Recessed at 3:30 p.m.)

MR. ROY EIGUREN: We will now formally go back on the record for this our public hearing being held on July llth, 1989 in Richland, Washington. It is now approximately 4:00 p.m., Pacific Daylight Time, and as per our prior announcement on the record, we went into recess at approximately 3:30, having received comment from three individuals at that point in time.

since then we have had one additional member of the public who has appeared at the door who's requested the opportunity to go on the record for public comment relative to the environmental issues associated with decommissioning of the eight surplus production reactors that are located at the 
Hanford Site near Richland, Washington.

We now have Eleanor Einkbeiner who is here and would like to testify on the record for the purposes. For the purposes of introduction, Mrs. Finkbeiner is from 1415 Baines Avenue?

MRS. ELEANOR FINRBEINER: Yes.

MR. ROY EIGUREN: Here in Richland, washington. 99352. Mrs. Finkbeiner, you have five minutes for the comment on the record. If you would like to proceed, we would like to hear your comment.

MRS. ELEANOR FINKBEINER: Okay. I see it as good stewardship to use what we have, and we have these reactors, it seems to me, with the big influx of population on the west side of the state, that we have a contribution to make environmentally and economically, ecologically, and that is, the use of power. We need power down through the centuries to come and this is a contribution that we can make to the state by the use of what reactors there are available for the use of power.

Last winter we came very short, to the spot, so the news media recorded, that we were running out of power in February. And it is poor stewardship to throw away something usable.

I come from the old school where you use what you have, and you use it until it's gone and worn out. And I 
think we need, not to be part of contributing to the factor of throwing away things that are usable, and that includes the

MRS. ELEANOR FINRBEINER: And I thank you for coming.

And I think that we have brains enough and insight enough collectively to use this, and to figure out ways that it can be helpful to humankind.

To destroy that which is not usable and to get rid of it, bury it, however, and to use what we have and to not be out searching for other things, but to be wise stewards of God's good earth. That is my message.

MR. ROY EIGUREN: Thank you. We have no questions, so thank you very much. We appreciate your being here. There being no further individuals who are here at this time to testify on the record, we will once again go into recess until the hour of $7: 00 \mathrm{p} \cdot \mathrm{m}$. this evening to resume our public hearing here in Richland. coning.

MR. ROY EIGUREN: It is now 7:0I p.m. on July 11th, 1989. We will once again go back on the record and 
resume our formal public hearing being held here in Richland, Washington, for the purpose of receiving public comment relative to the Draft Environmental Impact statement that's been prepared to analyze potential environmental impacts of decommissioning the eight surplus production reactors located at the Department of Energy's Hanford Site near Richland, Washington.

Prior to taking recess we received comment from approximately nine individuals during this, our July lith public hearing being held in Richland, Washington, which convened this morning at 10:00 a.m.

It has been the practice of this particular hearing panel to go into recess at those points in time when we do not have individuals who are here ready to comment on this Draft Environmental Impact Statement.

As I had mentioned in my opening marks earlier during this hearing, my name is Roy Eiguren. I'm an attorney in private practice with the law firm of Lindsey, Hart, Neil \& Weigler. I have been retained by the Department of Energy as an independent third party to serve as a hearings officer for this ser ies of public hearings that are being held here in the Pacific Nor thwest to receive public comment on this Draft Environmental Impact Statement.

In addition to the hearing that's being held here today in Richland, Washington, additional hearings are 
scheduled for Spokane, Washington, for Portland, Oregon and

Seattle, Washington, over the course of this and in the following week.

At this point we have now gone back on record as per the Federal Register notice that announced these particular hearings. The Federal Register notice provides that the hearings that will be held in the four cities will comments at 10:00 a.m. each morning and run until 5:00 in the afternoon, recommence at 7:00 in the evening and run until 10:00 p.m.

Given the fact that we have no pre-registered speakers and we only have one at-the-door registered commenter or speaker for this evening's hearing, it would be our intent to go ahead and receive the comment from the one commenter who is here, willing to testify, ready to testify.

We will then go into recess after the receipt of that comment and we'll stay in recess until the hour of $8: 30$ p.m. this evening. If in fact we have additional commenters who do arrive at this hearing room here at the Federal Building to provide comment for the record, we'll receive that comment. If we do not have any additional commenters who arrive prior to $8: 30 \mathrm{p} . \mathrm{m}$. this evening, then we'll formally close the record of this proceeding for this, the July llth, 1989 public hearing here in Richland, Washington. At this time we would now like to begin the receipt of public comment once again, and we're pleased to have with 
us one of the Benton County Commissioners, Raymond Isaacson, who is here to testify.

Commissioner, we would like to have you step forward, sir, to the podium, give us your name and address for the record.

The rules provide that you have five minutes to comment, but, Commissioner, under the circumstances we'll let you comment as long as you like to.

MR. RAYMOND ISAACSON: Well, thank you very much.

For the record, my name is Raymond E. Isaacson. I reside at 2106 Lee Boulevard here in Richland.

As Commissioner of Benton County, the district that I represent includes everything north of the Yakima River, up here to Lee, back to the Columbia River, and then at the county line, it continues south back to the Yakima River. So the Hanford Project, then, is entirely within my district, District I.

In my formal remarks, I do, and I will provide a typewritten copy, again, for the record, because some of it is a table that's very lengthy and I cannot read that into the record this evening, but it is apparent that the Environmental Impact statement for the decommissioning of the eight surplus reactors will cause essentially inconsequential damage to the environment, regardless of the method of decommissioning. 
However, I believe that the method of decommissioning that should be selected is the one that would result in the least amount of additional disturbance of the environment, and that would result in the least occupational radiation dose to the worker.

I would think that you should opt for that which creates the least consequences.

While the Draft Environmental Impact Statement appears to be quite thorough, land use planning is inadequate and does require further consideration. When the Banford Project was started approximately 570 square miles was acquired by condemnation and other methods and reserved for atomic materials -- atomic bomb materials -- production. The majority of this land area was required for radioactive isolation, public safety and security purposes.

Now that all of the Hanford reactors have been shut down and decommissioning is being considered for age of the nine reactors that were built, it is obvious that the land once taken out of agricultural production is no longer needed for isolation and security purposes.

Also the land that has not been adversely affected by radioactivity should be evaluated for return to productive use.

To put this issue in perspective it is necessary to know how much land could be made available for various crops 
by type. Considerable area was under irrigation when it was acquired for the Manhattan Project. The evaluation of returning land to productive agricultural use should include provisions for irrigation water systems that will deliver water to specific areas such as Cold Creek Valley adjacent to Highway 240. Reconsideration of the economic value of the arid lands ecology reserve should be included.

If there is justification for keeping this land out of productive agriculture, consideration must be given to providing payment in lieu of taxes to municipal local government so that the adverse economic impact that now exists can be rectified.

Tables of estimated acreage and incomes for various crops harvested in Benton County during 1988 are attached and can be used for reference in the studies. The total value of agricultural products was about $\$ 217,267,319$ in 1988 . These data were prepared by Mr. Jack Watson and Ms. Jean Smith of the Benton County Cooperative Extension.

Because of the time limitations this presentation must be kept brief. If additional dialogue is needed, I will be available and will provide any needed input.

The table is by acreage, yield per acre, total production, dollar price unit, and does include dryland wheat as well as irrigated land wheat.

And I believe that since the area talked about 
is in relative close proximity to the Columbia River, the irrigation, the crop type, should include only the irrigated types. And now we're talking about row crops and fixed crops such as our emergent grapevine vineyards and various kinds of orchards. And I would emphasize those. Also potatoes, asparagus, sweet corn, onions and carrots are grown in the county very effectively and very efficiently.

So with that, then, I would close my remarks and submit this, then, with the tables, for use in the studies that we are requesting.

MR. ROY EIGUREN: Thank you. Commissioner, I might point out, that the rules of the proceeding do allow the hearing panel, which includes myself and Mr. Roger Freeberg of the Department, to ask clarifying questions, and if I might, I would like to ask one clarifying question.

MR. RAYMOND ISAACSON: Certainly. MR. ROY EIGUREN: I believe it was Mr. Oliver from Benton County, the treasurer, earlier spoke to the same issue you did, sir, and that is, apparently Benton County is of the opinion or the position that once these eight reactors are decommissioned, that the land under which the government originally withdrew -- or the land that the government originally withdrew for these particular reactors may now revert back to non-governmental ownership. Is that correct? 
MR. RAYMOND ISAACSON: Yes. The point is, the lands were acquired by condemnation procedures for a specific purpose.

MR. ROY EIGUREN: Yes.

MR. RAYMOND ISAACSON: This is evidence that that purpose no longer exists. And even if discussions of such things as using some of the other area, such as W.P. No. 1 to return to a tritium production reactor, that has in essence been rejected, other sites have been selected. This site has been rejected.

Obviously the Department of Energy does not have an intent to continue defense materials production at this site, and for that reason we ask that that land that is not producing any revenue for the county, and by the way, this year the county had to reduce its expenditures by six percent in the face of increasing inflation. We had to reduce our number of employees by 16 out of 325, leaving about 309 left. We raised the property taxes the full allowable six percent. And we still are having to take about a quarter million dollars out of reserve and our reserve account is going down. In other words, there are not too many years that we can continue to run on the bank, so to speak, to balance the budget. So the county is in economic distress and we need to find some kind of economic development, replacement, to replace the defense production here so that this county 
can maintain its infrastructure, provide the services to the people that are required by law, and in order to do that, we must have a revenue base, and to leave those plants idle out there is totally unfair in our estimation, to leave them unproductive, because that just leaves it on the rest of the people in the county, rest of the taxpayers, without having, you know, as I say, a fair return for that land.

Commissioner, apparently it's the position of the Benton County Commission that the original purpose for which these lands were originally condemned by the government no longer exist because the facilities are being decommissioned, and so you believe as a matter of public policy, if not as a matter of law, these lands then should revert back to non-federal government ownership status?

MR. RAYMOND ISAACSON: Yes, where they can be. Now, I do realize, and I understand that there are areas that are radioactively contaminated and there are still areas that will have to be reserved from beneficial agricultural use because of the long term waste storage requirements, 200 Areas especially.

$$
\text { So with those considerations, then I think the }
$$
balance of the land that was taken should be returned and reverted to a productive use.

The constraints of residual radioactivity would 
limit the amount of land that could be made available. So the study should delineate those areas that could be released back to productive agriculture and identify those areas that would have to be reserved for isolation purposes and for safety reasons.

MR. ROY EIGUREN: I would think, then, that for the purposes of Mr. Freeberg and his staff in analyzing the record of this proceeding, if the Commission could provide additional supplementation record as to your legal and public policy analysis, as to why the land should revert back to non-governmental ownership status, that would be most helpful in their analysis.

MR. RAYMOND ISAACSON: Correct. And of course, I have to go back and examine the original Atomic Energy Act of 1946 to determine what reference there might be there.

We do recognize also that Atomic Energy Act of 1946 provisions for payments in lieu of taxes were provided for. However, they were never collected. There were some funds provided to the City of Richland but to my knowledge none have ever been provided to the county. Yet the county must maintain all the infrastructure required to support the Hanford Reservation, including services to those people who reside in the unincorporated area that still work on the Hanford Site. And so there are some other issues that need to be addressed and perhaps redress provided in those instances, 
as well.

MR. ROY EIGUREN: As I say, that legal analysis and public policy analysis as to that reversion issue will be very helpful.

It's not that we're trying to put, you know, the tap on the government, but having gone, literally, through hell last year in trying to balance this budget and being forced to reduce our budget, as I say, by six percent in the face of increasing inflation, it made it painfully obvious that the Department of Energy and its contractors were not carrying their fair share of the burden to provide the infrastructure to support that large industry that does exist here in Benton County.

MR. RAYMOND ISAACSON: Yes.

MR. ROY EIGUREN: If you would provide that, we would greatly --

MR. RAYMOND ISAACSON: We may have to hire some consultants to do that. It would impose a cost burden on this county, which we are not prepared to do at this time. We would hope that the funds that's essential to provide the background information could be provided by the Department of Energy.

MR. ROY EIGUREN: I'm sure that the Department would be glad to have further consultations with you to discuss that issue and try to bring some resolution to it. 
MR. RAYMOND ISAACSON: All right. I appreciate that very much. Thank you.

MR. ROY EIGUREN : Thank you, Commissioner.

We'll receive your written comments and mark them as Number 11 for the record, and include them as received. And we do appreciate your coming here, Commissioner, to present both your written as well as your oral testimony.

I would ask at this point, if there are additional individuals in the room here who have not had the opportunity to do so, we would be glad to give you that opportunity at this point. If not, it would be our intent to stand in recess until the hour of $8: 30$ p.m. this evening, in the event that we do have additional walk-in individuals walk in and register, commenters, who would like to comment, we will receive their comment.

If we have no one that does so, walk in prior to 8:30, the record will automatically and officially close for this, the July 1lth, 1989, Richland, Washington, public hearing at precisely 8:30 p.m.. Thank you.

\section{(Short recess.)}

MR. ROY EIGUREN: We'll go back on the record at $7: 25$ on July the 11th, 1989.

First I would like to correct the fact that the 
Hearing officer throughout the course of this hearing has inadvertently stated June lith as the date for the hearing when in fact it actually is July 11 th, and secondly, I would like to point out that the comments made by Commissioner Isaacson on behalf of Benton County were his personal comments as opposed to an official position as expressed by the County Commission.

(Recessed at 7:30 p.m.) 
STATE OF OREGON )

County of Umatilla, ss.

3

4

I, WILLIAM J. BRIDGES, do hereby certify that at the time and place heretofore mentioned in the caption of the foregoing matter, I was a Registered Professional Reporter and Notary Public for Oregon; that at said time and place I reported in stenotype all testimony adduced and proceedings had in the foregoing matter; that thereafter my notes were reduced to typewriting and that the foregoing transcript consisting of 62 typewritten pages is a true and correct transcript of all such testimony adduced and

proceedings had and of the whole thereof.
WITNESS my hand at Pendleton, oregon, on this day of July, 1989. 
-

.

\section{.}




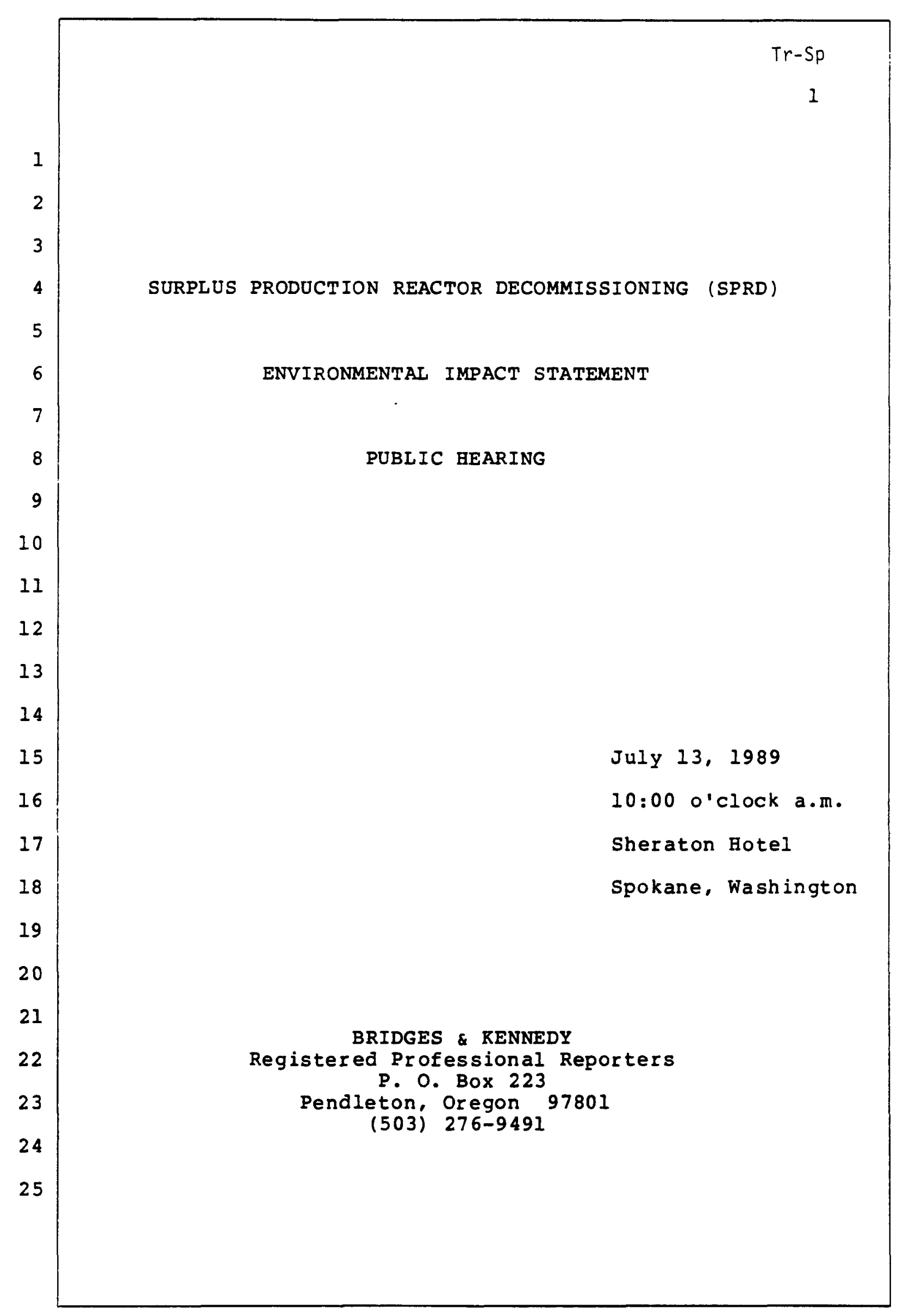




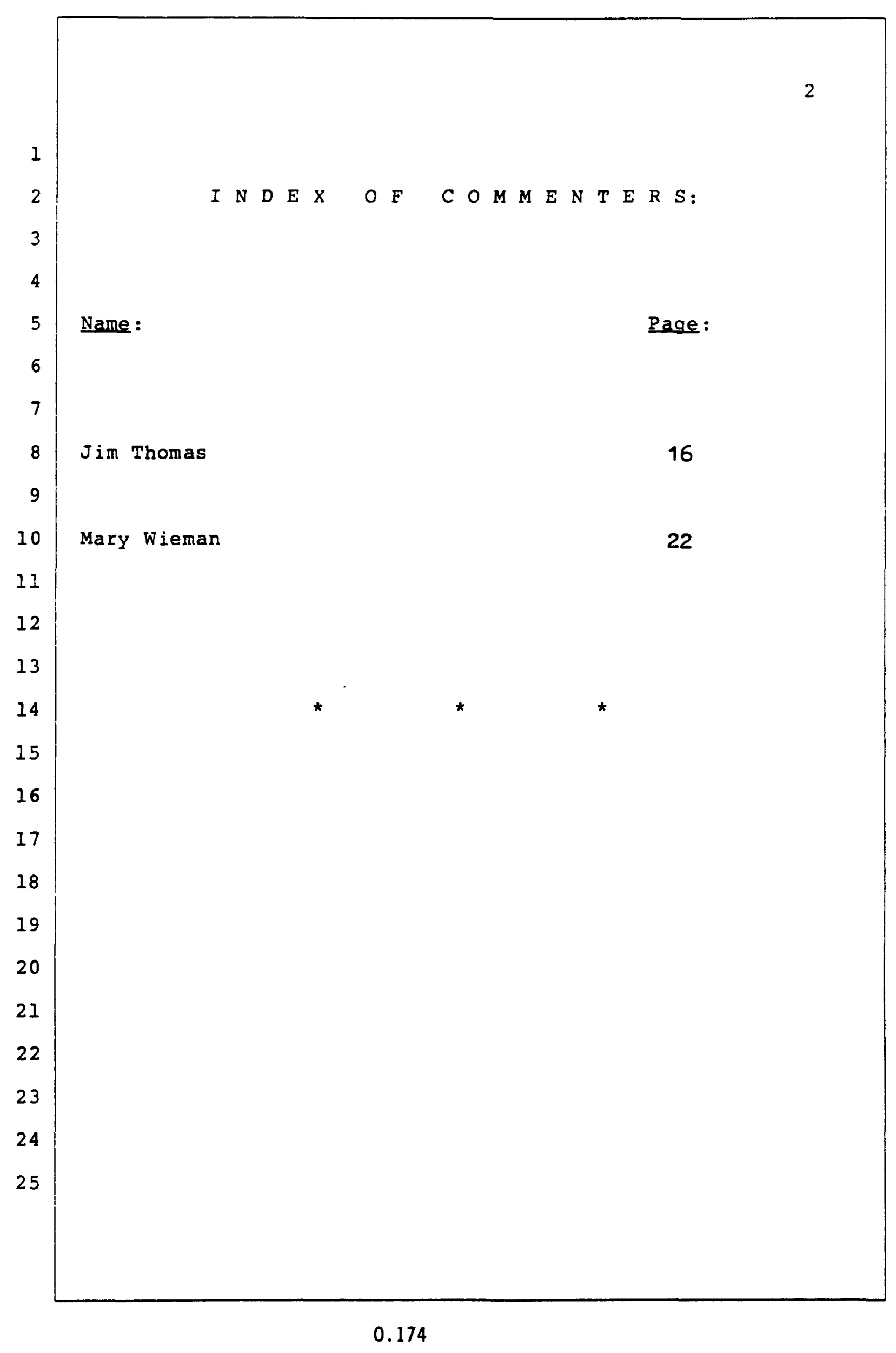


Because these remarks are identical to the first 16 pages of the Richland transcripts, they are not repeated here.

At this point I would be glad to respond to any questions that you have about the procedures or the conduct of this hearing.

If there are no questions, then we'll go ahead and begin the receipt of comments from those of you who have pre-registered as well as anyone else who would like to comment.

The first commenter today is Mr. Jim Thomas. MR. JIM THOMAS: Good morning. MR. ROY EIGUREN: Good morning. MR. JIM THOMAS: My name is Jim Thomas and I am staff researcher for HEAL, the Hanford Education Action League. Our address is South 325 Oak 'Street, Spokane, Washington, 99204 .

HEAL endorses the immediate one-piece removal option for all eight reactors, including the B-Reactor. The main reasons HEAL supports the immediate one-piece removal option are: 
One, it moves the reactors which are still

radioactive away from the Columbia River. the reactors should be buried away from their present location near the Columbia. By being along the river, the reactors would remain too accessible by the general public. The option of leaving them in their present location and burying them under a mound of dirt and gravel is not a demonstrated technology. The EIs does not even offer an estimate of how long the quote/unquote, engineering barrier might last before allowing the contaminated reactor blocks to be exposed to the environment. Two. By doing the job immediately, citizens have a greater assurance that the reactors will not be forgotten, that Hanford will be cleaned up, and that the federal government will restore the land to public use. It will also make it possible to keep the entire Hanford mess within the 30 year cleanup agreement.

In answer to a series of questions by HEAL on the Draft Environmental Impact Statement, Department of Energy responded in part that the start of the decommissioning will depend on the availability of funding and on the priorities established by the Department. Again, we apparently have a case of the Department not respecting the will of the citizens it is supposed to serve. On numerous occasions over the past several years the citizens of the northwest have made it abundantly clear that we want Hanford to be cleaned up 
immediately. We now have the greatest likelihood of obtaining the necessary funding and skilled work force to safely dispose of these atomic age relics. If we wait for 75 years as is proposed by two of DOE's options, we run a very high risk of not being able to complete the job of decommissioning.

Three. This option requires the least amount of land area to be barred from public access. HEAL has repeatedly raised the point that there is no overall government strategy for minimizing the amount of land at Hanford which will have to be off limits for centuries and in some cases millennia. We again call upon the state, EPA and the Department of Energy to develop a plan which will limit to the greatest extent possible the amount of land at Hanford which will be fenced off and in effect turned into a national sacrifice zone. Before such a plan is in place, it is only common sense to pursue those cleanup options which require the least amount of area that will be left contaminated. There is one other point which should be addressed. At various places throughout the Environmental Impact Statement, the Department of Energy states that once the reactor areas are cleaned up, they will be available for other DOE use. The Draft Enviconmental Impact Statement goes so far as to say that the federal ownership and the presence on the Hanford site is planned to be continuous. Nowhere does the Energy Department stipulate the basis for its claim to 
Hanford.

HEAL strenuously objects to the Department's regal attitude. The future use of Hanford is a decision which the citizens of Washington State and the affected Native American Tribes should and must make.

Thank you for listening to our concerns this morning.

MR. ROY EIGUREN : Thank you. Mr. Thomas, if I could ask you one clarifying question.

MR. JIM THOMAS: Sure.

MR. ROY EIGUREN : Obviously, you are very familiar with the various remedial efforts planned, and you say HEAL believes that this project should be high in the priority of what should be done in terms of cleanup.

Did you assign any particular prioritization to it? I mean, this set of projects versus other types of remediation projects at the site?

MR. JIM THOMAS: No. Obviously, we think that the continuing contamination that's happening with the operation of PUREX and its support facilities are dumping hundreds of millions of gallons of low-level radioactive water into the soil at Hanford should be stopped immediately. That's obviously, by far and away, the most serious environmental consequence that's happening at Hanford now. That needs to stop first. 
With regards to the decommissioning of these eight reactors and taking them to the 200 Areas is concerned, I think that the cleanup agreement establishes an adequate framework for both public comment and for the state and the EPA to assess the priorities and where in that 30 year time frame the decommissioning should occur.

MR. ROY EIGUREN: So you go to the agreement process as the mechanism for determining the relative prioritization of cleanup activities?

MR. JIM THOMAS: Yes.

MR. ROY EIGUREN: Thank you very much. We appreciate your being here.

Our next scheduled commenter is Mary Wieman.

She's not here. That's my complete list of scheduled commenters. I would ask if there's anyone else here who would like to comment at this point in time. If not, what we propose to do is recess until the hour of 11:00 o'clock at which time Mary Wieman is scheduled to be here. Both Mr. Goodenough and I are available for any questions that you may have in the interval, so in the meantime we will simply go off the record and be in recess until 11:00. Thank you.

(Recessed at 10:30 a.m.) MR. ROY EIGUREN: It is now $11: 00$ a.m. on July 
13th, 1989. We'll resume our public hearing being held in Spokane, Washington, the Departmnet of Energy Proceding Number EIS 0119-D.

The purpose of this hearing is to receive public comment regarding the Draft Environmental Impact Statement that has been prepared to analyze potential environmental impacts of decommissioning eight surplus production reactors located at the Department of Energy's Banford Site near Richland, Washington. This Draft EIS is scheduled to be finalized next summer.

The purpose of this public proceeding is to receive comment from members of the public to assist the Department in determining whether or not the Draft EIS needs to be modified in some fashion prior to its finalization.

The Final EIs, when prepared, will provide environmental information to federal decision makers regarding the selection of decommissioning alternatives for these reactors.

As I mentioned at the outset of this hearing earlier today, my name is Roy Eiguren. I'm an attorney in private practice with the law firm of Iindsey, Hart, Neil and Weigler. I'm an independent third party that has been retained by the Department for the purpose of conducting this meeting.

As a consequence, I am not an advocate for or against the Department's position. My only role is to provide 
interested parties the opportunity to comment on the record relative to their concerns about this particular issue.

Prior to going to recess, we had one commenter, Mr. Jim Thomas, on behalf of HEAL, who made his comments.

We now have our second scheduled commenter who is here, ready to testify this morning. This is Mary Wieman. You have five minutes for your comment. We would ask if you come up to the podium, please, use that so our court reporter can get down all of your comments. You do have five minutes for comment. If you would like to go longer than that, you are free to do so.

MRS. MARY WIEMAN: Like the vast majority of the American citizens, I wasn't consulted when nuclear weapons were developed originally, decades ago, but I'm taking the opportunity to speak to you DOE representatives today on nuclear reactor decommissioning alternatives.

In my opinion, stand-by $\mathrm{N}$-Reactor should be decommissioned, along with the eight surplus production reactors, since it appears to be in danger of Columbia River flooding from a 50 percent Coulee Dam failure, like seven others; that C-Reactor is within three meters of that fate; and that $B$-Reactor should not be included in the National Register of $\mathrm{Histor}$ ic Places for the same reason. Photos of the latter reactor will have to suffice for the record. From a map, it appears that 100 Areas aren't as 
distant from the river bank as are the 200 West Areas, when one piece removal and waste disposal are being considered. Immediate removal the greater distance is desirable. But decontamination measures could be affected at the existing reactor sites, instead of at the 200 West Areas, as an alternative.

a highly protective barrier to prevent new radioactivity

Hopefully, the 200 West Areas will be provided with leaking into the soil. mounting continuously, due to continuous price inflation, so it can't be too soon for decommissioning to begin.

problems, which I don't need to describe to you. There

Further delay will only worsen the present

should be some way in which the radionuclide tritium can be salvaged to preserve the usefulness of existing nuclear we apons. we apons.

To conclude, I'm a proponent of the immediate over 12 years' time one-piece plus the reactor block removal but still on the Hanford Reservation Site alternative, with the changes noted.

MR. ROY EIGUREN: Two minutes and 20 seconds. Thank you.

MRS. MARY WIEMAN: Is that all? MR. ROY EIGUREN: Yes. We have no questions for 
you. So we thank you very much for being here.

We would like to receive your written comments, if we could. We will include that in the record. This will be Exhibit Number 12 for the record.

The written comments of Mr. James Thomas on behalf of HEAL will be included in the record as Exhibit Number 11. I would ask if there is anyone else in the room who would like to comment who has not had the opportunty to do so. We would be glad to have you go on the record.

If not, given the fact that we have no other scheduled commenters at this time, we'll stand in recess until the hour of 7:00 p.m. this evening. In the event that we do have someone who presents themselves at the registration table before the hour of 5:00 p.m. today, we'll go ahead and reopen the record and take their comment when they arrive.

So we'll stand in recess, as I mentioned, until the hour of 7:00 p.m. this evening unless and until we have additional commenters who wish to testify. Thank you.

MR. ROY EIGUREN: It is now $8: 30 \mathrm{p} . \mathrm{m}$. We have been waiting since 11:15 this morning for other persons who wished to speak, and we have not had anyone register to speak. 
1 Therefore, the record is closed at this time. 2

3

4

5

6

7

8

9

10

11

12

13

14

15

16

17

18

19

20

21

22

23

24

25 
STATE OF OREGON )

) ss.

County of Umatilla,

I, WILLIAM J. BRIDGES, do hereby certify that at the time and place heretofore mentioned in the caption of the foregoing matter, I was a Registered Professional

Reporter and Notary Public for Oregon; that at said time and place I reported in stenotype all testimony adduced and proceedings had in the foregoing matter; that thereafter my notes were reduced to typewriting and that the foregoing transcript consisting of 25 typewritten pages is a true and correct transcript of all such testimony adduced and proceedings had and of the whole thereof. WITNESS my hand at Pendleton, Oregon, on this 24 day of July, 1989.

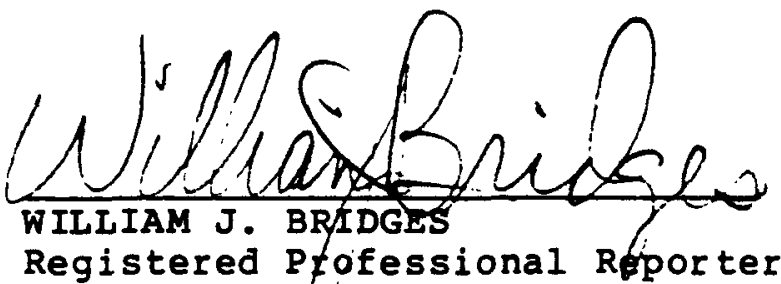
Notary Publif for Oregon My Commission Expires: 6/2/90 



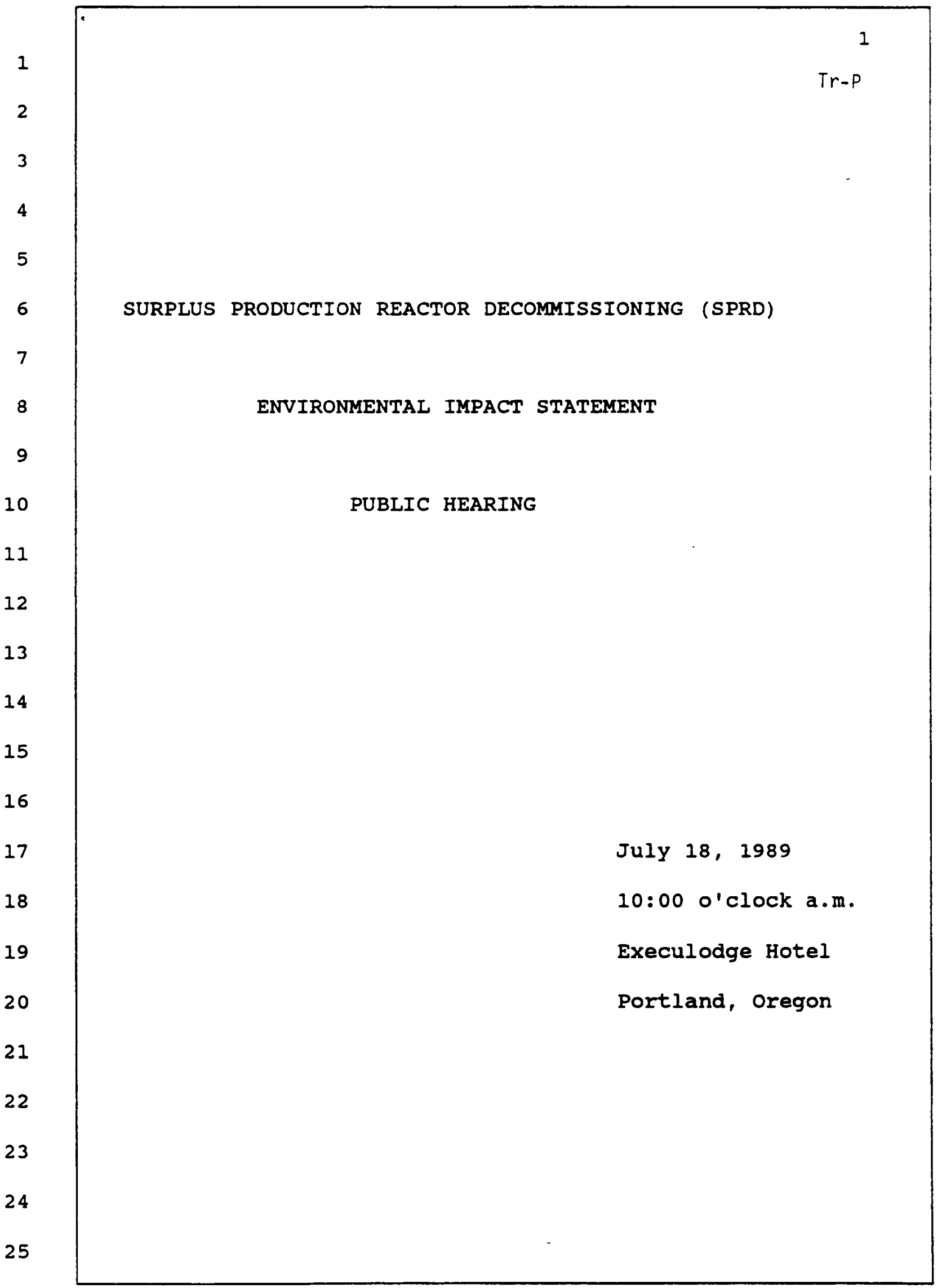




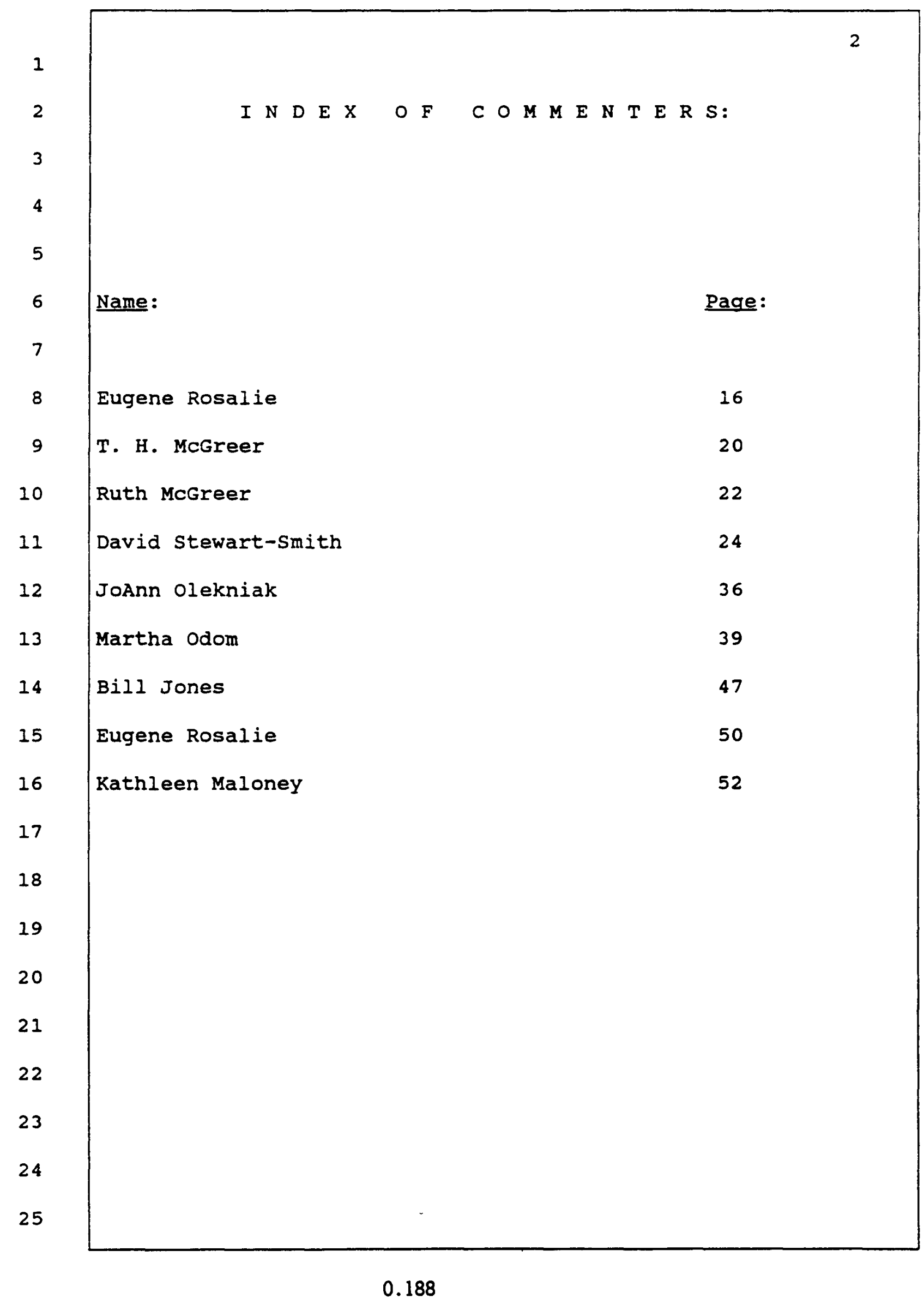


Because these remarks are identical to the first 16 pages of the Richland transcripts, they are not repeated here. 
At this point I would be glad to respond to any questions you may have. If there are none, we'll just go ahead and begin to receive comment.

MR. MCGREER: I have a question about the timing. The 20th is the day after tomorrow.

MR. EIGUREN: If I said the 20th, I meant to say the 28 th.

MR. MCGREER: That's what you said the first time.

MR. EIGUREN: The 28th. Excuse me. With that, then we will go ahead and receive public comment, and our first commenter is Eugene Rosalie. First give your name and address for the record.

MR. ROSALIE: My name is Eugene Rosalie and I represent Northwest Environmental Advocates at 408 Southwest Second, Suite 406, Portland, Oregon. ZIP code, 97204.

MR. EIGUREN: Thank you.

MR. ROSALIE: We will submit written comment by the July 28 th date. I do have several oral comments that I would like to make at this time. First of all, we would like to say we are in support of what is known as -or outlined as option one, which is the immediate onepiece removal of the eight reactors. We believe it's imperative that these reactors be removed from the 
Columbia River as soon as possible.

2

3

4

If the Department of Energy is serious about cleaning up the Hanford site, they will choose the immediate one-piece removal.

Second, I would also like to go on record opposing the designation of the $B$ reactor as a national historic site. I think the reasons for this are very clear. The B reactor was involved in making plutonium for the bomb dropped on Nagasaki. We do not believe that this is one of the bright spots in American history. In fact, it is a black mark in American history, and thus the $B$ reactor should not be designated as a national historic site.

\section{I guess my final comment would be -- has to} deal with the inclusion of the $\mathrm{N}$ reactor in the decommissioning plan. In the EIS it states that no further long-term use of any of the eight surplus reactors has been identified by D.O.E. and that D.O.E. has declared them surplus. We would like to see a statement from D.O.E. as to why the $\mathrm{N}$ reactor is not included in the decommissioning plan. That's about all the comments I have right now. MR. EIGUREN: Could I ask just one clarifying question?

MR. ROSALIE: Sure. 
MR. EIGUREN: You indicated that your group's

position, as option one, is the preferred alternative, because that would be the most immediate --

MR. ROSALIE: Option one as stated by you.

MR. EIGUREN: Right. I assume that you're

generally familiar with the various remediation programs

that are being contemplated by D.O.E. for the Hanford

site. To the extent that you are, where would you place

the decommissioning issue? Towards the very top of the

list priorities?

MR. ROSALIE: Well, that's a hard one. I

haven't thought about it. Everything is a priority, and

right now it's hard for me to say where that would fall.

I think it's something that needs to happen right away

along with everything else. I mean, there is a lot out

there and it's our understanding that there is some leaks

from the reactors into the soil and those leaks need to

be taken care of. It seems in the greater scheme of

things we are talking about approximately $\$ 190$ million

to do this work and get it started and get it going. And

I think in terms of -- It needs to happen along with

everything else and we need to make that commitment to do

it. And if D.O.E. is interested in showing the public

that it's serious about cleaning up Hanford and about

cleaning up the other military production sites around 


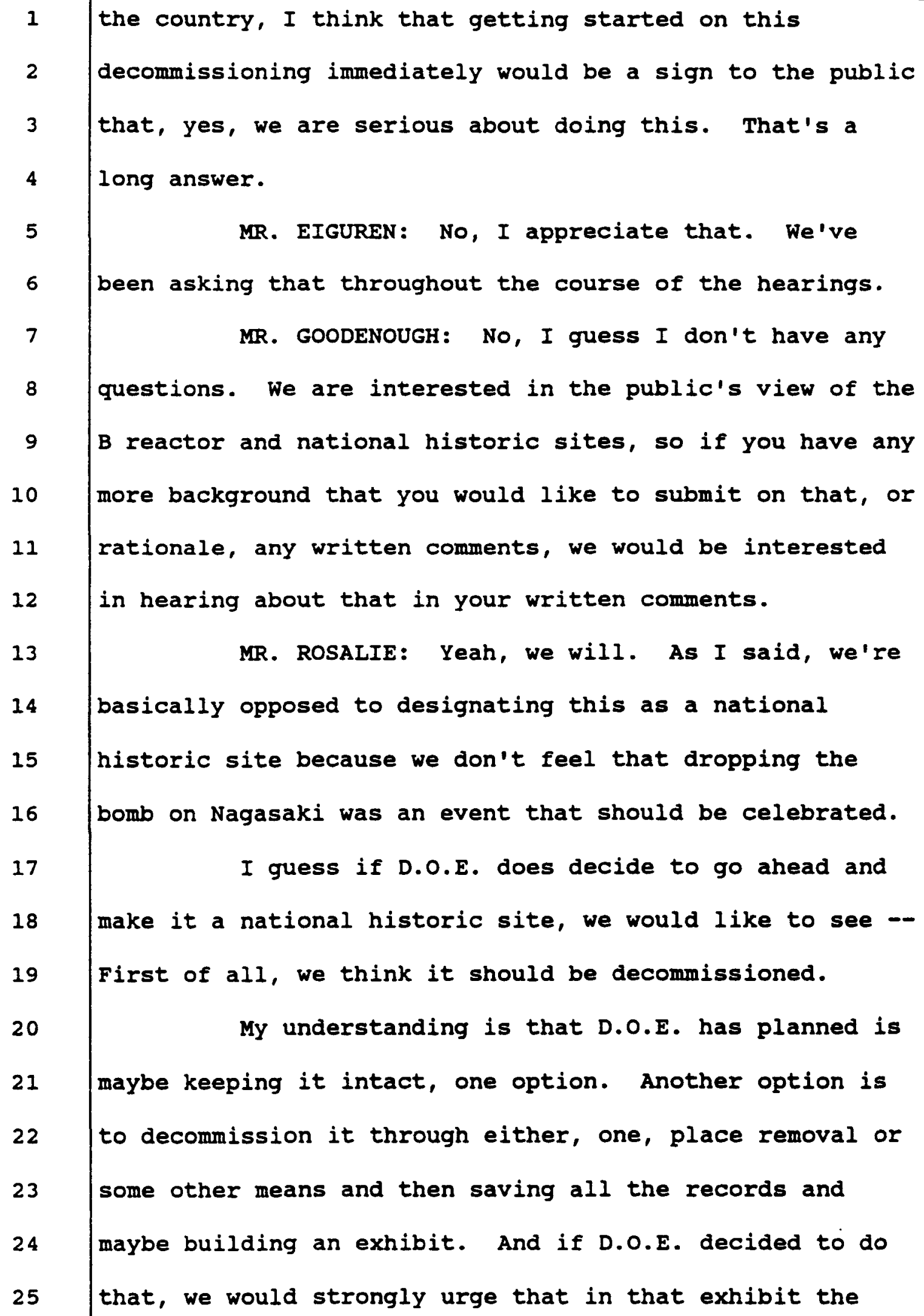

3




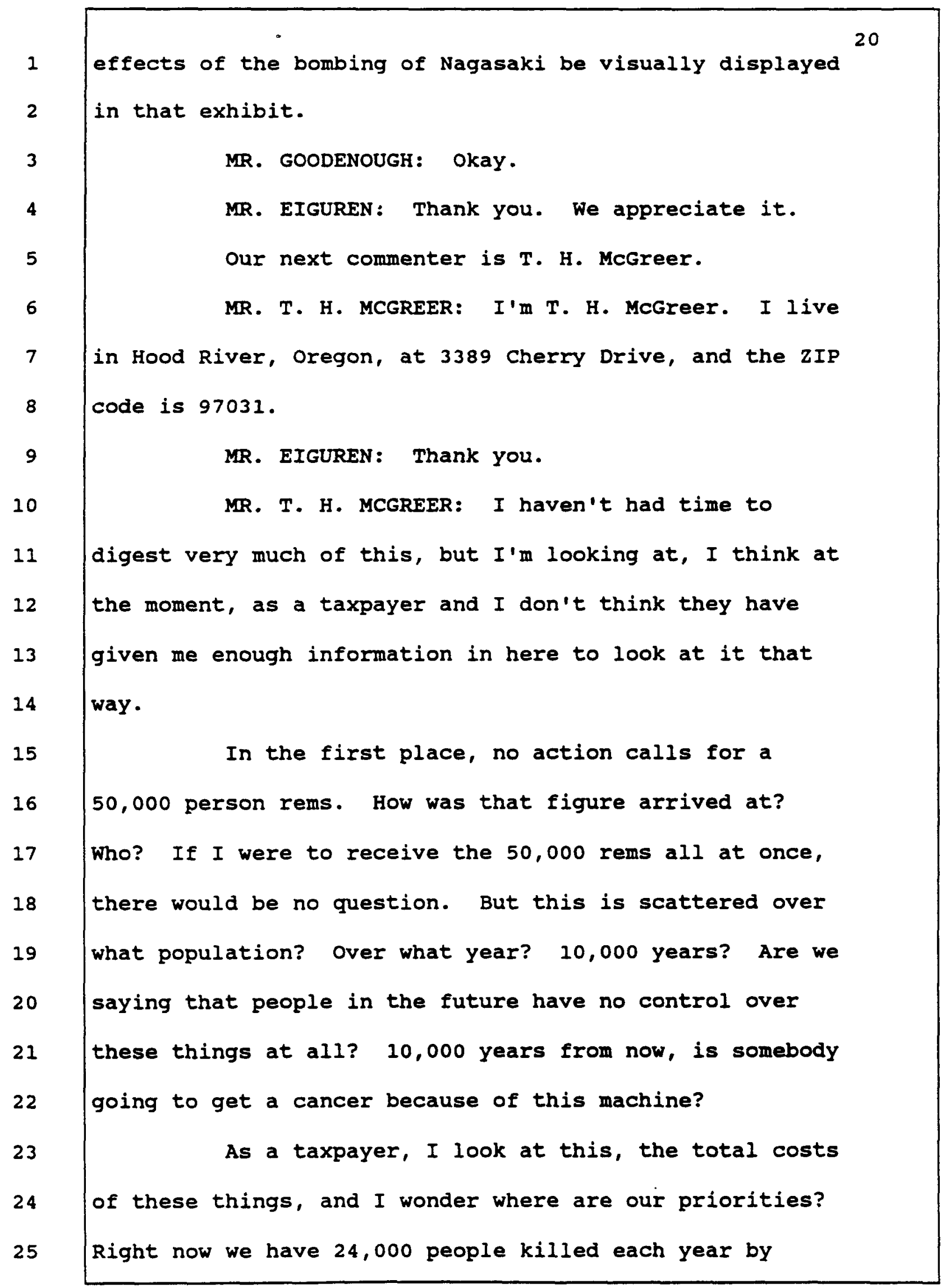


drunken drivers, most of them themselves. That difference of $\$ 140$ million, how many lives would that save versus spending $\$ 140,000$ to - or $\$ 140$ million to remove this reactor someplace else and bury it again?

Certainly the railroad people have given us an example of far less money and they've reduced the railroad crossing injuries and deaths remarkably. What could we do with $\$ 140$ million to reduce the deaths of cancer from tobacco? How many thousands of people can be affected? The same thing applies to alcohol-related deaths. What can we do educationally with our children, who some of them become addicted to alcohol in the grade schools. With that $\$ 140$ million would apply to educating these children and perhaps saving them? The same thing could be said about dope. Who knows which one of our daughters is going to become a prostitute to get enough money to maintain her habit.

Where are our priorities? I see this 50,000 rems. I know that would kill a few people, but who? Would somebody over in Eastern Oregon be affected by this? Are the people downriver going to be affected by it? Isn't this a "what if" proposition? What if there is a leak among these reactors? What if that leak gets into the groundwater? What if that leak gets into the Columbia River? What if som? fish becomes contaminated 
and some person eats the fish and some nuclide causes a cancer 5,000 years from now versus spending our money now for some of these other projects that prove and result in immediate lifesaving and better quality of life?

Now, I expect that I'll try to put this in

writing in the next seven or eight days and maybe get some better figures, but I would appreciate it if you could tell me where this 50,000 figure number comes from and where these cost estimates come from. You know, are these something that somebody just reached up and got a number out of the sky, or are they real figures that you can be documented?

MR. EIGUREN: Thank you. I have no other individuals who are registered to comment at this time. I'd ask if there is anybody in the room that hasn't commented that would like to comment, I would be glad to give you the opportunity at this point. Yes, ma'am? MRS. RUTH MCGREER: I am Ruth McGreer from Hood River.

MR. EIGUREN: Just a minute. Can you hear her? THE COURT REPORTER: I can hear her fine. MRS. RUTH MCGREER: Can you hear me fine? THE COURT REPORTER: Yeah. Thanks. MRS. RUTH MCGREER: I would like to know -- In speaking to other people, one of the questions that pops 
up is, who decided the early safety of Hanford? How safe is it, which they think it isn't. Nowhere in here do I find this record. How did you get there?

MR. EIGUREN: In the procedure for these

5

hearings don't provide for us to comment back. What we will do is we will go ahead and provide in writing a response to your oral questions.

MRS. RUTH MCGREER: Thank you. Thank you. MR. EIGUREN: Anyone else? If not, our next scheduled commenter is scheduled for one o'clock. He is speaking on behalf of the Oregon Department of Energy and is presenting the state's position. So what we'll do is we'll go into recess until the hour of one o'clock. However, in the event we should have someone else that would arrive at the door that would like to go on the record, then we will go on the record, if necessary. We will be in recess until 1:00 p.m. record and I will reconvene. This is a July 18th, 1989, hearing being held in Portland, oregon. This is the United States Department of Energy proceeding 0119-D, which is being held for the purpose of receiving comments

$$
\text { (Recess: 10:35 a.m. to 1:00 p.m.) }
$$

MR. EIGUREN: We'll now formally go back on the regarding the Draft Environmental Impact statement, which has been prepared to analyze the potential environmental 
impacts of decommissioning the eight surplus production

reactors located at the Department of Energy's Hanford site in Richland, Washington.

The DEIS when completed will provide additional environmental information to federal decision makers regarding selection of the decommissioning alternative for these reactors.

As I mentioned earlier, my name is Roy Eiguren, an attorney in private practice. I have been retained to be the hearings officer for this series of public hearings being held in Spokane and Seattle, in Portland and the Tri-cities to receive comment on the Draft EIS. We commenced the hearing this morning at 10:00 a.m for the purpose of receiving public comment. We did receive comment from two members of the public, at which time we then went into recess until the hour of one o'clock for the purpose of receiving comment from a representative of the state of oregon.

So without further adieu we' 11 go ahead and introduce David stewart-smith, a member of the oregon Department of Energy staff, speaking on behalf of the state of oregon. We welcome you, Mr. Smith, and we would ask that you first start by giving us your designation title for the record and proceed from there. MR. STEWART-SMITH: Thank you, Mr. Hearings 


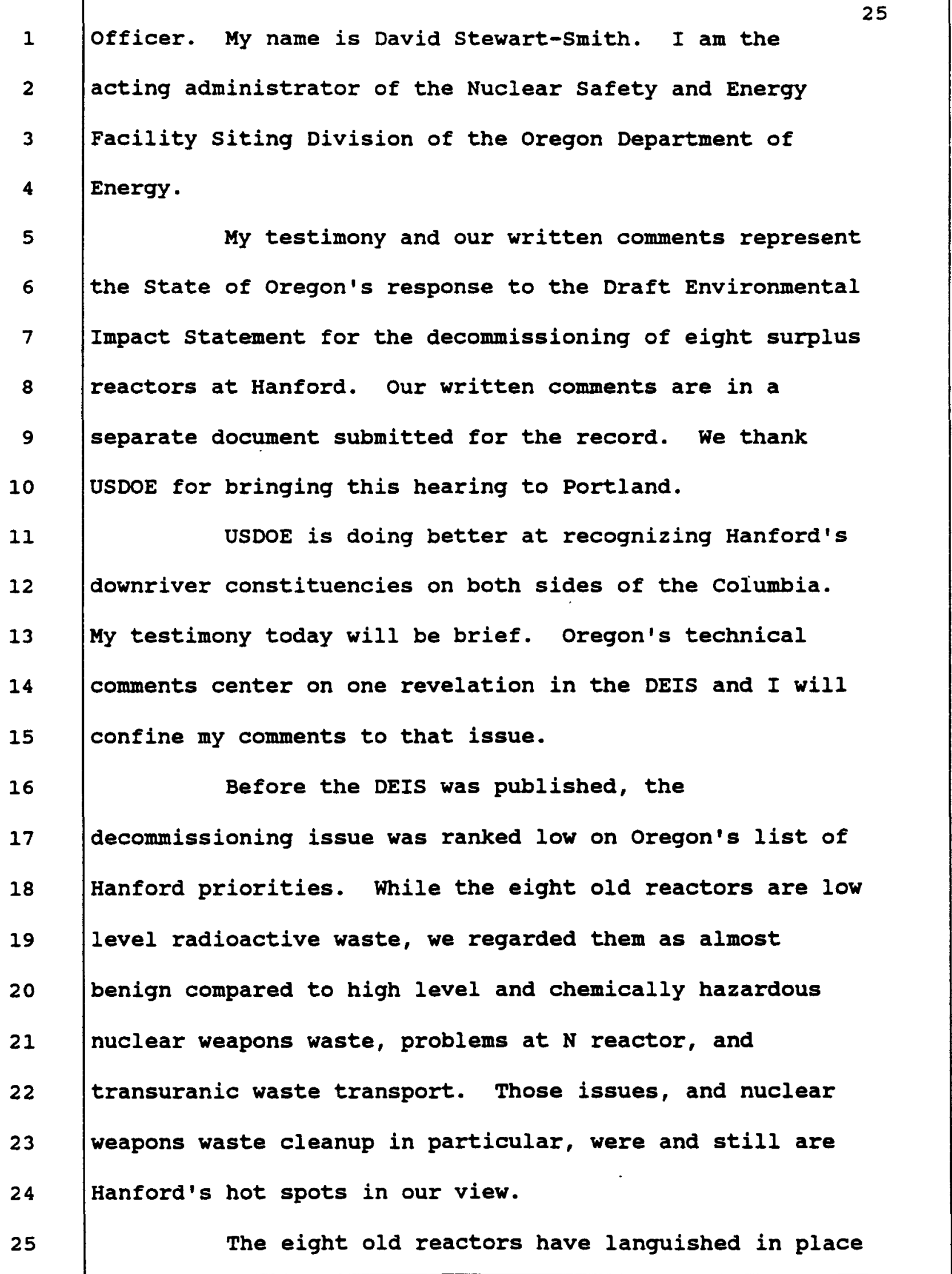


for 20 to 30 years. We didn't expect any surprises in the decommissioning DEIS. We were, in fact, poised to

old reactors posed no threat to the yeople or the environment, oregon was ready to counsel against any decision that might compromise cleanup of Hanford's high level and transuranic nuclear weapons waste. We cannot offer that counsel now. In fact, we're compelled to say that the eight reactors, their fuel storage basins, and any residual contamination should be moved away from the river immediately.

Why? Because the DEIS, in an almost casual aside, notes that a leak in a fuel basin has left a "significant inventory" of radionuclides and contamination.

$$
\text { That's it. One sentence, but it raises a host }
$$
of questions: How large was the leak? Precisely what is a "significant inventory" of radionuclides? Is there a flume? If so, where is it and where will it go? How fast will it travel? How much soil has been contaminated? Can the contamination be retrieved and disposed? What are the implications of various characterizations? Is the river in imminent danger? Does this mean that there is a higher likelihood of other undetected leaks? How soon will USDOE finish its studies 
on the leak and its implications? And last, in view of this litany of unknowns, how can USDOE opt for any action now but to complete an immediate removal of the reactors and the fuel basins? questions, Mr. Hearing officer, I would be happy to answer them.

That concludes my remarks. If you have any MR. GOODENOUGH: No, I don't have any questions. MR. EIGUREN: If I might, Mr. Smith, you had indicated in your testimony that the oregon Department of Energy had gone through essentially a ranking process in terms of priorities of issues that you felt should be addressed at the Hanford by way of remediation?

MR. STEWART-SMITH: Uh-huh (affirmative response). MR. EIGUREN: I am taking it that in terms of that initial inventory, that the decommissioning issue was relatively low in priority and now based upon the information you receive from this Draft document, that's now changed?

MR. STEWART-SMITH: That's right. Our understanding has changed because we were not aware of any fuel basin leak that happened at one of the reactors. We were not aware of an additional inventory of underground radioactive contamination. If it had not been for that, we were in fact ready to suggest that 
there are ever higher issues that the available federal funding needs to be applied to first at Hanford. Certainly cleaning up the high level waste in single or double-shelled tanks is a good example of that, as well as potential retrieval of the transuranic wastes at Hanford.

However, with the information and the scarcity of the information of DEIS on the potential for leaks in the past from these reactors, we have to suggest that concurrent cleanup, decommissioning of the old reactors as well as moving forward on high level waste vitrification at Hanford is necessary.

MR. EIGUREN: Okay. I might note for the record, Mr. Smith, that given the fact that the Department's position was publicly stated prior to the hearing and the department was aware of that, the department is in a position to be able to respond to some of the specific concerns that you've raised in advance of completing the final DEIS, which is scheduled a year from now. So, I'm sure at the conclusion of the hearing on the record today, they'll be glad to provide what information they have in hand that can be given to you and any additional information that you might request. MR. STEWART-SMITH: I would be happy to talk to them. 
MR. EIGUREN: Thank you very much, Mr. Smith.

We appreciate your being here. We will take the written testimony, provide it the oregon Department of Energy. I'll mark it as Exhibit No. 12 for the record of this proceeding and include it as received. So we have two separate sets. We'll mark it as Exhibit 12, which was the testimony presented by Mr. Smith, and Exhibit No. 13 will be a more detailed document in response to a number of specific issues in the Draft Environmental Impact statement.

At this time we have no further individuals who are registered to comment this afternoon. I'd ask if there is anybody in the audience who has not had a chance to comment, if you would like to do so, we would give you that chance at this point. If not, we will then be in recess until the hour of 7:00 p.m this evening, which pursuant to our Federal Register notice is the next time we will be going back into a hearing mode. I will note for the record, however, that we will be here, me, meaning myself, and the hearing panel as well as D.O.E. staff until 5:00 p.m. this afternoon to go back on the record in the event that we have any individuals show up that would like to comment on this Draft Environmental Impact statement. So with that, we will be in recess until 7:00 p.m. this evening. Thank you. 
Because these remarks are identical to the first 16 pages of the Richland transcripts, they are not repeated here.

At this point I have three individuals who have registered to comment. We'll take them in the order that we received them and then also if anyone else would like to comment, you will be free to do so once they have given their comments.

Our first scheduled commenter is JoAnn Olekniak. THE COURT REPORTER: JOAnn, if you could give your full name and spell your last name? MS. JOANN OLEKNIAK: MY name is JOAnn. MY last 

name is spelled O L E K N I A K.

I'm testifying on behalf of myself this evening and my comments are going to be brief. I am planning on submitting substantial written material to the record before it closes.

MR. EIGUREN: Thank you.

MS. JOANN OLEKNIAK: I favor the immediate removal and burial of all of the reactors and I think the $N$ reactor should be included in that list. We don't want to see the $N$ reactor functioning again as it's designed purpose. I think it should also be removed.

I would like to talk some about the concept of having the $B$ reactor be part of the National Register of Historic sites. It's just unbelievable to me that the U.S. Department of Energy is even considering such a plan. The times that I have heard B reactor described, phrases such as "engineering marvel", "ended World war II", et cetera, et cetera, have been thrown around and I think that it is exactly those kinds of limited thinking that has gotten us into our present predicament where we have some 60,000 odd nuclear weapons on the planet threatening our lives.

The B reactor, which produced the plutonium for the Nagasaki bomb, is responsible for the immediate deaths of some 80,000 people in the city of Nagasaki, 
with many more dying later because of radiation-related illnesses. To describe the $B$ reactor and its purpose as an engineering marvel is just beyond belief. It would be as though someone was describing the gas chambers in Germany and using glowing terms as to how effective they were in exterminating the people.

And I think we need to come back to real values of where we enhance life and respect life, and we cannot do that if we hold up places like the B reactor for people to visit and marvel at. So, I just abhore the very thought of placing $B$ reactor on the National Register of Historic Places.

The other thing that I would like to mention is these public hearings -- public such as they are with only a sprinkling of us here to testify -- I think enough of us have been through this process enough times and have watched Hanford issues over a long enough period of time to really feel very deeply that this whole process has nothing to do with us voting with our presence about which of the various probably inadequate plans are really going to solve the problem.

Now, you can read the document; it's an inch thick: and if you have the time and you really want to keep that by your bed and pick it up and maybe do a little light reading before you fall asleep. Maybe there 
are some people in this room that have read it and really

with it is it doesn't do any good for us to vote about

which of those proposals we think is preferable because if that were the case, then not only would many of

Hanford's facilities now be closed, but many of them

would not ever have been built if our little voices were actually taken into account.

And so I protest the whole process even as I

stand here before you. That's it. one more thing. I --

Hanford is no longer the secret, hidden project that it

has been for so long in the early '40s, during World war

II, and during the cold war times in the '50s and '60s.

We have watched with horror all of the things that have

happened there and the people that have been directly

affected by Hanford, and we're here to say that those

times are over and, repeatedly, we're going to tell you

that in a million different ways. Thank you.

MR. EIGUREN: Thank you. Our next commenter is

Martha Odom.

MS. MARTHA ODOM: MY name is Martha Odom. Last

name is $O D O M$.

My first question is I really don't understand

why the decommissioning of the reactors is essential, the stage of major production number, when considering the 
major problems at Hanford, this is a relatively small

one. And I don't want to downplay the problems of the reactors, but in comparison to the tank farm which in one leak in 1973 released 115,000 gallons. And I believe the 1988 total was something like 90,000 gallons of not only highly radioactive, but corrosive material is leaking.

This seems like a pretty fancy production number for relatively strong -- a small piece of the problem.

I do recall a quote earlier this year, I think it was January, when D.O.E. was responding to the total for 1988. The answer was, "The tanks get old and they leak. We're monitoring them. The tanks are a real problem. They have been an ongoing problem." And we will not be amused or deferred or distracted by, "Oh, look, we can move reactors." I would like to point out in response to a D.O.E. comment today about, "Well, the tanks have been public knowledge for a long time," that the manager of the group responsible for the analyses of leak detection brought the data to the attention of D.O.E., and it was suggested to him that it might be in his best interests not to report these things. And in a subsequent D.O.E. Rockwell report said that no leaks were determined and it was not cost beneficial to try and find a cause for these abnormal readings. 
We also have a concern that the test wells at

Hanford, the majority of which are unlined until early in this decade or until early 1980s, the test wells were unlined completely. In recent years I understand that the wells have been 1 ined and there does seem to be an indication that these wells that are designed to monitor groundwater contamination serves as the elevator, the conduit, the jet stream to get the contamination down into the groundwater.

Further, we have a question about is there groundwater technology? How do you vacuum up the groundwater, clean out the radiation and put it back as groundwater? Is there such technology? It's our groundwater you all are messing up.

I would like to just note that I really didn't want one of these. I think we should conserve paper and I have been told that there were copies available at the Multnomah Library, and I made several phone calls. Several people asked several other people and I believe the two references in the total EIS that they are available at the Multnomah county Library are in error for I find no one at the library who could find one of them.

Within the EIS I found no comparative evaluation of the risk to workers for immediate 
dismantlement and removement versus the release of contamination from the sludge and the leaking storage basins. Those seem to be really critical things. In other documents that I have read, the preferred mode of decommissioning is deferred, secured storage with future dismantlement for each removal because in 50 or 75,100 years allows a considerable amount of decay. So it's much safer in 75 or 100 years to go moving these blocks around. But I find no comparison that said, well, if we leave them there, the storage basins with $X$ amount of sludge are going to potentially put this amount of stuff in.

And there is a little part there that I have an attitude problem with. The D.O.E. has a history of making mistakes, oversights, disinformation and misinformation, so I want D.O.E. to really prove it to me.

\section{will} "Radiation dose". Now, it says radiation dose is a combination of the inventory, the release rates and the transport conditions. I'm going to take release rates just as a piece of this because it moves real easy back to Appendix D. And Appendix D says, well, to determine release rates, we took a lot of published literature and 
1

2

3

4

5

6

relevant reports and studies that had been done.

Sometimes we took them and adapted them and then we used these as part of our formula, and that reminded me a lot of the old whispering story around a circle: The 1948 report goes into the 1953 report that goes into the 1957 report. And then when the whispered story comes out, right here in this one, it never, ever whispers around the circle like it started.

$$
\text { Furthermore, on page D } 5 \text {, here is this one }
$$
paragraph that talks about the release rates of carbon 14 in graphite under dry storage conditions. And to the best of my knowledge, carbon 14 in the graphite is going to be one of the most significant isotopes in decommissioning. this, I'm going to skip some of the technical phrases and just give you the adjectives and the adverbs: "These approximately are a linear function for relative humidity", "statistically equivalent to about 25 percent", "possibly indicating", "it is quite probable", "if this is indeed the case, then the linear relationship might underestimate", "average relative humidity may well be higher", "a linear relationship will probably survive", "a best estimate given the uncertainties in the remainder of the calculations".

I tell you guys, if this was a physics term 
paper, you would have flunked. Okay. Now, that just seemed sort of interesting, but then we take this release page over here at Appendix $E$ and we are talking about radiation dose. This is one big -- one of the three factors that go into radiation dose. Already you've lost me on these approximate and complex equivalents and stuff like that. When you give me a dose of radiation, I don't think you know what you are telling me.

Now, there is this other little piece, you know, that just pisses me off. The doses calculated for this Draft Environmental Impact Statement are based on the metabolism of the standard man. An average male worker obviously does not fit every individual in the general public. Actual doses depend on age and sex specific relationships, body size, metabolism rate. The long-term differences, however, will tend to average out and may not be significant unless you are a three-year-old weighing 25 pounds getting a dose that this says of a 200-pound male is going to get, or unless you are a pregnant woman, or unless you are an elderly person with a somewhat erratic metabolism.

So, first of all, we don't have much confidence in what you say is coming in as release rates, and those translate also to those other things that are based upon the whisper around the circle. But then -- well, you 
know, this is just for the standard average man and any of you who weigh 98 pounds or 25 pounds or are over 70 or

3 a pregnant woman, well, it may not be significant.

Now, I can sort of emphasize -- what does it say? -- "It is also difficult, if not possible, to quantify these differences." So let's turn to page $\mathrm{E} 11$. We have this beautiful formula. Yeah, it's pretty. And we come to the factors involved in testing how plants get radiation, and I'm just going to skip through some of these because it goes on for three pages. It's too complex and difficult to measure the differences in humans, that a three-year-old child will get, what an elderly little lady will get with reduced calcium in her bones might get. But if we are going to measure plants, we can get average air concentration of the radionuclide, deposition rate, concentration in water use for irrigation, irrigation rate, fraction of initially deposited material retained in vegetation, weathering removal constant, time above ground for vegetation exposure, the yield, the fraction of the roots of the plow layer, time for buildup in the soil, soil surface density, thickness of the plow layer, concentration available for plant uptake from residual contamination in the soil plow layer. Sounds like a much more simple factor than if you weigh 30 pounds or 100 or 120 . And 
the hold up time between the harvest and food consumption.

That's a pretty complex formula. It takes up two big lines of a page. I sort of believe that plants give to their equivalent on the whole scale of it, but it does seem interesting that one can't come up with a little bit of a formula that will say at least body weight is involved.

I would like, in conclusion, to answer -- to speak to the B reactor. I find nothing where it talks about it's structurally sound, how it should be the first nuclear bomb park, how would people be secured from other Hanford contamination or contamination in the $B$ reactor. And I do not know how we memorialize, where I think we should never forget, that a hot summer morning in August of 1945 we were responsible for society laid to waste. We are responsible for a half a million deaths, including those of our own fathers, brothers and sons who were sent in after the bomb to bulldoze and to tend the wounded and the dying.

\section{Can we remember this as a historical landmark?}

I think not and I would hate to tribulize the B reactor as an engineering marvel when it is the source of so many deaths and a blot on our history that will remain forever. Thank you. 
MR. EIGUREN: Next scheduled commenter is Bill

MR. BILL JONES: I'm Bill Jones from Willard, Washington, formerly a resident of Southern Grand county in the late '40s when I got a dose of radioactive iodine. What it's going to do to me I don't know, but I am concerned about what's going to happen from now on. I am saddened by the fact that so few citizens attend these meetings, probably because they don't understand half-life and millirams and ignorantly trust the government. Some of them, on the other hand, think that it's worthless and it's a waste of time and people in Washington, D.C., will decide what they want to no matter what these hearings bear.

I'm a member of and represent the columbia River United, a group of people who got together when the shipping port reactor was barged up the river and we've been active ever since. We include Native Americans, board sailors, sports fishermen, and lots of other people who live in small towns along the Columbia River downstream from Hanford. We number about 100 people now and we've come to the realization that in Washington, D.C., our small numbers along the Gorge don't count for very many votes.

One of the things we are doing, we are trying 
to unite the people as a political voice to speak out against what's going on at Hanford. Our number one concern is the water quality in the Columbia River. All our attention is focused on that now. We want it to be clean enough to drink. Our other concerns, we're concerned that the Hanford reservation is a radioactive mess and the D.O.E. itself has 60 billion, 100 billion, 400 billion different amounts that they say it will take to clean it up.

We're concerned that the D.O.E. continues to authorize dumping at Hanford despite the mess, a bigger mess. We're concerned that the D.O.E. has a record of lying and withholding information from the public and we do not agree that burial is a safe way of disposing of anything. You only have to drive through the Gorge in the wintertime and see the ice whiskers popping out of the rock cliffs, out of the basalt, to know how well water travels through there and we know that waste will be leaching into the groundwater. They have already. We don't know how far because there is no monitoring of the river, say, in the area from below the Tri-cities to Bonneville Dam.

We're really in favor of the decommissioning the reactors and including the $\mathrm{N}$ reactor, but we certainly do not think they should be buried. Gas 
storage tank at refineries, not at service stations -- at service stations they just have all kinds of problems when they put them underground -- but at refineries they do not store underground. Underground storage of waste or gasoline or oil or whatever cannot be monitored. I think that scientifically we are a little shortsighted that we haven't considered some type of vessel in an earthquake active zone like Hanford, some type of vessel that goes on the surface where the waste is put in that

Residents of the Columbia Gorge from Umatilla to the Bonneville Dam are downstream from Hanford and are very much concerned about things they don't understand. And there are libraries in The Dalles, Binjon, Hood River, White Salmon and Stevenson and not one of these libraries received a copy of the Environmental Impact study. We do have copies of the Environmental Impact study which we have read which we received from Oregon Senator Wayne Fawbush, but the libraries did not get them.

I note in reading the Environmental Impact Study that the 100-Area is on an alluvial terrace. When I was in school taking geology, alluvium was not rock as the EIS says. Alluvium is soil deposited by this drop when the river slows down. That's an error in the EIs. 
This alluvium terrace in the 100-area is only nine meters above the normal river level, and I don't think it would take much time for radioactive liquids to leach nine meters. That concerns me.

Also, on page 1.19 of the summary it states that Washington Department of Ecology classifies the Columbia River from Grand Coulee to the mouth as A, and the latest thing that I have read, they have stated that human uses are not supported from Bonneville to the mouth, which means taking fish, swimming, wading and so on.

We are, the columbia River United Group, very actively writing to every politician that we can find who's interested. And among the things that we are doing, we are supporting the D.O.E.'s request for cleanup funding in our actions. We think it's time to clean up and we're supporting that 100 percent.

$$
\text { MR. ROY EIGUREN: All right. That concludes a }
$$
list of individuals that I have registered to comment. Is there anyone else here that would like to comment that is not registered? Yes, Eugene?

MR. EUGENE ROSALIE: You asked me a question and I would like to respond further to that.

MR. ROY EIGUREN: Why don't you give your name for the record. 
MR. EUGENE ROSALIE: My name is Eugene Rosalie with Northwest Environmental Activities. You asked me this morning about how I would place this in terms of priorities of cleanup actions out at Hanford, and I have been giving it some thought during the day.

And it seems to me, at least one thing I know that could be dropped or put on hold is the shipment of transuranic waste from Hanford to New Mexico. Obviously, there are numerous problems with the New Mexico site and we don't need to create another Hanford in New Mexico. It's doubtful that the WIP site in New Mexico will ever open anyway and so I think perhaps maybe taking money from the shipment of that transuranic waste, which in my understanding poses very little risk to the public, and using that money to proceed with decommissioning these reactors and doing other work up at Hanford would be more productive.

MR. ROY EIGUREN: Thank you for providing the education. Thank you for coming back. I might add, Gene, that I just finished conducting the SEIS hearings on the WIP project and your point of view is shared by several thousand people in New Mexico.

Are there other commenters this evening that would like to go on the record? I would mention once again that the record remains open through the 28 th day 
of July. Written comments receive the same weight as

leave it with me here this evening or at the registration

table or mail it to the department. We're going to be

MR. ROY EIGUREN: Okay. Note for the record we MS. KATHLEEN MALONEY: I would like to go on

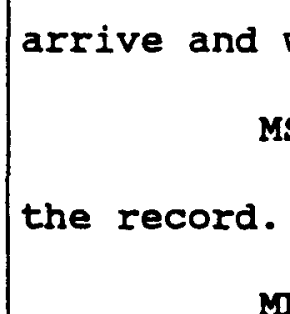


So if that's any indication of the public outreach that you are doing to solicit comment, maybe we should sit down and talk about public outreach programs.

MR. ROY EIGUREN: Point well taken. I have previously submitted for the record a listing of all of the things that the department did by way of public outreach. We will give a copy of that to you.

MS. KATHLEEN MALONEY: Great.

MR. ROY EIGUREN: Mr. Bauman is here and would be glad to visit with you, also, about what they have done. Thank you.

If there is no further comment, we will be in recess until 8:30 to take additional comment from folks who may arrive between now and then. If we have no additional commenters at 8:30, we will close the record at that time. Thank you for coming. We will be in recess until $8: 30$.

(Recess: $7: 40$ to $8: 22$ p.m.)

MR. EIGUREN: Once again, we resume our public hearing being held July 18th, 1989, in Portland, Oregon. It is now $8: 22 \mathrm{p} . \mathrm{m}$. and we have been at recess for approximately 45 minutes. We've had no additional individuals come forward to testify at this public hearing, so, accordingly, by prior decision of the department and the hearing officer, we will now formally 


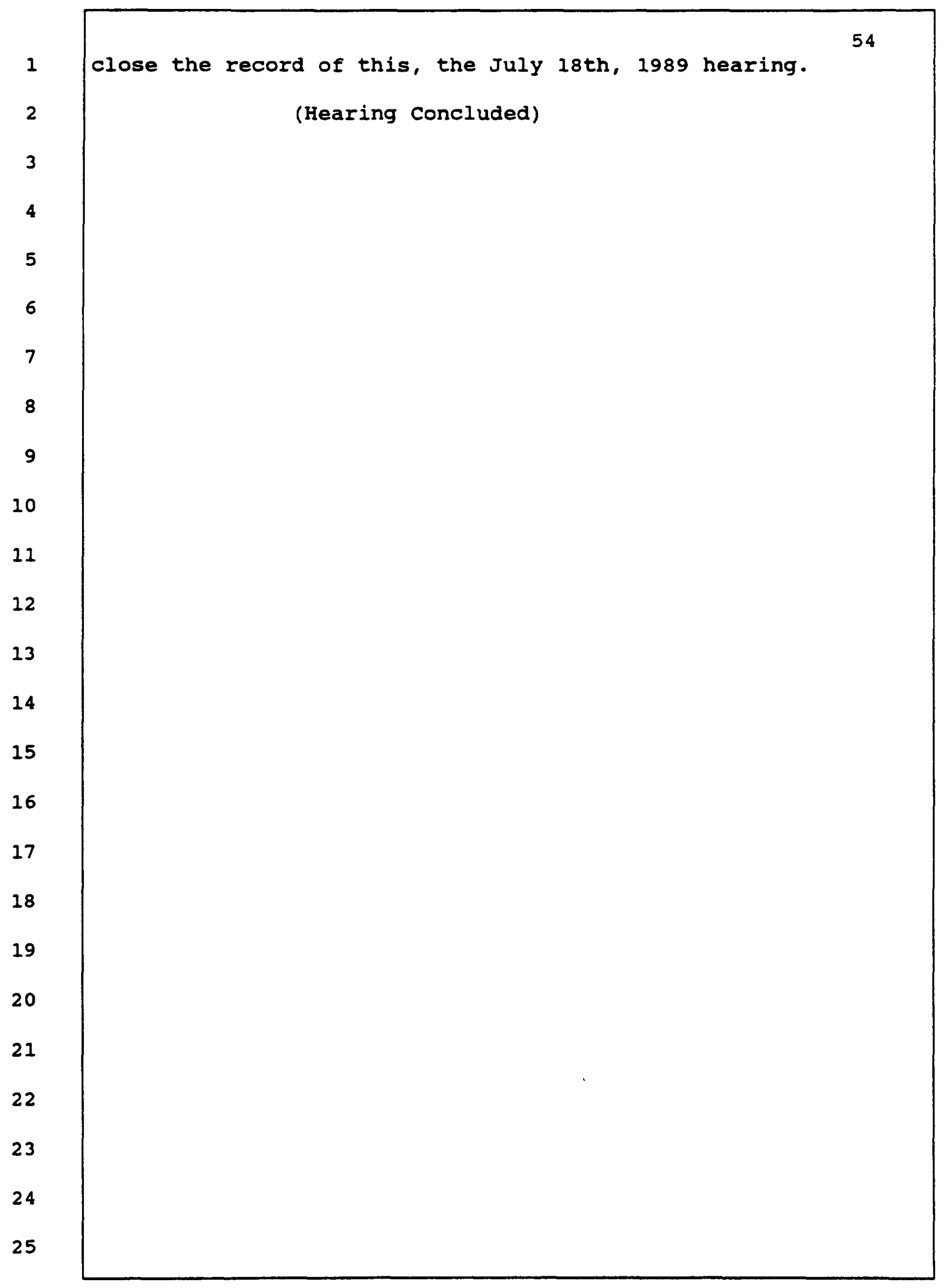


1

2

3

4

5

6

7

8

9

10

11

12

13

14

15

16

17

18

19

20

21

22

23

24

25

STATE OF OREGON )

County of Multnomah)

I, Julie La Fon Henderson, Registered Professional

Reporter and Notary Public for the state of Oregon, do hereby certify the commenters personally appeared before me at the time and place mentioned in the caption herein: that the oral presentation of said commenters was taken down by me in stenotype and thereafter reduced to typewriting; and, that the foregoing transcript, pages 1 to 54 , both inclusive, constitutes a full, true and accurate record of said hearing, and of the whole thereof.

Witness my hand and notarial seal at Portland, Oregon, this 24 th day of July, 1989.

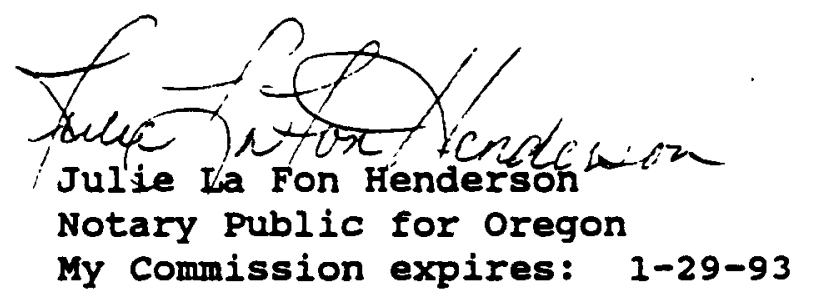


SURPLUS PRODUCTION REACTOR DECOMMISSIONING (SPRD)

6

ENVIRONMENTAL IMPACT STATEMENT

8

9

10

11

12

13

14

15

16

17

18

19

20

21

22

23 Timothy A. Hale, Reporter

24 Gee, Green, Anderson \& Associates

25 ! Seattle, Washington 


\section{INDEX OF COIMENTORS}

6

7

Name

Page

8

9 Mr. Dan Silver 15

10 Ms. Barbara Zepeda 24

11 Mr. Frank Hammond 48

12 i.1. Mark Bloome 52

13 Mr. Brendon Mahaffey 55

14 Ms. Donna Bernstein 60

15 Mr. Russ Childers 65

16 Mr. Mark Bloome 56

17

18

19

20

21

22

23

24

25 
Because these remarks are identical to the first 16 pages of the Richland transcripts, they are not repeated here.

The Council on Environmental Quality regulations that govern the NEPA proceedings require the Federal agencies to seek out with particularity comment from state and local governments, and as consequence of that, we're always pleased 
when we have official representatives from state or local governments here to comment on such documents. We have someone who is from the state of Washington serving in the capacity of Special Assistant to Governor Booth Gardner. Mr. Dan Silver is here to represent the Governor.

Mr. Silver, if you would like to take the podium, sir, I would we would like to hear your comments, and any written comments you have we will mark as an exhibit and include those in the record also.

MR. DAN SILVER: Good morning, Mr. Eiguren, Mr. Freeberg. Thank you very much for the opportunity to comment on the Draft Environmental Impact statement.

My name is Dan Silver. I am Special Assistant to Governor Gardner. My comments this morning will focus on the broad public policy issues involved in decommissioning the reactors, and we will submit detailed comments prior to the completion of the comment period next week.

Governor Gardner applauds the Department of Energy in its decision to move forward with the decommissioning of the surplus reactors, and we look forward to working with you on this very important project.

The Governor regards decommissioning to be our responsibility. We should not pass this nuclear waste problem down to our descendants three or four generations from now. Accordingly, he believes that the decommissioning of the 
reactors must not be delayed for 75 more years.

His preference is that all eight of the reactors be buried in the plateau of the 200 West Area well away from the the public and to the environment from natural catastrophe or human error.

Although the Draft Environmental Impact Statement briefly discusses the various regulatory authorities which may need to be considered during the decommissioning activities, the document understates the impact of the Resource Conservation and Recovery Act and the Washington Aadministrative Code on in situ decommissioning and safe storage. The final draft should more clearly describe the potential regulatory requirements for these alternatives. Whatever the final option, the final draft should also indicate that the decommissioning will be done in accordance with the terms of the Tri-party Agreement which we have recently negotiated with the Federal government.

The B Reactor has an exceptionally strong association with the history of the United States Atomic Energy Program and the development of the atomic bomb at the end of World War II. In view of it's historic significance, the future interpretive value of the $B$ Reactor should be preserved if it is technically, environmentally, or economically feasible. Varying degrees of interpretive value could be 
preserved by maintaining part of the facility in its present condition, creation of a $B$ Reactor representative at the site, displaying the control room at the Hanford Science Center or room at the Smithsonian Institure, or by providing extensive photographs and records at one of these sites.

The Final Environmental Impact Statement should evaluate the environmental cost, the scientific heritage, and cultural heritage impacts of each of these options. The evaluation should assess public accessibility and the ability to illustrate and meet construction and operational achievements.

Incremental costs associated with maintaining and monitoring the $B$ Reactor in place while the other seven reactor blocks are moved to the 200 West Area should also be included in the Final Environmental Impact Statement. of course, the Historic Register decision must not compromise protection of the public health, safety, or the environment.

The Washington State Shoreline Management Act states that it is the policy of the state to provide for management of the shorelines of the state by planning for and fostering all reasonable and appropriate uses. Although the Draft Environmental Impact statement assumes a time period of a hundred years for active institutional control with an intention to maintain institutional control in perpetuity, there is no discussion about allowing reasonable and 
appropriate public use of the shoreline.

Decommissioning of the reactors will remove a significant roadblock to opening major sections of the Hanford Reach shoreline to the public. If the Reach is designated as a part of the National Wild and Scenic River system, that portion of the river will remain open for boating and fishing, but not for shoreline uses.

Protection of historic, archaeological, and cultural property together with yet to be decommissioned sites would preclude opening of the entire Hanford Reach. However, the Final Environmental Impact Statement should articulate a Federal policy of shoreline use during the period of institutional control. We recommend a phased approach which would allow the public reasonable and appropriate use of the shoreline.

Thank you very much for the opportunity to comment. The Governor strongly supports the Department's effort to move forward on this key element of Hanford cleanup.

MR. ROY EIGUREN: Mr. Silver, I have with me Mr. Roger Freeberg who is a member of the DOE operations staff in Richland in the Environmental Restoration Branch. Under the rules of our proceedings, we're entitled to ask clarifying questions, and if you have no objections, at least I have a few just to clarify a few points.

MR. DAN SILVER: I would be very happy to answer 
questions.

MR. ROY EIGUREN: One issue relates to your reference to the Shoreline Management Act of the state of washington.

As I understand the Governor's position, that Act may in fact apply to this section of the Federal Reservation if, in fact, the reactors are removed from that location?

MR. DAN SILVER: It applies to all shorelines in this state.

MR. ROY EIGUREN: So you're asking that the Final Environmental Impact Statement articulate what the Federal policy will be relative to those shorelines?

MR. DAN SILVER: That's correct.

MR. ROY EIGUREN: And how that would be integrated with the State's Shoreline Management Act?

MR. DAN SILVER: YES .

MR. ROY EIGUREN: Secondly, you indicated that the Governor would like to have the Final Environmental Impact statement articulate additional options related to the

$B$ Reactor in terms of historical preservation.

MR. DAN SILVER: YeS.

At present, I think the Environmental Impact statement only identifies two options. We would like to see additional possibilities explored in the Final Environmental Impact statement. 
MR. ROY EIGUREN: Along the lines that you've

mentioned?

MR. DAN SILVER: YeS .

MR. ROY EIGUREN: Then finally, one issue that was not directly addressed in your comments but one that we have been asking representatives from other states who have appeared at these proceedings, and that perhaps it would be in the State's written comments we will receive, is there any particular ranking in terms of priority of this particular project, i.e., the decommissioning project at the Hanford Site versus other types of environmental mediation that might be contemplated for that site?

MR. DAN SILVER: No, nor will we make that ranking in our written comments either.

MR. ROY EIGUREN: So the State will have no position in terms of ranking of the priority?

MR. DAN SILVER: NO.

MR. ROY EIGUREN : Thank you . Mr. Freeberg?

MR. ROGER FREEBERG: I have no questions. Thank you very much.

MR. ROY EIGUREN : Thank you very much for coming, we appreciate it.

MR. DAN SILVER: Thank you .

MR. ROY EIGUREN: Are there others here who 
would like the opportunity to comment at this time?

There being no further scheduled commentors for our hearing at this particular point in time, it is my understanding that the next preregistered commentor is to appear at $3 \mathrm{p} . \mathrm{m}$. this afternoon, what we will do is remain at recess until the hour of 3:00 this afternoon.

In the event that we should have someone appear prior to that time who would like to go on the record, we will reopen the record and receive their comment.

We will also be taking a luncheon recess from 12:00 until 1:00, so unless someone else appears, we will once again resume this hearing at $3 \mathrm{p} . \mathrm{m}$. this afternoon. Thank you. (RECESS TAKEN.)

MR. ROY EIGUREN: We will now formally go back on the record for this our public hearing being held on July 20, 1989, in Seattle, Washington.

This is the United States Department of Energy proceeding No. 0119-D. It is being held for the purpose of receiving public comment on the Department of Energy's Draft Environmental Impact Statement that has been prepared to analyze the potential environmental impacts of decommissioning the eight surplus production reactors located at the Department's Hanford $S$ ite in Richland, Washington.

As I stated earlier in this hearing, my name is Roy Eiguren. I'm an attorney in private practice who has been 
retained for the exclusive purpose of serving as the hearings officer at this and the other public hearings in this particular proceeding.

We have had three public hearings to date. Prior to today, we have had hearings in Portland, Oregon; Spokane, Washington; and Richland, Washington. Today's hearing will conclude this particular series of hearings on the Draft Environmental Impact Statement.

I am an independent third party in this proceeding. By that I mean that I am not an advocate for or against the Department's proposed action in this proceeding. My role in being here is simply to provide an unbiased forum for all individuals to have a fair and equal opportunity to comment on the record on issues of concern relative to potential environmental impacts of this proposed action.

The action which is contemplated by the Department is the decommissioning of these eight surplus production reactors. There are five different options that the Department has currently under consideration by way of decommissioning these facilities. The options are examined in some considerable detail in the Draft Environmental Impact statement. The purpose of this hearing is to receive comment from the public on those options, and to receive input as to what members of the public as well as local and state governments think is the appropriate option that should be 
selected by the Department in decommissioning the reactors. The time frame for this particular proceeding is as follows:

The record will close on the 28 th day of July, so written comment is in order and will be received and included in the record of the proceeding if it is mailed to the Department of Energy prior to the 28 th day of July. Written comment as well as the transcript of the public hearings will be used by the Department of Energy in its decision making in the selection of the option it chooses.

Once the process of reviewing the record is complete, the Department then will do one of several things: It will either issue a Final Environmental Impact Statement in the same form as the draft Environmental Impact Statement; secondly, it may choose to modify the Draft Environmental Impact statement prior to putting it into its final form; or thirdly, it may choose to substantially revise the Draft Environmental Impact statement and reissue it in draft form after which there would be additional public comment on the reissued draft, and a Final Environmental Impact Statement would be prepared. The Final Environmental Impact statement will then lead to the preparation of a Record of Decision by the Secretary of Energy. The Record of Decision will select the Department's preferred alternative relative to decommissioning. If there are particular environmental impacts associated with that 
particular option, the Record of Decision will also define the various mitigation measures the Department will put into place to mitigate those particular environmental impacts.

I am here, as I mentioned, for the purpose of receiving comment from the public. Mr. Roger Freeberg, who is the Director of the Environmental Restoration Branch of the Richland Operations office of DOE, is also with me. We comprise the hearing panel.

Our purpose is to receive public comment and, as appropriate, to ask members of the public who are commenting clarifying questions after their comments to make sure we understand the full import of what they are telling us.

I mentioned prior to going to recess that this public hearing commenced this morning at $10 \mathrm{a} . \mathrm{m}$. for the purpose of receiving comment from members of the public. We did receive comment this morning from the Governor's representative, Mr. Dan Silver. I indicated that we would recess until the hour of 3 p.m., at which time, we had another preregistered commentor scheduled to be here.

That preregistered commentor is here a bit early, Barbara Zepada, so without further ado I will turn the microphone over to you, Barbara, for your comments on this particular issue.

MS. BARBARA ZEPEDA: I'm Barbara Zepada. I am speaking for the Washington Democratic Council, which has been 
very much concerned about the use of our rate paying ability under our Public Utility System to subsidize Hanford.

There's been no accounting for either the money, the dollars, or the waste, and how it has affected our direct electric rates. There has been a continuing issuing of WPPSS bonds using the City of Seattle's bonding capacity, City Light's bonding capacity. The waste is buried in an accounting system that the citizens can really not fathom. I don't even know what $k$ ind of physical or fiscal accounting system there is for finding out either past, present, or future waste that is being created by either the military or the so-called peaceful uses of the nuclear processes at Hanford.

I haven't received this report until just now. The question I have raised repeatedly over the last decade at these hearings is :

Is this country, the Department of Energy, actually lobbying for the international regulation of nuclear materials as both the Heart of America, Greenpeace, the other environmental organizations, and certainly the Washington Democratic Council has called for this at meetings over the last decade?

We need to begin an accurate accounting system of both the money that's being spent, the waste that's been deposited, and the actual proposals for both the accounting system and some $k$ ind of objective outside international 


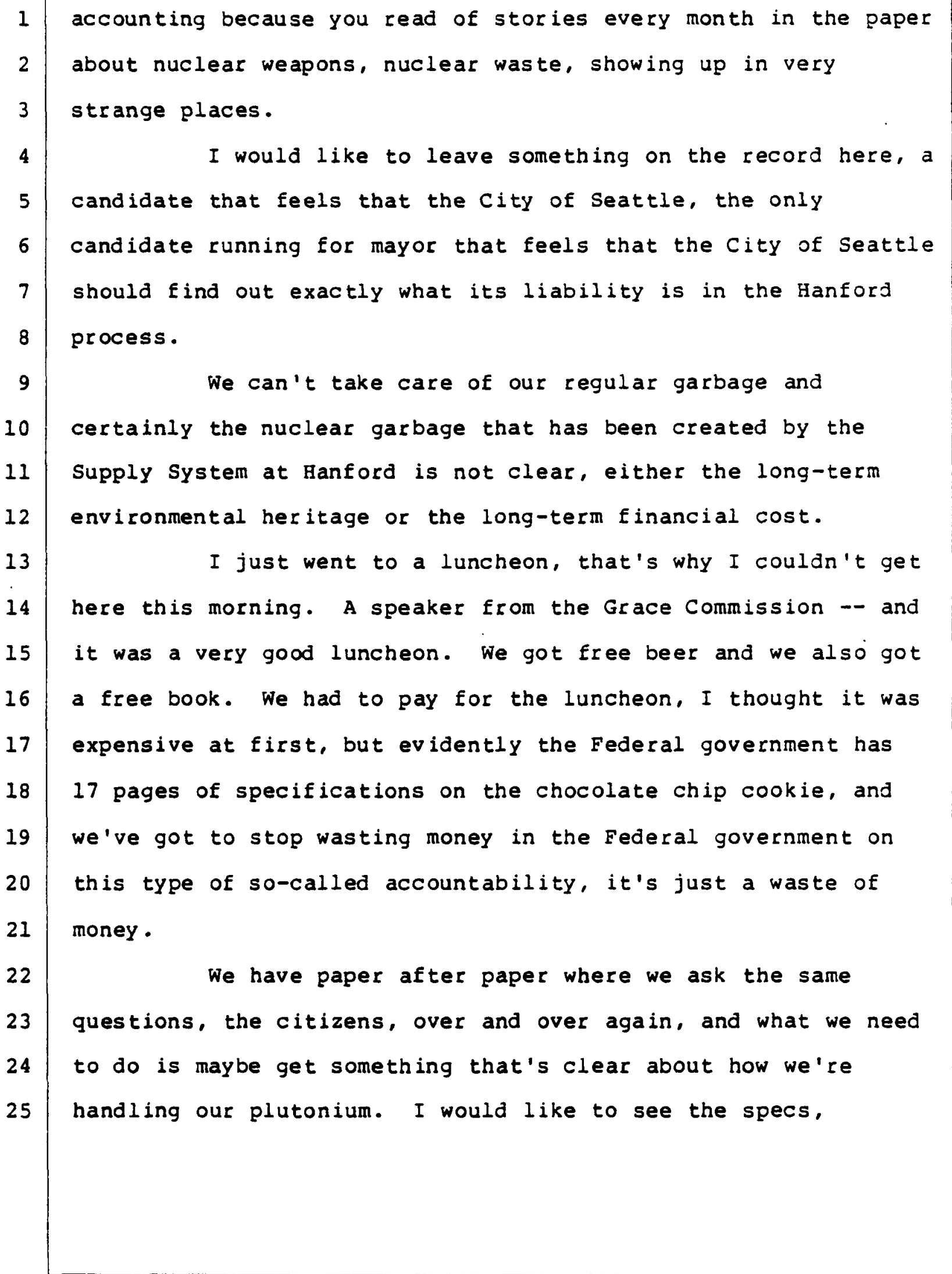




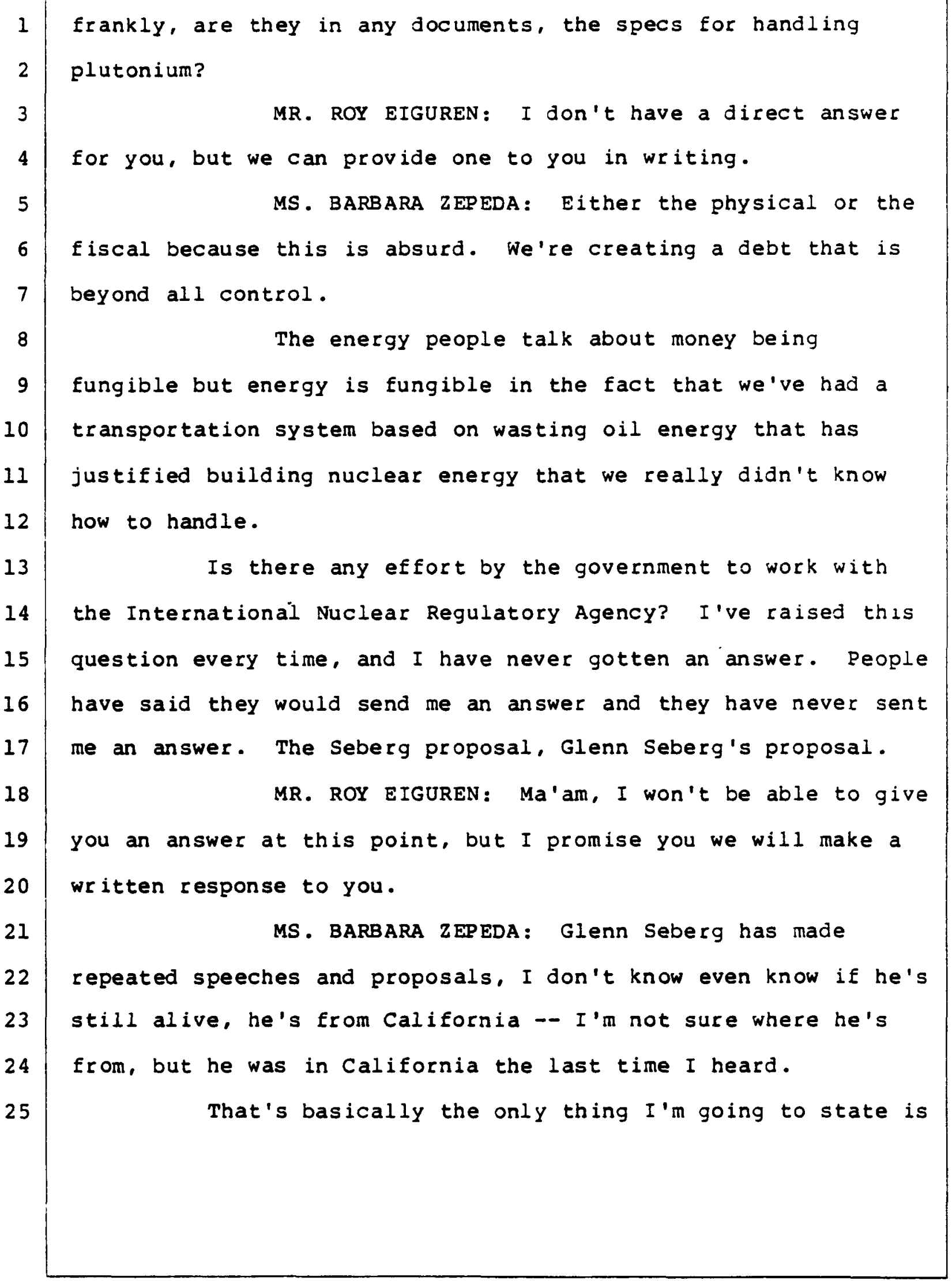


just the same old request that we set up standards that are accounting standards for the money, for the waste, that we know where we've been, where we are, and where we're going. Until we do that, we can't, proposals are paper. That's all I'm going to say.

MR. ROY EIGUREN: Would you like to include

those in the record, ma'am?

MS. BARBARA 2EPEDA: Yes.

MR. ROY EIGUREN: What I will do is mark those

for inclusion in the record.

Before you leave, I believe Mr. Freeberg has a question for you.

MR. ROGER FREEBERG: I just had a clarifying question.

You mentioned the Supply system several times and their bonding and so forth, and I wanted to make a clarifying statement that the Department of Energy has no connection or responsibilities to the Washington Public Power Supply System and their bonding. That's a separate public utility and it is not under the auspices of the Department of Energy. MS. BARBARA ZEPEDA: You mean nuclear energy is not under the Department of Energy, nuclear regulations, the NRC regulations?

MR. ROGER FREEBERG: The NRC is not under the Department of Energy. NRC is a separate regulatory body of the 
Federal government.

MS. BARBARA ZEPEDA: But it's supposed to be setting up funds and procedures by which these plants operate.

MR. ROGER FREEBERG: Yes, and they do that, they definitely do that.

MS. BARBARA ZEPEDA: The regulations of how something operates is almost an engineering requirement.

MR. ROGER FREEBERG: I wanted to make myself clear, though, in the context of your statement about the obligations of WPPSS and their accounting systems and their bonding and so forth. I just want to make it clear that the Department of Energy doesn't have any responsibility for the Washington Public Power Supply System.

MS. BARBARA ZEPEDA: It licenses it?

MR. ROGER FREEBERG: No, it does not.

MS. BARBARA ZEPEDA: Who Iicenses it?

MR. ROGER FREEBERG: The Nuclear Regulatory Commission, it's a separate regulatory agency within the Federal government, not the Department of Energy.

MS. BARBARA ZEPEDA: I'm sorry, but the Department of Energy has a budget and has oversight over the nuclear industry and proposes ways to -- I mean the NRC is a regulatory body that the DOE has some impact on. The DOE is the administrative body of energy in the country.

MR. ROGER FREEBERG: Not for all energy. The 
Department of Energy has its own key programs and we have responsibility for those programs. The nuclear energy under the Washington Public Power Supply System is regulated by the Nuclear Regulatory Commission, which is another separate Federal government regulatory body. I just wanted to make that distinction.

MS. BARBARA ZEPEDA: But you say the NRC doesn't have any relationship with the Department of Energy.

MR. ROGER FREEBERG: Well, it's an agency of the Federal government and it does exercise regulatory authority over some facets of the nuclear business that we're in, just like they have regulatory authority over the nuclear business of the Power Supply system.

MS. BARBARA ZEPEDA: That's what I'm saying. Maybe the problem"is that the discussion we're having here shows how fuzzy the whole thing is to the general public, I mean, how unclear it is to the general public.

MR. ROGER FREEBERG: I understand. I was just trying to clarify that.

MS. BARBARA ZEPEDA: It's hard to find anybody that's responsible for anything.

MR. ROGER FREEBERG: Your point is well taken. I was trying to make a clarifying distinction between the Washington Public Power Supply System which resides on the Hanford site, but they are on leased property and they work as 
a separate and distinct body and we have no government

the waste.

MS. BARBARA ZEPEDA: But you're responsible for

MR. ROGER FREEBERG: Not for the Washington

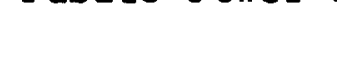
answer for that. There are many many documents that do identify where the Department of Energy waste inventories are. MS. BARBARA ZEPEDA: Are you saying that you're only responsible for the defense waste?

MR. ROGER FREEBERG: That's correct.

MS. BARBARA ZEPEDA: The Department of Energy is only responsible for defense waste.

MR. ROGER FREEBERG: Well, there is some waste generated in what we call the civilian nuclear energy program which would generate some waste, but that's under the Department of Energy.

MS. BARBARA ZEPEDA: Is this paid for by a line item in the Department of Defense budget at all? Defense. 
MS. BARBARA ZEPEDA: Is the Department of Energy considered a civilian agency?

MR. ROGER FREEBERG: Yes, it is .

MS. BARBARA ZEPEDA: Yet it handles defense

waste?

MR. ROGER FREEBERG : Yes .

MS. BARBARA ZEPEDA: Then that in itself is very

bad.

MR. ROGER FREEBERG: It handles defense waste Erom the programs -- This is going to get confusing again, but we have programs in the Department that support the National Defense Program and that is the production of material, nuclear material, for the Department of Defense. The wastes that are generated from the production of those nuclear materials are the responsibility of the Department of Energy.

MS. BARBARA ZEREDA: This is the justification of the original statement.

MR. ROY EIGUREN: I'm going to interject mysele at this point. The rules provide for clarifying questions, not a give and take.

At this point, what I think I will do is go ahead and bring this portion of the hearing to a close, and then I will have Mr. Bauman and Mr. Freeberg visit with Ms. Zepeda and provide some additional information.

With that, we will stand at recess until the hour of 
$7 \mathrm{p} \cdot \mathrm{m}$. this evening, or we will go back on the record if additional commentors come forward.

Prior to that, I am going to mark and include in the

\section{4} 11 Seattle Times. It is entitled "A Smart Cookie or a waste of Waste. It first appeared on Wednesday, July 19, 1989, in the Dough.?

The next exhibit, which will be marked as Exhibit No. 16, is produced by Citizens Against Government With that, we will stand in recess until the hour of $7 \mathrm{p} \cdot \mathrm{m}$.

(RECESS TAKEN.) 
Because these remarks are identical to the first 16 pages of the Richland transcripts, they are not repeated here.

\begin{tabular}{l|l|}
16 & This is not an interactive proceeding. We are here \\
17 & to receive your comments, so although you may have questions \\
18 & for the record, we are not in a position to respond directly to \\
19 & those questions this evening. However, when we finish the \\
20 & receipt of all of the comments here tonight and go of the \\
21 & record, the hearing panel as well as the DoE folks who are in \\
22 & the back of the room will remain here to respond to specific \\
23 & issues or questions you may have. \\
24 & with that, I will go ahead and take questions on the \\
25 & procedures at this point and then we will turn to receiving
\end{tabular} 
public comment.

$$
\text { Yes, ma'am? }
$$

MS. GANN: I would like to comment on the

location. I think it was very inconvenient for me to come out here.

MR. ROY EIGUREN: Could I have your name for the record?

MS. GANN: Yes, it is Sharon Gann. I think it was very inconvenient to come out to the airport. We have a relatively small turnout here, but I think had you had it in the city proper, perhaps at the seattle Center or even at the downtown Hilton, you would have had many more participants. MR. ROY EIGUREN:. Thank you, I will note that for the record.

Are there any other procedural issues? Hearing none, we will turn to the receipt of public comment.

As I say, everyone has five minutes. I am going to be liberal in terms of interpreting that so if you need to go beyond that, that's fine.

Our first scheduled commentor is Mr. Frank Hammond. MR. FRANK HAMMOND: MY name is Frank Hammond, I live at 109 East Roanoke Street, Seattle, and I'm speaking on behalf of the Cascade Chapter of the Sierra Club. The Sierra Club, Cascade Chapter, has reviewed the Draft Environmental Impact Statement on the decommissioning of 
the eight surplus production reactors at the Hanford Site. The Sierra Club thanks the Department of Energy for the opportunity to review and comment on the Draft Environmental Impact statement.

The Sierra club is highly concerned about the potential for serious environmental impact from the decommissioned production reactors if they are allowed to remain in their present location in the 100 Area of the Hanford site.

We feel that the decommissioning alternatives in the Draft Environmental Impact statement have been well described and well researched by the Department of Energy. We believe that excellent work was done by the Department of Energy in analyzing the various decommissioning alternatives. In this testimony today, we intend to provide comments on what we believe is the best decommissioning alternative.

The Sierra Club believes that the longer the eight surplus reactors are allowed to remain in their present condition, at the present site, even with adequate air, water, and soil monitoring, the greater will be the potential for a severe environmental disaster. In table B.2 of the Draft Environmental Impact statement, it illustrates that a catastrophic or 50 percent failure of the Grand Coulee Dam would place all but 1 one the surplus reactors below flood level at the first floor elevation level of the reactors. A 
severe seismic event could cause such a failure of the dam. Appendix $H$ of the Draft Environmental Impact Statement discusses flood protection in the case of decommissioning on-site. It does not discuss the case where severe seismic activity has simultaneously weakened the proposed riprap layer around the reactor. While the Environmental Impact Statement does indicate that severe seismic activity is very unlikely in the Hanford area, the possibility of a catastrophic occurrence is not impossible or totally improbable.

If this layer around the reactor decommissioned in place were also cracked at the time of the dam failure, we could have a severe flooded area within that area and we could have an impact on the river.

The closeness of the reactors to the river allows no space for leakage if there is any serious impact to the reactors themselves. While this has not occurred during the time the reactors have been in place, we cannot be certain it will not occur over the next century or longer if the reactors are left in that condition. Therefore, we feel that decommissioning of the reactors in place, an in situ decommissioning, is not the preferred alternative. It also happens to be as costly as any of the alternatives and leaves us with a higher contamination risk to the Columbia River. Our preference would be to eliminate the reactors and 
all the components from the Hanford site with the removal of all of the radioactive materials to the National Repository. However, there is no National Repository at this time to move the reactor materials to, so we feel that the reactors should be placed in a temporary storage, for whatever period of time we don't know, in the 200 Area.

The question then is should you do an immediate one-piece removal or a delayed one-piece removal. The sierra Club supports the immediate one-piece removal decommissioning alternative, and we support this for the following reasons:

The immediate one-piece removal option is less costly than any other acceptable alternative and it's only 9 million dollars more than leaving the reactors on-site and doing an in situ alternative. The environmental impact of the one-piece removal is minimal, and the radiation dosage to the general public off the reservation is low or lower than any other alternative shown.

The only negative impact we could find was a higher radiation dosage sustained by the workers on the decommissioning team. While we are concerned about situations where the workers are exposed to more than minimum permitted radiation levels, we feel in this case the Department of Energy will be required to use whatever sufficient number of workers over the 12-year span of the decommissioning project in order to assure that no single individual receives more than the 
acceptable level of radioactivity per the present maximum occupational dosage levels.

Again, we we will state that the immediate one-piece removal of the surplus reactors is the best alternative and the one that should be selected.

MR. ROY EIGUREN: Thank you, sir. If you have an extra copy of your written comment, I would be glad to include that as an exhibit.

MR. FRANK HAMMOND: Yes, I do.

MR. ROY EIGUREN : Thank you, Mr. Hammond. We will include as Exhibit No. 16 in the record to this proceeding the written comments of the sierra club on behalf of this particular issue. Thank you for your testimony. Our next scheduled commentor is Mr. Mark Bloome. MR. MARK BLOOME: My name is Mark Bloome. I'm Chairman of the Board of Heart of America Northwest, a citizen's organization that has been leading the fight for Hanford cleanup. We would like to comment upon the choices that have been put forth.

We, like the Sierra Club, support the immediate removal of the core materials from the reactors and making them immediately safe. Our country and our communities have all benefited from the services provided by those reactors. That has been the democratic process. But as those who have benefited, it is only fair that we pay the price now for the 
benefits we have received. It is eminently unreasoned to delay for 75 years the decommissioning.

The fact that there is absolutely no way in which anybody can predict the economic status of our country 75 years from now is quite plain. The gurus on wall street can't predict 75 hours from now. It would be a moral injustice for us to leave those reactors knowing that the likelihood of anything happening in 75 years is slim to none and therefore the results would be that we would have radioactive material that would be decaying. The people of the future generations would pay a terrible price for this problem.

The history of safe doses of radioactivity is clear. The greatest scientific minds have shown that what was acceptable levels of radiation in 1945 are grossly unacceptable levels of radiation in 1989. Evidence seems to continue to indicate that all exposures to radiation are negative impacting upon the health of our people. To have reactors there 60,70 , 80, a hundred years from now can only negatively impact upon our country and upon our people, not only the reactors, but the whole cleanup situation altogether.

We also would like to speak that we are deeply concerned for the economic well-being of our region and the health problems of our region. We have witnessed the devastation of Washington agriculture through an Alar scare. We have seen cherries that don't even use Alar have to be 
dumped at sea because in Taiwan there's an Alar scare on our cherries.

There is nothing more reactive than the American public when it comes to the fear of anything radioactive. I can quote you study after study out of $r$ isk analysis that show that that is the most fearsome thing in the American public's mind, and I would think from what I could discern, it is the most fearsome thing in most of the world population's minds.

Should our products become mildly radioactive in any way due to any leakages from these reactors or from anything at Hanford, our economic enemies would use this to destroy the well-being of our people, and our country cannot afford this kind of devastation. We are in economic trouble enough. We need no more health threats, we need nothing but to get this thing cleaned up.

I am reminded as I look at this problem of teenage adolescents and a dirty room, and what I'm hearing from DOE is that their alternatives are to clean it now or clean it 75 years from now. We would not allow adolescents to clean their room 75 years after making it dirty, and I don't think DOE as a responsible mature organization can adopt that policy with any sense of responsibility.

The State of Washington and the Northwest in the late forties the invited and allowed nuclear production at the Hanford Reservation because there was a deep need, our country 
needed this. We were at war and victory was unsure. While I will not speak for Heart of America, I can say that I supported personally those decisions to produce the bomb, and I supported the decision to use the bomb at the time because that's what war is all about. But time has come and time has gone, and we believe that we have been welcoming neighbors and allowed this to go on on our land, and it is time that as conscious human beings that the Department of Energy live up to its responsibilities.

I have been the president of a large corporation, and I know what it is to look at the bottom line. But the question that is going to be before DOE, which is an organization that is run primarily by human beings, is: Where does their conscience lie? Does it lie on the dollar sign or does it lie in human life. Thank you.

MR. ROY EIGUREN: I am informed that the next two prescheduled commentors, Andrew Gezesh and Marie Savorini are not here this evening. I would call their names just to make sure they are not.

Is Andrew Gezesh or Marie Savorini here? If not, I would then call Brendon Mahaffey.

MR. BRENDON MAHAFFEY: MY name is Brendon Mahaffey, I live at 424 Nor theast Maple Leave Place in Seattle. I'm here speaking partly on behalf of myself tonight, although I am a member of Heart of America Northwest. 
I guess my first comment is the location of this place is totally inadequate and not really acceptable. The meetings that I have been to in Seattle have had what I would feel is a decent turnout, and you can tell by the location that it definitely had its effect.

I don't know why we're here. A comment was made earlier about parking being a problem in seattle. I think that I would rather walk four or five blocks than drive 20 miles.

My stand on all this is that I feel like the reactors need to be cleaned up immediately. I don't claim to be an expert, and I think what the Sierra club says makes a lot of sense. I don't know exactly how to do it, but I know it needs to happen now.

I know that Department of Energy's irresponsibility of their nuclear waste disposal has directly effected the food chain in our state. Whenever there's nuclear waste in the water, it gets into plants, it gets into animals, and it gets into us. Nuclear waste doesn't go away real quick. So that really bugs me.

We know that there has been thousands of curies released into the air and covered up and lied about numerous times. We know that thousand of gallons of high level radioactive waste has been leaked into our aquifers. I have spoken with people who were at a high level at Hanford in the fifties and sixties saying that you can bet that there has been 
nuclear waste that has made it into the Columbia River and into the Pacific Ocean. Again, this is effecting not only our food chain but people everywhere.

I don't think that an organization like DOE has the right to make decisions for people all over the world, and that's what happens when nuclear waste gets into our oceans. I'm saying this because I think that DOE should clean it upr ight now.

From what I understand, the Department of Energy doesn't have the final say in their Environmental Impact statement anyway, it's under the jurisdiction of the Environmental Protection Agency, and I didn't hear them mentioned in the facts about Hanford. I would like to go on record as stating that I think it's important that the EPA does have a strong involvement. Obviously the DOE has not proven to us that they are trustworthy.

Also, I feel that the Environmental Impact Statement was nothing more than an academic exercise with inadequate records. As far as I know, there has not been any on-site, or has not been extensive on-site testing, and any $k$ ind of Environmental Impact statement that draws strict conclusions needs to have a lot more time than just one year or probably even a year and a half, and it needs to be a lot more than just 4 research from records that have been admitted time and time again by DOE that are scarce if none at all. 
We all know, including DOE, that records in the forties and fifties were very loosely kept if kept at all. We have all heard stores about radioactive jeeps being dug up by accident. They don't even know where all the sites are. I've also been reading through some newspaper articles in the Times about the eight forgotten reactors, and I notice that a quote from that, or a very close to quote was rumors of removal of reactors would open up river front. I would like to remind people about the court cases going on in Ohio about children playing in sand boxes and contracting leukemia, having their legs amputated. I don't know that anybody in their right mind would want to have any kind of fun in river front next to an ex-reactor, whether it's buried, moved, or whatever. I find this option ludicrous.

I don't think that leaving them for 75 years is an option. If the reason they want to leave them is because it's to dangerous for workers to go in there and decommission them, then are we talking about low-level waste. It was my impression that low-level waste could be worked around and high-level waste could not, so what is it, which brings me back to the Environmental Impact Statement.

How extensive is this Environmental Impact Statement? Is it high-level waste, is it low-level waste, what is it? If you can't have workers working around it, I find it hard to believe it's low-level nuclear waste. If it is low-level 
nuclear waste, then maybe we ought to change our standards.

I know that the Department of Energy seems to be pushing towards leaving the reactors, the only other reason I can imagine is because of funding. Again, it comes back to dollars versus people: How much is a human life worth and how much is our food chain worth, how much is the economy of Washington State worth? If this waste gets into the Columbia River, the next step is into our wheat fields in a big way, which ruins the economy of our state.

I think the immediate removal of the reactors is imperative to the quality of life in our state. I think that the Department of Energy has continually put us off, and we can't allow them to do it again.

Again, I can't say it enough times. I know from the experts I've talked to that EPA has the final jurisdiction over the Enviconmental Impact Statement. If they choose not to exercise their right, then it goes to the Department of Ecology.

Also, I know -- I don't know this, but I suspect that the reason they're pushing for a long-term waiting is that they don't want to spend the money. It hurts me to see our government more apt to spend money on producing more nuclear waste which they don't know what to do with and spending money in places that may not be the best place rather than safeguarding the human lives of our country. Thank you. 
MR. ROY EIGUREN: Thank you . Our next scheduled commentor is Donna Bernstein. We will include as Exhibit No. 17 in the record of this proceeding the written comments made by Donna Bernstein on behalf of Heart of America.

MS. DONNA BERNSTEIN: I am Donna Bernstein, I am also speaking on behalf of Heart of America Northwest. We are a 16,000 member group around the state dedicated to advancing our region's quality of life.

It has always been a big issue with us that Hanford is cleaned up in a credible and timely manner both for our economy and our environment. We do not feel this Draft Environmental Impact statement was done through legal means because under the alternative that they're leaning to, which is to leave it for 75 years, it says pretty much in their own wording, part of the reas on for this is budget.

Given all the facts already cited such as we don't know what will happen in 75 years, both environmental disasters or economy or simply public mood, given the fact that it is as Brendon said, it must be high level if it's so dangerous that workers can't touch it for 75 years, but is it only that dangerous because DOE has not funded the studies which would maybe let us see a way that workers could handle it?

I would like to read a definition of facility as contained in the law from CERCLA, "Any building, structure, 
installation, equipment, pipe or pipeline, well, pit, pond, et cetera. It is a facility, and it is covered under CERCLA. We do believe these reactors pose a significant

\section{We do believe these reactors pose a significant} threat of release. As we said, if it's so dangerous it has to be left for 75 years, you can just look at a map and see it sits on the Columbia River.

I would like to read again from the law, "Whenever there is a release or a substantial threat of release into the environment of any pollutant or contaminant which may present an imminent and substantial danger to the public health or welfare, the president is authorized to act consistent with the national contingency plan to remove or arrange for the removal of, et cetera, et cetera. It needs to be done. It is a threat.

I want to go on to the next paragraph of

Section 89604. "In no event shall a potentially responsible party be subject to a lesser standard of liability, receive preferential treatment, or in any other way benefit from any such arrangements, et cetera, et cetera." It seems to me that under the law DOE must spend the money necessary to do the studies required to provide a real Draft Environmental Impact statement.

They don't have the current records to even know what they're doing out there, they have not gone through all of the analysis that's required by CERCLA, so what we're looking at is 
an Environmental Impact Statement based on inadequate data with budget as a priority over human life. We feel DOE has sidestepped the $l$ aw and that their decision regarding the final dismantlement has been very biased for budget on their side and not human life and not within the statutes of our law.

I would like to go on with the second reason we feel

this Draft Environmental Impact Statement is not under the current law, which is that in the time line given, if they come out with their final decision next summer, the amount of time -- when I was at the last quacterly meeting with EPA on the Tri-party Agreement, it seemed that in their time line they were going to look at it sometime later. You can imagine that if DOE has already made a definite decision, has already started on the project and three years later EPA looks at it, EPA is then not given the final jurisdiction.

As this is a facility as defined under the law, as it is a potentially hazardous threat that we're talking about, under the law it is EPA or the Washington Department of Ecology that needs to have the final say on what happens with these reactors. We feel DOE is given preferential treatment. If they were in the private world, the agency that had the waste could indeed make their Draft Environmental Impact Statement if they went through the law-required analysis, which we don't believe DOE did, but they would not be the ones to give the final okay on the cleanup procedures. 
Here we're not talking about some chevron gas station spill in the Duwamish River. We read about all sorts of sites like that which are awful in themselves, but we're talking about radioactive nuclear waste in our rivers going out to our oceans. We feel strongly that the Washington Department of Ecology and EPA must stand strong, must regard the law and say that they have the final decision on this Draft Enviconmental Impact statement, that more studies must be done, and that these studies were not done in respect to that law. Again, we feel that immediate dismantlement is best. We feel that this alternative was not looked as because of budget decisions and that it is not in keeping with the 1 aw. It must be decommissioned immediately in full accord with state and Federal environmental laws. More studies must be done. Real studies must be done with the help of EPA and the Washington Department of Ecology and the final decision must be made by EPA or Washington Department of Ecology.

Just as a small aside, I find it very amusing, well, not really amusing, but the Department of Energy can $f$ ind $t$ ime to fund little things like Hanford visits Wenatchee where they presented very one-sided political views on such agenda items as scenic rivers and Canadian hydroelectric power and yet can't find the time to do the studies to save our population. Since you're making this longer, can I have one more second? 
MR. ROY EIGUREN: BY all means .

MS . DONNA BERNSTEIN: From my own personal perspective, not Heart of America, whatever their stand might be, on the monument. I read a few times that they were thinking of making it a national monument. Now, they haven't said in what context. Is it in the context of isn't this very fascinating that here we made a bomb that we had to use but it killed many civilians, or is it in the context of the glorification of the military, the glorification of the United States Army, or is it in the context of how wonderful nuclear power is and why we should all use it.

I think that's very very integral to any monument. You can look at two different monuments like the viet Nam Memorial in D.C. which has a very strong effect on the side of -- whether you're for or against war, either way -- it is not a high $r$ ising glorification of war. Then you can compare that to the Gettysburg Memorial in Pennsylvania and see that is a total glorification of the Army. I think that before you can decide if you're going to make that a memorial and whether the people would like it, you need to really make clear what kind of a view is this memorial going to give.

Again, all those comments were just from Donna Bernstein, they're not Heart of America on the memorial. That's what I have to say. Thank you very much.

MR. ROY EIGUREN : Thank You. 
Our next scheduled commentor is Russ Childers. MR. RUSS CHILDERS: My name is Russ Childers, I live at 223 14th Avenue East in Seattle. Most of what I want to say people have already said, but I will say it anyway. First of all, I'm also in favor of immediate cleanup of the eight reactors. Just the fact that they're on such a major important river, whether you're looking at it from the economic standpoint or health standpoint, they can't be left there for the next flood or earthquake or whatever could cause major damage to the economy and health of the people.

Again, the DOE does not have the right to be deciding what happens here as I understand it under the law. They have a right to come up with suggestions and let the EPA decide or whoever is in charge, but they shouldn't be making the decision here.

I don't consider myself to be a cynical person, but it's hard not to be when the DOE is involved. They, in my opinion, don't have much credibility in these issues. They have been covering things up for years. They have been lying for years about what has been going on with the way they are polluting the environment, and it's hard for me to accept that they're really trying now to do the right thing, take care of the people and the economy, the environment, and not just trying to prolong what they see as in their interests. I don't think they see the environment and the health of the people in 
their interests. I think they see the continued production of the weapons and whatever else goes on out there to be their interests.

They have been dumping out at Hanford for over 40 years and covering it up. The recent study by the GAO shows that when they have done studies they have not been interested in finding out the real facts, they've been setting up studies to produce results or at least to make it appear to produce desired results which show that they should continue on. I hope that's going to get a bit more press.

Again, the DOE says that this is low-level waste, but if they have to leave it there for 75 years for anybody to touch it, low-level waste must be very high level.

Also, on the point of having this meeting here, I personally don't own a car. I know a lot of other people don't own cars, and if I didn't know someone with access to a car who was coming here tonight, I wouldn't be able to be here. That's part of what makes me cynical about the DOE.

I think if they were interested in people showing up to these meetings and having input into how things are done in our state, in our country, they would have made these meetings far more accessible.

Just the fact, a minor thing, but my cynicism says that maybe even putting a phone number that you have to make a long-distance phone call to sign up for it is just another 
thing to perhaps convince a few more people to just not deal with it.

That's all I have to say. Thank you. MR. ROY EIGUREN : Thank you.

That concluded our 1 ist of preregistered commentors for this evening. I would ask if there is anyone else who is here who has not commented that would like the opportunity to do so? .

UNIDENTIFIED WOMAN: I would like to say some thing.

MR. ROY EIGUREN: Yes, ma'am. Please, amy we have your name and address for the record?

UNIDENTIFIED WOMAN: DO I have to give my. name and address to make public comment?

MR. ROY EIGUREN: We need to have your name. UNIDENTIFIED WOMAN: Is that right?

MR. ROY EIGUREN: Yes.

UNIDENTIFIED WOMAN: In order for me to comment as a public citizen, I have to give my name?

MR. ROY EIGUREN: Yes.

UNIDENTIFIED WOMAN: That's outrageous.

MR. ROY EIGUREN: I'm sorry.

Is there anyone else who would like to comment?

MR. MARK BLOOME: I have one additional comment. MR. ROY EIGUREN: Yes, sir. 
MR. MARK BLOOME: My name is Mark Bloome, and I spoke earlier. I would just like to stress in the strongest terms possible what was said by the speaker before me, that this meeting was not held in a place where public transportation was available for citizen input. I think that that needs to be very careful looked at, and I protest this entire meeting because of the place in which it was held.

I do not think it really complies with the intention of public input when a criteria to attend this meeting is either to pay for an extremely expensive taxicab which is beyond the norm of the average citizen or to own a car. This is a very undemocratic process devoted to this distance.

MR. ROY EIGUREN: It's noted for record, sir.

Are there fur ther comments?

UNIDENTIFIED WOMAN: Please note for the record also that I was here ready to speak and that you refused to take my comments without my name.

MR. ROY EIGUREN: Fine.

UNIDENTIFIED WOMAN: I can give plenty of testimony as to why I don't want to give my name.

MR. ROY EIGUREN: It's noted for the record. There being no further comment, we will go ahead and formally close this public hearing being held on the 20 th day of July, 1989, in Seattle, Washington. The hearing panel will remain here until $8: 30$ in the event that we should have 
1 additional individuals that arrive and would like to comment.

2 If that happens, we can go back on the record at that time. With that, we stand formally adjourned. Thank you. 


\section{EXHIBITS}

Exol

Ex02

Ex03

Ex04

Ex05

Ex06

Ex07

Ex08

Ex09

Ex10

Ex11
Ex 11

CEQ Guidelines

Notice of Intent

Notice of Availability

Schedule of Public Involvement Activities

Ivan M. A. Garcia

Alton Haymaker

John Burnham

Tri-Cities Industrial Development Council

Jim Stoffel(s)

The Honorable Claude 01 iver Benton County Treasurer

Harry Brown

Columbia Basin Section

American Society of Mechanical

Engineers

The Honorable Raymond E. Isaacson

Benton County Commissioner

Jim Thomas

Hanford Education Action League

(Exhibit 11 was misnumbered by the hearing reporter. The comments are recorded in the FEIS under L018.)

Ex12

Mary R. Wieman

Ex12, Ex13

David Stewart-Smith

Oregon Department of Energy

(Exhibit 12 was misnumbered by the hearing reporter. All of the State of Oregon's comments are recorded in the FEIS under Exhibit 13.)

Ex14

Hale Weitzman

Ex15

Barbara Zepeda

Washington Democratic Council 
Exhibits

Ex16

Frank Hammond

Sierra Club, Cascade Chapter

Ex17

Donna Bernstein

Heart of America Northwest

(2) 
the same fashion (excluslve of scopIng) as a draft and flnal statement unless alternative procedures arc approved by the Council.

$\$ 1502.10$ Recommended format.

Agencles shall use a format for environmental impact statements which will encourage good analysis and clear presentation of the alternatives including the proposed action. The following standard format for environmental impact statements should be followed unless the agency determines that there is a compelling reason to do otherwise:

(a) Cover sheet.

(b) Summary.

(c) Table of Contents.

(d) Purpose of and Need for Action.

(e) Alternatives Including Proposed Action (secs. 102(2)(C)(III) and $102(2)(E)$ of the Act).

(f) Affected Environment.

(g) Environmental Consequences (especially sections 102(2)(C) (1), (ii), (iv), and ( $v$ ) of the Act).

(h) List of Ereparers.

(1) List of Agencies, Organizalions, and Persons to Whom Copies of the Statement Are Sent.

$>$ (j) Index.

(k) Appendices (If any).

If a different format is used. It shall Include paragraphs (a), (b). (c), (h). (j), and ( $j)$, of this section and shall Include the substance of paragraptis (d), (e), (f), (g), and ( $k$ ) of this section, as further described in $\$ \$ 1502.11-1502.18$, in any appropr1ate format.

$\$ 1502.11$ Cover shcet.

The cove: sheet shall not exceed one page. It shall include:

(a) A list of the responsible agencles including the lead agency and any cooperating agencies.

(b) 'The title of the proposed action that is the subject of the siatement (and if appropriate the titles of related cuoperating ayency actions), together with the State(s) and county'(iss) (Oi other jurisdic. tion If applicable) where the action Is located.

(c) The name, address, and telephone number of the person at the agency who can supply further information.

(d) A designation of the statement as a draft, final. or draft or final supplement.

(e) A one paragraph abstract, of the statement.

(f) The date by which comments must be received (computed in cooperation with EPA. under $\$ 1506.10$ ).

The information required by this section may be entered on Standard Form 424 (in items 4, 6, 7, 10, and 18).

§ 1502.12 Summary.

Each environmental Impact staiement shall contain a summary which adequately and accurately summarizes the statement. The sumniary shall stress the major conclusions, areas of controversy (incluaing issues raised b5 agencies and the public), and the issues to be resolved (Including the choice among alternatives). The summary will normally not exceed 15 pages.

\subsection{Purpose ani need.}

The statement shall briefly spenify the underlying purpose and need to which the agency is responding in proposing the alternatives including the proposed action.

$\$ 1502.14$ Alternatives including the proposed action.

This section is the heart of the environmental impact siatement. Based on the information and analy. sis presented in the scctions on tire Affected Environment (\$1502.js) and the Environinental Conss. quences (5 1502.15), it should present the environmental impacts of the

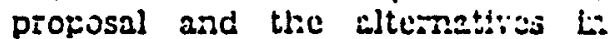
comparative form, thus sharviy defining the issues and providing a clear basis for cholce among opticins by the decisiormaker and the puiiic. In this section azencies srall:

(a) Rigorcusly explore and objec. tively evaiuate ail ieasonable aiternatives, and for alternatives which were eliminated from detalled stliciy. brichy discuss the rasces for their having been eliminaled.

(b) Devote sutistantial treatment tc ench alternative consicered in detail including the proposed acion 
so that revlewers may evaluate their comparative merits.

(c) Include reasonable alternatives not within the Jurisdiction of the lead agencs:

(d) Include the alternalive of no actlon.

(e) Identify the agency's preferred alternative or alternatives, if one or more exists, in the draft statement and identify such alternative in the final statement unless another law prohlbits the expression of such a preference.

(f) Include appropriate mitigation measures not already included in the proposed action or alternatives.

$\$ 1502.15$ Afrected environment.

The environmental impact state. ment shall succinctly describe the environment of the area(s) to be affected or created by the alternatives under consideration. The descriptions shall be no longer than is necessary to understand the effects of the alternatives. Data and analyses in a statement shall be commensu. rate with the importance of tine impact, with less inportant material summarized, consolidated, or siniply referenced. Agencies shall avoid useless bulk in statements and shall concentrate effort and attention on important issues. Verbose descrip. tions of the affected environment are themselves no measure of the adequacy of an environmental unpact statement.

$\$ 1502.16$ Envircnmental consequences.

This section forms the scientific and analytic basis for the compari. sons under $\$ 1502.14$. It shinll consol!date th- discussions oi those elements required by secs. $102(2)(C)$ (i). (Ii), (iv), and (v) of NEPA which are withln the scope of the statement and as much of sec. $102(2)(C)(i i i)$ as is necessary to support the comparisons. The discussion will include the environmental impacts of the alternatlves including the proposed actlon, any adverse environmental effects which eannot be ayoided should the proposal be implemented. the relationship between short-term uses of min's environment and the malntenance and enhancerncrit of long-tern productivity, and any irre- verslble or irretrievable commitments of resources whlch would be Involved in the proposal should it be Implemented. This section should not duplicate discusstons in $\$ 1502.14$. It shall include discussions of:

(a) Direct effects and their significance $(\S 1508.8)$.

(b) Indirect effects and their signiflcance ( $\$ 1508.8$ ).

(c) Possible conflicts between the proposed action and the objectives of Federal, regional. State, and local iand in the case of a rescrvation, Indian tribe) land use plans, volicies and controls for the area concerned. (See \$ 1505.2(d).)

(d) The environmental effects of alternatives including the proposed action. The comparisons under $\$ 1502.14$ will be based on this discus. sion.

(e) Energy requirements and conservation potential of various alternatives and mitigation measures.

(f) ivatural or depletable resuurce requirements and conservation po. tential of various a!ternatives and mitigation nieasures.

(g) Croan quality, historic and cal. tural resources, and line design of the juilt environment, includins the reuse and conservation potentiai of various alternatives and mitisation measures.

(h) Means to mitigate adverse environmental inpacts (if not fully covered uncier $\$ 1502.14(f))$.

\section{$\$ 1502.17$ List of preparers.}

The environmental impact state. ment shail list. the ramss. tozether with their qualifications (expcr:ise. experience. professional disciplines), of tise persons who nere primaruy responsible for preparing the environmental impact statemenc of significant backgrcund papers, iilc!uding basic components of tlic statethenl ( $\$ 1502.6$ and 1502.8). Where pessible the persons $\because$ ho are tesponsible for a particular analysis, includ. ing analyses in background papers, sliall be ideintified. Normally the list will not exceed $t$ wu pages.

\section{\$1502.1S Appendix.}

- If an agency prepares an uppendix tc an environmental impact statement the appendix shall: 
(a) Consist of malerial prepared in connection with an environmental Impact statement (as distinct from material which is not so prepared and which is incorporated by refer. ence (\$ 1502.21)).

(b) Normally consist of material which substantiates any analysis fundamental to the impact statement.

(c) Normally be analytic and relevant to the decision to be made.

(d) Be circulated with the environmental impact statement or be readily avallable on request.

$\$ 1502.19$ Circulation of the environmental impact statement.

Agencles shall circulate the entire draft and final environmental Impact statements except for certain appendices as provided in $\$ 1502.18(d)$. and unchanged state ments as provided in $\$ 1503.4(\mathrm{c})$. However, if the statement is unusually long, the agency may circulate the summary instead, except that the entire statement shall be fur. nished to:

(a) Any Federal agency which has Juriscicition by law or special expertise with respect to any environmental Impact involved and any appropriate Federal, State or local agency authorized to develop and enforce environmental standards.

(b) The applicant, if any.

(c) Any person, organization, or agency requesting the entire environmental impact statement.

(d) In the case of a final environmental impact statement any person, organization, or agency which submitted substantive comments on ts:a draft.

If the agency circulates the summary and thereafter receives a timely request for the entire state. ment and for additional time to comment, the time for that $r$ !questor only shall be extended by at least 15 days beyond the minimum piriod.

$\$ 1502.00$ Tiering.

Agencies ere encouraged to tler their environmental impact statements to eliminate repetitive discussions of the same issues and to focus on the actual issues ripe for decision at each level of cnvironmental review (\$ 1508.28). Whenever a brond environmental impact statement has been prepared (such as a prograin or policy statement) and a subsequent statement or environincntal asséss. ment is then prepared on an action included within the entire program or policy (such as a site specific action) the subsequent statement or environmental ussessment need only summarize the issues discussed in the broader statement and incorporate discussions from the bronder statement by reference and sliall concentrate on the issues specific to the subsequent action. The subsequent document shall state where the enrlier document is available. Tlering may also be appropriate for different stuges of actions. (Sec. 1508.28).

-\$1502.21 Incorporation by reference.

Agencjes shall incorporate mater. a) Into an environmental impact statement by reference when the effect will be to cut down on bulk without impeding agency and publlc revler; of the action. The incorrarated material shall be cited in the statement and its content briefly de-; scribed. No material may be inccrporated by reference unless it is reasonably available for inspection by potentially interested persons wit.hin the time allowed for comment. Miste. rial based on proprictary data which is Itself not available for review and comment shall not be incorporaied by reference.

$\$ 1502.22$ Incomplete or unurailable in. formation.

When an egency is eraluating sig. nificant adverse effects on the human environnent in an environ. mertal impact statement and there are.gaps in reievant information or scientific uncertainty. the agency shall always nuise clear that sucn information is lackine or that unier. tainty exists.

(a) If the information relevant to adverse impacts is essential to a rea. soned choice among alternativ's and is not known and the overa!l costs of obtaining it are not exorbitant. the agency shall include the information 


\section{DEPARTIENT OF ENERCY}

\section{Orlice of the Secretary}

Intent (NO) To Prepare an

Environmentel Impact Statement on Decommisaloning the Ejoht Shutdown Production Resctors Loented at the Hantord Sito Near Richtand, WA

Acsicr: Department of Enargy.

Acrnox Notice is hereby given that the Department of Energy (DOE) intends to prepare an Environmental Impact Statement (EIS) pertaining to the decommissioning of eight federally owned, shutdown production renctors located at the DOE Hanford Site, in the State of Washington.

summanr: The DOE announces its intent to prepare an $\mathrm{BS}$. in accordance with section 102(2)(C) of the National

Environmental Policy Act (NEPA), to provide environmental input into the decision on the proposed selection and implementation of a decommissioning alternative for the eight shutdown production reactors at the Hanford Site. near Richland. Washington. The DOEs Hanford Site is a $\mathbf{5 7 0}$ equare mile. controlled access area that in dedicated to a variety of nuclear-rolated activities which include producing nuclear power for commercial use, waste management. defense reactor operations, fuel fabrication/processing and nuclear research. This EIS will consider only the disporition of the eifht reactors. associated fuel storege basine, and buildinge used to house these systems. locsted in the 100 Ares of the Hanford Site in general.

The purpose of this NOI is to present pertinent beckground information on the proposed scope and contents of the EIS, and to invite interested agencies. organizations, and members of the general public to submit commerts or suggeations for consideration in connection with the preparation of the draft EIS.

Upon completion of the draft EIS, its availability will be announced in the Foderal Registor and local news media for public review and comments. Comments recuived on the draft will be used in preparing the final EIS.

aDoness: DOE invites interested agencies, organizations, and the general

$\rightarrow$ public to submit comments or suggestions for consideration in the preparation of th EIS. Written comments or suggestions on the scope of the EIS may be submitted to: Judy $L$ Torkaz. External Affairs Officer, US/DOE. RL. P.O. Bnx 550, Richland. WA 90352, (509) 376-7378.
For general information on the DOE EIS process, please contact: Office of the Arsistant Secretary for Policy, Safe'y. and Environment. U.S. Department of Energy, Attn: Ms. Carol M. Borgstrom. PE-252. Forrestal Building Room 3CO92. 1000 Independence Avenue SW. Washington, DC 20585, (202) 252-4600.

Written comments postmarked within 30 daye of publication of thir NOT in the Feder lBegister will be considend in the preparation of the diceft EIS. Comments received after that date will be considered to the degree practicable.

Beckground

In 1943, the Manhattan Engineer District of the U.S. Corps of Engineers selected the 570 square mile Hanford Site in Southeastem Waahington for production of special nuclear materials. principally plutonium, for national defense activities. Between 1943 and 1955. eight graphite moderated reactor were constructed at the Site, approximately 30 miles north of Richland, Washington, along the Columbia River, to support the plutonium production effort. They are the B, C, D, DR, F, H, KE and KW reactore. A ninth production reactor, $N$ Reactor, was started up in 1963 and is till in operation. The decommission of N Reactor is not within the scope of this EIS.

The Hanford reactors were operated by the U.S. Atomic Energy Commission and its successors the U.S. Energy Research and Development Administration (ERDA) and the U.S. Department of Energy (DOE).

In early 1964, a presidential decision to begin closing down the older Hanford reactore resulted in deactivating and removing the fuel from all eight reactor sites by the end of 1971. Due to the technical nature of the reactors, their unique design and purposes, and the age of the facilities, no future long-term beneficial use has been identitiod. The eight reactors contain irradiated reactor components, and the buildings that house the reactors are all contaminated to some degree with low levels of radioactivity. Safe storage of the resctors, since deectivation, has consisted of short-term surveillance and maintenance actiona adequate to protect the workers and the environment.

Proposed action

The proposed decommissioning of the shutdown reactors will permanent!y remove or better isolate any remaining radio active wastes in a manner that minimizes the potential health and afety impacts onthe pubic and the environment. The proposed EIS will evaluate several decommissioning alternatives for potential short-term and long-term environmental impects, and for engineering and cost contidarations.

Preliminary Dofinition of Alternatives To Be Considered in the EIS

\section{Safe Storage/Deferred Dismantlement}

This alternative involves temporarily storing the reactor in a safe, secure status for a predetermined period of time to allow decay of resident radionuclides to a level permitting hands-on. low radiation exposure dismantlement work For the eight ractors, the estimated storage period is 75 years. If this alternative were implemented, some additional upgrading of the reactor buildings would be needed, followed by a continued routine maintenance and suveillance program with major maintenance repairs of the buildings conducted every 20 years. After 75 years, the reactors would then be dismantled piece by piece and any remaining radioactive waste transported to approved low-level waste burial arees on the Hanford Site. The maximum distance from the reactors to the proposed burial site is approximately 15 miles, with the transport routes being entirely within the Hanford Site.

\section{Immediate Dismontlement}

In this altemative, the entire reactor facility is promptly removed from the present reactor site. All radioactive waste material is packaged and transported to an approved low-level waste burial area on the Hanford Site. Dismantlement is accomplished by first removing facility equipment and materials for reuse or disposal, and then demolishing the building. The reactor block is removed in one piece by excavating under the block, positioning a tractor crawler under it, and slowly lowering the block onto the platform. Once the reactor block is physically and radiologically secured aboard the crawler, the crawler is driven across the Hanford Site along predetermined route to the waste burial area. The 15 mile trip to the wast burial area would take approximately 48 hours per reactor.

\section{In Situ Disposa!}

In situ disposal involves leaving the reactor at its present location, as opposed to relocating it to an alternate waste disposal area on the Hanford Site. Facility equipment, reactor components. and other materials that have a potential for reuse are removed. The resctor block is left intact on its foundation, with special care taken to prevent damage to it during the in situ decommissioning process. Loose

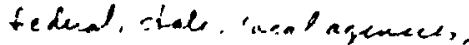

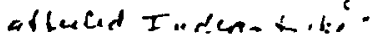


[6450-01]

\section{DEPARTYMETTI OF ENERGY}

Availability of Draft Environmental Impact statement on Decomissioning of Eight Suxplus Production Reactors at the Hanford Site, Richland, Washington

AGENCY: DEPARTMENT OF ENERGY

ACTION: Notice of Availability of Draft Environmental Impact statement (EIS).

SUMARAY: The Department of Energy (DOE) announces the availability of a draft EIS on "Decommissioning of Eight Surplus Production Reactors at the Hanford Site, Richland, Washington" (DOE/EIS-0119D). The draft EIS contains information on the potential environmental impacts of alternatives for the proposed decommissioning of eight surplus plutonium production reactors at the Hanford site in Richland, Washington. The DOE has not identified a preferred alternative. Public comments are invited on the draft EIS for consideration in preparing the final EIS. 


\section{Ex03}

Four public hearings will be held to receive oral comments on the draft EIS.

DAMEs: Written comments on the draft EIS should be sent to DOE by July 28, 1989, to ensure consideration in preparation of the final EIs. Comments received after that date will be considered to the extent practicable. Public hearings will be held on July 11, July 13, July 18, and July 20, 1989, as described in this notice. Individuals desiring to make oral statements at the hearings should notify Tom Bauman at the address below, so that DOE may arrange a schedule for presentations.

ADDRESSES: Requests for copies of the draft EIS, written comments on the draft EIS, requests to present oral comments at the hearings, and requests for further information concerning this draft EIs should be directed to:

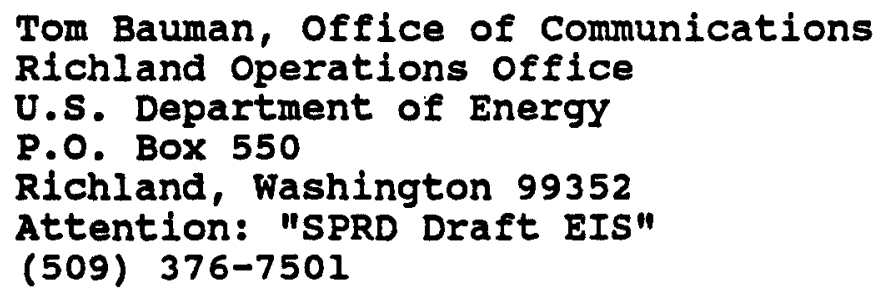

For general information on the procedures DOE followed in complying with the requirements of the National Environmental Policy Act (NEPA) contact: 
Ex03

Carol Borgstrom, Director

office of NEPA Project Assistance (EH-25)

U.S. Department of Energy

1000 Independence Avenue, S.W.

Washington, DC 20585

(202) 586-4600

PUBITC OUHREACR ACTIVITIES: Prior to the public hearings, public information and outreach activities related to the draft EIS are planned in multiple Northwest locations. The purpose of these activities is to present information on the alternatives and issues discussed in the draft EIS. This information may be helpful in preparing comments on the draft EIS. These activities will also serve to publicize the public hearings that will be held to receive oral comments on the draft EIS. There will be no formal record of the public outreach activities. The dates and locations of these activities will be announced in the news media.

PUBLIC HEARINGS: Public hearings on the draft EIS will be held at the following times and locations:

Federal Building Auditorium

825 Jadwin street Richland, Washington

Date: July 11, 1989

Time: 10:00 a.m. and 7:00 p.m.

Sheraton Hotel

North 322 Spokane Falls Court

Spokane, washington

Date: July 13, 1989

Time: 10:00 a.m. and 7:00 p.m. 


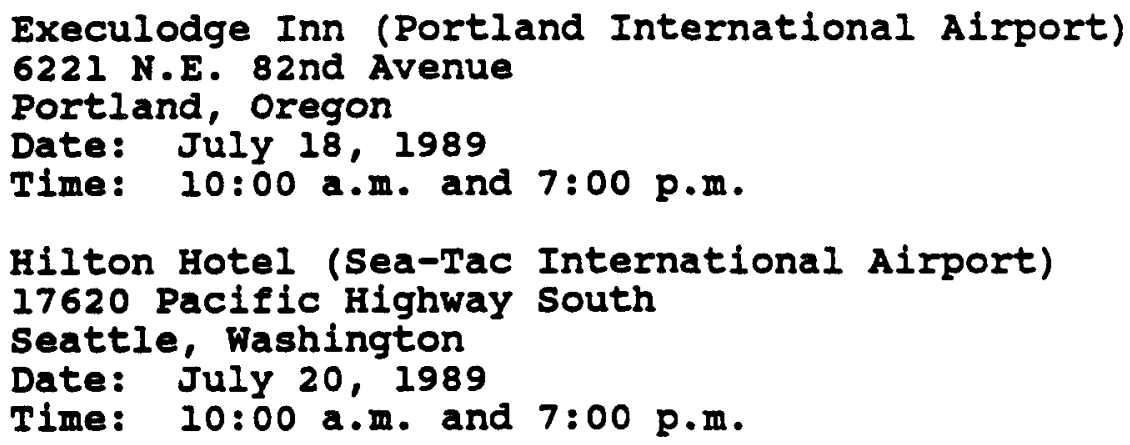

Members of the public, organizations, and government agencies are invited to present comments on the draft EIS at any scheduled hearing. Persons desiring to make an oral presentation should notify Mr. Bauman at the above address, so that the DOE may arrange a schedule for the presentations. Persons who have not submitted a request to speak in advance may register to speak at a hearing. To ensure that everyone has the opportunity to present comments, five minutes will be allotted to each speaker. Individuals and representatives of organizations or agencies presenting comments are requested, if possible, to have written copies of their comments for the hearing record. written and oral comments will receive equal consideration in preparation of the final EIS. The DOE will arrange the schedule of speakers and will establish rules and procedures for conduct of the hearings. The hearings will not be adjudicatory and there will be no cross examination of speakers. Any other procedural rules for the conduct of the hearings will be announced by the presiding officer at the 
beginning of each hearing. A verbatim transcript of the hearling will be prepared, and placed in the reading rooms and libraries indicated below.

The draft EIS and documents referenced in the draft EIS are avallable for public inspection at the following locations:

\author{
Room 157 \\ Federal Building \\ Richland, Washington 99352 \\ (509) 376-8583 \\ Multnomah County Library \\ 801 SW loth Avenue \\ Portland, Oregon 97205 \\ (503) 223-7201
}

U.S. Department of Energy Public Reading Room

The draft EIS and copies of major references used in

preparing the draft EIs are also available for public

inspection at the following locations:

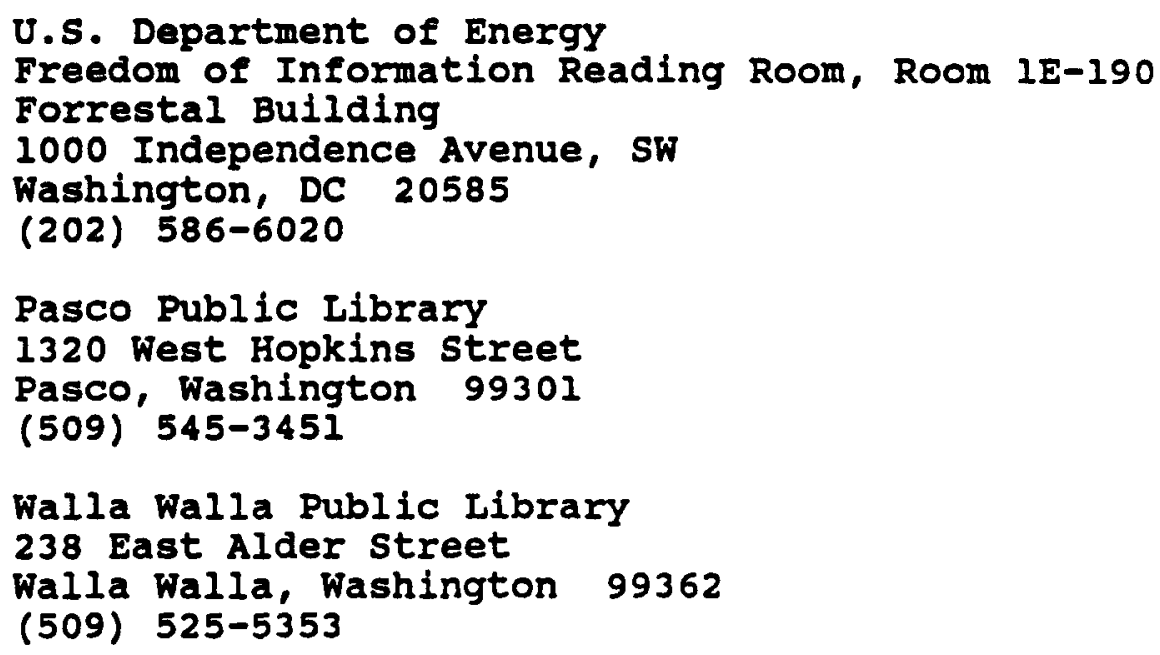




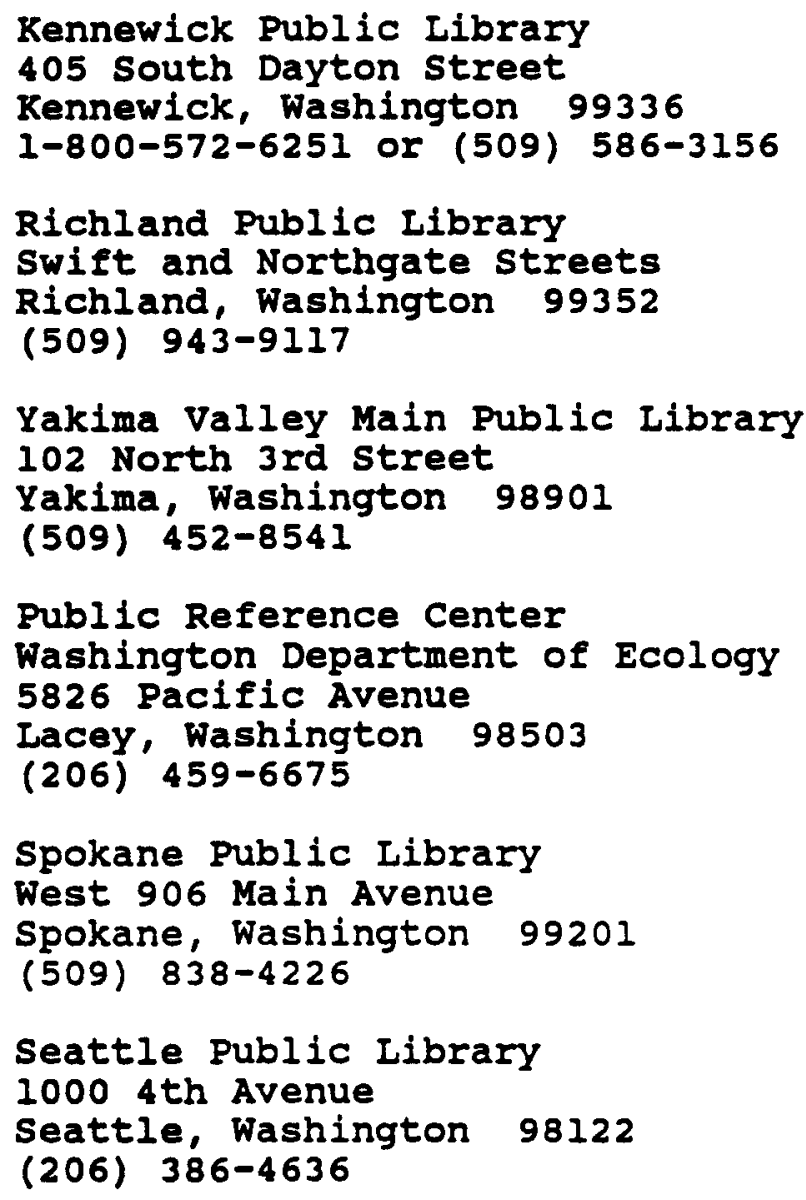

SUPPLEMENTARY INFORMATION: The U.S. Government established the Hanford site in 1943 to produce plutonium for military purposes. Nine water-cooled, graphite-moderated plutonium production reactors were constructed along the columbia River between the years 1943 and 1963 in a location designated as the 100 Areas. Eight of these reactors are now retired from service (B, C, D, DR, KE, $K W, F$, and $H$ ), have been declared surplus by DOE, and may be 
decommissioned. The ninth reactor $(N)$ is in a standby mode and its decomissioning is outside the scope of this EIS.

PROPOSED ACTION AND SCOPE OF THE DRAFT EIS: The proposed action is to decommission the eight surplus reactors. The purpose of the draft EIS is to provide environmental information that will assist the DOE in deciding which alternative action is most appropriate. The scope of the draft EIS includes the reactors, their associated fuel storage basins, and the buildings that house these facilities. All fuel elements have been removed from the reactor cores. The scope does not include the 100-Area cribs, burial grounds, or settling basins. These facilities were evaluated in the "Final Environmental statement, Hanford Waste Management Operations, Hanford Reservation," U.S. Energy Research and Development Administration, ERDA-1538, 1975. Further, the DOE is presently re-evaluating these facilities as part of DOE's responsibilities under the Comprehensive Environmental Response, Compensation, and Liabllity Act of 1980.

The purpose of decommissioning is to reduce the potential environmental, health, and safety impacts of contaminated facilities; decommissioning actions may include the stabilization, reduction, or removal of radioactive and hazardous materials or the demolition of facilities. 


\section{Ex03}

Because the reactors contain irradiated reactor components and because the buildings that house the reactors are contaminated with low levels of radioactivity, the DOE has determined that there is a need for action to ensure the long-term protection of the environment and public health and safety. Alternative actions considered in the draft EIS include:

1) immediate one-piece removal (to the 200-West Area) of the reactor-block assembly and the dismantlement and removal of contaminated equipment and components of the fuel storage basins and reactor building;

2) safe storage followed by deferred one-piece removal (i.e., continuation of current maintenance activities for up to 75 years followed by "one-piece removal");

3) safe storage followed by deferred dismantlement and removal of the reactor-block assembly and other contaminated components;

4) In situ decommissioning (i.e., the sealing and burial of the reactor facilities at their present location under an engineered protective mound); and 5) no action (i.e., continue present surveillance, monitoring, and maintenance).

FLOODPLAIN/WETLANDS: Because the reactors are located along the Columbia River, it is necessary to evaluate the effects of any decommissioning actions with respect to flood 
hazards, floodplain management, and wetlands protection. In accordance with Executive order 11988 (Floodplain Management), Executive order 11990 (Protection of Wetlands) and DOE regulations 10 CFR 1022 (Compliance with Floodplain/wetlands Environmental Review Requirements), DOE has prepared a floodplain/wetlands assessment for decommissioning of the surplus production reactors (see Appendix $B$ of the draft EIS). No reactor is in a wetland or the 500-year (critical action) lloodplain as defined by the regulations. As a part of the review of the draft EIS and in compliance with executive orders and regulations regarding floodplain management and wetlands protection, the DOE solicits public and agency comments on these determinations.

HISTORIC PRESERVATION: The DOE and the Washington state Historic Preservation officer have determined that the $B$ Reactor is eligible for inclusion in the National Register of Historic Places according to the procedures in 36 CFR 800 (Protection of Historic and Cultural Properties) and the criterla in 36 CFR 60 (Criterla for Inclusion in the National Register of Historic Places). These findings are discussed in Appendix $J$ of the draft EIS. The DOE solicits public and agency comments on whether or not the $B$ Reactor should be nominated for Inclusion in the National Register of Historic Places, on the potential impacts of 


\section{Ex03}

decommissioning on the inclusion of the $B$ Reactor in the National Register, and on means identified to mitigate the potential impacts of the decommissioning action.

Issued in Washington, DC on April /4, 1989.

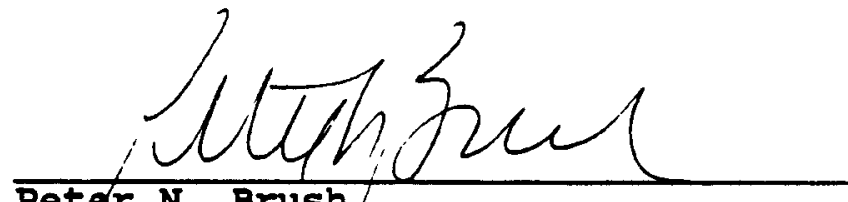

Peter N. Brush/

Acting Assistant secretary

Environment, Safety, and Health 


\section{PUBLIC OUTREACH EVENT STAFFING SCHEDULE}

(As of $5 / 10 / 89$ )

\section{Date \\ May 11 Thurs \\ 12 Fri \\ 13 Sat \\ May 18 Thurs \\ 19 Fri \\ 20 Sat}

May 25-27

Thurs-Sat

$\begin{aligned} \text { Jun } 1 & \text { Thurs } \\ 2 & \text { Fri } \\ 3 & \text { Sat }\end{aligned}$

Jun 9 Fri

10 Sat

Jun 15 Thurs

16 Fri

17 Sat

Jun 22 Thurs

23 Fri

24 Sat

Facility
Columbia Center, Richland
Same
Same

Riverpark Square, Spokane

Northtown Ma 11, Spokane

University City, Spokane
Tech Staffers
Goodenough/Speer
Goodenough
Goodenough

Moore/Heine

Moore/Heine

Mihalic/Heine
PR Assist

Harvey/Engel

Harvey/Engel Harvey/Engel

Harvey

Harvey

Harvey
Memorial Day Weekend

Moses Lake

Indian Offices, Toppenish*

Yakima Mall, Yakima

Red Lion Inn, Pendleton, OR

Eastgate Mall, Walla Waila

Seattle Public Library

Westlake Center Mall, Seattle

Same

Multnomah Pub. Lib., Portland Eastport Plaza Ma11, Portland Same
Goodenough
Clarke
Defigh-Price

Winship

Winship

Moore/Heine

Moore/Heine

Moore/Heine

Goodenough/Heine

Goodenough/Heine

Goodenough/He ine
Hol loway

Hall oway

Holl oway

Harvey

Harvey

Harvey

Harvey

Harvey

Enge l sman

Engel sman

Engelsman

Both technical and PR support individuals are responsible for assigned staffing positions. If they are unable to attend a scheduled assignment, please contact a replacement. Call $G$. Harvey for any required assistance in finding a suitable replacement and notify him of the schedule change as soon as possible.

* - This date is tentative and subject to change. 


\section{Ex05}

JuTy 11,1989

Mr. Tom Bauman

U. S. Department of Energy

Richland Operations Office

P. O. Box 550

Richland, Washington 99352

DOE/EIS 0119 DRAFT ENVIRONMENTAL IMPACT STATEMENT - DECOMMISSIONING OF EIGHT SURPLUS PRODUCTION REACTORS AT THE HANFORD SITE

I have read the subject draft and offer the following comments:

1. My appraisal of the draft is that it is very comprehensive, well detailed and documented and an excellent pattern for the proposed decommissioning activities at Hanford:

2. Seismicity is addressed in 4.3.2, floods are mentioned in 4.2.2. A comparison table should be included of the five alternatives versus natural disasters.

3. Paragraph 4.6.1, the estimate of employees on DOE related projects at Hanford should be revised downward.

4. Paragraph 3.2.5 recognizes that a major structural upgrade of the reactor foundation would be required. It should also consider banding or otherwise securing the upper structure to prevent fissures during removal and transit.

5. Paragraph 5.3.1 addresses to the block-drop accident. Two other accident scenarios, not as dramatic as the block drop, but more probable are the loss of synchronism of the four transporter drives while in transit, and the jamming of the hydraulic mechanism necessitating the sacrifice of the transporter in the pit at the 200 area. 


\section{Ex05}

6. Appendix $\mathrm{J}$ - National Historic Preservation. I support and endorse the option of no action for the B Reactor. I am completely opposed to the option of "Extensive Recordation". I have discussed these opinions with many of my engineering associates and they are all in agreement with them.

7. I believe that a national register of historic places nomination should be prepared for the $B$ Reactor. Aside from the Fermi Pile (CP-1) under the west stands of the stage field at the University of Chicago, the $B$ Reactor is the most historic in the controlled release of nuclear energy. The CP- 1 has been dismantled. The $B$ Reactor has the potential of being the mecca for scientific and technical personnel from all over the world.

Sincerely,

IVAN M. A. GARCIA
P. O. Box 682
Richland; WA 99352


Ex06

I

ilupt onengy

... - Joly ..11, 1987....

Richlend Operateri commente between

Pecommiscioning of 8 reactoro

Puslic hearing group,

L understend from the refort. thot the eight reactors are basicaly. structuraly sound.

lom proued to eay I was a menber of "that technotoy ccil team. I sopport." Continier Presut action". page 3.7, whech. I belive to be in the best interest of the Natinal budget.

I believe with the present rate of scien tifec advancement, wared weile, That the 8 reactors may grove to be a reseatch asset rather then the presunt thrught of licikitit.

Hareieh

Altor Dteymen 172 lottor waod an

0.288 Fasco. Um. 9530 


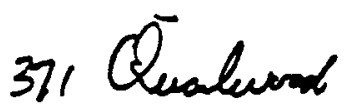 \\ Aunford Dansine of the}

My name is John Burnham, and I would like to speak for the 1 Tri-City Industrial Development Council of the Tri-Cities.

1 have 40 years of experience working in the nuclear industry. My work has included risk analysis and preparation of environmental impact statements. Now I work with the Hanford division of TRIDEC. We are interested in preserving the Hanford Site and developing site activities.

I am pleased to see the Department of Energy come out with this EIS on the site's retired production reactórs. The government has a responsibility to move forward with permanent, safe disposal of these reactors and the lowlevel wastes contained in the reactor blocks. Implementing one of these decommissioning options, along with the actions taken as part of the TriParty Agreement, is evidence of the Department's interest in cleaning up the Hanford Site efficiently and completely.

We are certainly interested in seeing that the reactors are decommissioned properly. This means the decommissioning work must insure worker safety, community safety and environmental safety. The decommissioning must be technically sound as well.

The draft EIS compares four alternatives, taking into account cost and health impacts. I am particularly interested in the health impacts, as safety is a prime consideration. The characteristics of the reactors blocks must be considered. The surplus reactors have been maintained safely since the shutdown of the last reactor in 1971 . 


\section{Ex07}

Ninety-five per cent of the radionuclides are contained within the blocks. Each block is protected by 20 to 25 centimeters of cast iron thermal shielding, plus a biological shield of alternating layers of steel plate and masonite which are 100 to 200 centimeters thick. This shielding provides excellent so there is no, danger of the low-level waste moving into the environment.

Keeping the block intact with its protective shielding is important. Because the radionuclides are contained within the block the less direct interaction required with the block the better. Because of this, DOE should not seriously consider the of dismantlement options which mean moving the reactor blocks to the 200 area. Once the protective shielding of the reactor block is breached, the risk of exposure to workers - and ultimately the public and our community .. is greatly increased.

As the EIS points out, there is a far greater opportunity for exposure to workers with these options. Common sense tells us that there are also practical risks in moving 9,000 and 11,000 ton blocks several miles inland. These risks need to be carefully weighed against the environmental benefit of moving the blocks to a higher elevation and a few miles from the columbia

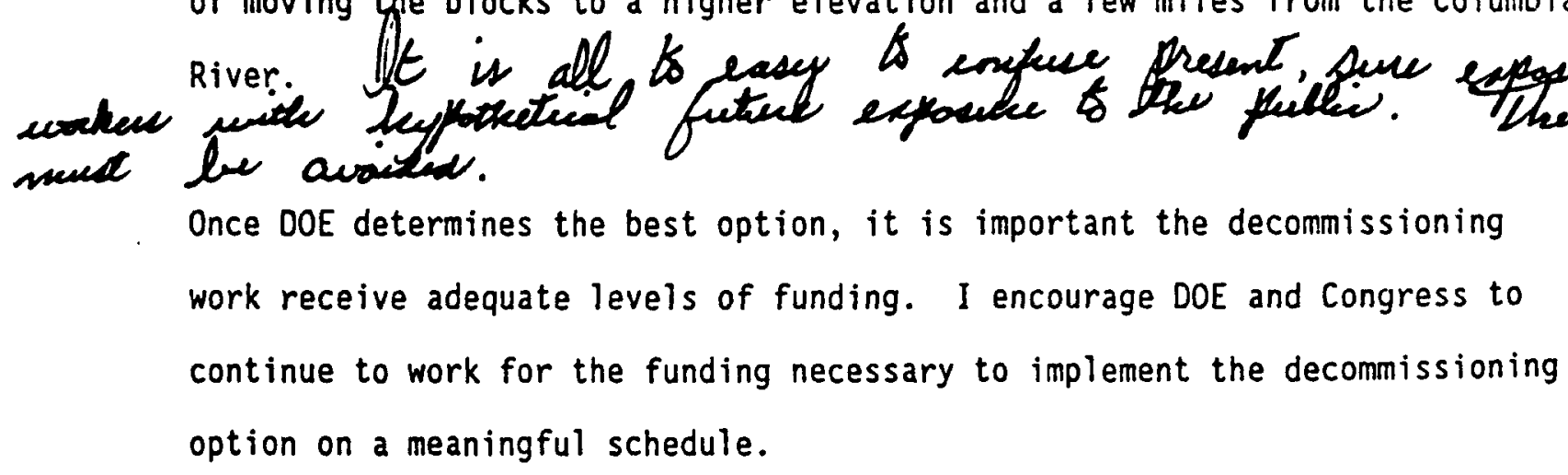


DOE has also asked for comments on the designation of B Reactor as a National Historic Site. I support this. B Reactor has been an important site in the evolution of U.S. history, in ending World War II, and certainiy in the history of the nuclear industry. B Reactor was constructed in 1944 -- just 45 years ago. That is a few short years in the scope of history. An appreciation of the historical significance of the first full-scale defense reactor will grow over the years. B Reactor should be preserved as much as possible to give the public an opportunity to share in the historical significance. Of course, with any efforts to preserve $B$ Reactor and make it more available to the public, health and safety must also be considered.

In summary, we support the Department of Energy's efforts to move forward in decommissioning the surplus reactors on the Hanford Site as part of the total cleanup effort. The final option that DOE chooses must make the best engineering and scientific sense and it must take into account the total risk to workers and the public. TRIDEC supports DOE's activities and cleanup efforts at Hanford.

On behalf of TRIDEC, thank you for this opportunity to express our views. 


\section{Ex08}

Save B-Reactor!

Were you ever in a place that made you tingle with a combined sense of awe, excitement, and eeriness?

I was two years ago when 1 toured Hanford's first plutonium production reactor, the historic B-reactor. I felt awe, excitenent, and eeriness.

Awe...al seeing that huge reactor face, massively scaled up in a matter of months from Enrico Fermi's first critical pile.

Fixcitenent... that must have been felt back then by the participants in the Manhattan Project. The excitement of a racea cleadly race for the survival of a free world.

Eeriness...as if the ghosts of Fermi and his co-workers still inhabited that empty control room.

The war that gave birth to the Manhattan Project, to Hanford, and to the B-reactor was one of the great human tragedies of our lifetine. The historical facts are that B-reactor produced the plutonium for the first manmade nuclear explosion-the Trinity test-and for the bomb that destroyed much of the city and people of Nagasaki.

By the grace of God, our need for nuclear weapons is rapidly disappearing. An era-the era of nuclear weapons-is passing. And while we cannot yet see the end of that era, we have already seen the beginning of the end.

This hearing on the decommissioning of the Hanford reactors is evidence of that hopeful reality for our future. And Hanford has a role in that future.

I believe that part of Hanford's future lies in its past, not in the preservation of its original mission, but in the preservation of its history. I want to see B-reactor preserved as a permanent monument to that passing era.

Because of the wartine secrecy in which the Manhattan Project was born, many Americans of the present do not know the history of the atomic bomb. This will be even more true of future generations unless we save some of the relics, such as B-reactor, for their immense historic and educational value.

Therefore, I urge that the Hanford B-reactor be

* preserved intact, onsite as a national historical inomument and museum; that it be

* upgraded with relevant histurical and educational displays; and that it be

* provided with public vehicle access from state highway 240 . 


\section{Ex08}

With these steps accomplished, many other Americans and neighbors from around the world can visit that historic place and tingle with awe, excitement, and eeriness for the past... and with hope for a future of peace.

Thank you.

Statement presented at the public hearing on llanford reactor decommissioning, Richland, Washington, 11 July 1989.

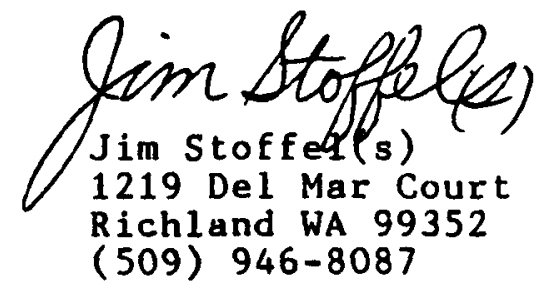




\section{Claude L. Oliver \\ Treasurer \\ BENTON COUNTY}

Prosser Phone 786-2255

Tri-Citues 783-1310

July 11, 1989

Mr. Mike Lawrence, Director RL

U.S. Department of Energy

Federal Building

P. O. Box 550

Richland, Washington 99352

RE: Decommissioning Environmental Impact Statement on Idled Hanford Nuclear Reactors

Dear Mr. Lawrence:

At this time of public input on the U.S. Department of Energy's planning process to de-activate eight nuclear production reactors, we should reflect on the original Hanford mission. What was the intent of Congress and President Franklin Delano Roosevelt when they created and activated this vast Federal Facility of over 350,000 acres in Benton, Franklin and Grant counties? National forces driven by the urgency of World War II against the background of a legitimate question of National survival compelled the United States to produce the ultra secret, "The Manhattan Project".

Even after details of perhaps the greatest World War II secret became known, the late 1940's and 1950's ushered us into an era of the Cold War stand off between the United States allies and the Soviet Union. In order to understand where we are today, it is important to clarify the activities of the Federal Government in our area occurred in an era which was largely void of public knowledge or involvement. From a National, State and local government objectives it is important that we give definition to original intent for Hanford "start-up" in order to properly plan "conclusion" for these facilities and lands.

The 1940 Federal Census gave Benton County 12,053 people. With the World War II activity it became necessary to provide a special census which was taken in 1944, which revised Benton County's total to 70,987 people. This six fold increase in population totally overwhelmed our local education systems, county roads deterforated without funds to repair or replace them and county courts and offices were sent reeling with totally unexpected and unplanned service demands. Though Benton County property values increased from 9 million dollars to 12 million dollars during this time, County taxes were being levied at the maximum 10 mills allowed under state law. It was necessary in addressing one emergency in 1946 to recelve $\$ 76,000$ from Washington State for Benton County operations for war time un-reimbursed expenses of the previous year. Courthouse 
journals evidence one financial impact after another on the people of this county. The people of Benton, Franklin and Grant counties, however, rallied to the War effort and the national policy of essential war victory gladly and in fact, recognized the need to make national sacrifices.as an accepted practice of the day. Thus Hanford was created.

So that we can now proceed to address resource use of 1 and and its impact on the people of Benton, Frarklin and Grant counties, please answer the following:

1. What was the original Congressional intent of taking and establishing the Hanford land area in carrying out the World War II "Secret" Manhattan Project?

2. Did the 1942-1943 United States Congress and the Department of Army Corp of Engineers evaluate their actions with knowledge that some portion or all of the Hanford Federal Reservation land taken for this project would be contaminated and unsuitable to return to its previous use? In their deliberations, did they offer consideration to assess the ultimate plan for future generations that are now in the genesis of this environmental impact statement on our communities?

3. What was the determination used in the amount of lands originally condemned for the Hanford Reservation in Benton, Franklin and Grant counties? Is it planned by the Federal Government or yet to be determined that this portion of land will be kept off of the tax rolls of Benton, Franklin and Grant counties indefinitely? What land set aside is necessary to address your environmental impact containment of the eight idled reactors?

4. Water allocation from the Columbia River for irrigation purposes has been conducted for a number of years. The resource of water combined with land grows crops in ready abundance throughout the world. Recognizing that the Hanford Reservation was created in the middle of a vast agricultural plane, has the U.S. Department of Energy given consideration for the need to reserve water rights for future irrigation needs of the Hanford lands now held in its trust? If not, why not?

5. With the original Hanford National mission now significantly declining, what consideration is being given by the U.S. Department of Energy for a future community Impact plan? Does the U.S. Department of Energy have any comparable environmental impact consideration plans for deactivation of any comparable facilities?

308 of Benton County's tax base, 16,000 acres in Franklin County and 25,000 acres of Grant County lands have been off the tax rolls since 1944, the main community and U.S. Department of Energy missions of World Peace Through Strength, though not conducted without incidence, has certainly worked. We could all pray the nuclear genie of Atomic War was not out of the bottle, but it is. We also do recognize the full value of the peaceful use and continuing development of the "Atom" that has and will significantly benefit mankind.

The people of Benton, Franklin and Grant Counties have played proud rolls these past 45 years. Their contributions to future endeavors by the U.S. Department of Energy both known and unknown in origin will be significant and valued as future generations will evidence. 


\section{Ex09}

However, we must now address legacy to one chapter of the Cold War and a community that accepted responsibility without hesitation. Let us adequately explain the basis of our genesis so that we can arrive at the best intelligent assessment of where we came from, so that we can truly plan for our future wisely. Recent national policy changes by the U.S. Department of Energy to deemphasize production and emphasize safety is indeed refreshing and highly professional. Though we live in a world that could be considered vast and boundless we certainly must recognize that responsible limitations for living standards and future generations can only be best maintained and enhanced if we are willing to preserve them. In this regard land use planning and socioeconomic impact needs much more attention and emphasis then it is given in the March 1989 draft Environmental Impact Statement. Answer specific to the issues enumerated above, especially item 5 , are respectfully requested.

Thank-you for taking this public comment.

Very truly yours,

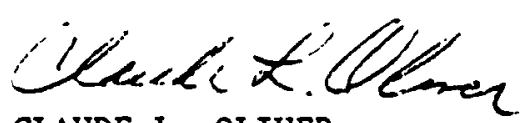

CLAUDE L. OLIVER

Benton County Treasurer 


\author{
A PROPOSAL fOI SPECIAL TREATMENT \\ for \\ THE HANFORD B REACTOR \\ DURING AND SUBSEQUENT TO DECOMMISSIONING TQ \\ PRESERVE AND COMMEMORATE ITS HISTORICAL STATUS
}

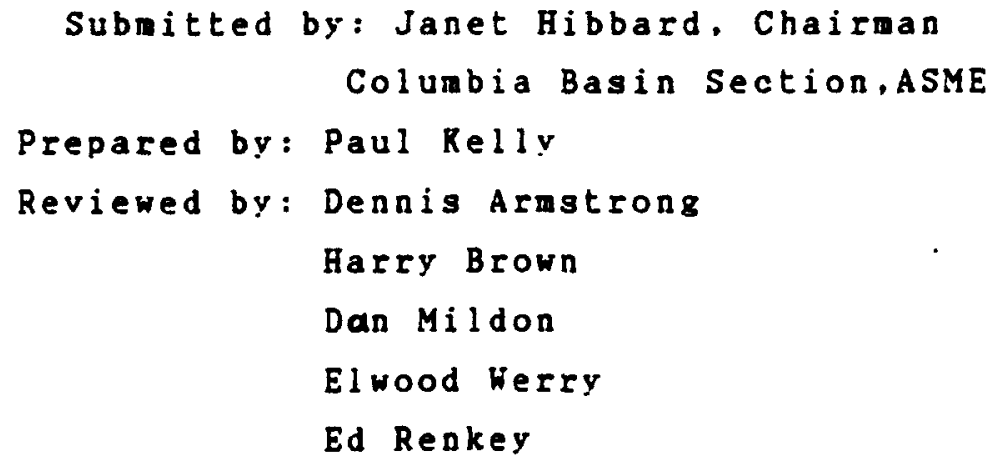




\title{
Ex10
}

\author{
A PROPOSAL fOr SPECIAL TREATMENT \\ for \\ THE HANFORD B REACTOR \\ DURIVG AND SUBSEQUENT TO DECOMMISSIONING TO \\ PRESERVE AND COMMEMORATE ITS HISTORICAL STATUS
}

\begin{abstract}
Subritted as comment to the Environmental Impact statenent (EIS) document DOE/EIS 0119D by the Columbia Basin Section of the American Society of Mechanical Engineers, Janet Hibbard, Chairman.
\end{abstract}

\subsection{INTRODUCTION}

EIS document DOE/EIS 0119D describes alternate methods of decomissioning the currently shut-down Hanford production reactors constructed beginning in 1943 for the production of plutonium for the first atomic bombs. The Anerican society of Mechanical Engineers (ASME), a nationally and internationally recognized technical society, acknowledged the historical significance of these reactors to the future nuclear industry by certifying the Hanford B reactor as a National Historic Mechanical Engineering Landmark in 1976.

ASYE supports the safe decomissioning of nuclear facilities, including total demolition and site restoration where necessary. However, in the case of Historic Landmarks such as the $B$ Reactor, ASME believes that steps should be taken to preserve and commerate the Landmark and retain sone degree of its historic status. For the Hanford B Reactor, various alternatives are offered by way of comment on the EIS. The historical background of the reactor and the ASME History and Heritage progran are also described briefly to provide a frame of reference for the ASME proposals. 


\subsection{HISTORICAL BACKGROUND AND SIGNIFICANCE OF THE HANFORD B REACTOR}

The Hanford B reactor was the first plutoniun production reactor to be placed in operation. Its startup followed successful operation of three test-scale reactors, including the Chicago pile and the Hanford Test Reactor, which proved that all of the physics calculations and engineering decisions required for construction of the graphite pile and cooling systen were correct and within proper limits to sustain a controllable chain reaction. ' From an engineering standpoint, the significance of B Reactor lies in achieving the results of the startup after designing the mamoth production reactor based on data from the much smaller test reactors. For example, the B Reactor moderating pile alone contains 2000 tons of graphite blocks. penetrated by over 2000 aluminum process tubes. The pile, as high as a four-story building. was surrounded by a skin of cast iron ten inches thick and a shield of nasonite, steel, and concrete four feet wide. The B Reactor complex is said to contain more concrete than Alonzo stags stadium under which the Chicago Pile operated.

However. outside of its contribution to the defense of the United states, the full significance of the B Reactor startup was realized in later years with the developnent of the domestic nuclear industry. Thus the successful operation of the Hanford B Reactor was a mor milestone for the Manhattan Project and made possible the subsequent development of comercial atomic energy utilization. The research, engineering, and planning required to make the reactor operate should be included in history as one of man's most brilliant scientific and advanced engineering achievenents.

Reference: Snyth, H. D. 1945. Atomic Energy for Military Purposes: The official Report on the Development of the Atomic Bomb Under the Auspices of the U. S. Government, $1940-1945$. University Press, . 


\section{Ex10}

Historically, B Reactor began as part of the Manhattan Project in 1942 with the breaking of ground in April, 19+3, for support facilities. Construction of the reactor started in June, 1943, and was completed during September, 1944. This was followed in rapid succession by fuel loading ard startup during the sane month. Three wonths later, on Christas day.19it, the first irradiated fuel was discharged from the reactor. The facility operated intermittently until it was shut down permanently in 1968 . 


\subsection{DESIGNATION OF B REACTOR AS A NATIONAL HISTORIC LANDMARK}

The ASME Historic Landmarks program is an outgrowth of a relationship between ASME and the smithsonion Institute. ASME contributes historical material particularly related to Mechanical Engineering to the U.S. National Museun of History and Technology in Washington. D.C. In 1971. ASME established its History and Heritage program for the society, and the Landmarks progran was added in 1973.

A National Landark is a mechanical engineering achievenent with national or international significance, one associated with persons or events that have contributed to the general

developaent of mankind. All noninations are approved by the ASME national History and Heritage Comittee. Once a nomination is approved, a history brochure and bronze plaque are prepared and presented to an appropriate organization for display in the vicinity of the monument being dedicated. The Hanford B Reactor placque is displayed in the Hanford Science Center.

Hanford B Reactor was noninated for Landmark status during 1975 by the Columbia Basin Section.ASME. This nonination was subsequently approved by the History and Heritage Conaittee, which cited the $B$ Reactor as a technical achievenent and because - nuch of the reactor core, cooling system, shielding, and auxiliary support systems were designed by mechanical engineers. although many different types of scientists and engineers contributed to the ultimate success. 


\title{
Ex10
}

\subsection{PRESERVATION OF B REACTOR AS AN HISTORIC LANDMARR}

\begin{abstract}
Alternative proposals described below are offered to support the belief by the Columbia Basin Section that the B Reactor represents such a significant achievenent that continued recognition of the facility as an Historic Landmark is warranted. The proposals are intended to be consistent with requirenents of the decomissioning mode selected based on the EIS.
\end{abstract}

\section{A. Information Kiosk}

Information kiosks located in rest areas located adjacent to the nation's interstate highways are effectively used to convey information to the traveler about features of the surrounding country. For example, a series of kiosks along Interstate 84 in Orezon effectively tell the story of the oregon Trail and its pioneers at various key locations in that state. A sinilar installation for B Reactor could be located at the Vernita Bridge rest area on Washington State Highway 240 . The kiosk. consisting of several information panels covered to protect then againgt the weather, could be designed to tell the B Reactor story, even if decomnissioning were to consist of total renoval of the facility.

\section{B. Enhanced Audio-visual Displav}

The B Reactor display currently located in the Hanford science Center could be enhanced by producing a videotape of the facility and periodically showing the videotape at the science Center or at the Fast Flux Test Facility (FFTF) Visitor's center. The videotape could be assembled from a conbination of historic still shots and videotape recordings of the exterior and interior of the reactor facility before, during, and after demolition for decommissioning. 


\section{Ex10}

\section{Reactor Menorial}

An obelisk detailing key features of B Reactor could be located along Washington state Highway 240 or sone other suitable location as an historical marker.

\section{Facility Access}

Some key part of the B Reactor facility, such as the control room, could be saved during demolition for deconissioning and converted for visitor access. Because B Reactor is relatively close to Hashington state Highway 240 , the control roon could be allowed to remain at the reactor site or moved to another location for public access. 


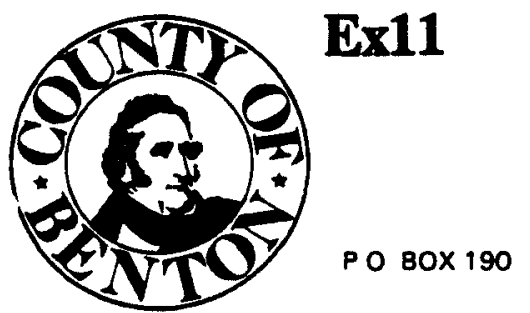

\section{Board of County Commissioners BENTON COUNTY}

PHONE (509) 786-5600 OR $783 \cdot 1310$
PROSSER, WASHINGTON 99350

July 11, 1989
Ray Isaacson District \#1

Robert J. Drake. Sr. District \#2

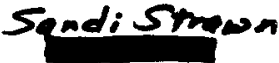

District \#3

Ms. Karen J. Wheeless

Ofice of Communications, Richland Operations Office

U.S. Department of Energy

Richland, Washington 99352

Re: Draft Environmental Impact Statement--Decomissioning of Eight Surplus Production Reactors at the Hanford Site, Richland, Washington. March 1989.

Dear Ms. Wheeless:

It is apparent that the environmental impact of decommissioning the eight surplus reactors will be essentially inconsequential regardless of the method of decommissioning. However, I believe that the method of decommissioning that should be selected is one that would result in the least amount of additional disturbance of the environment and that would result in the least occupational radiation dose to the worker.

While the draft environmental impact statement appears to be quite thorough, land use planning is inadequate and requires further consideration.

When the Hanford Project was started, approximately 570 square miles was acquired by condemnation and other methods and reserved for atomic bomb materials production. The majority of this land area was required for radioactivity isolation, public safety and security purposes. Now that all of. the Hanford reactors have been shut down and decomissioning is being considered for eight of the nine reactors that were built, it is obvious that the land once taken out of agricultural production is no longer needed for isolation and security purposes. Also, the land that has not been adversely affected by radioactivity should be evaluated for return to productive use.

To put this issue in perspective it is necessary to know how much land could be made available for various crops by type. Considerable area was under irrigation when acquired for the Manhattan Project. The evaluation of returning land to productive agriculture should include provisions for irrigation water systens that will deliver water to specific areas such as Cold Creek Valley adjacent to Highway 240 . Reconsideration of the economic value of the Arid Lands Ecology Reserve should be included. If there is justification for keeping this land out of productive agriculture, consideration must be given to providing 
payment in lieu of taxes to units of local goverment so that the adverse econonic impact that now exists can be rectified.

Tables of estimated acreage and incomes for various crops harvested in Benton County during 1988 are attached. The total value of agricultural products was about $\$ 217,267,319$. These data were prepared by Mr. Jack Watson and Ms. Jean Smith of the Benton County Cooperative extension.

Because of time limitations this presentation must be kept brief. If additional discussion and dialogue is needed, I will be available for any needed input.

Respectfully submitted,

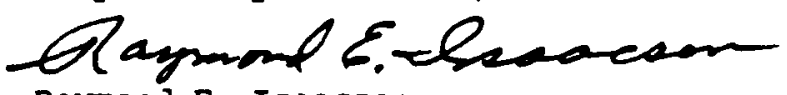

Raymond E. Isaacson

Attachments (2) 


\section{Ex11}

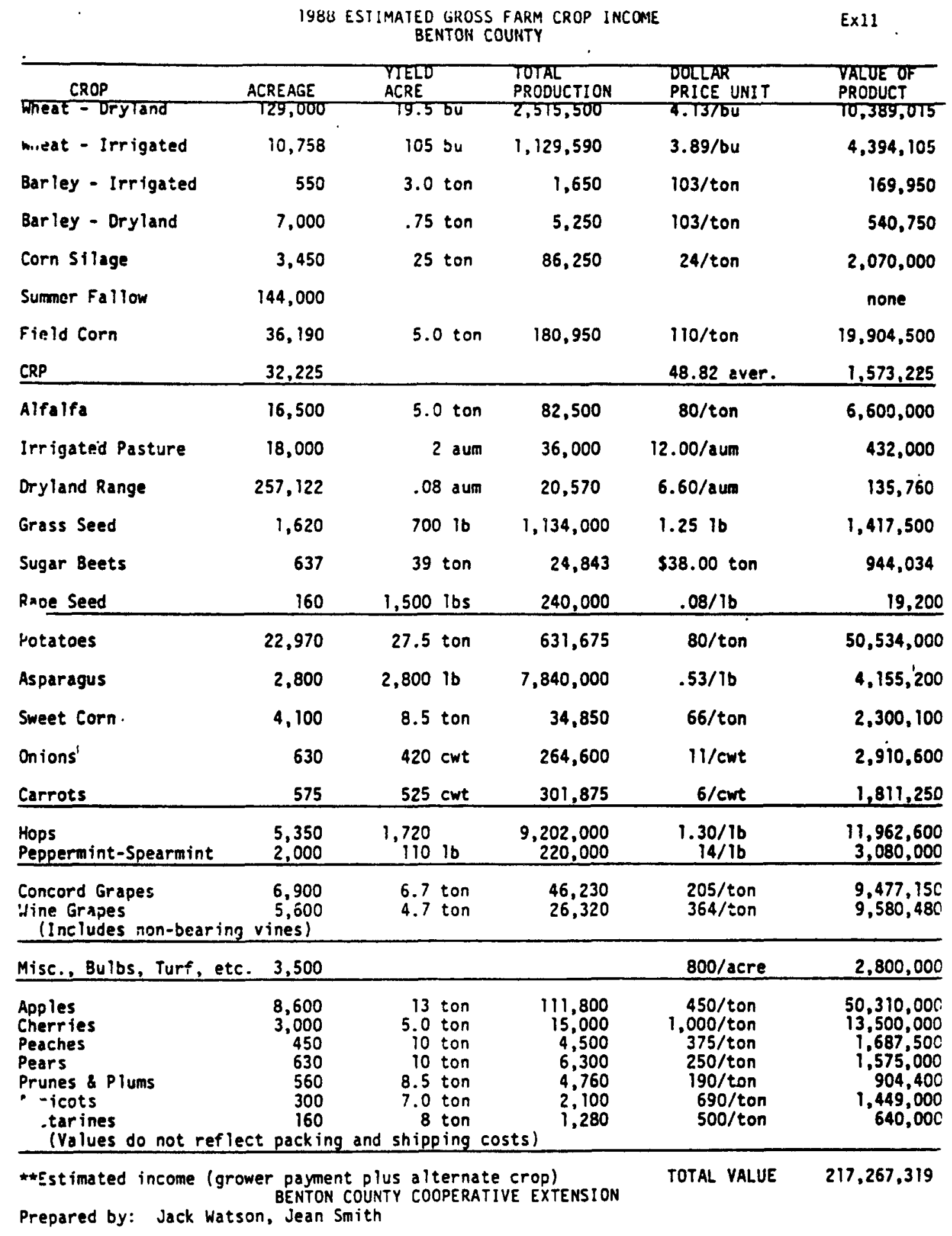


BENTON COUNTY CROP ACREAGE \& LIVESTOCK NUMBERS

Ex11 COUNTY AGENT'S BEST ESTIMATES

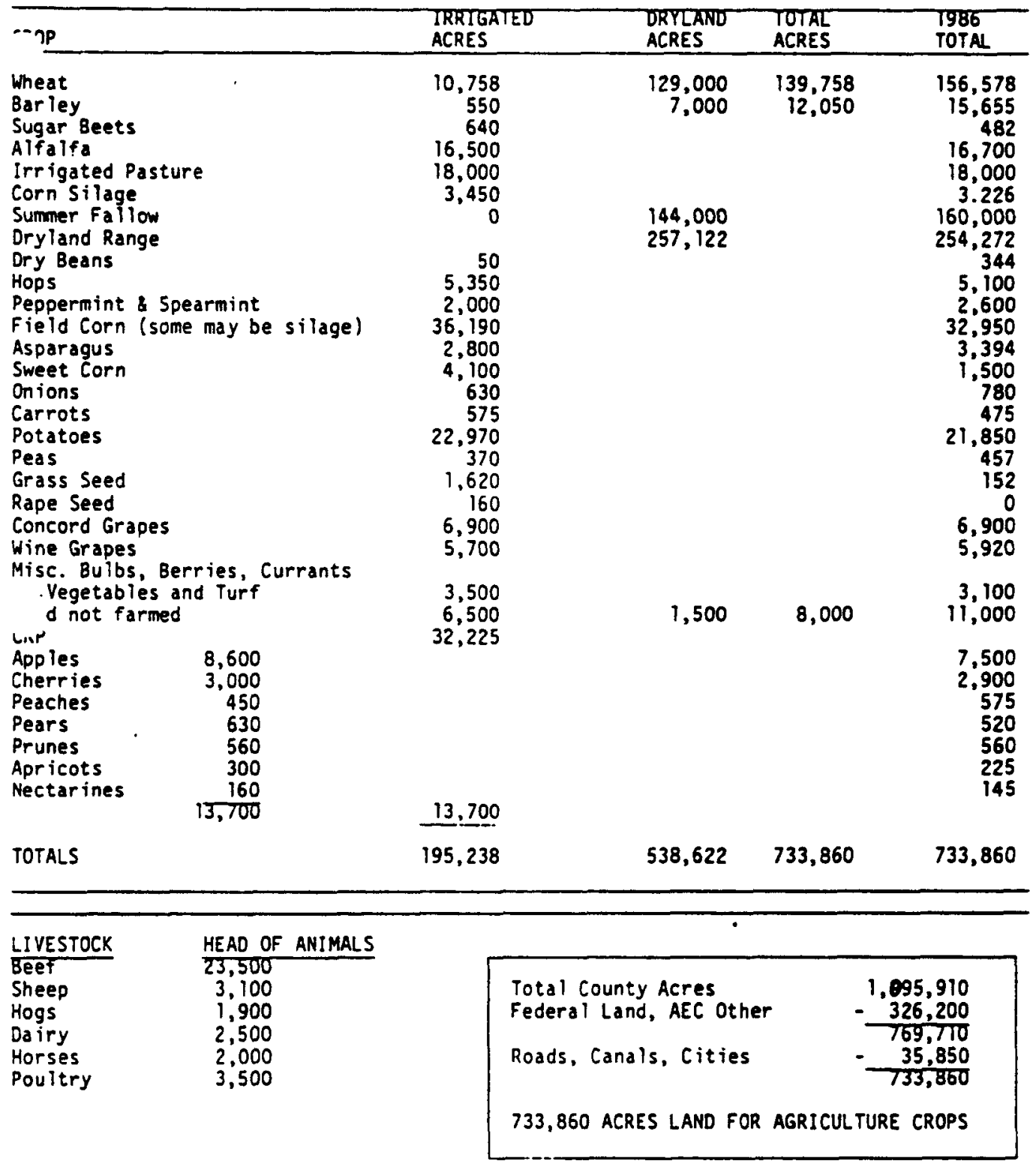

pared by: Jack Watson

Jean Smith, Livestock and Economics

$2 / 89 / \mathrm{rt}$ 
Testimony of the Hanford Education Action League on the Draft Environmental Impact Statement:

"Decomissioning of Eight Surplus Production Reactors at the Hanford Site, Richland, Washington"

July 13, 1989

My name is Jim Thomas and I am Staff Researoher for HEAL, the Hanford Education Action League. Our address is S. 325 Oak Street. Spokane, WA. 99204.

HEAL endorses the Immediate One-Piece Removal option for all eight reactors, including the $B$ reactor.

The main reasons HEAL supports the Immediate One-Piece Removal option are:

1. It moves the reactors, which are still radioactive, aray from the Columbia River.

The reactors should be buried aray from their present location near the Columbia. By being along the river, the reactors rould remain too accessible by the general public. The option of leaving them in their present location and burying them under a mound of dirt and gravel is not a demonstrated technology. The EIS does not even offer an estimate of how long the "engineered barrier" might last before allowing the contaminated reactor blocks to be exposed to the environment.

2. By doing the job imediately, citizens have a greater assurance that the reactors will not be forgotten, that Hanford will be cleaned up, and that the federal government will restore the land to public use. It will also make it possible to keep the entire Hanford mess within the thirty-year cleanup agreement.

In answer to a series of questions by HFAL on the EIS, the Department of Energy responded in part that the "(s)tart of the decomissioning vill depend on the availability of funding and on the priorities established by the Department." Again we apparently have a case of the Department not respecting the will of the citizens it is supposed to serve. On numerous occasions over the past several years the citizens of the Northrest have made it abundantly clear that we want Hanford to be cleaned up imediately.

We nor have the greatest likelihood of obtaining the necessary funding and skilled workforce to safely dispose of these atomic age relics. If we wait for 75 years as is proposed by two of DOE's options, we run a very high risk of not being able to complete the job of decomissioning. 
3. This option requires the least amount of land area to be barred from public access.

HEAL has repeatedly raised the point that there is no overall government strategy for minimizing the amount of land at Hanford which will have to be off-limits for centuries, and in some oases, miliennia. We again call upon the state, EPA and the DOE to develop a plan wich will limit (to the greatest extent possible) the amount of land at Hanford which will be fenced off and in effect, turned into a national sacrifice zone. Before suob a plan is in place, it is only conmon sense to pursue those cleanup options which require the least amount of area that will be left contaminated.

There is one other point which should be addressed. At various places throughout the EIS, the DOE states that once the reactor areas are cleaned up, they will be available for "other DOE use." The EIS goes 80 far as to say that "federal ownership and the presence on the Hanford Site is planned to be continuous." Norbere does the Energy Department stipulate the basis for its claim to Hanford. HEAL strenuously objects to the Department s regal attitude. The future use of Hanford is a decision which the citizens of Washington and the affected Native American tribes should and must make.

Thank you for listening to our concerns this morning. 


\section{Ex12}

TO: Denstment of Energy

Subject: Public commentson riraft EIS

Date: July 12, 1989

FROLI: Hary R. Hiemen

7. 242 Riverside ive., , ": 311

Snokene, "\#A 99001

Iike the vast majority of American citigens, I rasn't consulted when nuclear weanons were develoned, oricinally, 'but I'm taking the obnortiunity to sne: k to you J.0.J. renresertetives focry on nuclear reactor decolmigioning sltematives.--

In my oninion, Standby $\mathrm{N}$ Reactor should be decommissioned along with the 8 surnlus production reactors, since it annears to be in danger of Columbi= river flooding from a 5 , , soviee Iam. soven

failure like the others; that $C$ leactor is vitilin 3 seters of that fate; snd that 3 neactor should not be inluded in the National Register of Historic Flaces for the seme reason.-- Photos of the l-tter reador will have to suffice for the record.

From a man, it annears that the 10 areas eren't as distant from the river bonk as are the 200 mest areas, when one-niece removol and we disnospl are being considered. Immediate removal the greater distance is desirable, but decontrmination measures could be effected st the existing reactor sites,instend of at the 200 yert ereas, as an altemative.

Honefully, the no ilest arens pill be provided with an highly protective brrrier to nrevent/redioactive leaching into the soil. As you know, costs of the work-to-be-done are mounting continuou $=1 y$, due to continuous orice infletion, so it con't be too soon for decomiseionino to becin. Further delay will only wroen 
cont.-

the nresent problems, which I don't need to describe to you.

There should be some wey in which the radionuclide tritium can be salvaged to reserve the usefulness of existing nuclear wes.ons.

To conclude, I'm a nrononent of the Immediate (over 12 yerrs' time) One-Piece (nlus the reactor block) Removel (but still on the Henford Reserv-tion site) Alternative, with the changes noted. 


\title{
Ex13
}

\section{TESTIMONY}

\author{
Of The
}

\section{STATE OF OREGON}

On the U.S. Department of Energy's

Draft Environmental Impact Statement for the

Decommissioning of Eight Surplus Reactors at the Hanford Nuclear Reservation

$$
\text { July 18, } 1989
$$

Portland, Oregon 
Members of the Panel, ladies and gentlemen: I am David Stewart-Smith. I am Acting Administrator of the Nuclear Safety and Energy Facility Siting Division of the Oregon Department of Energy.

My testimony and our written comments represent the State of Oregon's response to the Draft Environmental Impact Statement (DEIS) for the decommissioning of eight surplus reactors at Hanford. Our written comments are in a separate document submitted for the record.

We thank USDOE for bringing this hearing to Portland. USDOE is doing better at recognizing Hanford's downriver constituencies on both sides of the Columbia.

My testimony today will be brief. Oregon's technical comments center on one revelation in the DEIS and I will confine my comments to that issue. 


\section{Ex13}

Before the DEIS was published, the decommissioning issue was ranked low on Oregon's list of Hanford priorities. While the eight old reactors are "low level radioactive waste" we regarded them as almost benign compared to high level and chemically hazardous nuclear weapons waste, problems at $\mathbf{N}$ Reactor, and transuranic waste transport. Those issues - and nuclear weapons waste cleanup in particular - were and still are Hanford's "hot spots" in our view.

The eight old reactors have languished in place for 20 and 30 years. We did not expect any surprises in the decommissioning DEIS. We were, in fact, poised to support an option for deferred action. So long as the old reactors posed no threat to people or the environment, Oregon was ready to counsel against any decision that might compromise cleanup of Hanford's high level and transuranic nuclear weapons waste.

We cannot offer that counsel now. In fact, we are compelled to say that the eight reactors, their fuel storage basins, and any residual contamination should be moved away from the river immediately. Why? Because the 
DEIS, in an almost casual aside, notes that a leak in a fuel basin has left a "significant inventory" of radionuclides and contamination.

That's it. One sentence. And it raises a host of questions:

-How large was the leak? Precisely what is a "significant inventory" of radionuclides?

-Is there a plume? If so, where is it? Where will it go? How fast will it travel?

-How much soil has been contaminated? Can the contamination be retrieved and disposed?

-What are the implications of various characterizations? Is the river in imminent danger?

-Does this mean there is a higher likelihood of other undetected leaks?

-How soon will USDOE finish its studies on the leak and its implications? And last: 


\section{Ex13}

In view of this litany of unknowns, how can USDOE opt for any action now but complete and immediate removal of the reactors and fuel basins?

That concludes my remarks. If you have questions, I will be glad to answer them.

Thank you. 


\author{
OREGON COMMENTS \\ on the \\ DRAFT ENVIRONMENTAL IMPACT STATEMENT (DEIS) \\ Regarding the \\ DECOMMISSIONING OF EIGHT SURPLUS PRODUCTION REACTORS \\ AT THE HANFORD SITE, RICHLAND, WA.
}

\title{
SUMMARY OF COMMENTS
}

1. The U.S. Department of Energy has listed four options by which the eight surplus nuclear reactors and fuel basins could be disposed. USDOE did not identify its preferred option.

2. In a one-sentence aside, uSDOE notes a "significant leak" in one fuel storage basin in the 100 Area. The leak contaminated soil under the basin and could contaminate local ground water. Option 2, which includes removal of the basin and contaminated earth, addresses this issue.

3. USDOE has failed to develop the data and scientific knowledge needed to support any option but Option 2 -- "Immediate One-Piece Removal" of the reactors.

4. In our view, cost is not a factor among the choices. The cost of each option is within 17 percent of the cost of the others.

The Tri-Party Cleanup Agreement between the state of Washington, the US DOE and the US EPA includes the surplus reactors. This agreement has a 30-year schedule for cleanup of all defense wastes. The schedule depends on Congressional funding.

Funds for decommissioning also come from Congress. The cost of surplus reactor decommissioning must not compete with current and future levels of funding for cleanup of nuclear weapons waste at Hanford.

\section{CONCLUSION}

Unless or until USDOE assures us that this or other leaks do not put the river at risk, Oregon must support option 2 . 


\section{Ex13}

\section{BACKGROUND}

The U.S. government built eight reactors at Hanford between 1943 and 1955. These and $\mathbf{N}$ reactor made plutonium for nuclear weapons. The mothballed $\mathrm{N}$ reactor is not included in this DEIS.

The reactors are situated along the Columbia River. All nuclear fuel has been removed. The reactor parts and buildings are "low level radioactive waste".

\section{QPTIONS}

1. Continued present action (continued surveillance and monitoring). Estimated cost-\$41 million.

2. Immediate one-piece removal.

One piece removal means moving the reactor block on a tractortransporter about ten miles to the 200 West Area. The intent is to bury the wastes and cover them with a protective barrier. A ground water monitoring system and markers would be installed.

The option also calls for removal and disposal of fuel storage basins by similar shallow burial in the 200 West Area.

Estimated cost-\$191 million

3. Safe storage and deferred one-piece removal.

The same plan as in (2) except removal would be put off for 75 years. The long delay allows cobalt-60 to decay to less than one tenthousandth of its initial radioactivity. This would reduce the radiation dose to workers.

Estimated cost $-\$ 198$ million

4. Safe storage and deferred dismantlement.

Dismantle the reactors after 75 years. Package and transport the contaminated equipment and transport to the 200 Area for burial. Dispose of the fuel storage basins in the same way.

Estimated cost-\$217 million

5. In Situ (In-place) decommissioning.

Build a protective barrier mound over the reactors and the fuel storage basins.

Estimated cost $-\$ 181$ million 


\section{COMMENTS}

These comments address only issues of geology and hydrology.

page 3.4

TEXT: "The soil column under the KE fuel storage basin contains a significant, but not yet fully characterized, radionuclide inventory from a past leak that has been repaired."

COMMENT: Then did the leak occur? Is there a radioactive plume? The depth to which this leak has moved toward the water table is a serious concern. Could there be other undiscovered leaks?. Has fluid waste moved to the water table? could it take considerably less than the DEIS estimate of from 260 to 880 years? The DEIS admits that the travel time models are "...based on a simple one-dimensional view of the problem." The DEIS states that estimated ground water travel time to the Columbia River is only one year after reaching the water table. The water table is only about 20 meters below the reactors. This close proximity to the water table and the river does not allow for any error in estimating ground water travel time of pollutants.

Characterization plans and schedules on this issue should be included in the final DEIs. When will characterization studies be complete? Will the results be published for public comment?

One sentence in the DEIS about the fuel storage basin leak falls far short of addressing an important public safety and environmental issue. US DOE raises the spectre of radioactive contamination seeping into the Columbia River.

This treatment reveals an unfortunate but familiar USDOE/Hanford mindset" that is insensitive to public perception and opinion. 


\section{Ex13}

page 3.57

TEXT: "Climatic changes that alter the flow of the Columbia River could result in long-term erosion under a reactor in the 100 Areas and eventual immersion of that reactor in the river."

COMMENT: More information would be helpful on how US DOE reached this conclusion. A time frame and probability are needed. A specific reference would help. There are 13 references cited in section 3.8 . Lack of a specific reference requires the reviewer to obtain and read all 13. The image of a reactor submerging in the Columbia River deserves more than one paragraph in the DEIS.

page 5.19

TEXT: "For the 100 Area alternatives, there is no difference in dose between the two recharge rates." $(0.5 \mathrm{~cm} . / \mathrm{Yr}$ and $5.0 \mathrm{~cm} / \mathrm{yr})$.

COMMENT: The different recharge rates produce different dose rates in the 200 Area calculations due to dilution factors. Is dilution not a factor in the 100 Areas? This needs clarification.

Appendix C, page 1:

TEXT: "Water travels downward at rates measured years per meter in the Hanford environment."

COMMENT: Should read.... "meters per year."

Appendix $C$, page 6:

TEXT: The DEIS discusses travel time calculations for water moving down through the vadose zone to the water table. On page C.6, travel time is 4,200 years (200 Area). Data were taken from or agree with Volume 3, Appendix Q, of the Final EIS, Disposal of Hanford Defense High Level Wastes. The DEIs assumes that the protective barrier keeps recharge to $.1 \mathrm{~cm} / \mathrm{yr}$ and no breach. However, the 1987 Defense EIS also includes assumed recharge rates of $5 \mathrm{~cm} / \mathrm{Yr}$. Recharge at that rate shows travel time to the water table of 100 years. This points out how ground water travel time calculations are greatly affected by changes in recharge rate input. These additional recharge rates and their shorter travel times are important. The DEIS should include all available data. 
Page 5.41 says: "Impacts from Hanford defense wastes were calculated for ...0.5 and 5.0 and for $15 \mathrm{~cm} / \mathrm{yr}$ for failure over 10 percent of the barrier." (Dose rates). The DEIS did not include the travel time calculations for these recharge rates. The dose rates were included.

It appears that only the least conservative travel time data was selected for the DEIS. All available, relevant data should be included in the final EIS.

Appendix $C$, page 8:

TEXT: "The geohydrology of the 100 Areas is not well defined. For that reason, a detailed ground water model is not available..... Modeling is based on a simple one-dimensional view of the problem.....n

The text also states that from the 100 Area the ground water travel times in the vadose zone ranged from 260 to 880 years (using . I cm/Yr infiltration rate) and then one year to the river after reaching the water table.

COMMENT: What were the travel time calculations to the water table for $.5,5.0$ and $15 \mathrm{~cm} / \mathrm{yr}$ recharge rates in the 100 Area? Why are they not included?

Based on the above statements "Geohydrology ... is not well known... Modeling is based on a simple...view of the problem...", the public cannot be expected to have any great confidence in a decision for In-situ decommissioning. The fear of contamination of the Columbia River from nuclear and associated chemical wastes will demand more definitive scientific assurance upon which to base decisions.

Appendix $\mathrm{H}$, page 1:

TEXT: Discusses the leak protection system, liner/leachate collection system, marker system and ground-water monitoring systems. "..... and leak-detection systems are omitted from in situ decommissioning because of the impracticality of installing these systems under the reactor blocks."

COMman: Plans include a leak detection system seven miles from the river and $200 \mathrm{ft}$. above the water table in the 200 Area. A similar system within 200 meters of the river and 20 meters above the water table is considered impractical. Why is a 
Ex13

detection system important away from the river and not essential near the river? If such a system is important in the 200 Areas, it is vital in the 100 Areas. Has the US DOE considered lifting the reactors (as in the one piece removal option) to install the leak detection systems?

Appendix H, page 4:

TEXT: (Ground-water monitoring) "Quarterly water-level monitoring, batch sampling, and water-well analysis would be carried out. ......specifically for lead and radioactivity."

COMAENT: The DEIS does not outline the long term goals of the monitoring. What level of lead or radioactivity will require action? Is there some plan to deal with elevated levels? How long does the monitoring continue? At some time the well seals will fail in the monitoring wells. Will they be replaced? Will the eventual deterioration of monitoring well seals allow an avenue of faster travel time to ground water?

This could be of special concern in the 200 Area where tank wastes leaked. Retrieval of tank waste options are under review. Retrieval decisions are scheduled for the year 2004.

The location of monitoring wells in relation to leaked tank wastes is a concern.

\section{EINDINGS}

The overall cost of each option (except Continued Present Action-\$41M) is within 17 percent of the others. Thus, cost is not a major factor.

The DEIS admits that scientists know very little about the hydrogeology of the 100 Area. This implies that the reliability of groundwater computer models cannot be taken for granted.

We must know how serious the contamination is in the 100 Area. Needed characterization studies could show that any deferred option is risky. It is also essential to build a hydrologic data base. This work is imperative before making long range decisions.

The US DOE does not have the data and hydrogeologic knowledge needed to support any option but One-Piece Removal. To protect the Columbia River, US DOE should move the reactors, radioactive wastes, and fuel disposal basins away from the river as soon as possible. 
IDontwant to die From Radiation

$7 / 18 / 89 \mathbf{E x 1 4}$ why hearing held nice away fum Bus lines, etc.

j

The United States General accounting office sars the department of energy's report stating little on no environ mental thereat from nuclear storage tanks on the Columbia is false. The Reactors that you ane proposing to move have already also begun to leak. This Radiation has the potential of Killing humans and causing birth defects For many future generations.

our government has enough warheads to blow this planet to bits many times over. It's time you officials that wonk for as get oven the illusion that anything goes to protect us from Russia with Nuclear warheads, while slowly poiseming us from within from dead li nuclear leaks. To u keep saying the in "ha mas" "No danger" etc. until another independat study contasdictside.

personally as a tax parer I think we should par what even it takes to dis mantle every reactor and entomb them above ground whine we can keep an exon them why il kep ane relatiliels safe to bury. I believe its a crime to fine up the Savannah Riven Reactor to make more tritium and to plan on producing more plutonium when we can recycle "some from existing wan heads without losing "Blowing up earth potential" for possibly enough time to leaves how to get along with other countries. without theneatenimg tee only planet with know Life on it.

Owe other conserers is a compentaincy test given to the people that hove the authority to push the unclean puttees that could e end all bite on earth and give that test yexp!y, with aindependent cqupetayt discos.

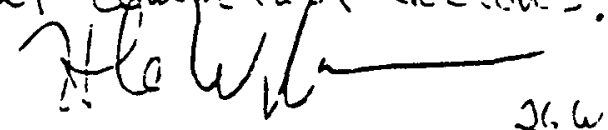

Hale viE iT Z MAN

0.323

idteceswero or.

9703,5 


\section{Ex15}

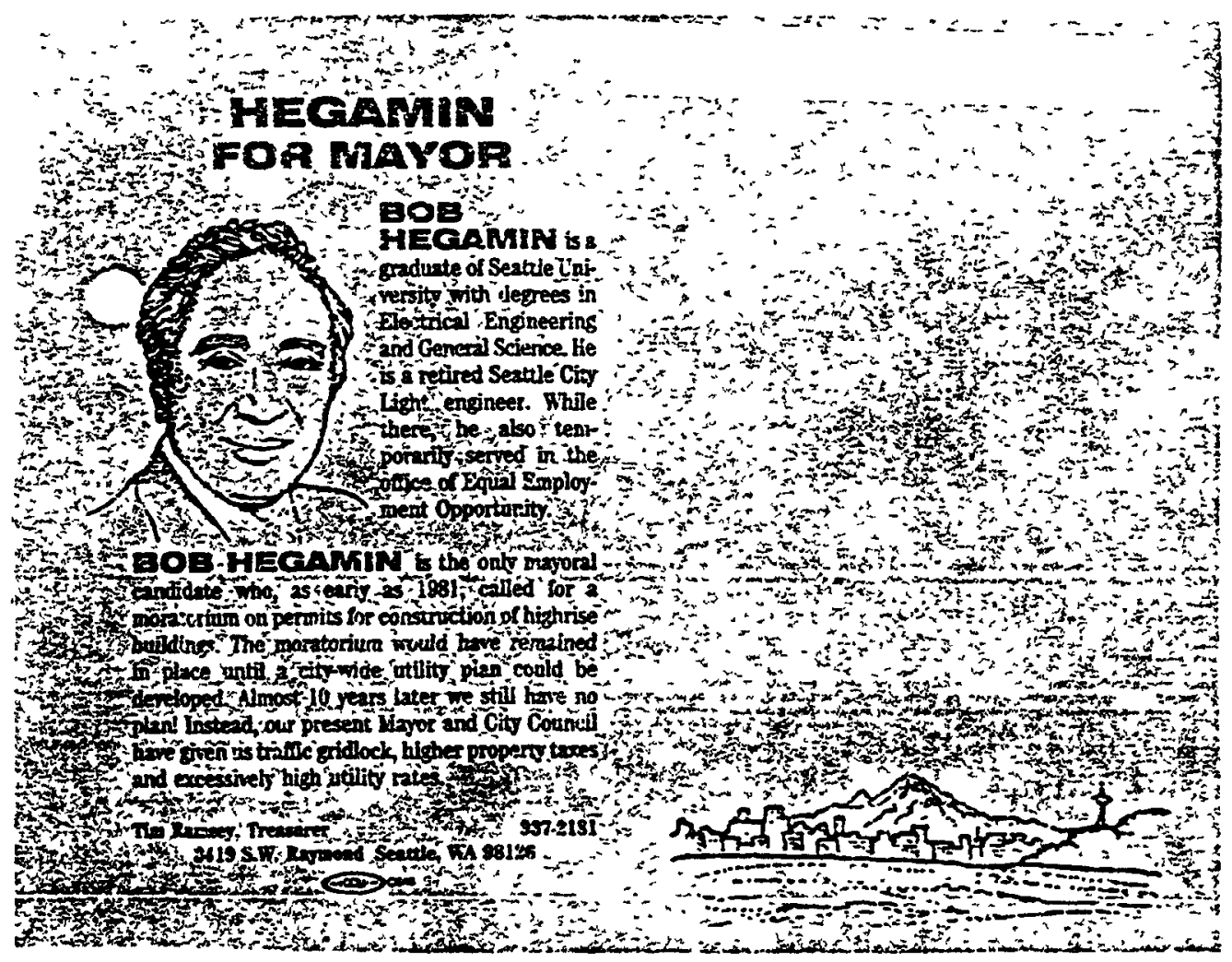




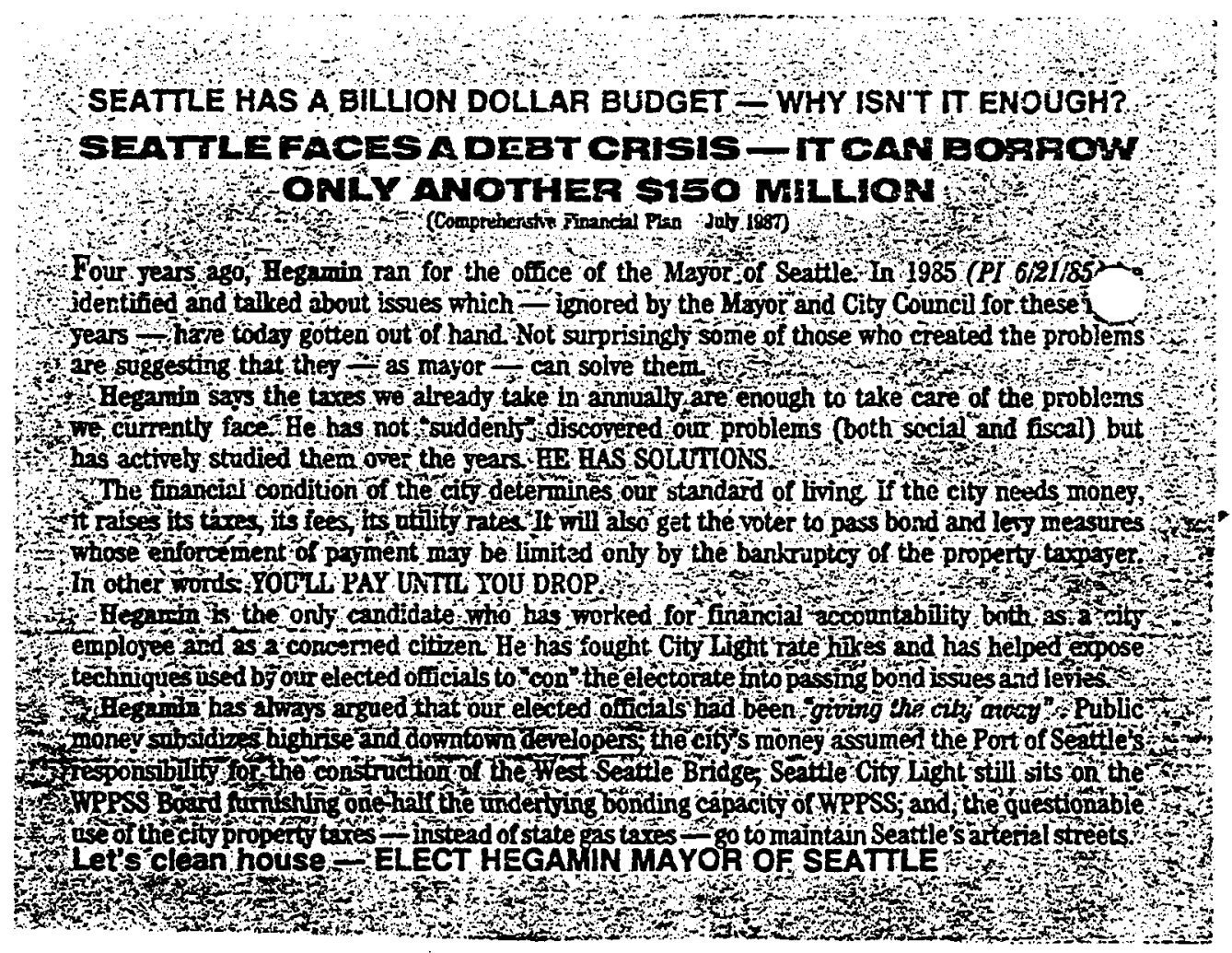




\section{Ex16}

\section{Testimony for the Sierra Club}

\section{Comments on the Decommissioning of Eight Surplus Production Reactors at the Hanford Site, Richland, Washington}

\section{To be Given at the Public Hearing Thursday, July 20, 1989 Hilton Hotel (Airport), Seattle, Washington}

The Sierra Club, Cascade Chapter has reviewed the draft environmental impact statement (EIS) on the decommissioning of eight surplus production reactors at the Hanford site. The Sierra Club thanks the DOE for the opportunity to review and comment on the draft EIS.

The Sierra Club is highly concerned about the potential for serious environmental impact from the decommissioned production reactors if they are allowed to remain in their present location in the 100 area of the Hanford site.

We feel that the decommissioning alternatives in the Draft EIS have been well described and well researched by DOE. We believe that excellent work was done by the DOE in analyzing the various decommissioning alternatives. In this testimony today we intend to provide comments on what we believe is the best decommissioning alternative.

The Sierra Club believes that the longer the eight surplus reactors are allowed to remain in their present condition, at the present site, even with adequate air, water and soil monitoring, the greater will be the potential for a severe environmental disaster. Table B.2 in the Draft EIS illustrates that a Catastrophic $(50 \%)$ failure of the Grand Coulee Dam would place all but one of the surplus reactors below flood level at the First-Floor Elevation level of the reactors. A severe seismic event could cause such a failure of the dam.

Appendix $\mathrm{H}$ of the Draft EIS discusses flood protection in the case of the In Situ Decommissioning Alternative, however, it does not discuss the case where severe seismic activity has simultaneously weakened the proposed riprap layer around the reactor. While the EIS indicates that severe seismic activity is unlikely in the Hanford area, the possibility of a catastrophic occurrence is not impossible, or totally improbable. If this riprap layer were also cracked at the time of the dam failure, the reactor building would be in the flooded area without the benefit of the protective layer. In addition, the closeness of the reactors to the river allow no space for leakage without serious impact into the river. While this has not occurred, we cannot be certain that it will not over the next century, therefore we feel that In-Situ decommissioning is not the preferred alternative. The In-Situ alternative is as costly as one-piece removal and it leaves us with a higher risk of contamination of the Columbia River. 
Our preference would be to eliminate the reactors and all components from the Hanford site. This is impractical as no storage facility exists at this time to relocate the radioactive and contaminated material. In addition, the reactors are too "hot" to be dismantled in the near future. In addition, we are very concerned about the transportation of the material to another site; it would be hazardous and have possible environmental consequences, particularly if an accident occurred in transporting the reactor parts.

At this time the only realistic alternative seems to be to transport the reactors to the 200 area and place them in temporary storage. The question then is one of immediate one-piece removal vs. delayed one-piece removal.

The Sierra Club supports the one-piece immediate removal decommissioning alternative. We support this for the following reasons.

The immediate one-piece removal option is less costly than any other acceptable alternative and only $\$ 9$ million more than the $\ln$-Situ alternative. The environmental impact of one-piece removal is minimal and the radiation dosage to the general public (off the reservation) is as low or lower than any other alternative.

The only negative impact is the higher radiation dosage sustained by the workers on the decommissioning team. We are concerned with situations where workers are exposed to more than minimal radiation levels. We feel that in this case the DOE will be required to utilize a sufficient number of workers over the twelve year span of the decommissioning project in order to ensure that no single individual receives more than an acceptable level of radioactivity per the present maximum occupational dosage levels.

Again, we feel that the immediate one-piece removal of the surplus reactors is the best alternative and the one that should be selected. 


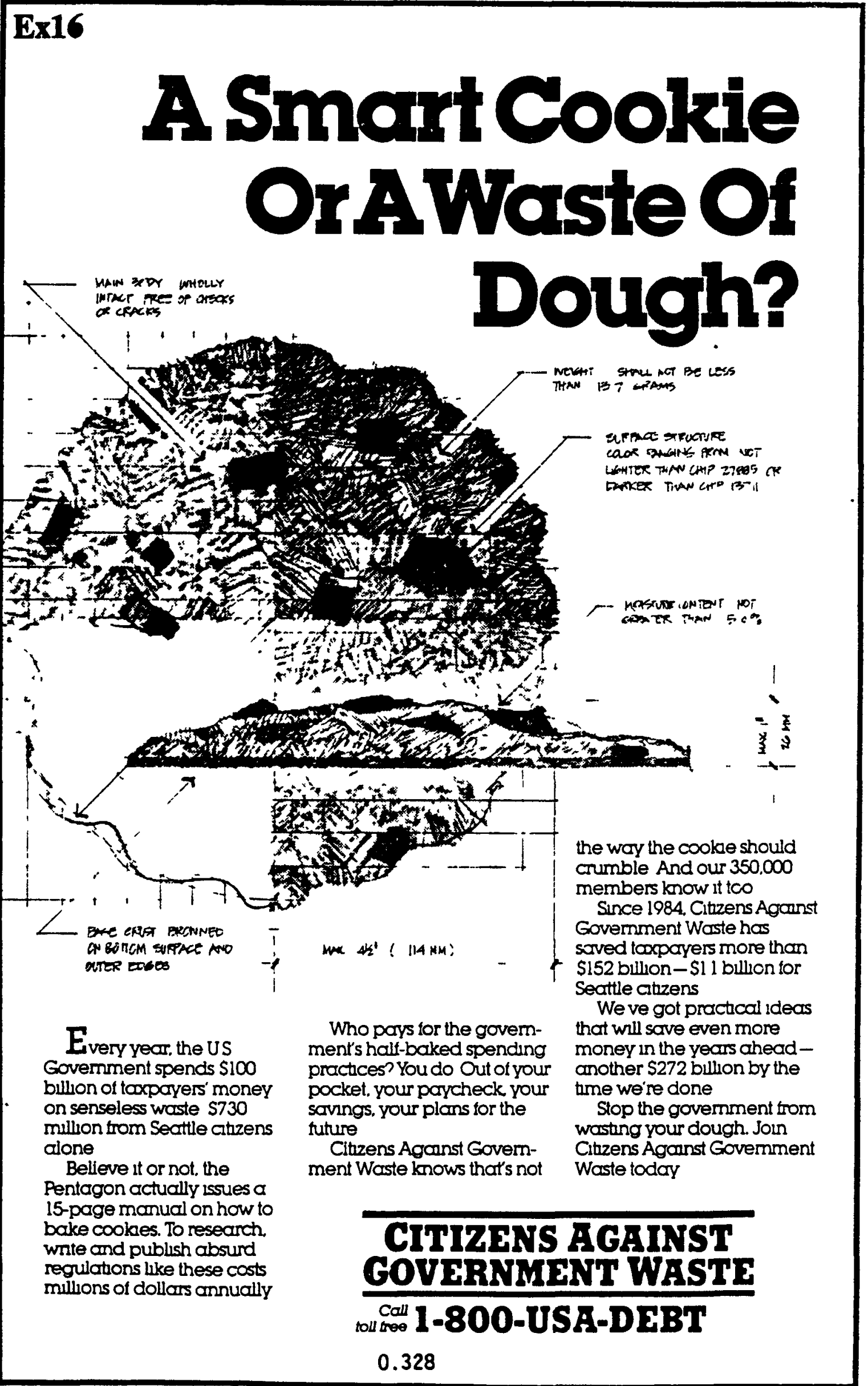




\section{STATEMENT OF HEART OF AMERICA NORTHWEST \\ ON}

DRAET ENVIRONMENTAL IMPACT STATEMENT:

DECONTAMINATION AND DECOMMISSIONING OF

EIGHT PRODUCTION REACTORS,

HANEORD NUCLEAR RESERVATION

\section{OVERVIEW:}

Heaft of America Northwest is a citizens group of 16,000 members dedicated to advancing our region's quality of life. As such, we have been in the forefront of efforts to secure a credible and timely clean-up of nuclear and chemical wastes at the Hanford Nuclear Reservation in accord with federal and state environmental laws. Hanford Clean-Up is an issue vital to both the economic and environmental vitality of our region.

The Nuclear Reactors which line the banks of the Columbia River at Banford are more than overwhelmingly stark bymbols of the need to clean up the Hanford site. They are facilities which pose significant risks of releases of radionuclides and chemical wastes to the Columbia River and the environment of the Northwest. Our position is that they must be cleaned up decontaminated and decommisioned - in full accord with all procedures and standards of the relevant laws governing such threats. We are not an organization with any position on the production of nuclear weapons material, or which calls for Hanford shutdown. We do insist that Hanford be cleaned up in accord with the law.

The Draft EIS (Environmental Impact Statement) produced by the USDOE (US Dept. of Energy) FAILS TO ACKNOWLEDGE THAT THE CLEAN UP OF THE REACTORS MUST BE DONE IN ACCORD WITH FEDERAL AND STATE ENVIRONMENTAL LAWS. .

THOSE ILAWS DO NOT GIVE THE DEPARTMENT OF ENERGY THE AOTHORITY TO MAKE THE FONDAMENTAL DECISION AS TO THE FATE OF THE REACTORS AS CALLED FOR IN THE EIS.

THE DRAFT EIS CALLS FOR A DECISION TO BE MADE BY THE DOE PRIOR TO THE INTENSIVE ON-SITE CLEAN-UP STUDIES (i.e., remedial -investgations and feasibility studies) CALLED FOR BY FEDERAI AND STATE LAW PRIOR TO ANY DECISION REGARDING CLEAN-UP AND DECOMMISSIONING OF A FACILITY WHICH POSES SUCH A CLEAR POTENTIAL THREAT OF RELEASE OF CONTAMINATS TO THE ENVIRONMENT. THE POLICIES, PROCEDORES AND STANDARDS OF THOSE ACTS ARE IGNORED BY THE OSDOE IN THIS DRAFT EIS.

THE STATE OF WASHINGTON, DEPT. OE ECOLOGY, AND THE U.S. ENVIRONMENTAL PROTECTION AGENCY (EPA) SHOULD BE THE FUNDAMENTAL DECISION-MAKERS REGARDING THESE EIGHT REACTORS, RATHER THAN DOE.

$$
\text { BUDGETARY CONSIDERATIONS HAVE APPARENTLY DRIVEN THE }
$$

EVALOATION BY THE DSDOE OF ALTERNATIVES IN THE DRAFT EIS , LEADING TO A BIAS TOWARDS LEAVING THE REACTORS IN PLACE ALONG THE COLUMBIA RIVER, EITHER PERMANENTLY OR FOR A SEVENTY FIVE YEAR PERIOD - WHEN SOME FUTURE GENERATION CAN BE FACED WITH A DECISION, IF THERE HAS NOT BEEN A PRIOR RELEASE. THIS BIAS LED THE USDOE TO FAIL TO CONSIDER THE ALTERNATIVE OF IMMEDIATE DISMANTLEMENT , WITH APPROPRIATE WORKER AND ENVIRONMENTAL HEALTH SAFEGUARDS - DUE TO COST. 